NATIONAL LABORATORY

MANAGED BY UT-BATTELLE

FOR THE DEPARTMENT OF ENERGY

\title{
PM Motor Parametric Design Analyses for a Hybrid Electric Vehicle Traction Drive Application
}

R. H. Staunton

S. C. Nelson

P. J. Otaduy

J. W. McKeever

J. M. Bailey

S. Das

R. L. Smith

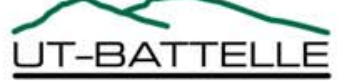


This report was prepared as an account of work sponsored by an agency of the United States Government. Neither the United States Government nor any agency thereof, nor any of their employees, makes any warranty, express or implied, or assumes any legal liability or responsibility for the accuracy, completeness, or usefulness of any information, apparatus, product, or process disclosed, or represents that its use would not infringe privately owned rights. Reference herein to any specific commercial product, process, or service by trade name, trademark, manufacturer, or otherwise, does not necessarily constitute or imply its endorsement, recommendation, or favoring by the United States Government or any agency thereof. The views and opinions of authors expressed herein do not necessarily state or reflect those of the United States Government or any agency thereof. 
Engineering Science and Technology Division

\title{
PM Motor Parametric Design Analyses for a Hybrid Electric Vehicle Traction Drive Application - Final Report
}

\author{
R. H. Staunton \\ S. C. Nelson \\ P. J. Otaduy \\ J. M. McKeever \\ J. M. Bailey \\ S. Das \\ R. L. Smith
}

September 2004

Prepared by the

OAK RIDGE NATIONAL LABORATORY

Oak Ridge, Tennessee 37831

managed by

UT-BATTELLE, LLC

for the

U.S. DEPARTMENT OF ENERGY

Under contract DE-AC05-00OR22725 


\section{TABLE OF CONTENTS}

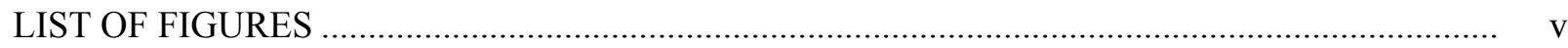

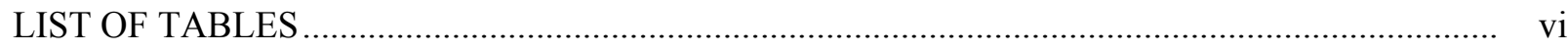

ACRONYMS, ABBREVIATIONS, AND INITIALISMS ................................................... vii

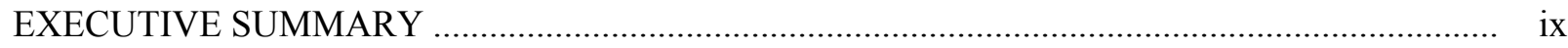

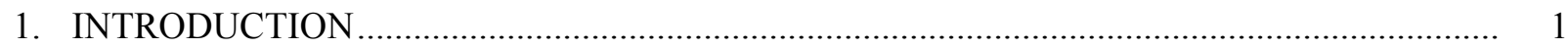

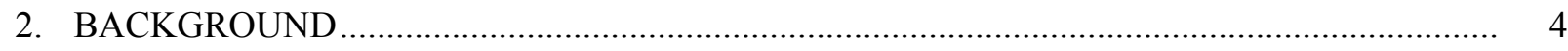

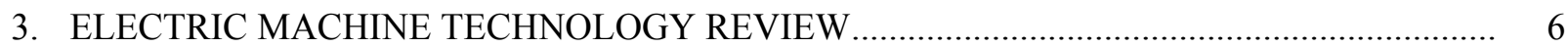

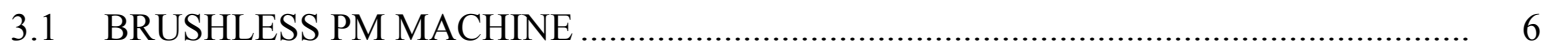

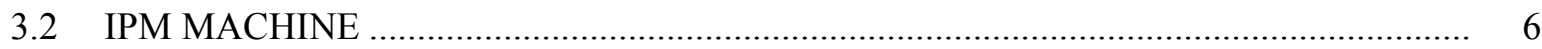

3.3 SURFACE MOUNT PM MACHINE ….............................................................. 9

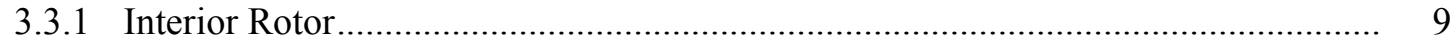

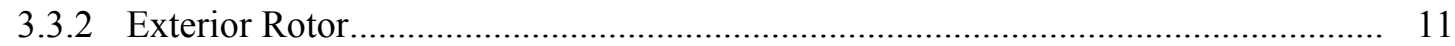

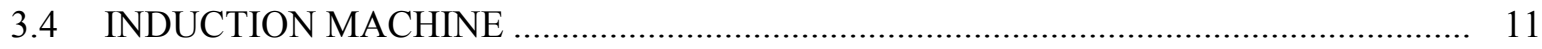

3.5 SWITCHED-RELUCTANCE MOTOR ….................................................................. 12

4. IPM MACHINE DESIGN POTENTIAL ....................................................................... 13

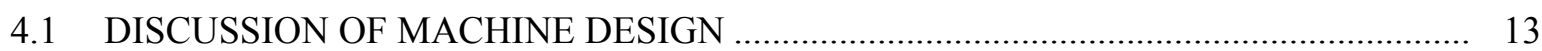

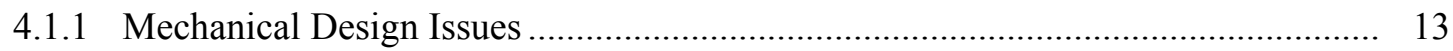

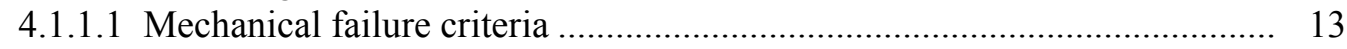

4.1.1.2 Mechanical operating speeds of IPM motors ......................................... 14

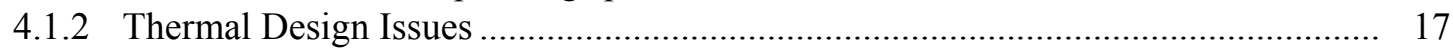

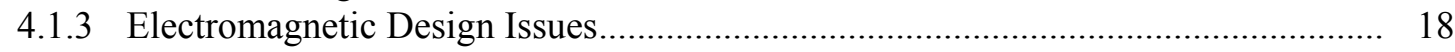

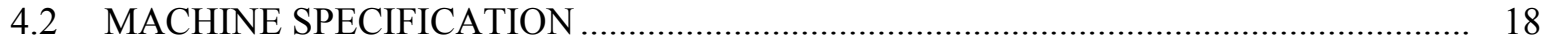

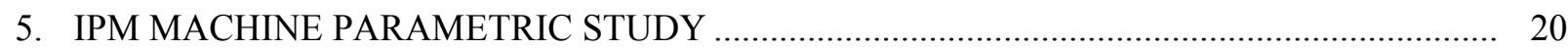

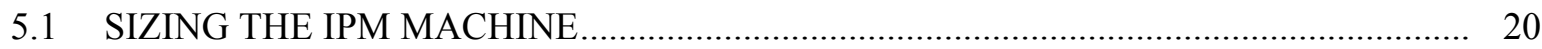

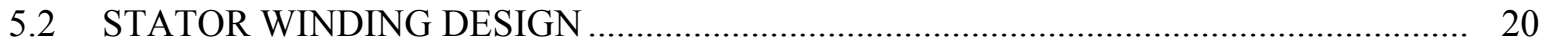

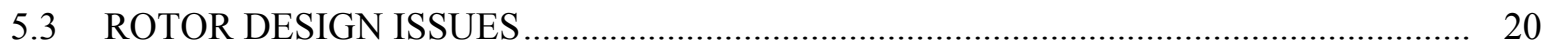

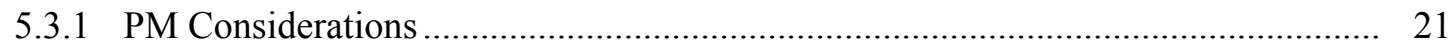

5.3.1.1 PM strength and other key properties ............................................ 21

5.3.1.2 Orientation of PM flux ................................................................... 23

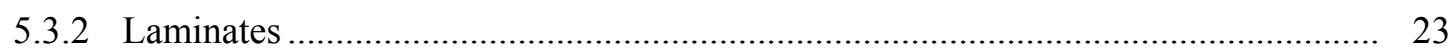

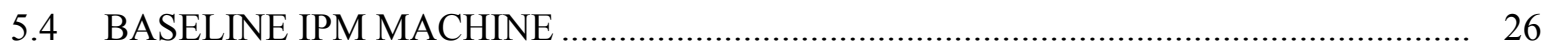

5.4.1 Lumped Parameter Data Set for Baseline Case .................................................. 26

5.4.2 Lumped Parameter Results for Baseline Case .................................................... 28

5.4.3 FEA Modeling and Results for Baseline Case ................................................... 31

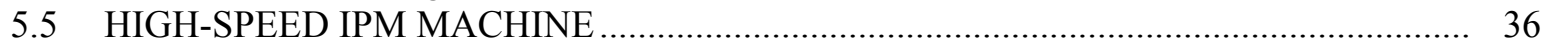

5.5.1 Lumped Parameter Data Set for IPM ............................................................ 36 


\section{TABLE OF CONTENTS (cont'd)}

5.5.2 Lumped Parameter and FEA Results for High Speed IPM.

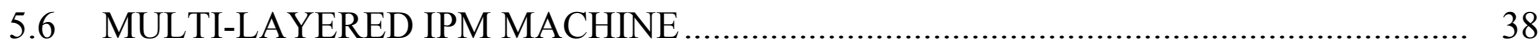

5.6.1 FEA Modeling and Results for Multi-Layered IPM Machines.............................. 40

5.6.2 FEA Modeling Results for Multi-Layered IPM Machines Without Center Posts .... 40

5.6.3 FEA Modeling Results for Multi-Layered IPM Machines With Steel

Center Posts

5.6.4 FEA Modeling Results for Bi-State Center Posts and Bridges ............................... 45

5.6.5 FEA Modeling Results for Two Layered IPM With Steel Center Posts ................... 47

5.7 RECESSED MAGNET MACHINE .......................................................................... 48

6. ROTATING ELECTRIC MACHINES WITH SURFACE-MOUNTED MAGNETS ................. 50

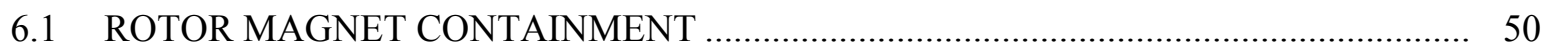

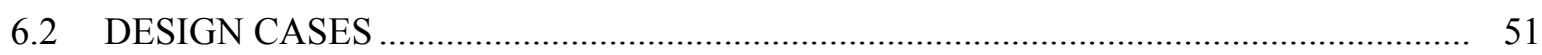

6.2.2 Design Study of Cases 1, 2, 3, 4, 5, 6, and 10 ................................................. 52

6.2.3 PM Rotors with Magnet Encasement ............................................................ 54

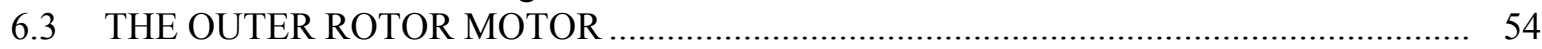

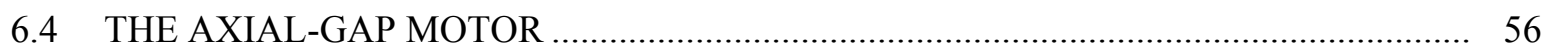

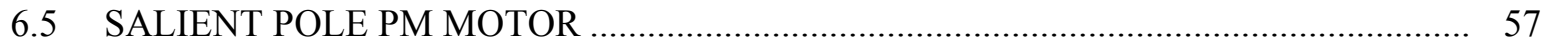

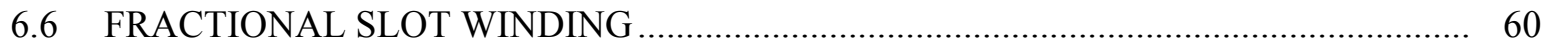

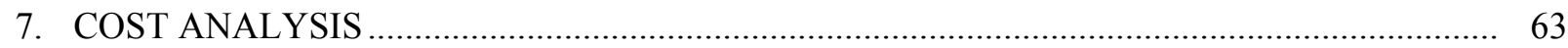

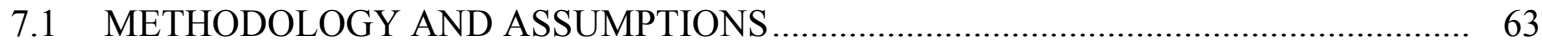

7.2 COST ESTIMATES FOR THE ALTNERATIVE IPM MACHINE DESIGNS ................ 64

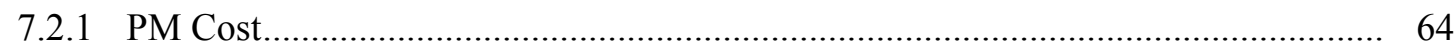

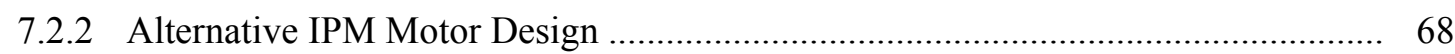

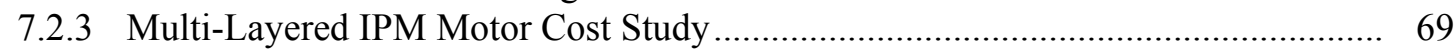

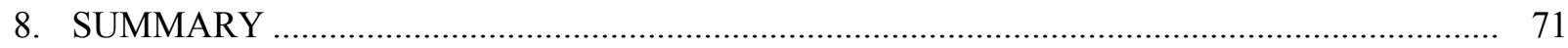

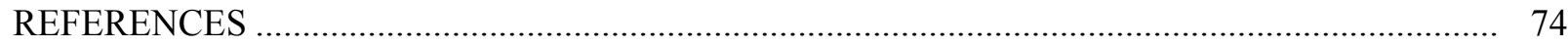

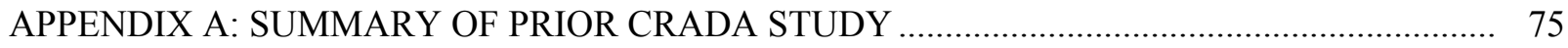

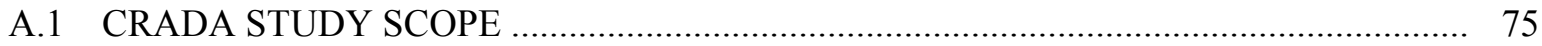

A.2 SUMMARY OF RESULTS OF THE PARAMETRIC STUDY …................................. 76

A.3 SUMMARY OF THE RESULTS OF MOTOR TESTING …......................................... 78

A.3.1 Axial-Air-Gap PM Machine, Inverter, and Universal Controller Testing ............... 78

A.3.2 Switched-Reluctance Machine ..................................................................... 81

APPENDIX B: SUMMARY OF THE AEMD TEAM 1 STUDY …............................................ 84

B.1 TOP-TIER TARGETS AND COMPARISON OF MACHINE TYPES .......................... 84

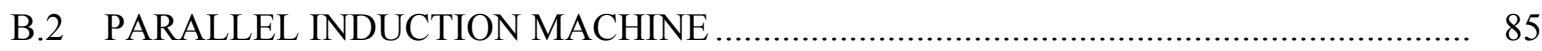

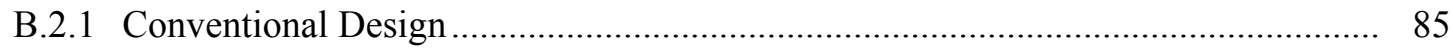

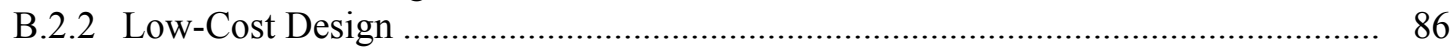

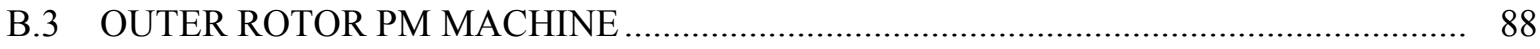




\section{TABLE OF CONTENTS (cont'd)}

Page

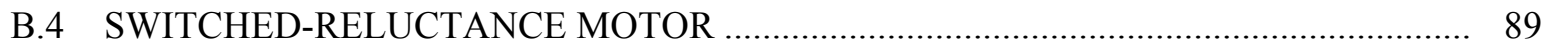

APPENDIX C: SUMMARY OF THE AEMD TEAM 2 AXIAL-GAP MOTOR STUDY ................ 91

C.1 IRON-FILLED AND IRONLESS AXIAL-GAP MACHINE DESIGNS ........................ 91

C.1.2 PMBLDC, Axial-Gap, Ironless Motors ............................................................. 91

C.1.3 PMBLDC, Axial-Gap, Iron-Filled Motors....................................................... 91

C.1.4 Iron-Filled vs. Ironless Axial-Gap Motors .......................................................... 92

C.2 MACHINE SYSTEMS FOR COMPARATIVE ANALYSIS ..................................... 93

C.2.1 System 1 (Baseline): PMBLDC Radial-Gap CPA Motor System ............................ 93

C.2.2 System 2: Ironless PMBLDC Axial-Gap DMIC Motor System Loss

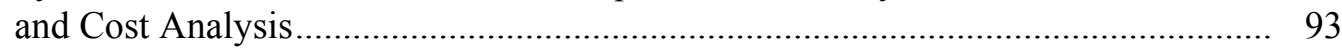

C.2.3 System 3: Ironless PMBLDC Axial-Gap H-Bridge Motor System Loss

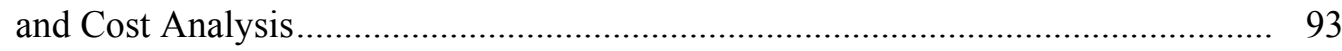

C.2.4 Systems 4 and 5: Iron-Filled PMBLDC Axial-Gap DMIC/CPA Motor System Loss and Cost Analysis .................................................................... 94

C.2.5 System 6: Iron-Filled PMBLDC Axial-Gap H-Bridge Motor System Loss and Cost Analysis........................................................................................ 94

C.2.6 Rotor/Stator/Rotor vs. Stator/Rotor/Stator Construction of Axial-Gap Motors........ 95

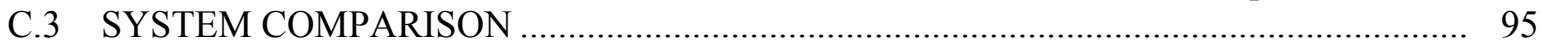

C.4 SUGGESTIONS FOR CONTINUING MOTOR TECHNOLOGY RESEARCH.............. 96

APPENDIX D: PARAMETER DEFINITIONS FOR THE SPEEDCAD MODEL ........................... 98

APPENDIX E: FIELD-WEAKENING TECHNIQUES FOR SURFACE-MOUNTED

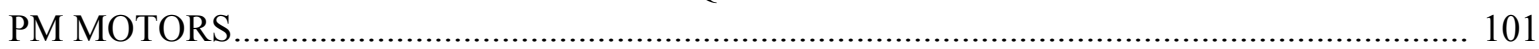




\section{LIST OF FIGURES}

Figure

$\underline{\text { Page }}$

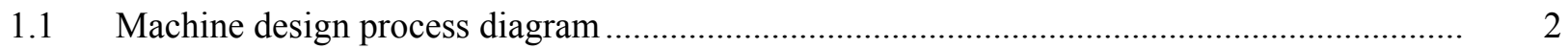

3.1 Two variations of an IPM machine rotor ....................................................................... 7

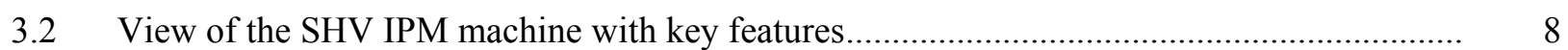

3.3 Examples of rotor and magnet configuration in surface-mounted PM machines .................. 10

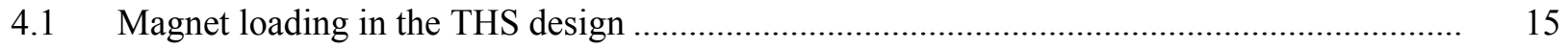

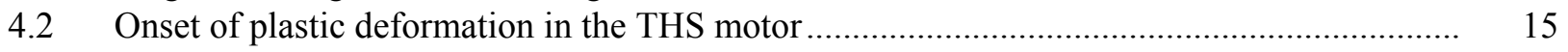

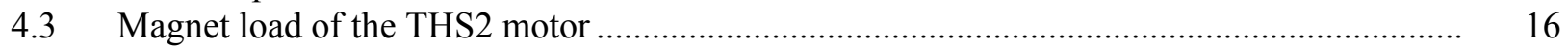

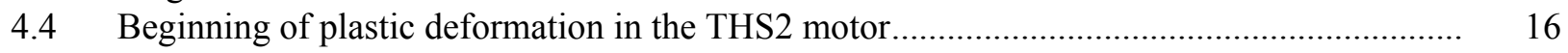

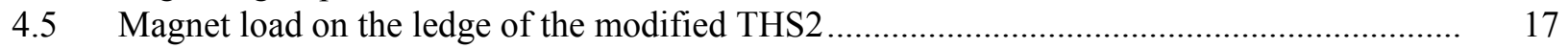

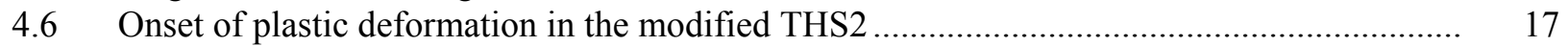

5.1 Magnet field orientation as defined in the Flux2D model ............................................ 23

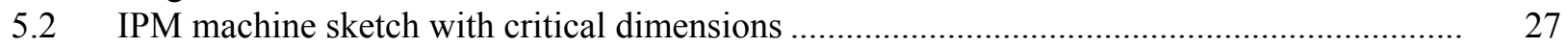

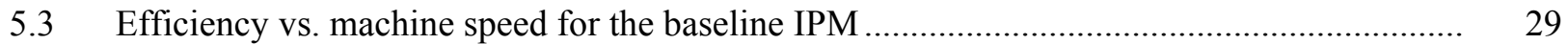

5.4 Stator current vs. machine speed for the baseline IPM ..................................................... 29

5.5 Torque vs. machine speed for the baseline IPM ......................................................... 30

5.6 Mesh of elements reflecting an emphasis on precision at critical machine areas .................. 31

5.7 Torque vs. rotor position (mechanical degrees) for $200 \mathrm{~A}$ peak.

5.8 Flux density color-coded map of rotor sector and portion of stator with a 2 Tesla ceiling ..... 33

5.9 Flux density and relative permeability over a pre-defined path across stator teeth ................ 34

5.10 Torque vs. current plot for baseline IPM with 1.12 T and no PMs..................................... 35

5.11 Torque vs. current for varying strength magnets for baseline IPM ..................................... 45

5.12 Torque constant vs. current for varying strength magnets for baseline IPM ....................... 36

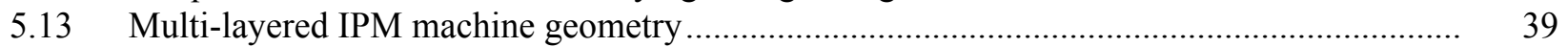

5.14 Torque vs. phase current for multi-layered IPM machine without center posts .................... 40

5.15 Torque constant vs. phase current for multi-layered IPM machine without center posts........ 41

5.16 Torque capability of baseline and multi-layered IPM machine without center posts ............. 41

5.17 Torque vs. phase current for multi-layered IPM machine with steel center posts ................. 42

5.18 Torque constant vs. phase current for multi-layered IPM machine with steel center posts .... 43

5.20 Torque comparison of multi-layered IPM with 0.4 T PMs with and without steel center posts

5.21 Torque comparison of multi-layered IPM machine with 0.6 T PMs with and without steel center posts

5.22 Percentage torque capability loss of multi-layered IPM machine with 0.4 and $0.6 \mathrm{~T}$ PMs due to steel center posts.

5.23 Torque comparison of multi-layered IPM with 0.4 T PMs with bi-state and steel bridges and center posts

5.24 Torque comparison of multi-layered IPM with 0.6 T PMs with bi-state and steel bridges and center posts

5.25 Percentage torque capability increase of multi-layered IPM machine with 0.4 and $0.6 \mathrm{~T}$ PMs due to bi-state bridges and center posts

5.26 Torque capability comparison two- and three-layered IPM machine with 0.4 T PMs ........... 48

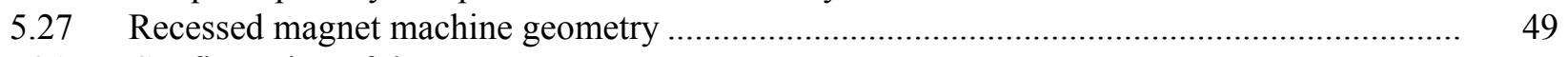

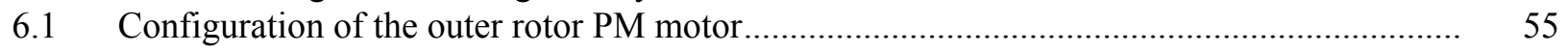

6.2 Elements of ORNL's axial-gap PM motor ............................................................... 57

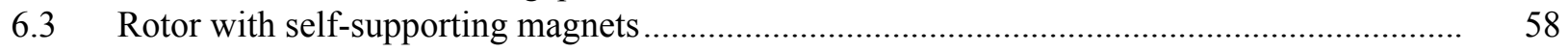




\section{LIST OF FIGURES}

Figure

$\underline{\text { Page }}$

6.4 Self-supporting load along the magnet/rotor interface................................................... 59

6.5 Von Mises stresses induced by rotor bending and magnet loading ..................................... 59

6.6 Radial stresses confirming compression at magnet/rotor interface and

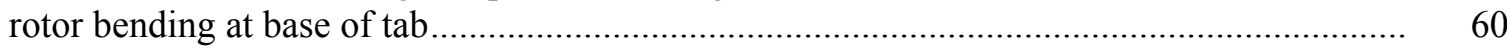

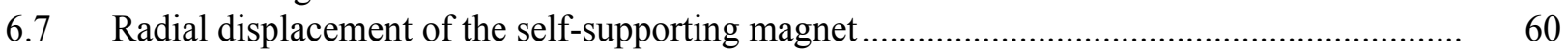

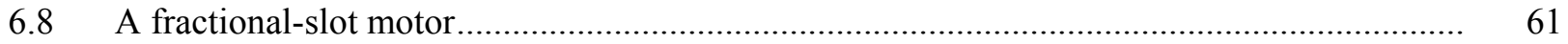

7.1 Multi-layered IPM weight and cost sensitivities to magnet strength ................................. 67

7.2 Multi-layered IPM motor cost sensitivity to steel center post ............................................. 69

7.3 Multi-layered IPM motor cost sensitivity to alternative magnet manufacturing

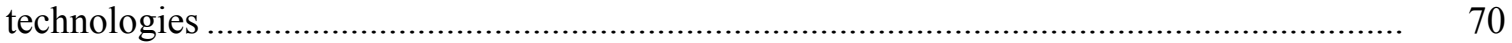

D.1 Physical parameters used in the SPEEDCAD model (IPM machine) .................................. 98

E.1 Common variable-speed inverter topology and PMSM motor model ................................. 102

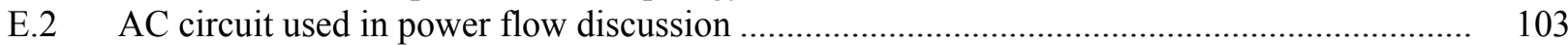

E.3 Constant power performance of the PMSM driven by sinusoidal PWM.............................. 107 


\section{LIST OF TABLES}

$\underline{\text { Table }}$

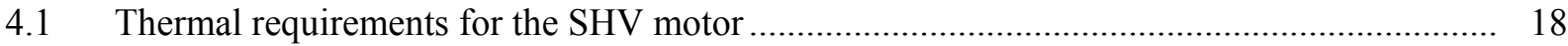

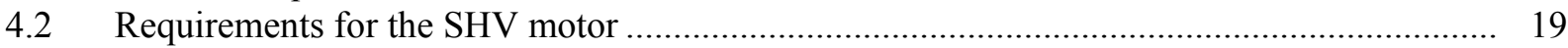

5.1 Comparison of selected neodymium and highest-performance samarium

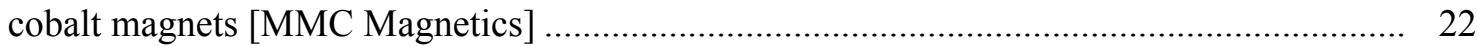

5.2 Physical properties of neodymium and samarium cobalt magnets .................................... 23

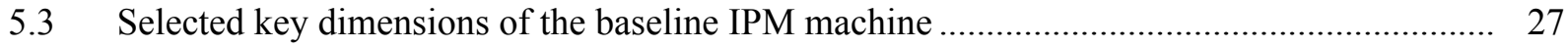

$5.4 \quad$ Additional key parameters of the baseline IPM machine ................................................ 27

5.5 Selected key results of the baseline IPM machine at $1040 \mathrm{rpm}$ and $5400 \mathrm{rpm} \ldots \ldots \ldots \ldots \ldots \ldots \ldots . . . . . . . . . .28$

5.6 LPM characterization of the baseline IPM machine for numerous key parameters

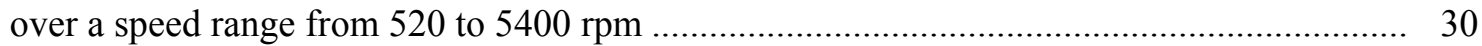

$5.7 \quad$ Selected key dimensions of the high-speed IPM machine............................................. 37

5.8 Additional key parameters of the high-speed IPM machine.................................................. 37

5.9 Selected LPM results of the high-speed IPM machine at $2000 \mathrm{rpm}$ and $8000 \mathrm{rpm} \ldots \ldots \ldots \ldots \ldots . . . . . .37$

5.10 Selected FEA results of the high-speed IPM machine at $2000 \mathrm{rpm}$ and $8000 \mathrm{rpm} \ldots \ldots \ldots \ldots . . . . . . .38$

5.11 Dimensional parameters for the multi-layered machine ................................................. 39

5.12 Selected dimensions of the recessed magnet machine ................................................ 48

5.13 Selected lumped parameter results for 8-pole recessed magnet machine ........................... 49

5.14 Selected lumped parameter results for 12-pole recessed magnet machine .......................... 49

6.1 Old target design specification for power electronics and electric machines ....................... 50

6.2 Limiting values of inductance for BDCM operation ................................................... 51

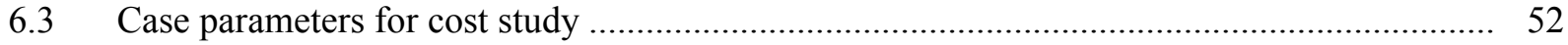

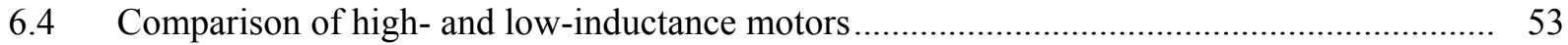

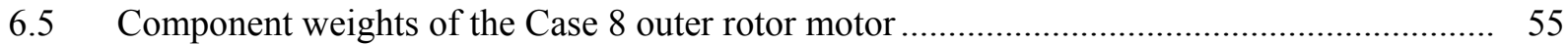

6.6 Outside rotor motor losses at $30 \mathrm{~kW}$ useful power....................................................... 56

6.7 Component weights of the Case 7 axial-gap PM motor ................................................... 57

6.8 Losses of the fractional-slot motor at 20\% torque .......................................................... 61

7.1 Estimated magnet cost of alternative IPM motor design scenarios .................................. 66

7.2 Motor mass and cost distribution of three alternative IPM designs .................................... 68

A.1 Efficiency as a function of motor torque …..................................................................... 79

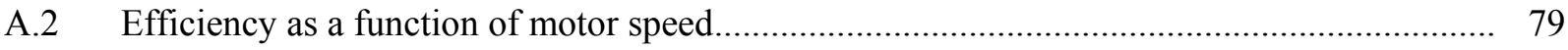

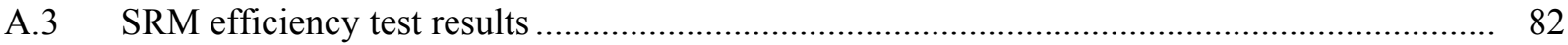

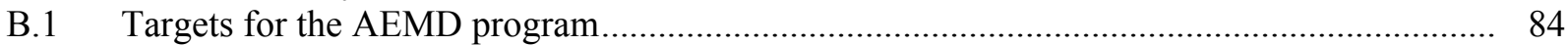

B.2 Comparison of selected performance parameters for AEMD Team 1 machines.................... 85

B.3 Design geometry of the conventional induction machine................................................ 86

B.4 Design geometry of the low-cost induction machine.................................................... 87

B.5 Summary of design changes for the AEMD Team 1 outer-rotor PM machine....................... 88

C.1 Ironless motor comparison with 75\% iron-filled motors ................................................ 92

C.2 Pugh analysis results for the baseline and axial-gap motor designs .................................. 96

D.1 SPEEDCAD parameters relating to machine dimensions ............................................... 99

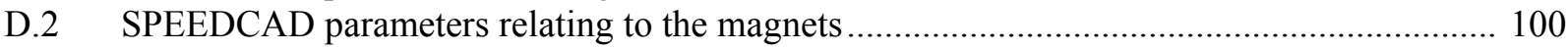

D.3 SPEEDCAD parameters relating to control data ......................................................... 100 


\section{ACRONYMS, ABBREVIATIONS, AND INITIALISMS}

$\begin{array}{ll}\text { AEMD } & \text { Automotive Electric Machine Drive } \\ \text { BDCM } & \text { brushless dc motor } \\ \text { CPA } & \text { conventional phase advance } \\ \text { CPSR } & \text { constant power speed ratio } \\ \text { CRADA } & \text { cooperative research and development agreement } \\ \text { CRML } & \text { cold-rolled motor lamination } \\ \text { DEEMS } & \text { Delphi Energy and Engine Management Systems } \\ \text { DMIC } & \text { dual mode inverter control } \\ \text { DOE } & \text { Department of Energy } \\ \text { DSP } & \text { digital signal processor } \\ \text { EETT } & \text { Electrical and Electronics Technical Teams } \\ \text { emf } & \text { electromagnetic force } \\ \text { FEA } & \text { finite element analysis } \\ \text { GNO } & \text { grain-non-oriented } \\ \text { HEV } & \text { hybrid electric vehicle } \\ \text { IPM } & \text { interior permanent magnet } \\ \text { ISP } & \text { current limit setpoint } \\ \text { IGBT } & \text { insulated gate bipolar transistor } \\ \text { LPM } & \text { lumped parameter model } \\ \text { OD } & \text { outer diameter } \\ \text { OEM } & \text { original equipment manufacturers } \\ \text { ORNL } & \text { Oak Ridge National Laboratory } \\ \text { PEEMRC } & \text { Power Electronics and Electric Machinery Research Center } \\ \text { PM } & \text { permanent magnet } \\ \text { PMBLDC } & \text { permanent magnet brushless de } \\ \text { PMSM } & \text { permanent magnet synchronous motor } \\ \text { PNGV } & \text { Partnership for a New Generation of Vehicles } \\ \text { PWM } & \text { pulse width modulation } \\ \text { RFP } & \text { request for proposals } \\ \text { SHV } & \text { series hybrid vehicle } \\ \text { SPEEDCAD } & \text { Scottish Power Electronics and Electric Drive Computer-Aided Design } \\ \text { SRM } & \text { switched-reluctance motor } \\ & \end{array}$




\section{EXECUTIVE SUMMARY}

The Department of Energy's (DOE) Office of FreedomCAR (Cooperative Automotive Research) and Vehicle Technologies office has a strong interest in making rapid progress in permanent magnet (PM) machine development. The DOE FreedomCAR program is directing various technology development projects that will advance the technology and hopefully lead to a nearterm request for proposals (RFP) for a to-be-determined level of initial production. This aggressive approach is possible because the technology is clearly within reach and the approach is deemed essential, based on strong market demand, escalating fuel prices, and competitive considerations.

In response, this study began parallel development paths that included a literature search/review, development and utilization of multiple parametric models, verification of the modeling methodology, development of an interior PM (IPM) machine baseline design, development of alternative machine baseline designs, and cost analyses for several candidate machines. This report summarizes the results of these activities as of September 2004.

This report provides background and summary information for recent machine parametric studies and testing programs that demonstrate both the potential capabilities and technical limitations of

- brushless PM machines (axial gap and radial gap),

- the IPM machine,

- the surface-mount PM machines (interior or exterior rotor),

- induction machines, and

- switched-reluctance machines.

The FreedomCAR program, while acknowledging the progress made by Oak Ridge National Laboratory (ORNL), Delphi, Delco-Remy International, and others in these programs, has redirected efforts toward a "short path" to a marketable and competitive PM motor for hybrid electric vehicle (HEV) traction applications. The program has developed a set of performance targets for the type of traction machine desired. The short-path approach entails a comprehensive design effort focusing on the IPM machine and meeting the performance targets. The selection of the IPM machine reflects industry's confidence in this market-proven design that exhibits a high power density.

\section{$\underline{\text { Preliminary Conclusions }}$}

In order to meet original equipment manufacturers (OEM) machine target specifications to the maximum extent possible, machine designers and analysts must explore the following:

1. Voltages closer to the $600 \mathrm{~V}$ insulated gate bipolar transistors (IGBTs) limit should be considered, at least during low-speed operation, to prevent violation of the IPM machine current limit and achieve the high efficiency requirements;

2. New rotor configurations and innovative lamination materials should be explored for potential performance advantages; and 
3. The use of injected magnets should be evaluated as a means of more fully meeting the cost per $\mathrm{kW}$ requirement.

$\underline{\text { IPM Design Considerations }}$

The major focuses of this study were the complex mechanical and electro-magnetic design issues of a high-speed, high-power-density IPM machine. For instance, at high speeds, rotor structural integrity and mechanical balance are critical design issues. Also, a low-voltage, IPM machine requires a reduced number of turns in the stator poles or flux weakening to deliver the same amount of power at low and high rotor speeds. In order to conserve PM energy, the rotor's bridge must operate in a saturated state even at zero stator current condition. If this is not the case, a very significant percentage of the PM flux is wasted.

Any HEV traction motor application tends to place restrictions on machine weight, size, source voltage, maximum current, available cooling, etc. It has become clear during the IPM design process that high stator currents are a characteristic of low-speed operation where a limitedduration, peak-power capability is required. Direct results of high current operation are the significant zones of saturation or near-saturation conditions that result in the stator and rotor. Of course, this is expected in any well-designed, high-power-density, IPM machine.

A potential conclusion reached during the design process is that machine performance goals need to reconcile conflicting design impacts such as efficiency and high power density during lowspeed, peak power operation. It will be difficult to meet all of the performance targets at the same time. Also, analysts believe that a significant improvement in performance can be achieved with the use of bi-state and improved ferromagnetic materials that are able to minimize the parasitic magnetic flux paths in the rotor and reduce saturation levels in the stator.

\section{$\underline{\text { IPM Machine Modeling }}$}

This study relied on numerous, complex executions of lumped-parameter and finite element analysis (FEA) models where scripting subroutines were necessary for varying numerous parameters to arrive at designs with optimized performance. The results of the FEAs were used to improve the accuracy of the lumped parameter model (LPM) results. The modeling effort first required that both the models and the modeling approach be verified by considering a machine with known performance characteristics. The only commercially available IPM machine filling this requirement was the traction motor used in the Toyota Prius. The 2004 Prius traction motor was used in this task as the "baseline case" motor. After many lumped-parameter and FEA model runs, the analysts were able to use FEA model results effectively in "fine-tuning" the LPM to account for magnetic saturation and other phenomena that were not fully captured.

Next, the IPM machine was scaled down in size to one that would be capable of operating at higher speeds and an FEA was used to evaluate mechanical stresses and retention of the PMs. Then the study used the adjusted LPM to simulate the high-speed IPM machine at 2,000 to 8,000 rpm. The high-speed IPM machine was shown to have an overall efficiency similar to that of the baseline case. Further work is required for the high speed machine to address saturation issues with the rotor. 
A multi-layered IPM machine configuration was analyzed with three layers of PMs in the rotor. A parametric evaluation of the machine performance capability was performed varying the strength of the PMs, evaluating designs with and without steel center posts, and evaluating the effects of bi-state bridges and center posts. See Sect. 5.6 for results from the parametric study.

A recessed magnet machine was evaluated in Sect. 5.7. The 8-pole machine configuration requires additional evaluation and a higher pole machine configuration is probably required.

\section{$\underline{\text { Non-IPM Designs }}$}

Because the FreedomCAR project retains a strong interest in alternative machine designs, LPM of the following PM machines was performed:

- four 18-pole, radial gap (with cost study),

- three 8-pole, radial gap (with cost study),

- one outer-rotor,

- one fractional-slot winding,

- $\quad$ one Honda-type (T-shaped PMs with tabs for retention), and

- one axial gap.

These machines were designed to have a base speed of $1500 \mathrm{rpm}$, a constant power speed ratio (CPSR) of 4 , and a base power of $30 \mathrm{~kW}$ to reflect performance targets that were in effect earlier in the study when much of the work took place. Some type of field weakening was used in each design between 1500 and $6000 \mathrm{rpm}$.

Although a study with fully integrated lumped parameter/FEA analysis was not performed for these machines, as it was for the IPM, modeling has produced limited results for most of the listed machine types. The Honda-type machine with T-shaped PMs was also analyzed using an FEA to determine stresses in the PMs. Analyses will continue for assessing PM-retention rotor wraps and machine performance in general.

\section{Cost Study}

The cost estimation in this study assumes a bottom-up approach in a large-scale motor manufacturing facility with favorable and realistic economic conditions. The cost structure for a motor manufacturing facility was developed based on conversations held with appropriate manufacturers. Each motor is considered at the major component level, where it comprises seven main constituent elements. Motor component sizing information, obtained from parametric modeling runs, is used as essential input for the cost estimation.

Based on the cost analysis, the cost for the high-speed, high-speed IPM machine is $\$ 368$, compared with $\$ 404$ for the baseline IPM machine. As expected, the cost of magnets dominates the overall motor material cost distribution. The magnet material prices vary widely in the market today, increasing the uncertainty of motor cost estimates. 
Cost estimates were also generated for the surface-mounted, inner rotor machine. Attractive pricing resulted for the four 18-pole machines, ranging from $\$ 240$ to $\$ 401$. 


\section{INTRODUCTION}

The goal of this study is to analyze selected electric motor designs that presently show the greatest promise for use in HEV traction drive applications. Specifically, the application is for a single source of mechanical propulsion force in a fuel-cell-powered vehicle. It is referred to as a series hybrid vehicle (SHV) application, as opposed to a parallel hybrid vehicle that uses an electric motor to supplement power from a gasoline engine primarily during acceleration.

This report provides the results of analyses completed in September 2004. Much of the work described in this interim report has to do with developing and verifying models, understanding model agreement/disagreement, baselining results relative to known machine performance specifications, and evaluating results at different machine speeds. This work is essential prior to evaluating other proposed machine designs for which performance data do not exist.

The following sections describe the work for the full parametric study that is scheduled to conclude in September 2004.

\section{$\underline{\text { Scope of Work }}$}

In this project, ORNL engineers will use a number of analytical models and supplemental calculations to characterize new electric machine designs with the performance characteristics best suited for automotive applications. Physics-based models, recently developed models capable of analyzing new and innovative PM machine designs, and FEA methods will be used extensively in the study to evaluate the electric machines. In parallel with this effort, a closely coordinated cost study will develop baseline cost estimates for the selected machine designs. In the end, the study will effectively reduce the uncertainties pertaining to selected machine designs to allow the program to progress to the eventual selection and commercialization of an SHV traction motor design.

At the end of FY 2004, ORNL will assess the overall results of the study and the program status to determine what additional technical studies, if any, are needed before making a recommendation of a prototype motor. This task will consider feasibility of IPM type machines meeting performance targets, impact of parametric variations, and positive and negative attributes of various machine types.

The primary focus of this work is the IPM machine. In IPM machines, the PMs are fully embedded (i.e., buried) in the rotor steel structure. The study will analyze IPM machines for various design variations, using LPMs to identify they key design parameters. In parallel with the IPM machine design parametric study, but with a smaller scope, analysts will evaluate other motor types, specifically surface-mounted, inner-rotor, and outer-rotor PM machines.

The scope of the study will be limited to the motors themselves while remaining fully cognizant of the motor-inverter systems. Essential inverter characteristics/effects, such as phase advance and types of electrical waveforms, will be carefully considered in exploring the full potential of the motor. A careful approach will be used in evaluating low-induction motor designs so that 
high machine performance is attained without high electrical stresses and losses in the inverter system.

This study will make use of the results of other electric-machine-related studies conducted by ORNL and other organizations during the last 10 years. Results from prior cooperative research and development agreements (CRADAs) and the automotive electric machine drive (AEMD) tasks will be reviewed and applied as appropriate as a technical foundation. ORNL will also use open literature and consultation with recognized national experts to provide additional insight into efforts that have recently been investigated by industry, universities, and other government laboratories.

\section{Methodology}

ORNL will make efficient use of lumped-parameter models, primarily Scottish Power Electronics and Electric Drive Computer-Aided Design (SPEEDCAD ${ }^{\mathrm{TM}}$ ), to initially explore ranges of machine geometry, size, and other parameters to determine optimal parameters and/or sets of parameters as indicated in Fig. 1.1. The process indicated in the three central blocks of the figure is repeated until it becomes evident that an optimal design has been achieved. The model will help in obtaining the optimal design by providing the analyst with the results of both static and dynamic design results. Scripting routines are used as essential tools for varying large numbers of machine design parameters to find optimal combinations for attaining the machine performance goals. The FEA iterations are performed generally toward the middle and end of the analysis.

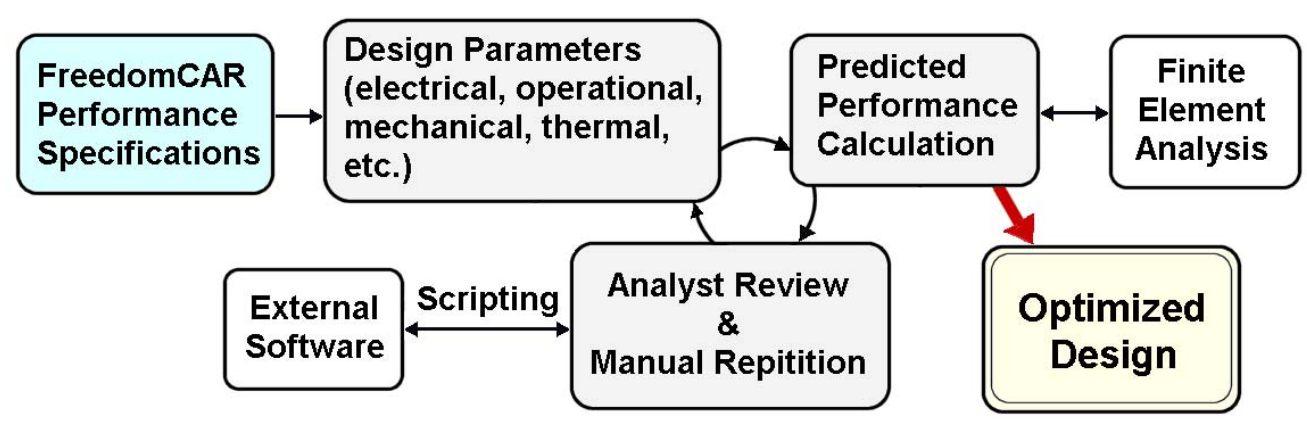

Fig. 1.1. Machine design process diagram.

The analyses will provide estimates of performance and the magnetic field distribution within the electric machine. The low-speed torque and constant power range will be maximized and correlated with an analysis of current, supplied voltage, and back-electromagnetic force (emf). Inductance and torque variations according to rotor position will be assessed. Electrical circuit parameters will be determined for the electric machine being evaluated and optimization of parameters will be performed.

FEA methods will be used to derive a detailed model of the selected electric machines and to confirm and refine the selected designs. FEA methods will be used to evaluate flux density, relative permeability, and isoflux mapping based on the size, shape, and type of PMs. The PM demagnetization curve will be determined and utilized in the FEA to calculate concentrations of 
magnetic flux density throughout the machine. Machine saturation effects, inductances, and torque variation according to rotor position will be determined.

The FEA will also evaluate detailed machine features, including the geometry and lamination stack length. The analyses will also consider stator winding layout, including coil pitch, interconnections, number of turns, etc. However, the greatest emphasis will be parameters pertaining to the rotor, which will be modeled rigorously. The designs will be assessed for any potential problems requiring resolution, and motor designs with attractive performance specifications will be determined.

A cost study will be prepared on the baseline IPM motor design and will include a trade-off study of machine cost vs. variations in selected design characteristics or operational limits. These variations include PM quality, laminate design, saturation limits, machine speed, machine diameter, and stack length. The analysis will then be repeated in lesser detail for the other machine configurations included in the study.

For a machine design to be considered commercially viable at low risk, some assurance is needed that reliability and cost goals for a given traction motor drive design are attainable. The electric motor's lifetime can be considered to be a function of the material used in the motor, such as the stator insulation, and the operational stresses imposed on the unit. Aging of insulation is normally viewed as a chemical process that occurs more rapidly at higher temperatures. Thus, the life of the machine can be increased by reducing the normal operating temperature of the stator and rotor by reducing losses, improving heat transfer, and minimizing any temperature excursions experienced by the machine. These considerations will be integrated into the study. 


\section{BACKGROUND}

The U.S. DOE directed the AEMD task efforts over several years to improve technology in many critical areas in support of the HEV. ORNL and other AEMD technical development teams were contracted to conduct research on different machine designs, primarily in the $15-30 \mathrm{~kW}$ range, and their progress was assessed during quarterly DOE/Technical Team meetings. As part of the DOE-AEMD contracts, axial-gap PM motors, radial-gap PM motors with an outer-rotor configuration, and induction machine designs were explored (see Appendices A, B, and C). Electric machines were researched in analytical studies, experimental prototypes were constructed, and tests were conducted for both the series and parallel HEV applications.

Another important initiative was the Partnership for a New Generation of Vehicles (PNGV). PNGV's goal was to manufacture an affordable family car that attains 80 miles per gallon, with production of a prototype by 2004. However, in January 2002, Secretary Abraham announced that the FreedomCAR (CAR = Cooperative Automotive Research) initiative would take the place of the PNGV.

As the last of the AEMD tasks are completed, the ongoing HEV development effort is now largely supported under the FreedomCAR program, which is funded by DOE's FreedomCAR and Vehicle Technologies Office. FreedomCAR seeks to support research and development for all promising traction motor designs/configurations, in addition to supporting development in many related technology areas that are of crucial importance, including thermal management, power electronics, and system integration. The broader FreedomCAR program is also supporting research in associated areas such as fuel cells, hydrogen cost reduction, and hydrogen storage. Thus, FreedomCAR is an industry/government research initiative focused on collaborative, highrisk research to develop the component technologies necessary to provide a range of affordable vehicles that will free the United States from petroleum dependence and harmful emissions sources. The program intends to accomplish this without sacrificing freedom of either mobility or vehicle choice.

Several automotive OEM, that are members of FreedomCAR's Electrical and Electronics Technical Teams (EETTs), are recommending that analysts begin to narrow their focus to the development of IPM motors to meet FreedomCAR goals. This recommendation reflects the rapidly growing desire of the OEMs to select and commercialize a viable design in the near future. This OEM priority will be accommodated in the present study through a strong emphasis on the IPM while preserving serious consideration of other machine designs that merit continued interest in the program.

The FreedomCAR goals and specifications have been established to provide direction and guidance for the electric machine design goals set for this task. These design goals were subsequently reviewed and modified to meet the needs of both DOE and the EETTs. The specifications call for a $30-\mathrm{kW}$ machine with $>93 \%$ efficiency and a 15 -year life, costing $<\$ 7$ per $\mathrm{kW}$. The full set of specifications (Sect. 4.2) contain several operational conditions, limitations, and performance measures that present a medium or high degree of technical challenge. Meeting the full set of specifications represents a very significant challenge, given current technology. 
Priority has been assigned to certain characteristics of the electric machine based on guidance from DOE and the EETTs. For example, the cost and high-speed efficiency of the electric machine could be assigned priority. In this study, priority or emphasis will be placed on the analysis of IPM motor designs, in part because successful commercialization of this machine type has already been demonstrated successfully in the automotive industry. 


\section{ELECTRIC MACHINE TECHNOLOGY REVIEW}

There are several types and configurations of rotational electric machines to be considered in this study, each having specific strengths and weaknesses. It is anticipated that certain machine configurations will not be acceptable to the automotive industry because of their inability to meet specific requirements such as specific power at peak load, continuous power, volumetric power density, cost per kilowatt, efficiency, maximum weight, and lifetime. The estimation of programmatic risk relative to the commercialization of a given design is also of critical interest.

\subsection{BRUSHLESS PM MACHINE}

Brushless PM machines are constructed with the electric winding on the stator and PMs on the rotor. There are several conventional PM machine configurations and other more novel concepts conceived in recent years to improve performance. The configuration of a PM machine and the relationship of the rotor to the stator determine the geometry and the shape of the rotating magnetic field. The shape of the back-emf is a fundamental characteristic. PM machines in which the magnetic flux travels in the radial direction are classified as radial-flux machines. They are cylindrical in shape, and the rotor is usually located inside the stator but can also be placed outside the stator. PM machines in which the magnetic flux travels in the axial direction are classified as axial-gap machines. They can have multiple disk- or pancake-shaped rotors and stators. The stator-rotor-stator configuration is typical. The shape of the back-emf of PM machines matches that of the driving currents and can be trapezoidal or sinusoidal. Although both kinds are brushless and synchronous, PM machines with trapezoidal back-emf are often called brushless de motors (BDCMs), while PM machines with sinusoidal back-emf are referred to as PM synchronous motors (PMSM).

In general, PM machines have a higher efficiency as a result of the passive, PM-based field excitation. PM machines have the highest power density compared with other types of electric machines, which implies that they are lighter and occupy less space for a given power rating. The amount of magnet material that is required for a given power rating is a key cost consideration. The cost of magnet material is high compared with the cost of the other materials used in electric motors, and design attributes that minimize the required amount of magnet material are important considerations in motor selection. The stators of PM machines are generally fabricated in the same manner as induction machine stators; however, modifications are sometimes necessary, such as the design of a stator lamination to accommodate high flux density.

\subsection{IPM MACHINE}

In contrast to surface-mounted PM machines, buried-magnet or IPM machines offer certain advantages, their suitability for high-speed operation being perhaps the most obvious. The fundamental difference is that in a surface-mounted rotor, the flux cannot be moved tangentially within the magnet to provide a rotor-to-stator phase advance, while in a buried-magnet rotor the flux can be moved tangentially above the magnets in the rotor iron so that a quite significant rotor-to-stator phase advance can result. The flux may be skewed to such a degree by the time it passes through the stator that areas of saturation may exist in pairs of adjacent teeth at each pole. 
In favor of surface mounting, the presence of ferromagnetic material at the rotor surface increases the air gap inductance.

As a result of the rotor-to-stator phase shift, buried magnets add a reluctance component to the torque produced by the motor, which tends to improve the constant-power speed range. This avoids the power dropoff that is common in surface magnet PM machines operating at high speeds. IPM machines can provide torque under certain conditions with less $\mathrm{I}^{2} \mathrm{R}$ losses than other PM machines.

The saturation that may occur in the quadrature axis ( $\mathrm{q}$ axis or interpolar axis, extending out radially from the interpolar space) of IPM machine stators is not all good. The saturation represents magnetic flux that is not used efficiently in producing torque. All forms of field weakening, regardless of the PM motor type, represent a loss in motor efficiency. However, the reluctance torque benefit in the IPM may be well worth this drawback.

IPMs facilitate the use of easily manufactured rectangular magnets or other convenient geometries. Yet another design consideration is that IPM machines with high-energy magnets can be designed to provide rapid acceleration because of their high torque/inertia ratio; this is why compact versions of IPMs are commonly used in servo systems.

Figure 3.1 shows conceptual depictions of IPM rotor configurations; Fig. 3.1a shows a version with straight or flat magnets, and Fig. 3.1b depicts magnets that have been split and oriented in a V-configuration. This second version can accomplish different objectives, depending on the precise geometry. It might allow the use of slightly longer magnets within the same magnet arc. This would provide more magnetic flux for performance enhancement. A different configuration would place more rotor yoke iron between the magnets and the air gap and allow for different flux line paths in the yoke.

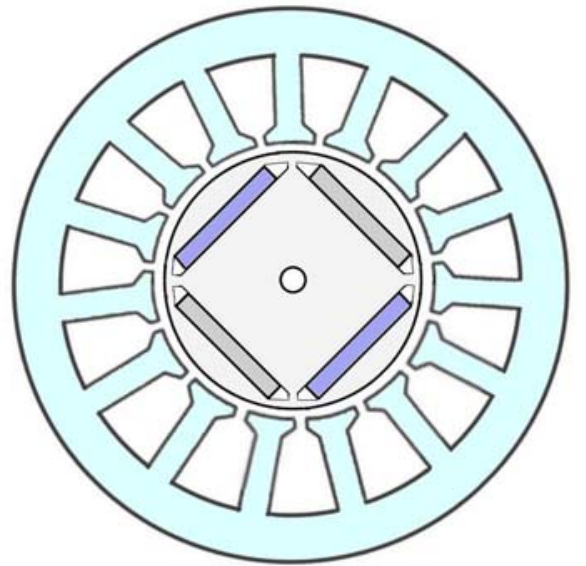

a) Interior Magnets

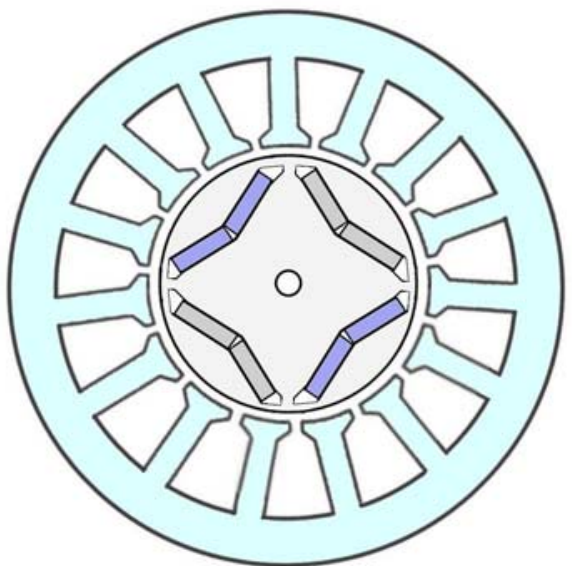

b) Split Interior Magnets

Fig 3.1. Two variations of an IPM machine rotor. 
The SHV version of the IPM that will be considered in this study is more sophisticated than the depiction in Fig. 3.1 and is more accurately depicted in Fig. 3.2. Note that the machine has a high stator slot count and that the rotor magnets are positioned very close to the rotor-to-stator gap. This positioning and the air pockets at the ends of the magnets are necessary to reduce saturation that could otherwise be a serious path of flux leakage, as indicated in the sketch. The figure illustrates an issue with rotor mechanical integrity resulting from the fact that the magnets are held in place only by two narrow metal bridges located between the magnet air pocket and the air gap. This rotor mechanical integrity issue must be fully addressed to permit operation at the target high rotational speed.

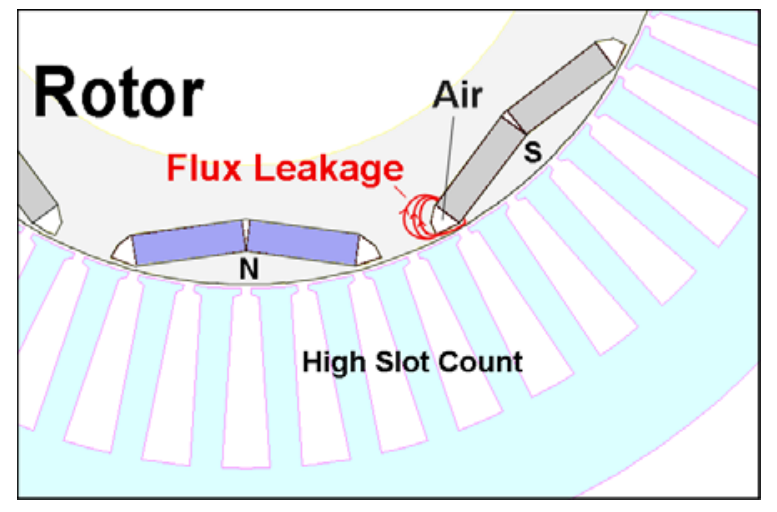

Fig. 3.2. View of the SHV IPM machine with key features.

To fully define and model an IPM machine suitable for the SHV, numerous parameters must be defined for each of several categories that include dimensions, windings control, thermal, and magnetics. Through modeling, the designer and analyst are able to identify which parameters are critical to machine performance and which have an effect on the machine performance that may not be intuitive. Inductance, maximum current, rated voltage, wire size, magnet size, and magnet arc are just a few examples of critical parameters that must be set consistent with the assigned values of other parameters. For more on critical machine parameters, see Sect. 4.3.

In IPM machines, the PMs are entirely encased in rotor cavities. This arrangement may lead one to conclude that the iron or laminated steel alloy provides good containment at high speeds. However, this is not necessarily the case. The magnets slice through the rotor in a sizable 2-dimensional plane that tends to result in a weaker rotor if corrective measures are not used. What rotor material is left provides limited structural integrity, since the material is a soft magnetic steel alloy or iron. High-speed rotor operation is still possible, but it must be designed for and verified using structural calculations (e.g., via an FEA). Rotor strengthening can be accomplished through the use of high-strength end rings, effective bonding in the magnet cavity, and/or the use of outer diameter (OD) rotor containment - either a high-strength metal can or a fiber-composite wrap. Most of these strengthening techniques increase the effective rotor-tostator air gap and can adversely affect the machine performance. 


\subsection{SURFACE MOUNT PM MACHINE}

This section discusses the interior-rotor, surface-mount configuration of the PM machine and the exterior-rotor configuration of the same.

\subsubsection{Interior Rotor}

The interior-rotor, surface-mount PM motor has as one of its most distinguishing characteristics a high torque/inertia ratio. The shaft torque increases proportionately with rotor length and with the square of the rotor diameter. The specific power and volumetric power density are also generally higher than in other non-PM machine types.

The stator of this machine is quite similar to that of an induction motor or synchronous motor. As with an induction motor, winding the stator is a difficult operation and is best performed using specialized, automated equipment. The stator yoke and rotor are generally made of laminations of magnetic steel, and the rotor laminations come from the hole pieces punched out of the stator laminations. Alternatively, the rotor yoke may be machined from a soft iron or low-carbon steel; however, eddy current losses will be higher than for a laminated rotor.

Figure 3.3 shows conceptually a number of different rotor designs that are used in surface-mount PM machines. Shown in Fig. 3.3a is a traditional rotor configuration where the surface magnets are curved both at the top and bottom. Four poles are shown, but several more poles can be added to the rotor and generally are added as the diameter of the rotor increases. Shown in Fig. 3.3b is the "bread loaf" design where the magnets are contoured on the top and flat on the bottom. The flat bottoms are more easily fabricated and bonded to the rotor yoke.

Shown in Fig. 3.3c is a substantial modification of (b) in which only half as many magnets are used. If the magnets have the same polarity, the design is called a consequence-pole rotor. The other two poles are nothing more than salient segments of the soft iron rotor yoke. Using only half the number of magnets reduces cost; however, the machine operates with a lower permeance coefficient. The double air gaps that the magnet flux must cross require a thicker magnet to avoid demagnetization. Additional poles may be added to the rotor design. If the two magnets in Fig. 3.3c were different poles, this configuration would represent a cross between a PM motor and a synchronous reluctance motor. ${ }^{1}$ 


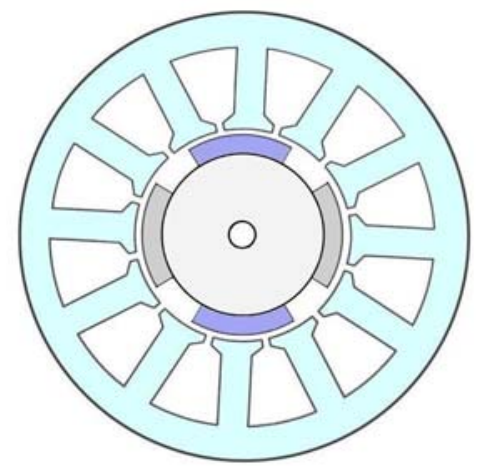

a) Bonded Arcs

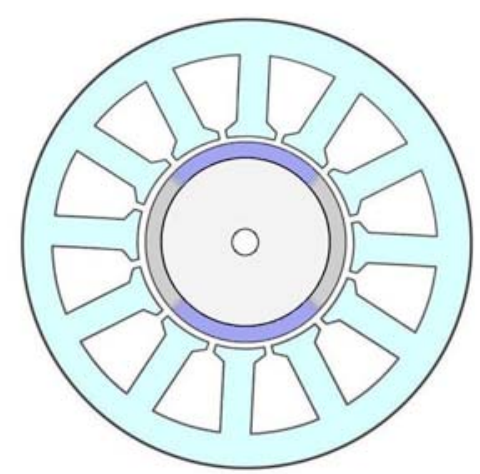

d) Bonded Ring

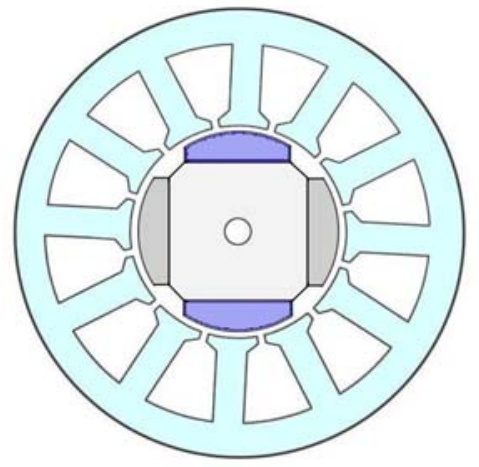

b) Bread Loaf

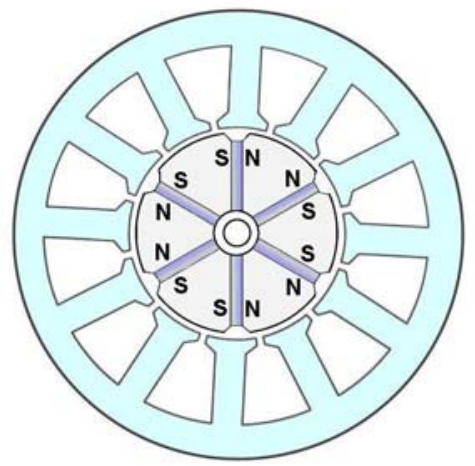

e) Spoke Magnets

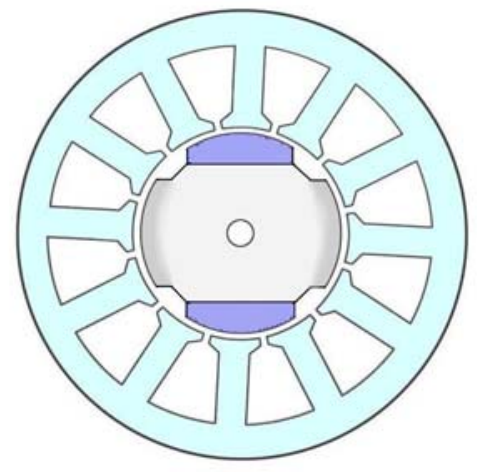

c) Consequence Pole

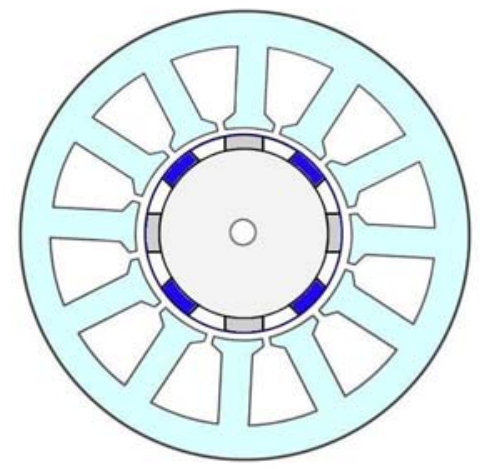

f) Arc and Ring

Fig. 3.3. Examples of rotor and magnet configurations in surface-mounted PM machines.

The rotor configuration shown in Fig. 3.3d features a ring of magnet material bonded over the rotor yoke. The ring is magnetized after its placement on the rotor yoke. The mechanical integrity of the magnet is enhanced by the 1-piece ring construction.

The spoked, internal (but not buried) magnet configuration in Fig. 3.3e has the advantage of using bar magnets with no curved surfaces. Since the magnet surface area is considerably greater than the rotor surface area over which the magnet flux passes, flux concentration occurs. ${ }^{2}$ This configuration is effective in getting improved performance from low-cost ferrite magnets.

The configuration in Fig. 3.3f shows curved surface magnets contained by a ring or shell. Although this design provides good magnet containment strength, the manufacturing cost of the magnets and rings may be somewhat higher. Effective and consistent containment requires a precise machined fit to tight tolerances.

The surface-mounted PM machine can be driven electrically by either trapezoidal or sinusoidal waveform. The position can be determined either by a sensor or by zero crossing, depending on the waveform. These electrical and control considerations can affect performance in terms of parameters such as torque density and torque pulsations.

As with the IPM machine, one of the most challenging design and manufacturing issues in producing an interior-rotor, surface-mount PM machine is magnet retention. Centrifugal forces 
tend to limit the rotational speed of the machine. Failure to retain the magnets will almost certainly destroy both the rotor and the stator assemblies. Magnets are usually bonded to the rotor yoke in a process that is carefully controlled with regard to cleanliness, adhesive specifications, and curing. ${ }^{1}$ Many designs use additional methods of containment, such as a tightfitting steel shell over the rotor made of non-magnetic 300-series stainless steel or Inconel ${ }^{\mathrm{TM}}$ or wrapping of the rotor with an epoxy-impregnated, high-strength fiber.

\subsubsection{Exterior Rotor}

The HEV is a high-torque machine application at the low-speed range. Since torque increases with the square of machine diameter, the high torque requirement leads to diameter sizes that, in internal rotor machines, can present magnet containment design challenges during high-speed operation. However, the exterior-rotor, surface-mount PM motor offers unique advantages for medium- to-high speed applications. One of these is the outer shell construction of the rotor, which is well suited for containing and securing the surface magnets. Also, the high inertia of the rotor structure is very effective in reducing torque ripple. For these reasons, the external rotor machine continues to be of high interest for the SHV traction drive.

This is not to say that the exterior rotor machine does not have its disadvantages. The rotating outer shell may be helpful in some machine applications, but in the HEV, the rotating shell may pose a potential rotating hazard if it is not enclosed or covered with a shield. This is not a major disadvantage, especially in light of the modest machine length that would be required. It also is somewhat more difficult to provide a coolant flow path to the interior stator than to the exterior stator in the interior rotor machine.

\subsection{INDUCTION MACHINE}

The induction motor has a long history of successful operation in industrial applications and has proved to be a rugged and reliable machine. Electric motor manufacturers have a great deal of knowledge and expertise in the design and fabrication of induction machines, which can be readily applied to a traction motor design. For the sizes of interest in the FreedomCAR project, the induction motor has been shown to have a lower efficiency and lower power or torque density than PM and reluctance motors (see Appendix B).

Although some promising cost-saving concepts have been investigated in recent years, there appears to be a dearth of new ideas for making substantial improvements to efficiency. Only small incremental improvements may be expected in the performance characteristics (i.e., efficiency, power density, etc.) of induction machines in the near future. Thus, high reliability and low technological risk will likely remain the primary advantages of this technology in the foreseeable future. 


\subsection{SWITCHED-RELUCTANCE MOTOR}

Reluctance machines are synchronous machines with certain unique features pertaining primarily to their doubly salient stator and rotor pole design. The machines are robust, use simple construction, and are suitable for high speeds. They include two types, switched and synchronous.

The synchronous reluctance motor is used in industry, where motors are required to operate in synchronism or where highly regulated speed control is required using a variable-frequency drive. The motors provide constant, unvarying (or highly controlled) speed from no load to full load with no slip.

The switched-reluctance motor (SRM) is excited by current pulses applied to each phase. The current pulses are applied based on precise rotor position. The inductance profile is triangular, with maximum inductance when it is in an aligned position. When voltage is applied to the stator phase, the motor creates torque in the direction of increasing inductance.

Both synchronous and SRMs require a position sensor unless new, sensorless technology is employed. Position sensors are a source of increased cost and reduced reliability.

In reluctance machines, torque is produced by the tendency of the rotor to move to a position where the inductance of the excited stator winding is maximized (i.e., rotor tooth aligns with active stator phase to minimize reluctance). The rotor is typically constructed of soft magnetic iron shaped so as to maximize the variation of inductance with rotor position. Opposite poles form a phase, and the phases are magnetically independent of one another. The machines tend to be noisy; a characteristic that has limited their applications in the past and has also limited their use in vehicles. Research has been on going for years in an attempt to address the noise issue, but little has been accomplished in actual noise mitigation. Reluctance machines are relatively lowcost machines, and they generally do not contain PMs.

Novel electric machines are being developed that have attributes that are unique or that combine features of PM, induction, or reluctance machines. There are several novel electric machine concepts that are being investigated by government laboratories, universities, and industry. 


\section{IPM MACHINE DESIGN POTENTIAL}

\subsection{DISCUSSION OF MACHINE DESIGN}

\subsubsection{Mechanical Design Issues}

Electric motors are readily designed to provide specific torque and useful power; however, a crucial question for any motor design is its maximum speed capability. Estimates may be made using force balance equations and elastic equations for rotational systems axisymmetric about an axis. These techniques, which may be matched to estimate circumferential stress and radial interference requirements (radial stress), provide only a rough idea of the speed capabilities of a particular configuration. In each design, the magnets generate an equiangular load that adds bending stresses to the tensile stresses; consequently, a finite element code is needed to determine a more representative picture of the stresses and deformation of the components of the motor. ORNL has used ALGOR stress analysis to examine the mechanical capabilities of the IPM motors.

\subsubsection{Mechanical failure criteria}

Since the rotor material is ductile, if failure is generated in the rotor, an excellent way to determine its maximum rotational speed is to adjust that speed so that the von Mises stress equals the rotor's yield strength. Yield strength is obtained from a uniaxial tensile test at the onset of plastic flow. Although one is tempted to use the ultimate strength, this is not wise because plastic flow allows the components to move, which may create imbalances that will lead to failure.

For ductile materials, experience has shown that the von Mises stress provides a dependable and non-conservative estimate of failure. This approach assumes that yield, which is the onset of plastic deformation, is caused by a critical shear stress on an octahedral plane. The normal to the octahedral planes have equal direction cosines with the three axes. The expression for octahedral shear stress is

$$
\tau_{\mathrm{oct}}=\frac{1}{3} \sqrt{\left(\sigma_{\mathrm{x}}-\sigma_{\mathrm{y}}\right)^{2}+\left(\sigma_{\mathrm{y}}-\sigma_{\mathrm{z}}\right)^{2}+\left(\sigma_{\mathrm{z}}-\sigma_{\mathrm{x}}\right)^{2}+6\left(\tau_{\mathrm{xy}}^{2}+\tau_{\mathrm{yz}}^{2}+\tau_{\mathrm{zx}}^{2}\right)} .
$$

where,

$\sigma_{\mathrm{i}}=$ stress in the direction indicated by the subscript

$\mathrm{T}_{\mathrm{ij}}=$ shear stress on the plane perpendicular to the first subscript and in the direction indicated by the second subscript

In the uniaxial test, all components of stress except for $\sigma_{\mathrm{x}}$ are zero. The value of the critical octahedral shear stress may be obtained from the uniaxial test data by substituting $\sigma_{\mathrm{x}}=\sigma_{\text {yield }}$ in Eq. (1). The result is

$$
\tau_{\text {oct }}=\frac{\sqrt{2}}{3} \sigma_{\text {yield }}
$$


When more complex loading occurs, for which terms in Eq. (1) are not zero, Eq. (1) may be set equal to Eq. (2). The result is that

$$
\sigma_{\text {yield }}=\sqrt{\frac{\left(\sigma_{\mathrm{x}}-\sigma_{\mathrm{y}}\right)^{2}+\left(\sigma_{\mathrm{y}}-\sigma_{\mathrm{z}}\right)^{2}+\left(\sigma_{\mathrm{z}}-\sigma_{\mathrm{x}}\right)^{2}+6\left(\tau_{\mathrm{xy}}^{2}+\tau_{\mathrm{yz}}^{2}+\tau_{\mathrm{zx}}^{2}\right)}{2}},
$$

where the term on the right of Eq. (3) is known as the von Mises stress or the effective stress.

Different failure modes may require different criteria to determine maximum operating speed. For example, if the failure mode is fracture of the magnets, which are brittle materials, the criteria for operation will necessitate a Weibull distribution of the magnet's transverse fracture strength. From this distribution, a maximum stress may be determined to achieve the required probability of fracture. ${ }^{3}$

\subsubsection{Mechanical operating speeds of IPM motors}

The IPM machines are progressing through an evolution that significantly increases their speed capabilities. Three types of machines, two of which are already in the market, have been examined using the ALGOR finite element program. The two are the Toyota Prius THS motor (2003) and the Toyota Prius THS2 motor (2004). The third is being proposed by ORNL as a modification of the THS2 to deliver increased torque and power using the principles of the highstrength undiffused brushless (HSUB) motor.

The interior PMs move within cocoons of M19 steel during operation. To observe how they load the M19 with the finite element code, it is necessary to use gap elements, which come into play only when their initial dimension is reduced. Such a reduction indicates that the materials are trying to overlap. Although this is mathematically possible, it is realistically not permissible. To prevent this from happening, their stiffness normal to the surfaces is incorporated as part of the stiffness matrix. Since this is a non-linear calculation, the model in the configuration must be elastically stable when the first load increment is applied. This stability is provided by using a spring element so soft that it will not significantly impact the final solution. After each load increment, the gap elements are checked to see which ones have diminished; and one by one, those that have diminished are added to the stiffness matrix. The load along each active gap element is calculated. The load for inactive gap elements is zero.

In each IPM model, the load of the magnets and all of the material to the outer radius must be supported by the remaining spoke-like portions of the rotor. The significant mechanical contribution of the Toyota Prius THS motor is the use of two 1-mm-thick peripheral bridges of M19 silicon steel between the loaded region and the spokes to support each IPM. This magnet loading is shown in Fig. 4.1, in which it appears that the rotor interface between the magnet and the periphery bends, allowing the magnet load to be applied only at its outer edge. Because of symmetry, the total magnet load appears to be $240 \mathrm{lb}$. Figure 4.2 shows the onset of plastic deformation in the inner surface of the bridge near the spoke, indicating that the maximum operating speed is $5686 \mathrm{rpm}$. 


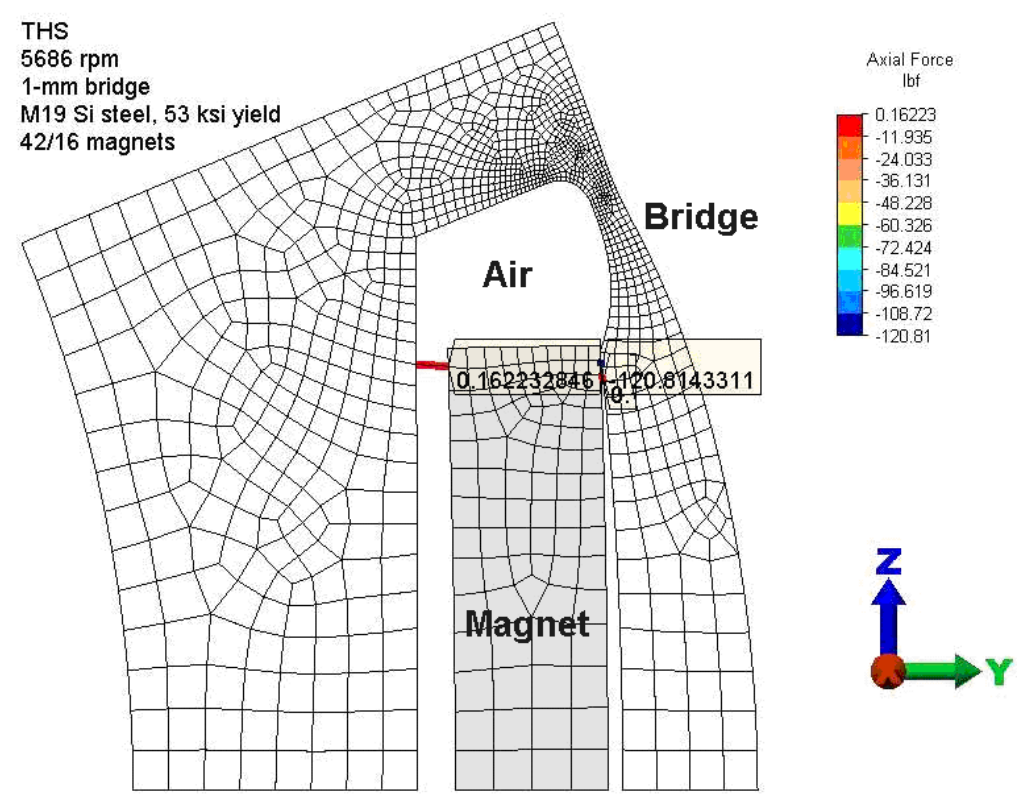

Fig. 4.1. Magnet loading in the THS design.

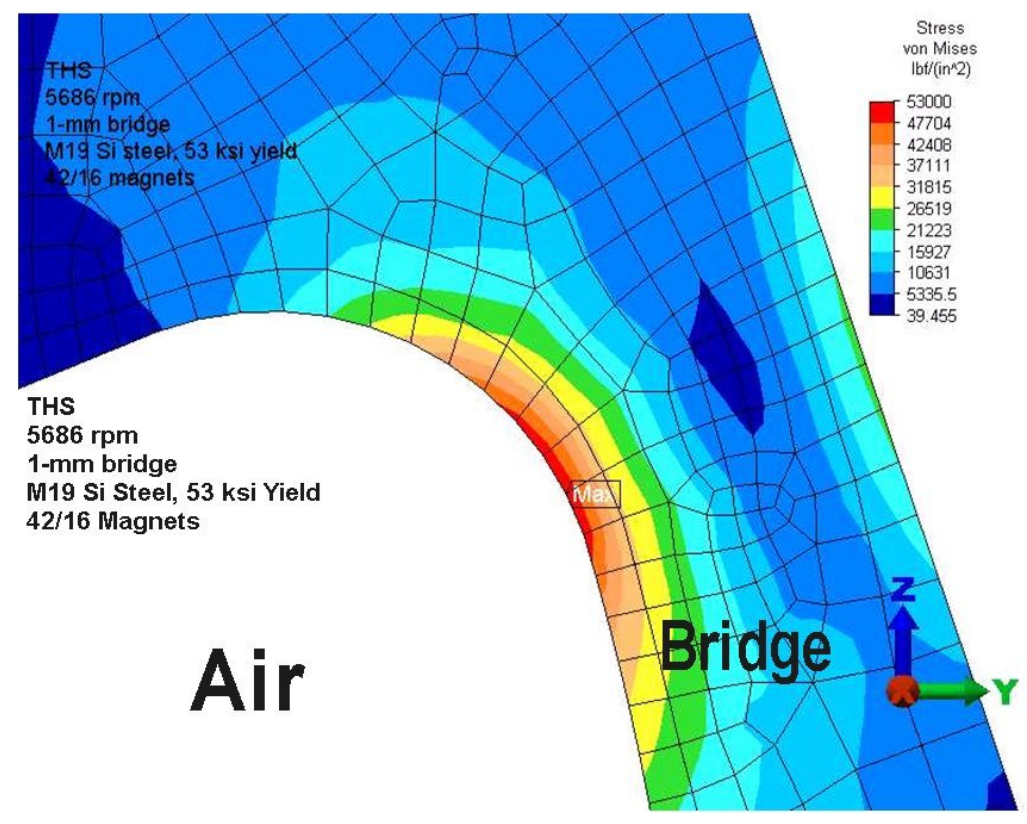

Fig. 4.2. Onset of plastic deformation in the THS motor.

The impressive additional mechanical contribution of the THS2 motor is the addition of a ledge on the spoke side to carry a large part of the magnet load and relieve the load on the bridge. Figure 4.3 shows that the magnet load supported by the ledge on the spoke side of the cocoon is $102 \mathrm{lb}$. The result of this load redistribution is that the maximum operating speed prior to the onset of plastic deformation is increased by $10 \%$ to $6231 \mathrm{rpm}$. Figure 4.4 shows that the bridge is similar to that of the THS motor. 


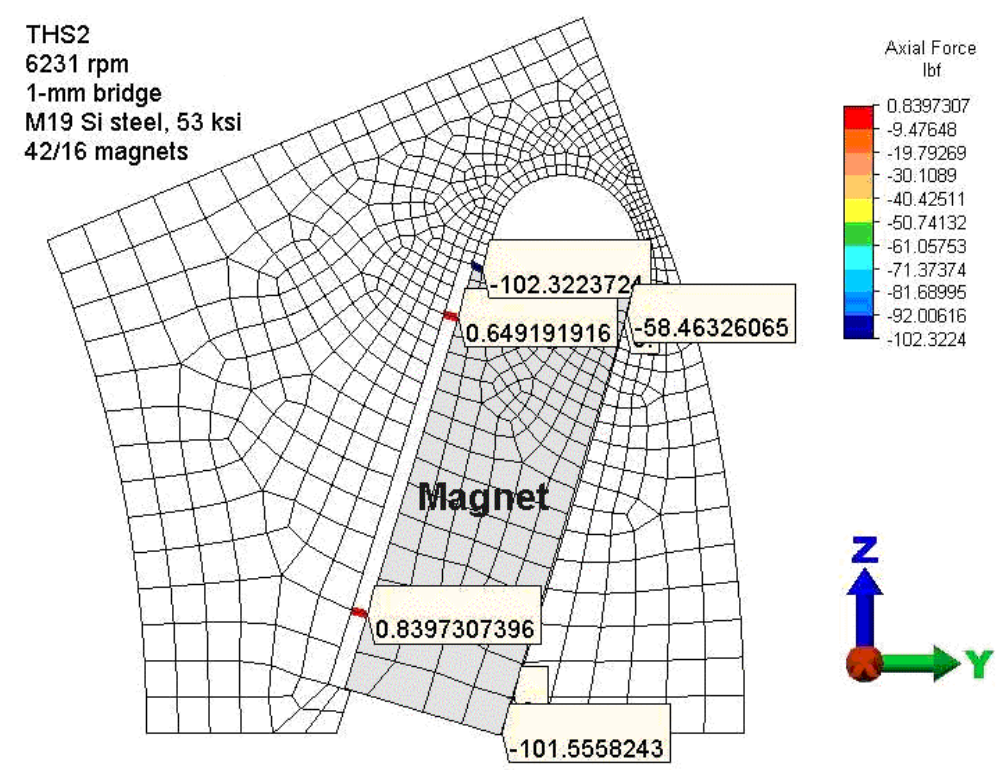

Fig. 4.3. Magnet load of the THS2 motor.

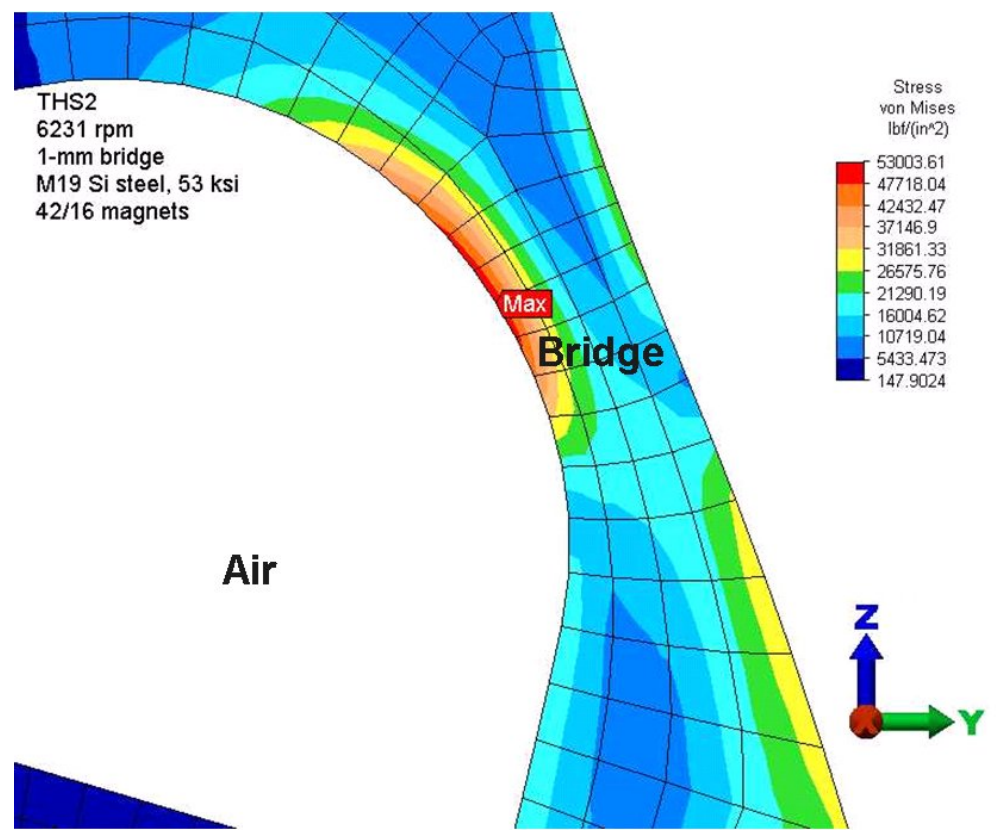

Fig. 4.4. Beginning of plastic deformation in the THS2 motor.

The third type of motor proposed by ORNL is the modified THS2 motor, which uses the ledge of the THS2 with the two magnets rotated into a radial orientation, adds an inner magnet to connect their inner corners, and employs a post or pile to provide additional support between each end of the inner magnet and the large region loaded by the magnets. Initial examination using the finite element approach indicated that the maximum operating speed prior to the onset of plastic deformation of the HSU configuration, using 1.2-mm bridges and 1.2-mm piles, is $9716 \mathrm{rpm}$. The magnet loading on the ledge is shown in Fig. 4.5, and the onset of plastic deformation at the inner pile is shown in Fig. 4.6. 


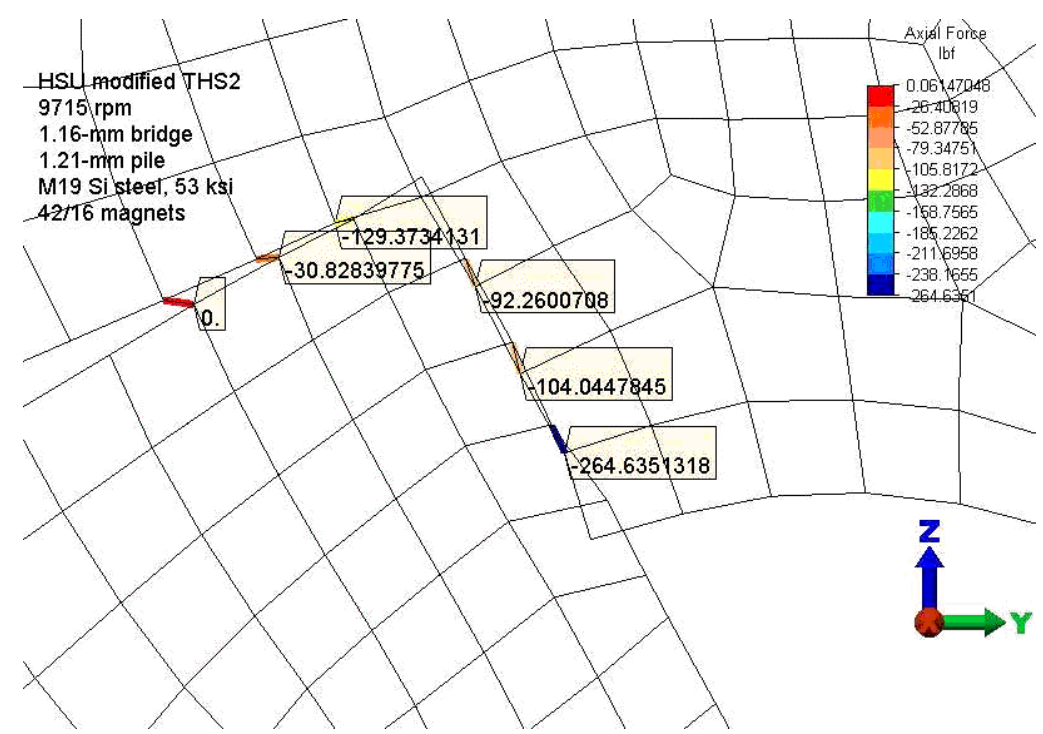

Fig. 4.5. Magnet load on the ledge of the modified THS2.

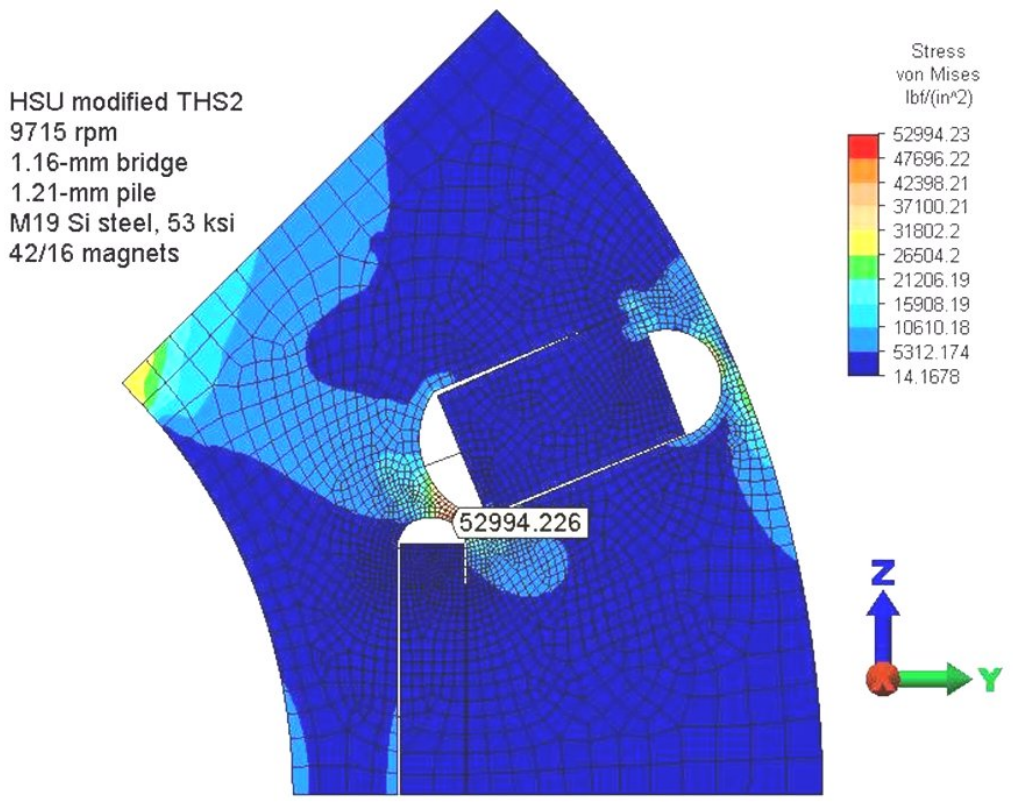

Fig. 4.6. Onset of plastic deformation in the modified THS2.

\subsubsection{Thermal Design Issues}

The full set of thermal requirements specified by the FreedomCAR program is listed in Table 4.1. The interpretation of these requirements is that a $10 \mathrm{~L} / \mathrm{min}$ flow of coolant in the temperature range of -40 to $+105^{\circ} \mathrm{C}$ shall be sufficient to cool the machine under all operating conditions defined in the general specifications and during severe driving cycles. 
Table 4.1. Thermal requirements for the SHV motor

\begin{tabular}{|l|c|}
\hline \multicolumn{1}{|c|}{ Thermal Requirement } & Specification \\
\hline Coolant inlet temperature $\left({ }^{\circ} \mathrm{C}\right)$ & -40 to 105 \\
\hline Ambient (outside container) operating temperature $\left({ }^{\circ} \mathrm{C}\right)$ & -40 to 105 \\
\hline Flow rate of coolant $(\mathrm{L} / \mathrm{min})$ & 10 \\
\hline Maximum coolant pressure drop $(\mathrm{psi})$ & 2 \\
\hline Maximum coolant inlet pressure $(\mathrm{psi})$ & 20 \\
\hline Storage temperature $\left({ }^{\circ} \mathrm{C}\right)$ & -50 to +125 \\
\hline
\end{tabular}

The machine design calls for a "dry" stator and rotor system and for the stator assembly to be encased in an aluminum housing with a built-in cooling jacket adjacent to the stator's outer surface.

\subsubsection{Electromagnetic Design Issues}

An electromagnetic design issue for the IPM is whether the selected design has a lower impedance than desirable. If the impedance is too low, the motor may deliver the required $30 \mathrm{~kW}$ mechanical power, but with higher-than-desirable current in the inverter. For instance, in terms of electrical power, the inverter may be supplying $50 \mathrm{~kW}$ inrush with $20 \mathrm{~kW}$ regenerative power in the motor.

\subsection{MACHINE SPECIFICATION}

The machine specifications have been under a rigorous and ongoing review by DOE and the EETTs. During the last several months of this study, the specifications have been revised on multiple occasions. Changes during March 2004 included increasing the rotation speed (both base and maximum speed) specification, a motor life specification, and additional thermal specifications. Meeting the full set of specifications is a significant challenge that will require widening the present technology envelope.

Table 4.2 lists most of the requirements from the revised specification and the estimated relative degree of technical challenge that is anticipated in meeting each requirement. To meet all of the requirements will present a significant technical challenge. The high-challenge requirements are related to power density in terms of mass and volume, the maximum estimated motor cost, and thermal considerations that relate to the power density.

Other requirements that are not listed, such as the minimum motor inductance, have a direct effect on the design of the motor and inverter and will be managed within the bounds of the primary requirements (in the table) and appropriate technical considerations or "engineering judgment." The battery operating voltage may need to be set at the high end of the range or increased further to reduce the current required for a given power rating and/or to ensure adequate current (i.e., for overcoming back-emf during high-speed operation). This may have vehicle maintenance safety implications that will have to be fully addressed before any final design selection process. Priority has been assigned to certain characteristics of the electric 
machine based on guidance from DOE and the EETTs. For example, the cost and high-speed efficiency of the electric machine are considered high priorities.

Table 4.2. Requirements for the SHV motor

\begin{tabular}{|c|c|c|}
\hline Requirement & Motor & $\begin{array}{l}\text { Degree of } \\
\text { challenge }\end{array}$ \\
\hline Specific power@peak load (kW/kg) & $>1.2$ & High \\
\hline Volumetric power density $(\mathrm{kW} / \mathrm{l})$ & $>5$ & High \\
\hline Cost per kW (\$) & $<7$ & High \\
\hline Efficiency, $10-100 \%$ speed, $20 \%$ rated torque $(\%)$ & $>93$ & Medium \\
\hline Peak power $(\mathrm{kW})$ & 55 & Low \\
\hline Continuous power $(\mathrm{kW})$ & 30 & Low \\
\hline Back-emf at maximum speed, line-to-line (V) & $<600$ & Medium \\
\hline Battery operating voltage (Vdc) & $325(200-450)$ & Low \\
\hline Maximum current at motor, rms (A) & 400 & Low \\
\hline Torque ripple $(\%)$ & 5 & Low \\
\hline Coolant inlet temperature $\left({ }^{\circ} \mathrm{C}\right)^{a}$ & -40 to 105 & High \\
\hline Flow rate of coolant $(\mathrm{l} / \mathrm{min})$ & 10 & High \\
\hline Life (years) & 15 & Medium \\
\hline
\end{tabular}

${ }^{a}$ For the full set of thermal requirements, see Sect. 4.1.2.

Note: To meet all requirements presents significant technical challenges. 


\section{IPM MACHINE PARAMETRIC STUDY}

This section considers the evaluation and modeling of (1) an 8-pole, 6000-rpm IPM machine, (2) a high-speed version of the same machine, (3) variations of a multi-layered IPM machine configuration, and (4) two recessed magnet machines. The analyses described in this section entailed numerous, complex modeling runs (i.e., lumped parameter and FEA). The results of the FEAs were used to improve the accuracy of the LPM results.

\subsection{SIZING THE IPM MACHINE}

The overall sizing of the machine is of great importance in terms of performance, structural integrity, cost, and weight. This study first considered the geometry of a commercially produced IPM machine with known performance to serve as a baseline for the LPM and the FEA model to ensure that the results were consistent and fully understood.

Once the baseline case was well established and the LPM was adjusted using the results (e.g., saturation levels) of the FEA, the study was able to proceed to other machine sizes and geometries. As indicated in the following sections, the overall scaling of the rotor was necessarily a predominant consideration in meeting the target performance goals.

The modeling of a commercially produced IPM machine early in the study was limited to $5400 \mathrm{rpm}$, the maximum specification speed of the motor. The power produced by the machine and many other parameters were consistent with the target performance goals.

\subsection{STATOR WINDING DESIGN}

For the baseline IPM machine, the stator design is a 48-slot design with 6 slots per pole. Each phase has 8 coils connected in series with 9 turns per coil (i.e., 72 turns per phase). Each turn has 13 strands of AWG 19 wire. The stator ID was reduced for the high-speed IPM design, consistent with the scaling down of the rotor as described in Sect. 5.3. The other dimensions of the stator were adjusted in order to manage tooth flux saturation and to accommodate the required current in the slots based on the results of lumped parameter and FEA modeling. The lamination stack length was varied independently based on modeling.

\subsection{ROTOR DESIGN ISSUES}

The rotor is the most critical design challenge for developing an IPM machine that will meet the performance targets. The design must consider centrifugal forces and mechanical stresses early on, since it would make little sense to model numerous design cases when few or no rotor designs would hold together mechanically.

The IPM "V-magnet" rotor baseline design is taken from a commercially produced motor and, based on the precise dimensions, the stresses were determined for the rotor at $5400 \mathrm{rpm}$. One of the first steps in scaling the IPM machine down in size to one that would operate at a higher rotor speed was to design the rotor so that it would experience the same stresses at the higher design speed as the baseline design does at $5400 \mathrm{rpm}$. The greatest stresses in the rotor are in the bridges (i.e., a pair of thin strips of metal retaining the magnets and a triangular steel segment in the rotor structure). 
First, consider the forces:

$$
\text { centrifugal force }=M * \omega^{2} * r,
$$

where $M$ is the mass prone to fly off the rotor, $r$ is the radius of its center of mass, and $\omega$ is the rotor's angular velocity. An expression for the mass is

$$
M=F^{*} r^{2 *} L,
$$

where $F$ is a factor accounting for the product of densities and cross-sectional fractions, and $L$ is the length of the rotor.

Considering the shear stresses at the rotor bridges,

average shear stress $=$ centrifugal force $/($ total bridge thickness $* L)=$

$F * \omega^{2} * r^{3} /$ total bridge thickness.

In scaling down the rotor assembly as described, one can assume that the speed changes by a factor, $k_{w}$, and the cross-sectional dimensions by a factor, $k_{r}$; then

The ratio NewStress/Stress $=k_{w}{ }^{2} * k_{r}^{3} / k_{r}=\left(k_{w} * k_{r}\right)^{2}$.

Hence, if $k_{r}=1 / k_{w}$, then there will be no change in the magnitude of the stress. For instance, for an 8000-rpm machine, $k_{w}=10,000 / 8,000=10 / 8$, a new value of $k_{r}=8 / 10=0.8$ will maintain the same level of stress. For this reason, the rotor assembly must be scaled down by approximately 0.8 .

Aside from geometry, the rotor parameters such as magnet strength, steel type, and amount of back iron were determined based on modeling. The stator and machine stack length were optimized in the high-speed (i.e. scaled-down) machine, independently based on lumped parameter and FEA modeling.

\subsubsection{PM Considerations}

The PM industry has improved both the properties and cost-value ratio of PMs in the last 20 years through the development of improved metallurgy and material sources/suppliers. This section will review the properties of various types of PMs, including a discussion of demagnetization considerations.

\subsubsection{PM strength and other key properties}

The various types of PMs include the following:

- Alnico - a family of magnets made from aluminum, nickel, and cobalt characterized by excellent temperature stability, high residual induction, and enough energy for a number of industrial and commercial applications.

- Ceramic - a hard, low-cost ferrite made of barium and strontium ferrite with excellent stability. Ceramic magnets tend to be brittle, hard, and resistant to corrosion. 
- Ferrites - a softer (non-sintered) version of the ceramic magnet. These are the lowest-cost magnets.

- Samarium cobalt $\left(\mathrm{Sm}_{2} \mathrm{Co}_{17}\right)$-a rare-earth magnet with outstanding magnetic properties including high BHmax, excellent thermal stability, and excellent corrosion resistance. Samarium cobalt is formulated as $\mathrm{SmCo}_{5}$ (1:5 material) and $\mathrm{Sm}_{2} \mathrm{Co}_{17}$ (2:17 material). This magnet is well suited for applications demanding high magnetic strength in a hightemperature environment.

- Neodymium iron boron ( $\mathrm{NdFeB}$ ) — an advanced, rare-earth magnet that is the most powerful commercialized PM available. The sintered form provides the highest magnetic properties, but the bonded version can be made in more shapes and sizes. The sintered neodymium magnet ranges in strength from a BHmax of 28-50 mega-gauss-Oersted (MGOe).

Bonded magnets are combinations of magnetic powders and either thermo-elastomers or thermoplastic resins. These blended materials can be injection molded or compressed. Compressionbonded magnets have greater magnetic output but can be shaped into only simple geometries.

Neodymium magnets offer the best value in performance and cost; however, designers should be aware that this type of magnet is temperature-sensitive and susceptible to oxidation if not properly coated. The magnet is high in $\mathrm{Br}, \mathrm{Hc}$, and $\mathrm{BHmax}$. Table 5.1 compares key properties of selected neodymium magnets and the most powerful samarium cobalt magnets. Neodymium magnets clearly have a potential for greater magnetic strengths but do not have the hightemperature capability of the samarium cobalt magnets. Depending on the specified grade, neodymium magnets may have a working temperature of up to $200^{\circ} \mathrm{C}$ and samarium cobalt magnets a working temperature of up to $375^{\circ} \mathrm{C}$.

Other properties of interest are shown in Table 5.2 for general applications for neodymium and samarium cobalt magnets. Neodymium has twice the bending strength of samarium cobalt and also significantly higher resistivity. Note that the thermal expansion of neodymium is roughly a third of what it is for samarium cobalt. For comparison, cast iron has a thermal expansion of $10.6-13.5 \times 10^{-6} /{ }^{\circ} \mathrm{C}$, which is at least three times that of neodymium; and aluminum alloys have an even higher coefficient of $22-24.1 \times 10^{-6} /{ }^{\circ} \mathrm{C}$, or nearly seven times that of neodymium. 
Table 5.1. Comparison of selected neodymium and highest-performance samarium cobalt magnets [MMC Magnetics]

\begin{tabular}{|c|c|c|c|c|}
\hline Grade & $\begin{array}{l}\text { BHmax } \\
\text { (MGOe) }\end{array}$ & $\begin{array}{c}\text { Remanence, Br } \\
\text { (kG,Tesla) }\end{array}$ & $\begin{array}{c}\text { Coercive force, Hc } \\
(\mathrm{kOe})\end{array}$ & $\begin{array}{r}\text { Working } \\
\text { temp. }\left({ }^{\circ} \mathrm{C}\right) \\
\end{array}$ \\
\hline \multicolumn{5}{|c|}{ Neodymium magnets } \\
\hline N33 & $31-33$ & $11.5,1.15$ & $>10.5$ & 80 \\
\hline $\mathrm{N} 33 \mathrm{M}$ & $31-33$ & $11.5,1.15$ & $>10.5$ & 100 \\
\hline $\mathrm{N} 33 \mathrm{H}$ & $31-34$ & $11.5,1.15$ & $>10.5$ & 120 \\
\hline $\mathrm{N} 33 \mathrm{SH}$ & $31-34$ & $11.5,1.15$ & $>10.6$ & 150 \\
\hline N30UH & $28-31$ & $11.0,1.10$ & $>10.2$ & 180 \\
\hline $\mathrm{N} 30 \mathrm{EH}$ & $28-31$ & $11.0,1.10$ & $>10.2$ & 200 \\
\hline N45 & $43-46$ & $13.5,1.35$ & $>11$ & 80 \\
\hline $\mathrm{N} 48$ & $46-49$ & $14,1.40$ & $>10.5$ & 80 \\
\hline N50 & $47-51$ & $14.2,1.42$ & $>10.5$ & 80 \\
\hline $\mathrm{N} 45 \mathrm{M}$ & $43-46$ & $13.5,1.35$ & $>11$ & 100 \\
\hline $\mathrm{N} 44 \mathrm{H}$ & $42-45$ & $13.3,1.33$ & $>12.6$ & 120 \\
\hline \multicolumn{5}{|c|}{ Samarium cobalt magnets } \\
\hline $\mathrm{Sm}_{2} \mathrm{Co}_{17} 28 \mathrm{~A}$ & 28 & $10.9,1.09$ & 10 & 300 \\
\hline $\mathrm{Sm}_{2} \mathrm{Co}_{17} 28 \mathrm{~B}$ & 28 & $10.9,1.09$ & 10 & 300 \\
\hline $\mathrm{Sm}_{2} \mathrm{Co}_{17} 28 \mathrm{H}$ & 28 & $10.9,1.09$ & 10 & 300 \\
\hline $\mathrm{Sm}_{2} \mathrm{Co}_{17} 30 \mathrm{~A}$ & 30 & $11,1.10$ & 10.2 & 300 \\
\hline $\mathrm{Sm}_{2} \mathrm{Co}_{17} 30 \mathrm{~B}$ & 30 & $11.2,1.12$ & 10.2 & 300 \\
\hline $\mathrm{Sm}_{2} \mathrm{Co}_{17} 32$ & 31 & $11.5,1.15$ & 10 & 300 \\
\hline
\end{tabular}

Source: MMC Magnetics, www.mmcmagnetics.com, Happague, NY.

Table 5.2. Physical properties of neodymium and samarium cobalt magnets

\begin{tabular}{|l|c|c|}
\hline \multicolumn{1}{|c|}{ Property } & NdFeB & $\mathbf{S m}_{\mathbf{2}} \mathbf{C o}_{\mathbf{1 7}}$ \\
\hline Specific gravity & 7.4 & 8.2 \\
\hline Resistivity, $\mu \Omega$-cm & 150 & 86 \\
\hline Thermal expansion coefficient, $10^{-6} /{ }^{\circ} \mathrm{C}$ & 3.4 & 9 \\
\hline Saturation $H, \mathrm{kA} / \mathrm{m}$ & $>2400$ & $>3200$ \\
\hline Temperature coefficient of $\mathrm{Br}, \% /{ }^{\circ} \mathrm{C}$ & -0.1 & -0.025 \\
\hline Bending strength, $\mathrm{kg} / \mathrm{mm}^{2}$ & 24 & 12.3 \\
\hline Compressive strength, $\mathrm{kg} / \mathrm{mm}^{2}$ & 80 & $30-90$ \\
\hline
\end{tabular}

\subsubsection{Orientation of PM flux}

The orientation of flux from the IPM design with V-configuration of the PMs is generally as indicated in Fig. 5.1. This orientation was verified in an IPM motor mass produced for the automobile industry. This configuration is useful for concentrating magnetic strength within a limited magnetic arc at the rotor pole. The use of this configuration in conjunction with highstrength magnets represents a unique design. The flux orientation was modeled in the FEA consistent with Fig. 5.1. 


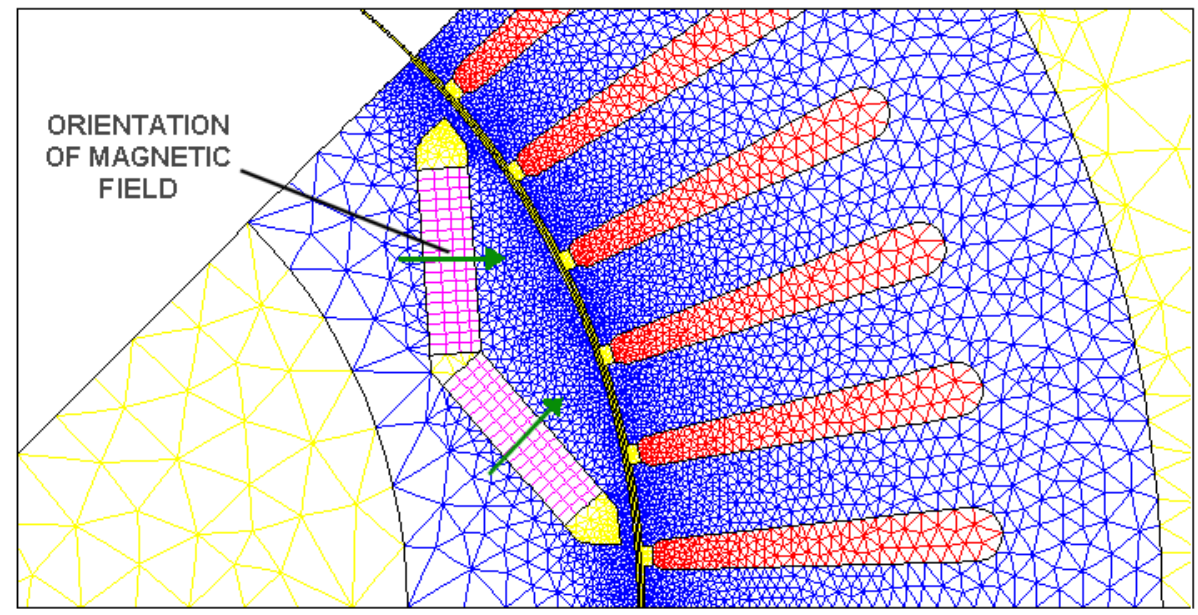

Fig. 5.1. Magnet field orientation as defined in the Flux2D model.

\subsubsection{Laminates}

Motor applications generally used in industry use low-carbon laminated steel for the rotor and stator. Such steel typically has electrical losses of $\sim 6.6$ watt per kg. High-efficiency motors are built with high-grade silicon steel, which typically reduces hysteresis and eddy current losses by half, to only $\sim 3.3$ watts per $\mathrm{kg}$. Reducing the lamination thickness in rotor and stator steel also lowers eddy current losses. Improved insulation between laminations, when applied with enhanced quality control, further reduces these losses.

The IPM design calls for laminations both in the stator and in the rotor. Because of the complex shapes involved, it is expected that stamping the shapes out of thin steel and stacking them is the most cost-effective manufacturing approach. This cost-effective approach will also be advantageous in reducing eddy currents in both structures.

Currents will be induced in any conductor when it is rotated in a magnetic field. The induced currents are perpendicular to the flux and result in the generation of waste heat. The induced currents in a stator or rotor are called eddy currents. Hysteresis represents the power expended in a magnetic material as the flux density varies cyclically, and it may be thought of conceptually as the "magnetic friction" of a material.

The eddy current losses and hysteresis losses are often combined and referred to as core or iron losses. These losses are a function of the magnetic flux density, which, for the IPM designs considered in this study, are expected to be relatively high and comparable to those in fieldwound motors. This level of loss is due to the high-strength magnets and the magnet geometry in the rotor. The change in core losses as the motor load level changes is generally negligible.

The losses, in watts, for eddy current and hysteresis effects can be calculated using the following equations [Perrine]:

$$
\operatorname{Loss}_{h}=\frac{0.1445 \beta B_{r} H(\text { freq }) W}{\text { density }},
$$




$$
\operatorname{Loss}_{e}=\frac{0.4818 \alpha B_{m}^{2}(\text { Lam })^{2}(\text { freq })^{2} W}{(\varepsilon) \text { density }}
$$

where

$$
\begin{aligned}
\beta & =\text { hysteresis loss factor } \\
B_{r} & =\text { residual induction, kilogauss } \\
B_{m} & =\text { max. magnetic induction, kilogauss } \\
H & =\text { coercive force, oersteds, } \\
\text { Lam } & =\text { lamination thickness, inches } \\
\text { Freq } & =\text { excitation frequency of the motor, } \\
\alpha & =\text { anomalous loss factor, } \\
\mathcal{E} & =\text { electrical resistivity, microohm-cm, and } \\
W & =\text { lamination weight, pound }
\end{aligned}
$$

The hysteresis equation, Eq. (8), shows that hysteresis losses increase with the excitation frequency. The eddy current losses, Eq. (9), are proportional to the square of the excitation frequency and the square of lamination thickness. To minimize eddy current losses, this equation shows the high importance of relying on thin laminations for motors that operate at high excitation frequencies, such as the IPM design considered in this study.

The anomalous loss factor, $\alpha$, shown in Eq. (9) is used to account for differences between the observed eddy current losses and those calculated from electrodynamic theory. The disparity is generally due to magnetic domain wall effects. The anomalous loss factor increases as core loss decreases or lamination thickness decreases.

\section{$\underline{\text { Materials }}$}

Laminations are generally made from low-carbon lamination steels, electrical steels, or silicon steels. Terminology is not always used consistently for what are, in reality, two major classes of materials. Most electrical steels are cold-rolled, non-alloyed, and low in carbon. These may be referred to as cold-rolled motor lamination (CRML) steel or simply as lamination steel. ASTM standard A726 describes CRML steels as follows.

CRML steels differ from common carbon steel in that

1. Manganese and phosphorous are added to increase electrical resistivity.

2. Mill processes are designed to enhance grain growth to reduce hysteresis.

3. Annealing is often used to reduce core loss and alter permeability.

The types of CRML steel include

- Type 1 -Beginning with material with controlled chemical composition, the lamination stock is either (1) shipped full hard and annealed after stamping or (2) annealed by the mill and shipped without any guarantee of magnetic properties. 
- Type 2-Optimal magnetic properties are attained by controlling the chemical composition, annealing the material, and then performing a critical reduction on a temper mill. The magnetic properties are not guaranteed.

- Type 2S-This is the same as Type 2, with an additional guarantee of magnetic properties.

The other major class of laminate material is silicon steel or electrical steel. This type of lamination material is about twice as expensive as CRML material. Silicon steel laminations can be either grain-oriented or grain-non-oriented (GNO). The silicon promotes crystal orientation in grain-oriented silicon steel, which is used primarily in power transformers. However, of greater interest to the present study are GNO silicon steels, in which the silicon not only increases the volume resistivity of steel to reduce eddy currents but also affects the grain structure to reduce hysteresis. GNO silicon steels are used in motors, generators, and lighting ballasts.

Silicon steels contain from $\sim 0.5 \%$ to $3.25 \%$ silicon. As the amount of silicon is increased, the core losses are reduced by increased resistivity; however, the permeability of the steel is reduced in the presence of strong magnetic fields. At low and medium inductions, permeability improves with increasing silicon content.

Small amounts of manganese and aluminum may also be added to the steel primarily for metallurgical reasons; however, they are also helpful in affecting the grain structure and reducing hysteresis losses. Carbon, sulfur, and other elements are undesirable impurities that are kept low, especially in the high-grade steels. The carbon content can be lowered by annealing. The overall quality of magnetic steels for a given grade has improved over the years as a result of the improved control of impurities. As the impurities are reduced, hysteresis is reduced because of a decreased resistance to domain wall motion.

GNO silicon steels are available with a variety of surface coatings. These include an inorganic finish with natural oxides, inorganic insulation formed by a varnish applied to the surface of the material, inorganic insulation formed by a chemical treatment applied to the material, and inorganic/organic insulation applied to the surface of the material (http://www.acesita.com.br/eng/index.html). The material is available in coils, strips, and sheets.

Additional considerations of material properties, manufacturing, metallurgical properties, and classifications by ASTM and the American Iron and Steel Institute (AISI) are available in a handbook by R. C. Perrine. ${ }^{5}$

\subsection{BASELINE IPM MACHINE}

Much of the preliminary work described in this report relates to verifying models, understanding model agreement/disagreement, baselining results relative to known machine performance specifications, and evaluating results at different machine speeds. This work is essential before evaluating other proposed machine configurations for which performance data do not exist.

The IPM machine has been produced commercially since 2000 in a vehicle traction application for the Toyota Prius, a parallel hybrid vehicle. The motor design was modified in 2004 to provide higher torque at low speeds. 
This section describes the analysis of a commercially produced IPM machine for which certain types of performance specification data are available. Specifically, published specifications exist for the Toyota Prius traction motor, although there is a lack of data relative to electrical current demand and/or efficiency. Cost estimates for this IPM design are provided in Sect. 7.2.

\subsubsection{Lumped Parameter Data Set for Baseline Case}

The basic geometry of the IPM baseline case is shown in Fig. 5.2. Many key dimensions are defined in the figure as angular, linear, arc, or radial dimensions. The rotor, which is typically defined as the laminations and magnet for an IPM machine, for the purposes of this study and the modeling also includes the outer ring of the shaft (not shown in Fig. 5.2) because the steel ring of the shaft acts as additional iron in the rotor assembly and carries some of the magnetic flux. The detailed portion of Fig. 5.2 shows the three dimensions that define the tips of the stator teeth and the width of the slot openings. The bridge, as depicted at the ends of the magnets, is a critical dimension that is intentionally made small to encourage magnetic saturation to limit PM flux losses.

Tables 5.3 and 5.4 list and numerically define many of the key dimensions and other miscellaneous parameters for the baseline IPM machine. Most of the listed dimensions can be found in Fig. 5.2 or are self-explanatory. These parameters match those that were used in both the LPM and the FEA model (where required by the model). Many other parameters were required by both models; this is especially true for the LPM. Definitions for the full set of parameters used in the LPM, exceeding 300 in number, can be found in Appendix D.

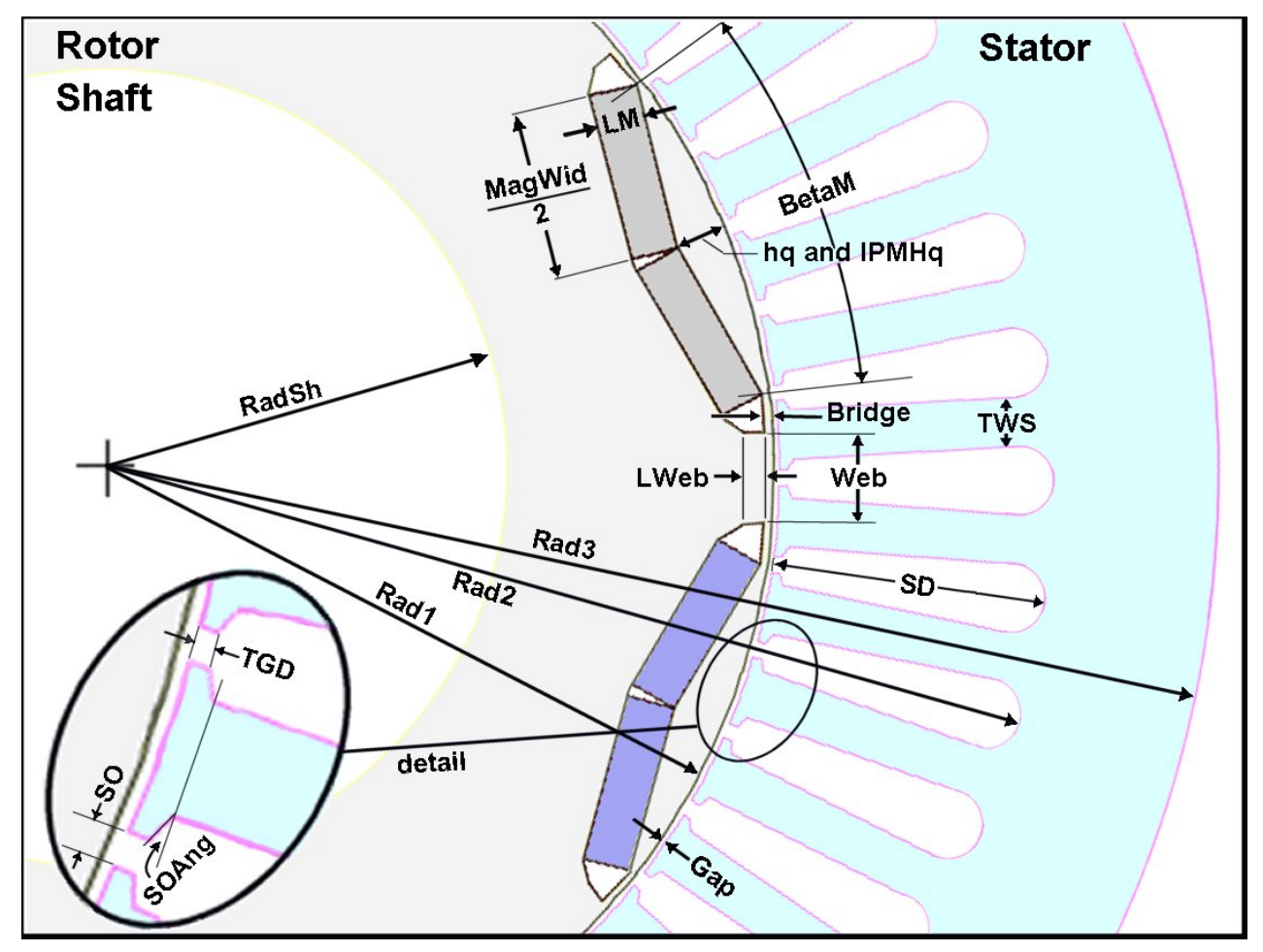

Fig. 5.2. IPM machine sketch with critical dimensions. 
Table 5.3. Selected key dimensions of the baseline IPM machine

\begin{tabular}{|l|c|c|}
\hline \multicolumn{1}{|c|}{ Selected dimensional parameter } & Abbrev. & Value \\
\hline Stator outside radius, $\mathrm{mm}$ & Rad3 & 134.62 \\
\hline Radial distance to end of slot, $\mathrm{mm}$ & Rad2 & 116.5 \\
\hline Rotor outside radius, $\mathrm{mm}$ & Rad1 & 80.19 \\
\hline Shaft radius (minus ring), mm & RadSH & 50.46 \\
\hline Lamination stack length, mm & Lstk & 83.57 \\
\hline Magnet width, mm & MagWid & 38.48 \\
\hline Magnet thickness, mm & LM & 5.31 \\
\hline Bridge width, mm & Bridge & 1.45 \\
\hline
\end{tabular}

Table 5.4. Additional key parameters of the baseline IPM machine

\begin{tabular}{|l|c|c|c|}
\hline \multicolumn{1}{|c|}{ Key design parameters } & Abbrev. & Low speed & High speed \\
\hline Angular speed, rpm & RPM & 1040 & 5400 \\
\hline Sinusoidal voltage, V & Vs & 500 & 500 \\
\hline Line current setpoint, A & ISP & 225 & 84 \\
\hline Gamma, deg & gamma & 22.5 & 60.7 \\
\hline Turns in stator coil & TC & 9 & 9 \\
\hline Layers in stator slots & Layers & 1 & 1 \\
\hline Magnet strength, Tesla (T) & BrT & 1.12 & 1.12 \\
\hline
\end{tabular}

\subsubsection{Lumped Parameter Results for Baseline Case}

The results obtained from the LPM are summarized in Table 5.5 for the parameters defined in Sect. 5.4.1. The table indicates that the machine, when operated at $1040 \mathrm{rpm}$, had an efficiency of $87.7 \%$ and produced $275.7 \mathrm{Nm}$ of torque, of which $10.7 \%$ was due to reluctance. These lowspeed data do not fully account for magnetic saturation, as will be further discussed. When the machine was operated at $5400 \mathrm{rpm}$, it had an efficiency of $96.5 \%$ and produced $53 \mathrm{Nm}$ of torque, of which $29.6 \%$ was due to reluctance.

Table 5.5. Selected key results of the baseline IPM machine at $1040 \mathrm{rpm}$ and $5400 \mathrm{rpm}$

\begin{tabular}{|l|l|c|c|}
\hline \multicolumn{1}{|c|}{ Selected parameter } & \multicolumn{1}{c|}{ Abbrev. } & Low speed & High speed \\
\hline Total machine torque, Nm & Torque & 275.7 & 53.0 \\
\hline Reluctance torque, Nm & RelTorq & 29.5 & 15.7 \\
\hline Mechanical power, W & Pmech & 30,020 & 30,000 \\
\hline Efficiency, \% & Eff & 87.7 & 96.5 \\
\hline Peak current in winding, A & IWpk & 225.2 & 77.1 \\
\hline RMS current in winding, A & IWrms & 158.0 & 54.3 \\
\hline
\end{tabular}

In addition to the two data sets described, numerous other simulation cases were made using the LPM to characterize machine performance over the entire specification speed range. These data are presented in the next series of plots. Furthermore, subsequent to the results presented above, FEA results showing significant magnetic saturation below $1200 \mathrm{rpm}$ were factored into the LPM. Therefore, the low-speed data presented in plots and in Table 5.6 will contain certain results with improved accuracy compared with the above 1040-rpm data. 
Table 5.6. LPM characterization of the baseline IPM machine for numerous key parameters over a speed range from 520 to $5400 \mathrm{rpm}$

\begin{tabular}{|c|c|c|c|c|c|c|c|c|c|c|c|}
\hline $\begin{array}{c}\text { Speed } \\
(\text { RPM) }\end{array}$ & Vs (V) & ISP (A) & $\begin{array}{c}\text { Torque } \\
(\mathbf{N m})\end{array}$ & $\begin{array}{c}\text { Power } \\
(\mathrm{kW})\end{array}$ & $\begin{array}{c}\text { Efficiency } \\
(\%)\end{array}$ & $\begin{array}{l}\text { Stator } \\
\text { current } \\
\text { (A rms) } \\
\end{array}$ & $\begin{array}{c}\begin{array}{c}\text { Stator } \\
\text { current } \\
\text { (A peak) }\end{array} \\
\end{array}$ & $\begin{array}{c}\begin{array}{c}\mathrm{Jrms} \\
\left(\mathrm{A} / \mathbf{m m}^{2}\right)\end{array} \\
\end{array}$ & $\begin{array}{c}\text { Torque: } \\
\text { reluctance/total } \\
(\%) \\
\end{array}$ & $\begin{array}{c}\begin{array}{c}\text { Gamma } \\
\text { advance } \\
\text { (deg) }\end{array} \\
\end{array}$ & $\begin{array}{r}\text { HeatFlux } \\
\left(\mathrm{kW} / \mathrm{m}^{2}\right)\end{array}$ \\
\hline 520 & 500 & 250 & 308.2 & 16.8 & 76.6 & 176.2 & 250.9 & 20.8 & 0.5 & 8 & 26.1 \\
\hline 1040 & 500 & 225 & 275.7 & 30.0 & 87.7 & 158.0 & 225.2 & 18.6 & 10.7 & 22.5 & 21.4 \\
\hline 2000 & 500 & 125 & 152.5 & 31.9 & 95.5 & 86.6 & 124.8 & 10.2 & 11.5 & 22.5 & 7.6 \\
\hline 3000 & 500 & 100 & 98.1 & 30.8 & 97.3 & 65.2 & 99.4 & 6.9 & 17.5 & 31 & 5.2 \\
\hline 4000 & 500 & 85 & 75.5 & 31.6 & 97.1 & 55.9 & 84.1 & 6.6 & 23.4 & 45 & 4.9 \\
\hline 5400 & 500 & 84 & 53.0 & 30.0 & 96.6 & 54.3 & 77.1 & 6.4 & 29.6 & 60.7 & 5.5 \\
\hline
\end{tabular}


Figure 5.3 shows the estimated efficiency for the machine over the full speed range. The efficiency is quite high above $2000 \mathrm{rpm}$, even exceeding 97\%; however, saturation adversely affects efficiency at low speeds.

Figure 5.4 shows the line current (peak and rms) considering only a single phase vs. speed for the IPM machine. The high current at low speeds results in significant levels of magnet saturation in the stator teeth.

Figure 5.5 shows the torque (total and reluctance) for the machine. The torque capability of the machine is about $300 \mathrm{Nm}$ below base speed (i.e., $1040 \mathrm{rpm}$ ), and power is constant above base speed to approximately $5400 \mathrm{rpm}$. These data and other related data are summarized in Table 5.6.

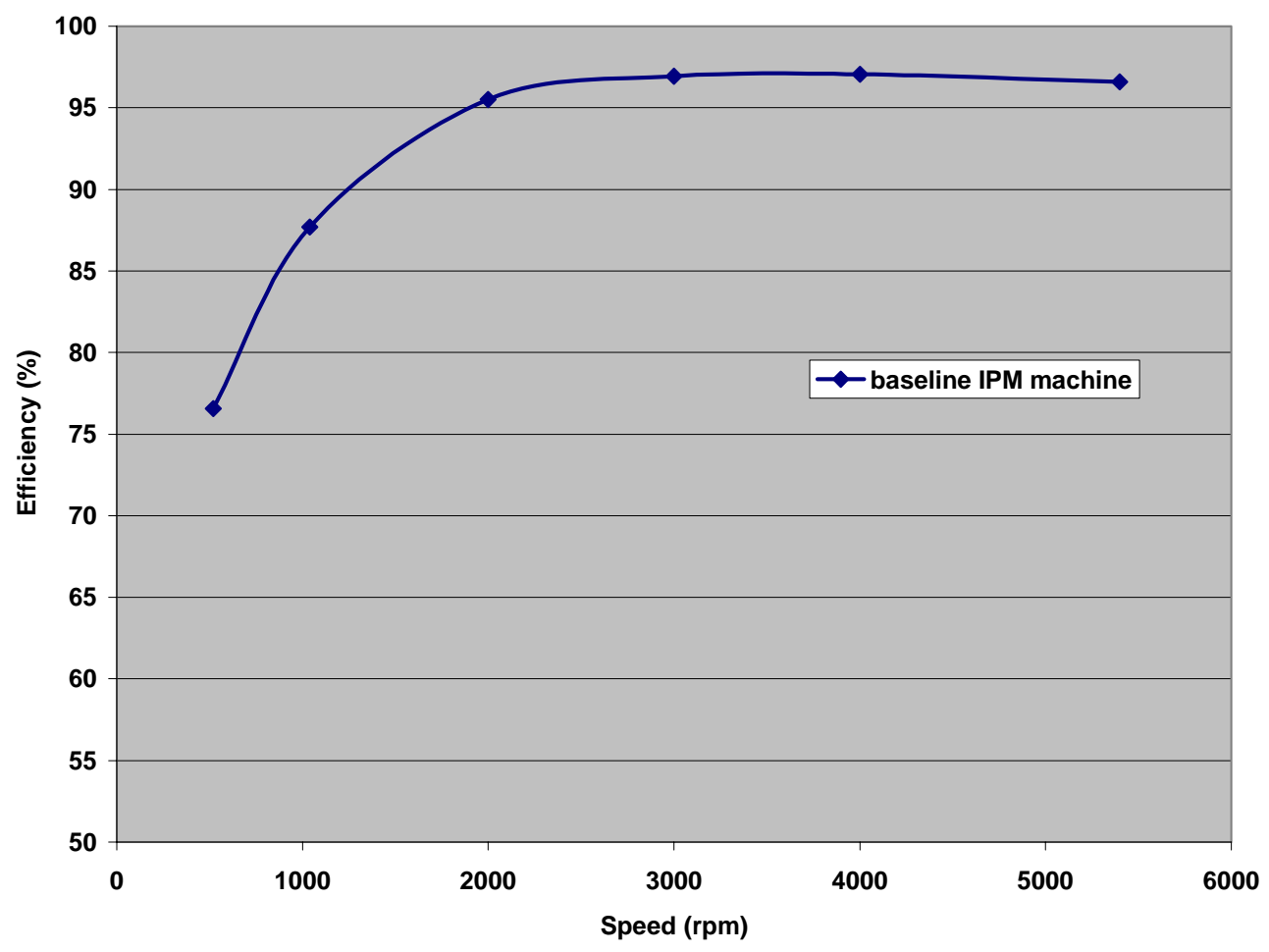

Fig. 5.3. Efficiency vs. machine speed for the baseline IPM. 


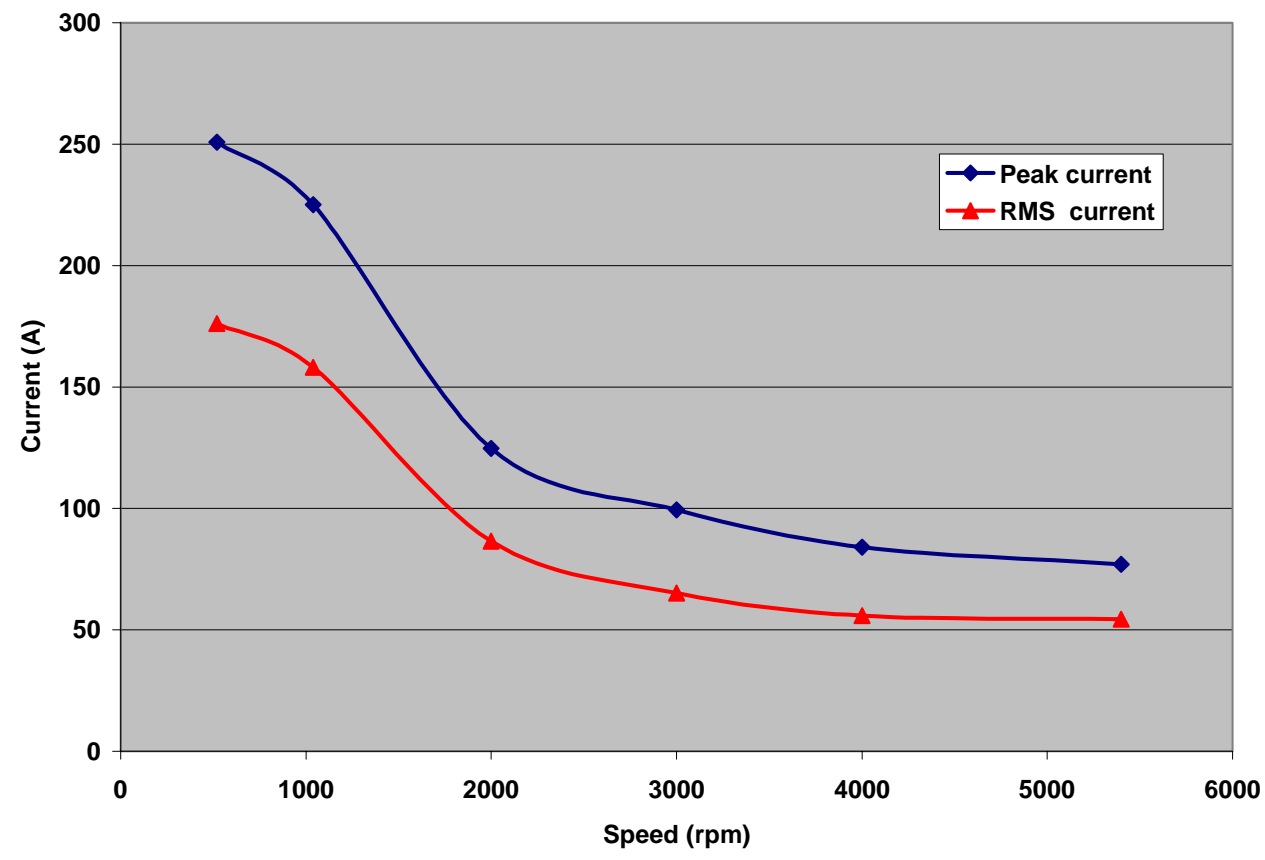

Fig. 5.4. Stator current vs. machine speed for the baseline IPM.

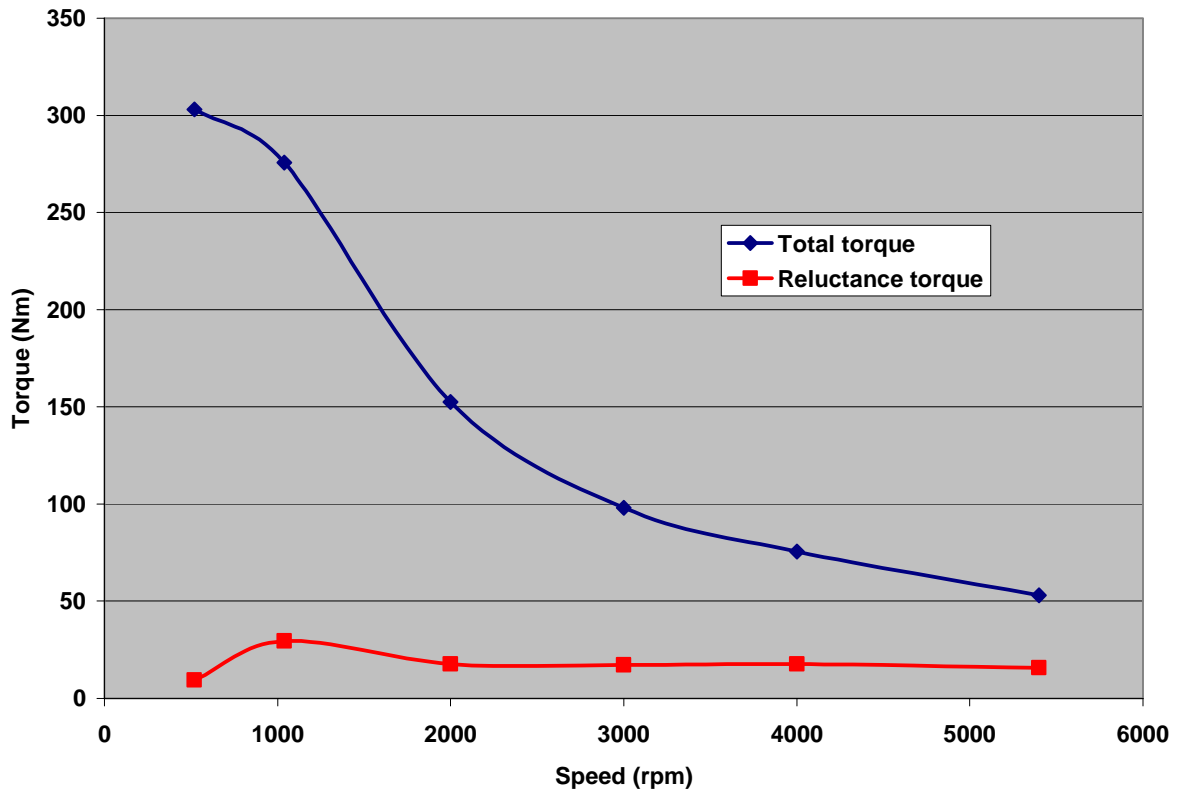

Fig. 5.5. Torque vs. machine speed for the baseline IPM. 


\subsubsection{FEA Modeling and Results for Baseline Case}

The first goal of the FEA modeling task was to model the same IPM machine for which the LPM had produced results to determine how well the two models agree and to resolve differences. The resolving of differences included (1) making double checks and identifying errors, (2) assessing phenomena that the LPM either does not account for or does not thoroughly account for, and/or (3) taking the results of the FEA to fine-tune the LPM. This last activity generally amounts to telling the LPM how badly the permeability of the steel is being affected by saturation and helping the LPM account for other losses. Once this is accomplished, the LPM can be used with greater confidence to quickly evaluate other similar motor designs. Using LPMs is faster than using FEA. This is because FEA is a kind of microscopic analysis while lumped parameter, as its name implies, is a macroscopic analysis.

The first step in preparing the FEA is do develop the machine model to accurately reflect the proposed machine in terms of geometry, materials, magnet properties, and electrical current in the stator slots. Once the geometry is precisely defined, it is meshed as shown in Fig. 5.6 to permit the integration calculations of the elements. As indicated in the figure, the mesh is very fine at locations such as the rotor bridge and near the air gap where precision is necessary.

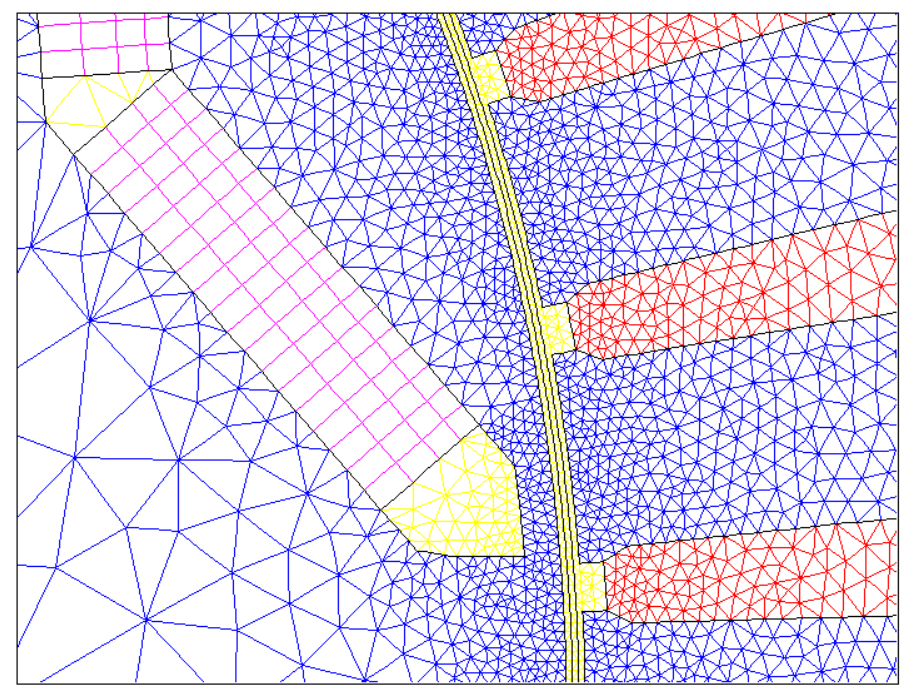

Fig. 5.6. Mesh of elements reflecting an emphasis on precision at critical machine areas.

After the machine is fully defined, FEA methods are used to solve for static and/or dynamic characteristics. Although characteristics, such as torque, can be solved with either analysis technique, the dynamic model can be solved with an electrical circuit model to provide waveforms, back-emf, and torque fluctuations with time. The static model is less cumbersome to use and provides useful parameters such as flux density, permeability, flux maps of the geometry, and torque relative to the rotor position.

The total torque the baseline IPM machine was capable of producing was described in Sect. 5.4.2 for the LPM. FEA produces a more precise estimate of the machine torque capability. Figure 5.7 shows the torque vs. rotor position based on FEA for one segment of the rotor with a current of 
$200 \mathrm{~A}$. The estimated torque is about $33.5 \mathrm{Nm}$ at 8 mechanical degrees for one segment of the machine. The estimated total torque for the machine is eight times that amount or $268 \mathrm{Nm}$.

\section{PRIUSDCTORQUE}

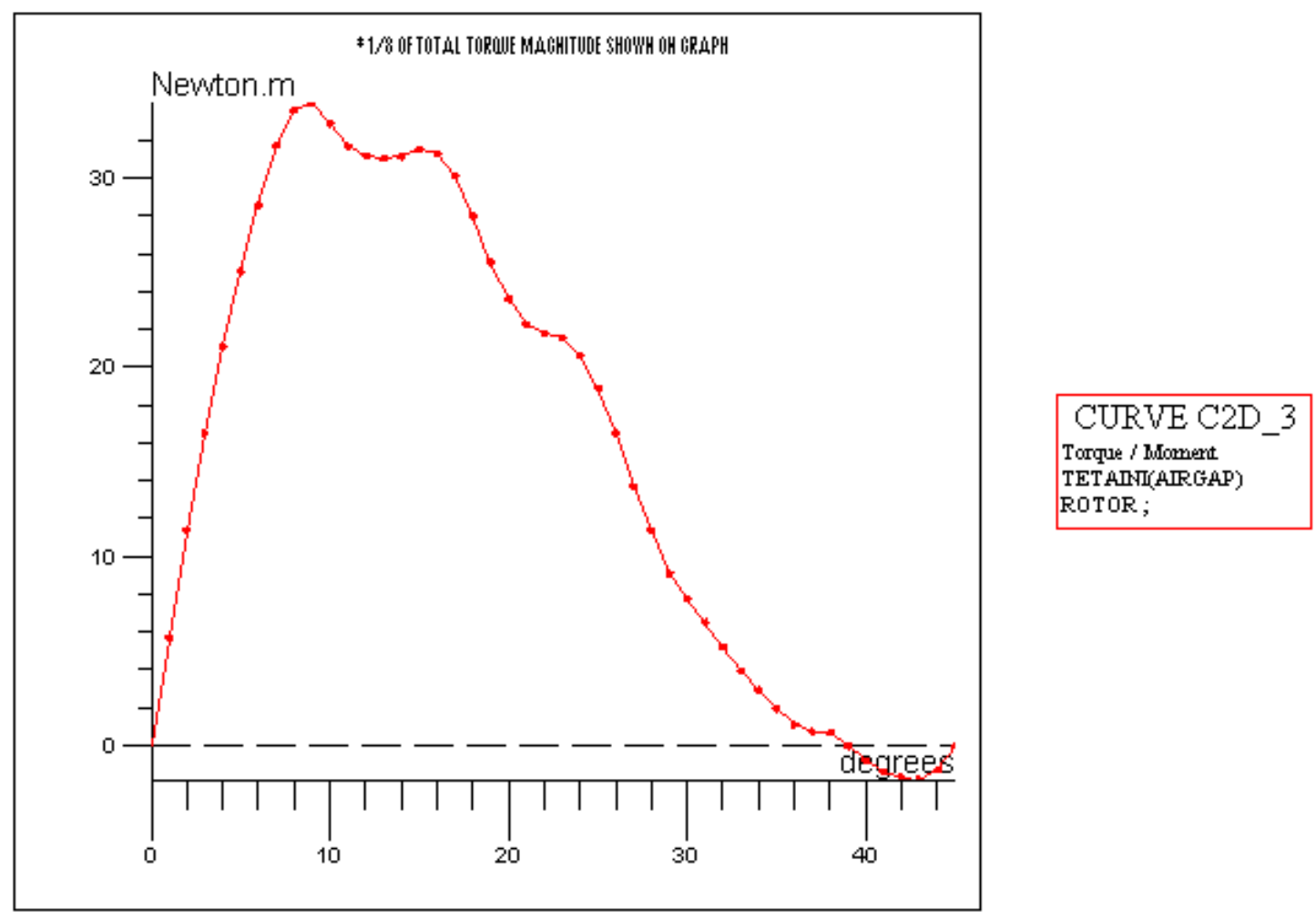

Fig. 5.7. Torque vs. rotor position (mechanical degrees) for 200-A peak.

Once the developed torque was compared for the two types of machine models, the FEA model was used to explore other potential issues such as saturation in the rotor and stator steels. Figure 5.8 shows the flux density mapping of a portion of the machine geometry. In order to better highlight areas of severe saturation, the maximum flux density was set at $2 \mathrm{~T}$, which caused areas with flux density above $2 \mathrm{~T}$ to be depicted as white. Although the flux density map changes as the rotor is turned, severe saturation was generally observed at or near the two bridge areas and at a corner of a stator tooth, as indicated in the figure. Of course, saturation at the bridges is highly desirable.

Flux density maps such as this will be generated for other candidate machines, and comparisons will be made to aid in determining when undesired or unacceptable saturation is occurring in stator teeth or in rotor or stator back iron. 


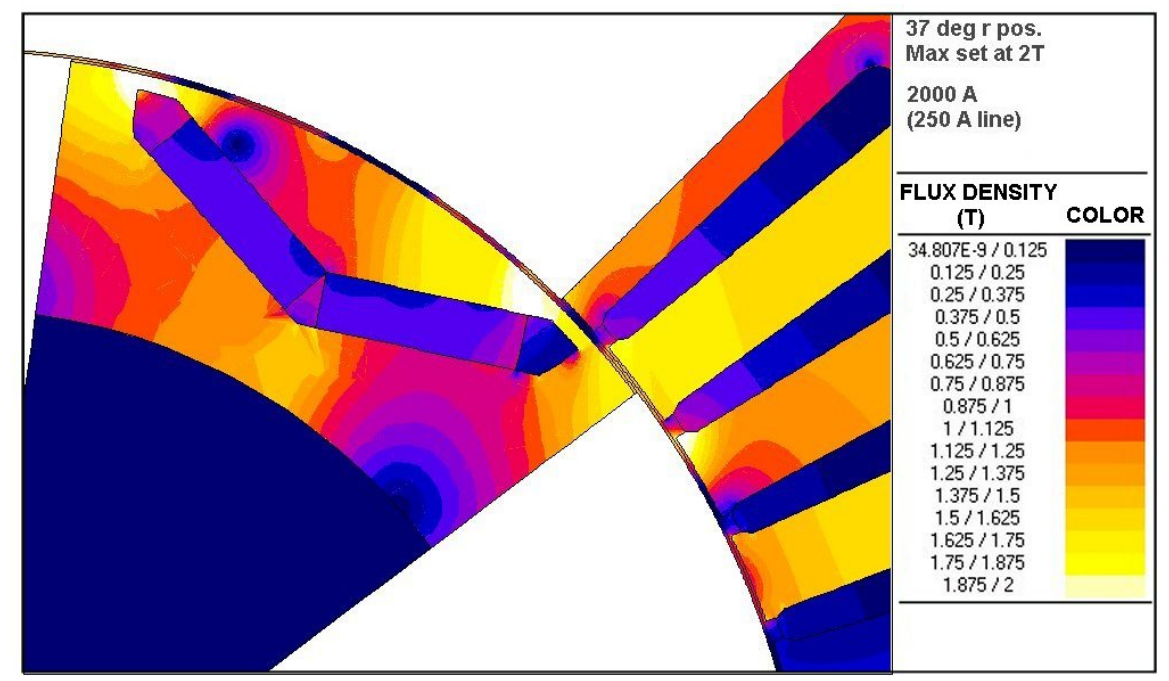

Fig. 5.8. Flux density color-coded map of rotor sector and portion of stator with a 2 T ceiling.

In the evaluation of magnetic saturation, Fig. 5.9 was generated to assess the flux density in the stator across an arc-shaped path that cuts through five stator teeth and parts of two other teeth. At the top of the figure, a number of isoflux lines passing through stator slot \#1 suggests that, in at least some portion of the tooth, the flux density is likely high. In the \#1 stator tooth, the flux density plot shows a flux density peak that is flat-topped and is reaching flux densities of up to 1.8 T. This value exceeds the saturation level of the steel, which, for this particular modeling run, was selected at a very high value of $1.7 \mathrm{~T}$. The right-hand plot in the figure shows that the relative permeability of the steel has dropped to near zero in slot \#1 as a result of the saturation condition that exists. The figure makes it clear that saturation cannot be avoided even through the use of expensive lamination steel.

Figure 5.10 plots torque vs. current for the baseline IPM based on FEA. The figure shows the expected torque with 1.12-T magnets and with no magnets in the rotor. Figure 5.11 plots the expected torque with magnets of varying strength in the baseline IPM rotor. The magnets' strength $\left(\mathrm{B}_{\mathrm{r}}\right)$ include $0.2,0.4,0.6,0.8$, and $1.12 \mathrm{~T}$. Figure 5.12 plots the torque constant (i.e., torque/amperes) for magnets of varying strength. The torque constant, in general, decreases with increasing currents as a result of the saturation effects of the machine. 

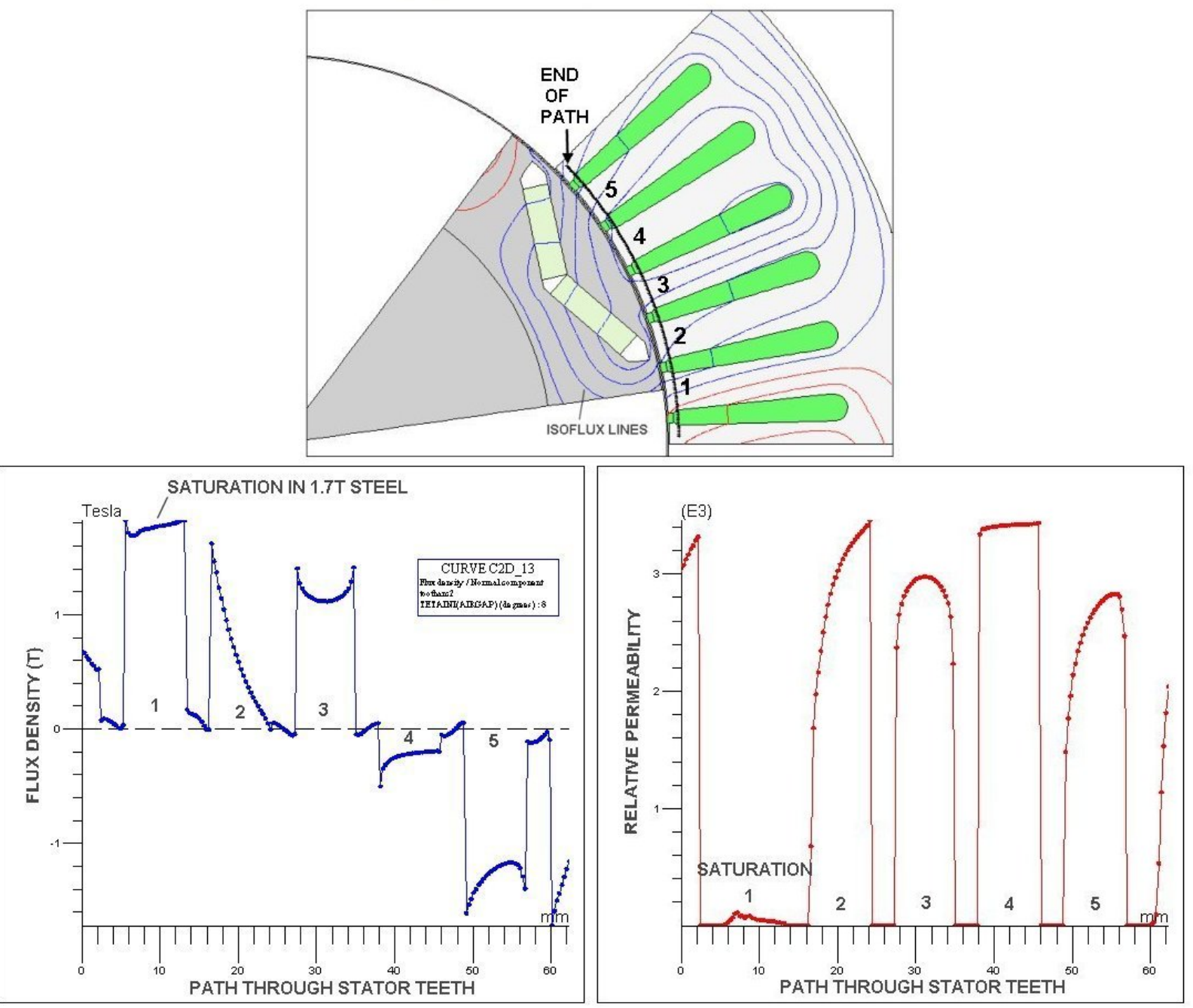

Fig. 5.9. Flux density and relative permeability over a pre-defined path across stator teeth. 


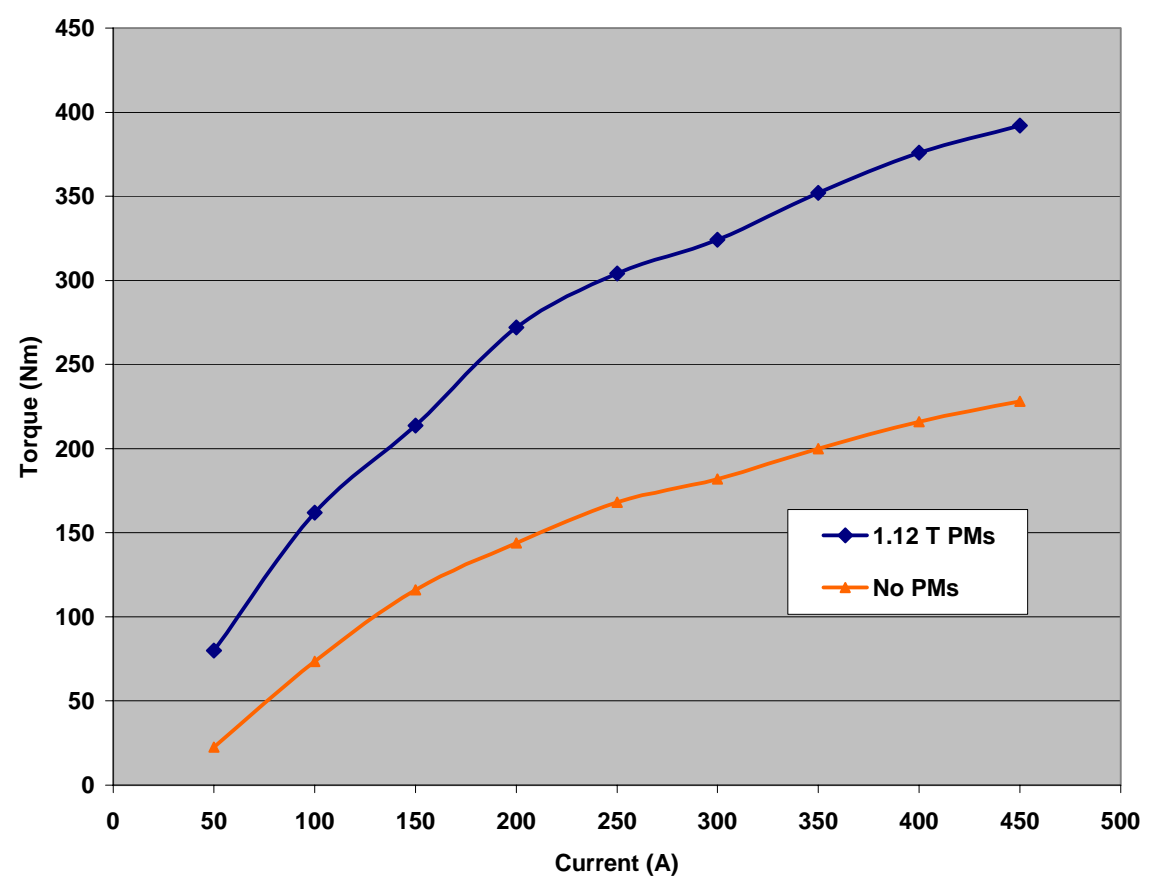

Fig. 5.10. Torque vs. current plot for baseline IPM with 1.12 T PMs and no PMs.

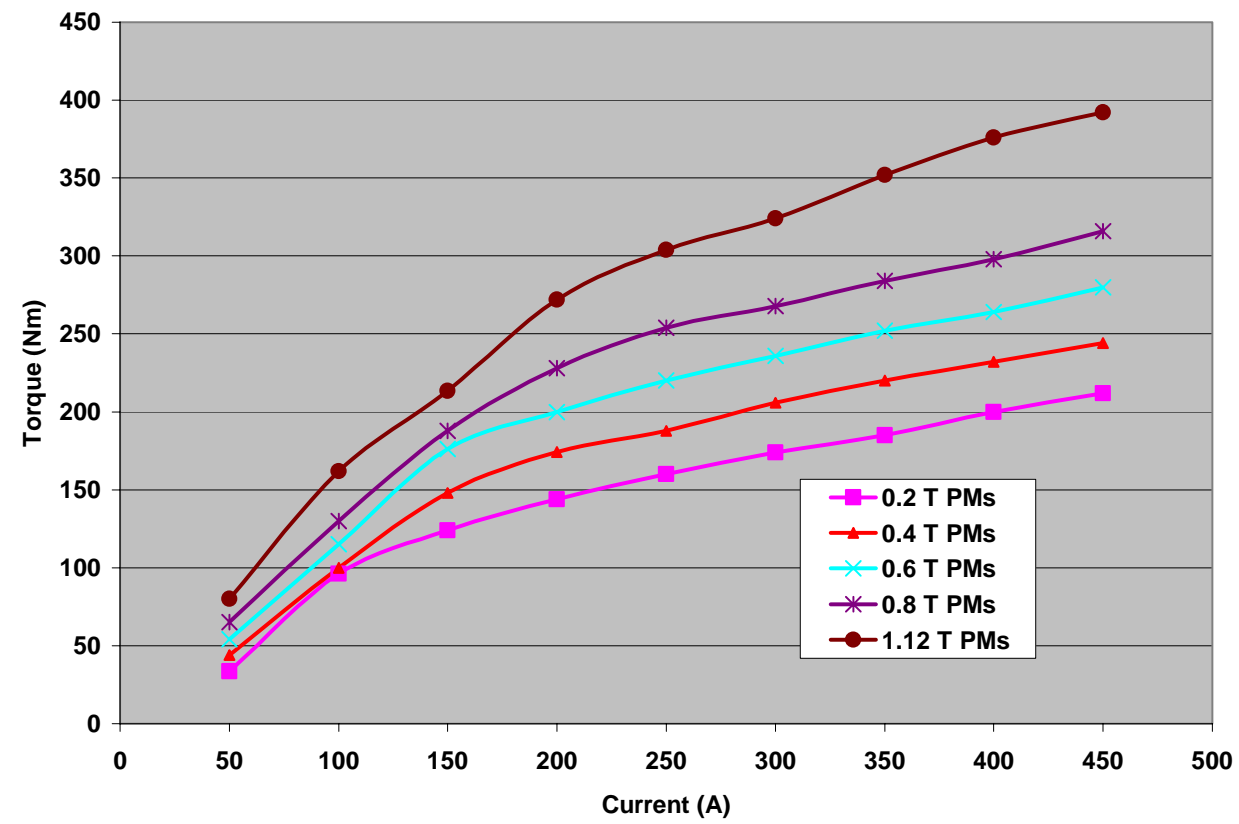

Fig. 5.11. Torque vs. current for magnets of varying strength for baseline IPM. 


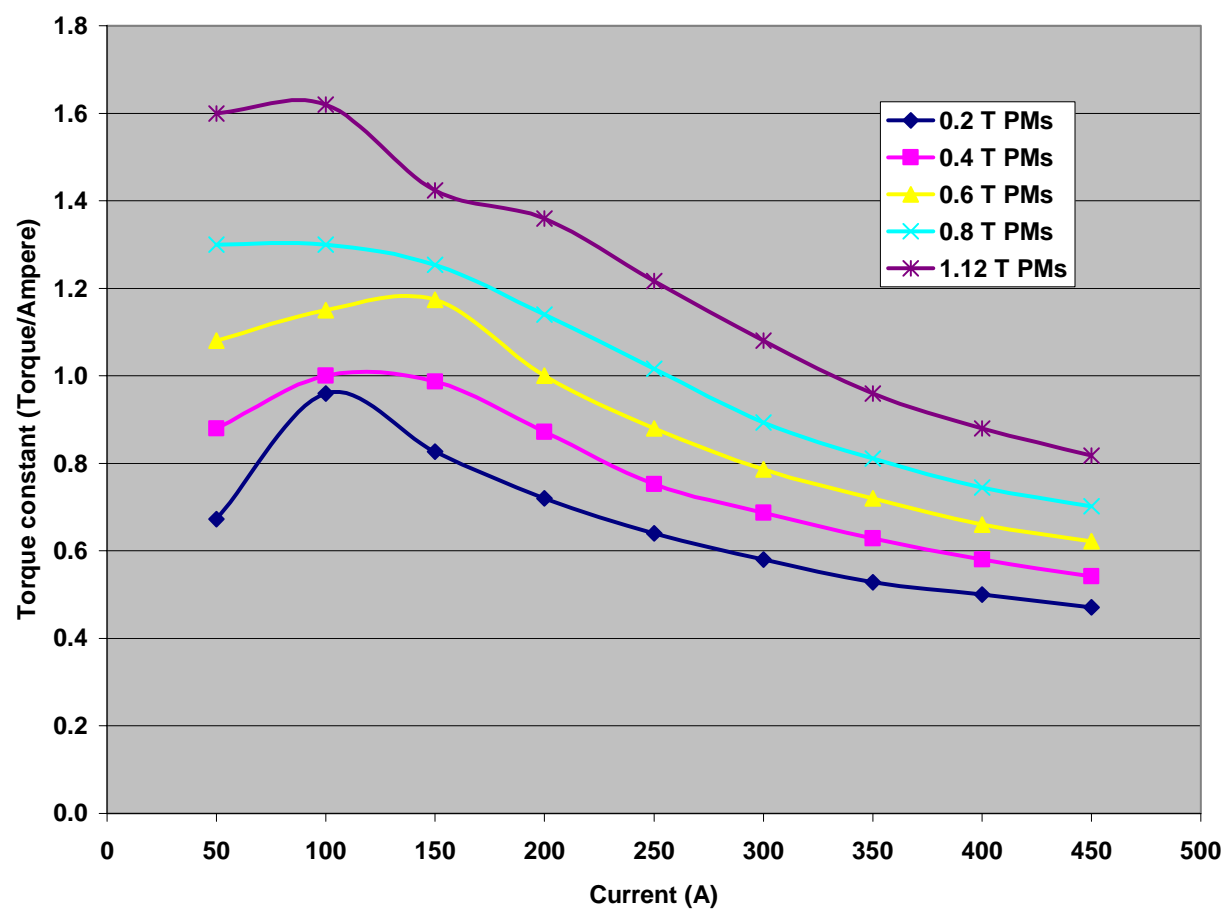

Fig. 5.12. Torque constant vs. current for magnets of varying strength for baseline IPM.

\subsection{HIGH-SPEED IPM MACHINE}

This section describes the LPMing of an IPM machine similar to the baseline case except that it is scaled down to accommodate higher-speed operation. The high-speed machine has potential cost savings due to the use of less material, such as PMs. The rotor and shaft were scaled by approximately 0.8 to maintain the same stresses at $8000 \mathrm{rpm}$ as the baseline machine experienced at $5700 \mathrm{rpm}$. The stator was scaled down to a lesser extent in order to manage tooth flux saturation and to accommodate the required current in the slots. The lamination stack length was also varied independently. Cost estimates for this IPM design are provided in Sect. 7.2.

\subsubsection{Lumped Parameter Data Set for IPM}

Tables 5.7 and 5.8 list and numerically define many of the key dimensions and other parameters for the high-speed IPM machine. The parameters match those that were used in both the LPM and the FEA model (where required by the model). Definitions for the full set of parameters used in the LPM, exceeding 300 in number, can be found in Appendix D. 
Table 5.7. Selected key dimensions of the high-speed IPM machine

\begin{tabular}{|l|c|c|}
\hline \multicolumn{1}{|c|}{ Selected dimensional parameter } & Abbrev. & Value \\
\hline Stator outside radius, $\mathrm{mm}$ & Rad3 & 116.2 \\
\hline Radial distance to end of slot, $\mathrm{mm}$ & Rad2 & 100.7 \\
\hline Rotor outside radius, $\mathrm{mm}$ & Rad1 & 61.75 \\
\hline Shaft radius (minus ring), $\mathrm{mm}$ & RadSH & 43.35 \\
\hline Lamination stack length, mm & Lstk & 83.57 \\
\hline Magnet width, mm & MagWid & 29.63 \\
\hline Magnet thickness, mm & LM & 4.1 \\
\hline Bridge width, mm & Bridge & 1.12 \\
\hline & & \\
\hline
\end{tabular}

Table 5.8. Additional key parameters of the high-speed IPM machine

\begin{tabular}{|l|c|c|c|}
\hline \multicolumn{1}{|c|}{ Key design parameters } & Abbrev. & Low speed & High speed \\
\hline Angular speed, rpm & RPM & 2000 & 8,000 \\
\hline Sinusoidal voltage, V & Vs & 450 & 450 \\
\hline Current set point, A & ISP & 130 & 120 \\
\hline Gamma, deg & gamma & 56. & 57.5 \\
\hline Turns in stator coil & TC & 9 & 9 \\
\hline Layers in stator slots & Layers & 1 & 1 \\
\hline Magnet strength, Tesla & BrT & 1.12 & 1.12 \\
\hline
\end{tabular}

\subsubsection{Lumped Parameter and FEA Results for High Speed IPM}

The results obtained from LPM are summarized in Table 5.9 for the parameters defined in Sect. 5.5.1. The table indicates that when operated at $2000 \mathrm{rpm}$, the machine had an efficiency of $97.5 \%$ and produced $146.6 \mathrm{Nm}$ of torque. When the machine operated at $8,000 \mathrm{rpm}$, it had an efficiency of $95.3 \%$ and produced $40.4 \mathrm{Nm}$ of torque.

Table 5.9. Selected LPM results of the high-speed IPM machine at 2000 and 8000 rpm

\begin{tabular}{|l|l|c|c|}
\hline \multicolumn{1}{|c|}{ Selected parameter } & \multicolumn{1}{c|}{ Abbrev. } & Low speed & High speed \\
\hline Total machine torque, Nm & Torque & 163.6 & 40.4 \\
\hline Mechanical power, W & Pmech & 34,260 & 33,890 \\
\hline Efficiency, \% & Eff & 97.6 & 95.3 \\
\hline Peak current in winding, A & IWpk & 98 & 94.6 \\
\hline RMS current in winding, A & IWrms & 70.2 & 64.9 \\
\hline
\end{tabular}

A FEA was performed for the high-speed machine at $2000 \mathrm{rpm}$ and $8000 \mathrm{rpm}$ and a brief summary of the expected capability of the machine is presented in Table 5.10. The torque and power capability of the high speed IPM is lower based on the FEA when compared to the LPM due to saturation of ferromagnetic materials. 
Table 5.10. Selected FEA results of the high-speed IPM machine at 2000 and 8000 rpm

\begin{tabular}{|l|l|c|c|}
\hline \multicolumn{1}{|c|}{ Selected parameter } & Abbrev. & Low speed & High speed \\
\hline Total machine torque, Nm & Torque & 147.5 & 36.0 \\
\hline Mechanical power, W & Pmech & 30,900 & 30,160 \\
\hline
\end{tabular}

\subsection{MULTI-LAYERED IPM MACHINE}

A multi-layered IPM machine configuration with three layers of PMs in the rotor is analyzed in this section of the report. Variations to the basic multi-layered IPM machine that are considered include (1) machine without center posts, (2) machine with steel center posts, (3) machine with bi-state metal bridges and center posts, and (4) machine with two layers of PMs.

The basic geometry of the multi-layered IPM machine that is evaluated is shown in Fig. 5.13. The relative performance capability of the multi-layered IPM machine is compared with the baseline IPM machine in this section. The strength of the PMs (i.e., residual induction, $\mathrm{B}_{\mathrm{r}}$ ) in the multi-layered machine is varied so that the contribution of magnet strength to machine performance can be quantified.

The outside radius of the multi-layered rotor is the same radius as in the baseline IPM machine (i.e., $134.62 \mathrm{~mm}$ ). The length of the multi-layered machine is $80.57 \mathrm{~mm}$, which is $3 \mathrm{~mm}$ shorter than the baseline IPM machine. The baseline stator configuration was used by the models to drive the multi-layered rotor so that a relative comparison of the baseline and the multi-layered IPM machine can be performed.

Multi-layered machine configurations are modeled with and without center posts to investigate the effect of steel center posts on machine performance. Center posts will increase the mechanical strength of the rotor, allowing the potential to operate at high speeds, but will result in additional flux losses in the center post.

The multi-layered machine configuration allows weaker PMs to be utilized, which may reduce the cost of the machine. The multi-layered IPM machine's rotor can be injected with a mixture of magnet in the powdered form and an organic or inorganic binder material that can be cured in the rotor cavities. The injected magnets are not capable of obtaining the magnetic strengths associated with sintered magnets, but the magnet strengths can be customized for the needed application by varying the percentage of magnet and binder material. Another potential plus is that the weaker magnets may have characteristics that are better suited for the expected 160 to $180^{\circ} \mathrm{C}$ temperature of the rotor. Cost-versus-performance tradeoffs will determine the attractiveness of the multi-layered machine.

Variations in the baseline stator configuration should be considered in future work to optimize the stator design for the multi-layered rotor configuration. 


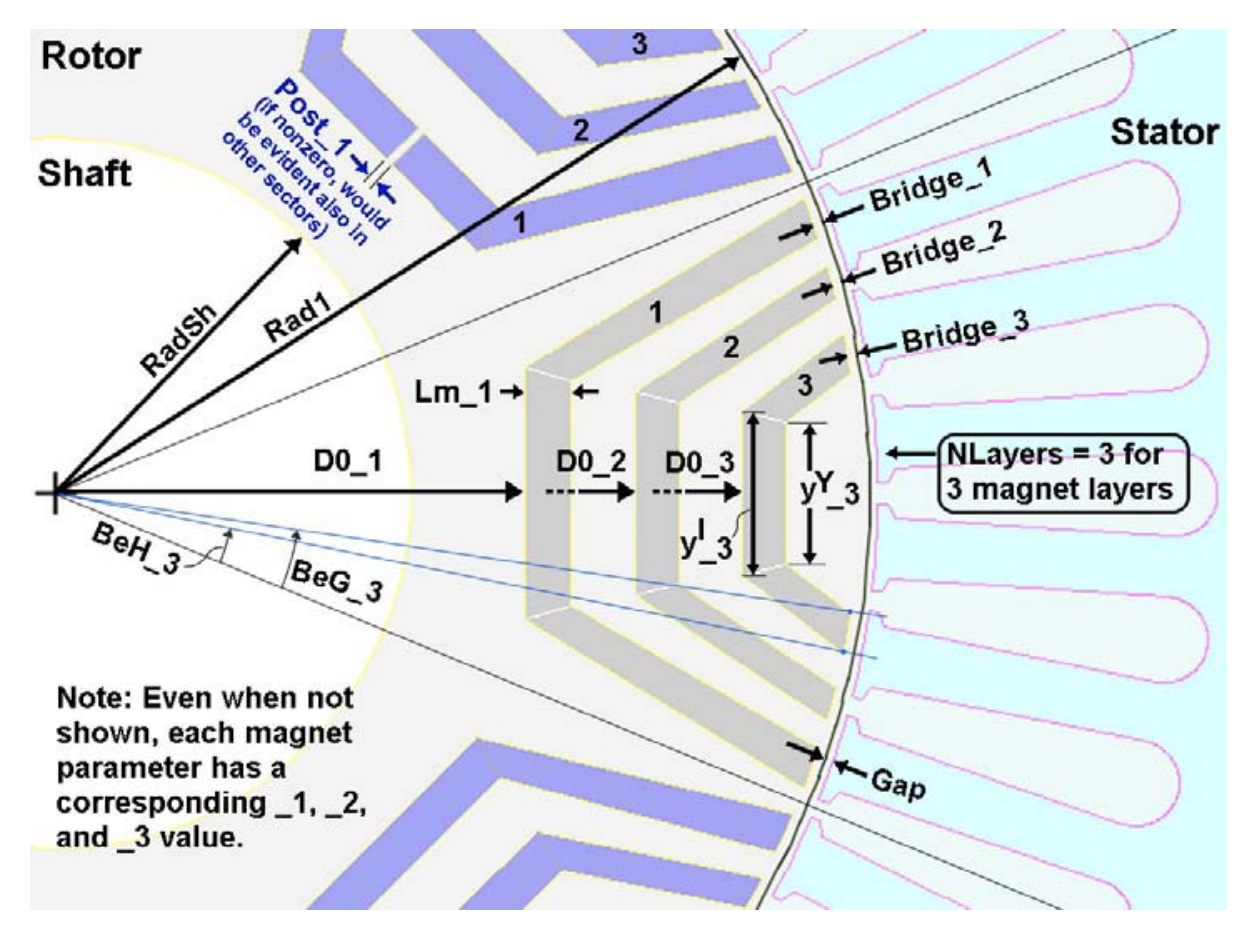

Fig. 5.13. Multi-layered IPM machine geometry.

Table 5.11. Dimensional parameters for the multi-layered machine.

\begin{tabular}{|c|c|c|}
\hline Machine characteristic & Abbrev. & Parameter \\
\hline Rotor outside radius, $\mathrm{mm}$ & Rad1 & 80.19 \\
\hline Stator outside radius, $\mathrm{mm}$ & $\operatorname{Rad} 3$ & 134.62 \\
\hline Rotor radius to layer $1, \mathrm{~mm}$ & DO_1 & 50.5 \\
\hline Rotor radius to layer $2, \mathrm{~mm}$ & DO_2 & 59 \\
\hline Rotor radius to layer $3, \mathrm{~mm}$ & DO_3 & 67.5 \\
\hline Outer base length of layer $1, \mathrm{~mm}$ & $\mathrm{Y}^{\mathrm{I}}-1$ & 12.4 \\
\hline Outer base length of layer $2, \mathrm{~mm}$ & $\mathrm{Y}^{\mathrm{I}}{ }_{2}^{2}$ & 10 \\
\hline Outer base length of layer $3, \mathrm{~mm}$ & $\mathrm{Y}^{\mathrm{I}} 3$ & 7.8 \\
\hline Inner base length of layer $1, \mathrm{~mm}$ & $\mathrm{Y}^{\mathrm{Y}} 1$ & 11 \\
\hline Inner base length of layer $2, \mathrm{~mm}$ & $\mathrm{Y}^{\mathrm{Y}} 2$ & 8.7 \\
\hline Inner base length of layer $3, \mathrm{~mm}$ & $\mathrm{Y}^{\mathrm{Y}} 3$ & 6.6 \\
\hline Bridge length, $\mathrm{mm}$ & Bridge 1 & 1 \\
\hline Bridge length, $\mathrm{mm}$ & Bridge_2 & 1 \\
\hline Bridge length, $\mathrm{mm}$ & Bridge 3 & 1 \\
\hline Magnet width, mm & $\begin{array}{c}\mathrm{LM}_{-1} 1=\mathrm{LM} \_2= \\
\text { LM } 3\end{array}$ & 4.5 \\
\hline Air gap, mm & Gap & 0.8 \\
\hline
\end{tabular}




\subsubsection{FEA Modeling and Results for Multi-Layered IPM Machine}

FEA models were created based on the geometry of the multi-layered machine rotor with and without 1-mm center posts. The baseline IPM stator was used for the multi-layered machine FEA model. A stack length of $80.57 \mathrm{~mm}$ was used for the multi-layered machine. Phase currents were varied from 50 to $450 \mathrm{~A}$ in steps of $50 \mathrm{~A}$; the strength of the PMs (i.e. flux density, $\mathrm{B}_{\mathrm{r}}$ ) was ranged from 0.2 to $1.2 \mathrm{~T}$ in steps of $0.2 \mathrm{~T}$. The peak torque capability of each machine configuration was estimated based on the FEA model.

\subsubsection{FEA Modeling Results for Multi-Layered IPM Machine without Center Posts}

Figure 5.14 shows the estimated torque capability vs. current for the multi-layered IPM machine without center posts, while Fig. 5.15 shows the estimated torque constants (i.e., torque/ampere) for the same conditions. In general, the torque constant reaches a peak at about $100 \mathrm{~A}$ and decreases at higher currents as a result of saturation effects in the ferromagnetic materials.

Figure 5.16 compares the torque capability of the multi-layered machine without center posts (i.e., 0.6, 0.8, and $1.0 \mathrm{~T}$ magnets) with that of the baseline IPM machine. The baseline and the multi-layered IPM machine without center posts (and 0.6-T PMs) have about the same torque capability at 275 A.

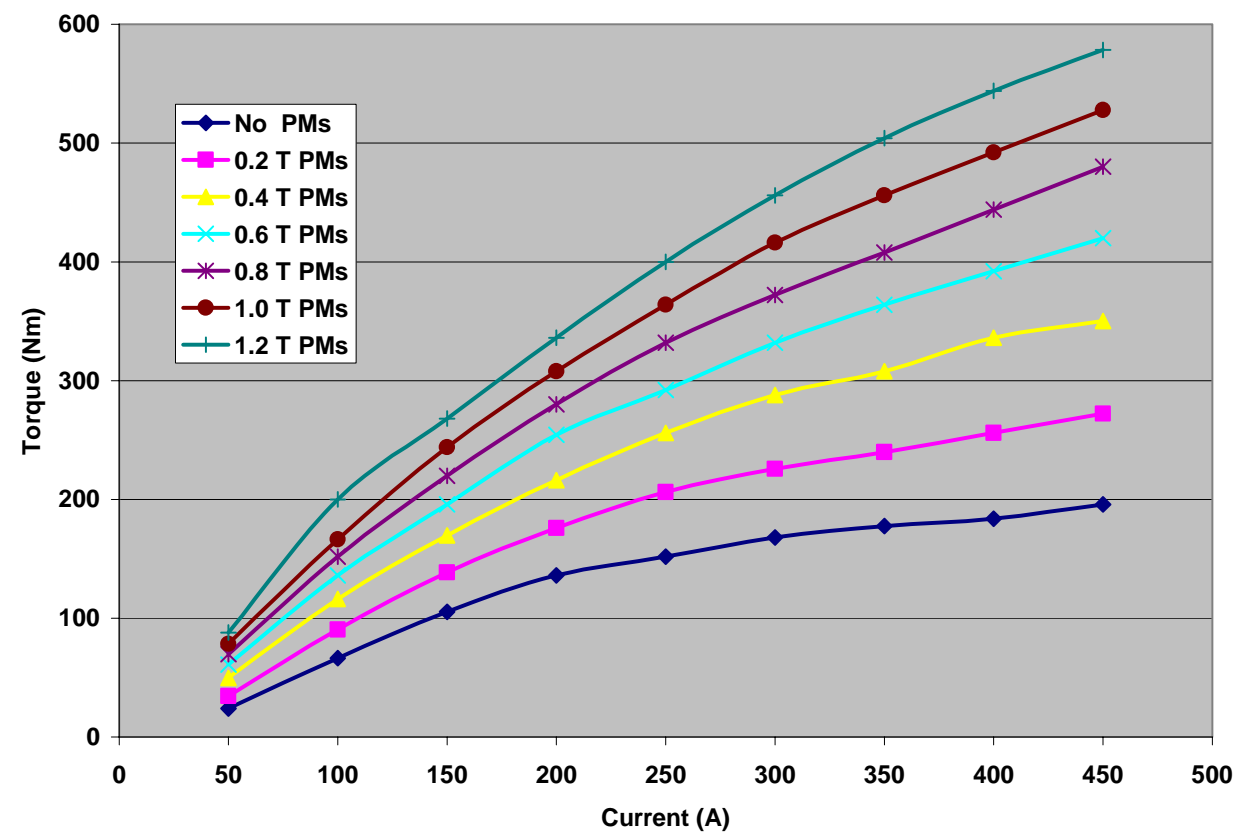

Fig. 5.14. Torque vs. phase current for multi-layered IPM machine without center posts. 


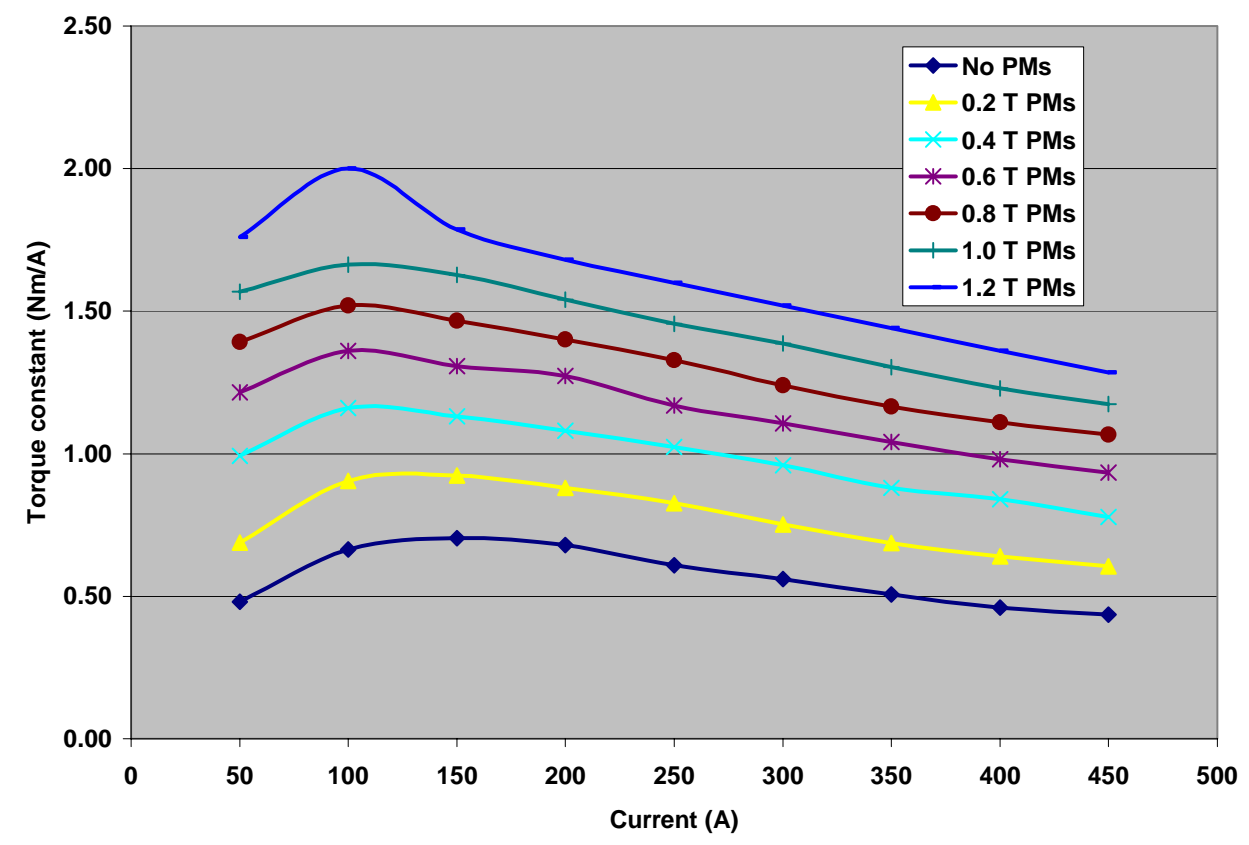

Fig. 5.15. Torque constant vs. phase current for multi-layered IPM machine without center posts.

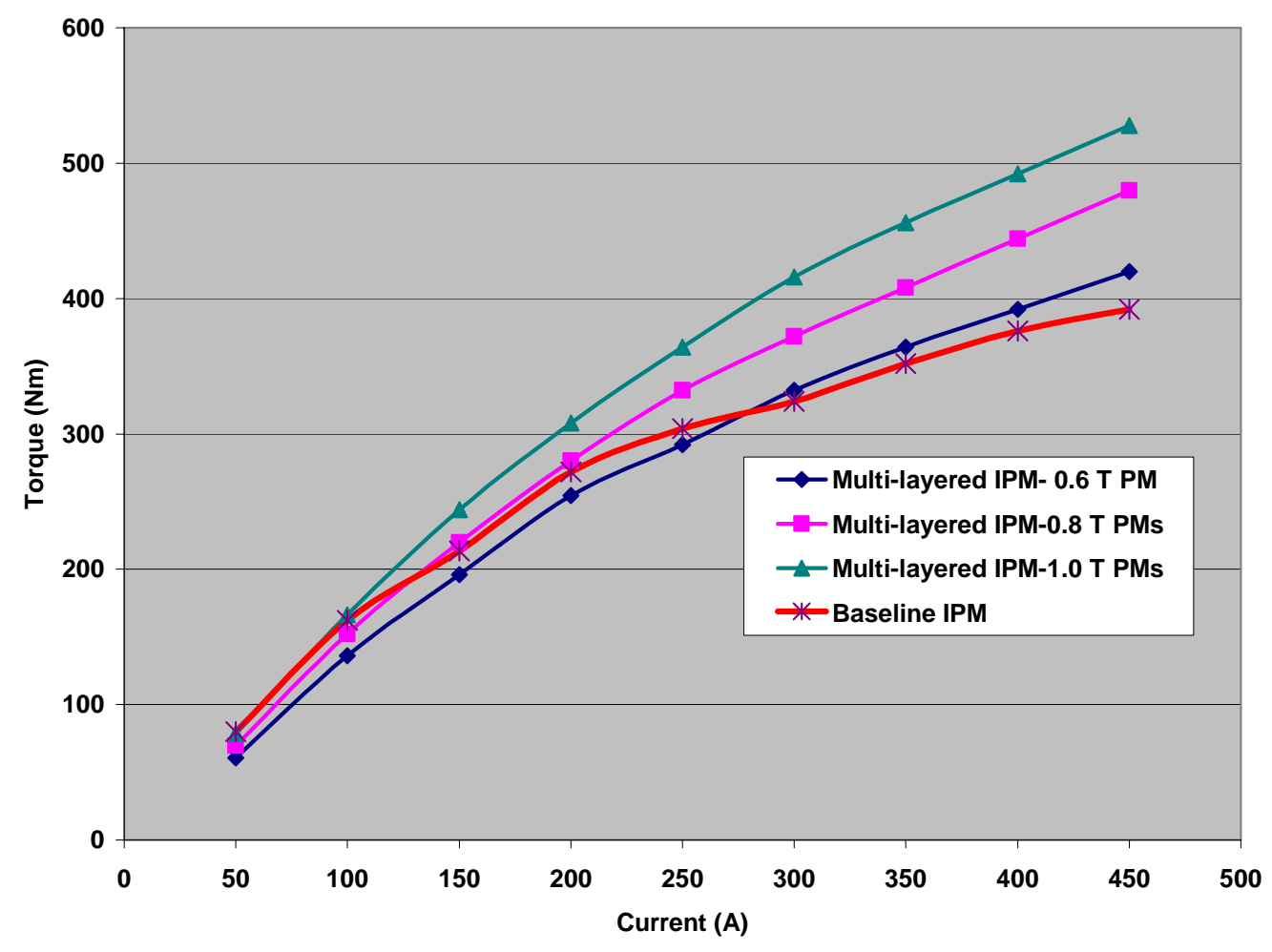

Fig. 5.16. Torque capability of baseline and multi-layered IPM machine without center posts. 


\subsubsection{FEA Modeling Results for Multi-Layered IPM Machine With Steel Center Posts}

Figure 5.17 shows the estimated torque capability vs. current for the multi-layered IPM machine with steel center posts. The torque capability is reduced as a result of the flux leakage at the center posts. Figure 5.18 shows the estimated torque constants (i.e. torque/ampere) for the multilayered IPM machine with steel center posts. The torque constant reaches a peak at about $100 \mathrm{~A}$ and decreases at higher currents as a result of the saturation effects.

Figure 5.19 compares the torque capability of the multi-layered machine with steel center posts (i.e., 0.6, 0.8, and $1.0 \mathrm{~T}$ magnets) with that of the baseline IPM machine. The baseline and the multi-layered IPM machine with steel center posts (and 0.6-T PMs) have about the same torque capability at about $300 \mathrm{~A}$.

Figures 5.20 and 5.21 compare the torque capability of the multi-layered IPM with $0.4-$ and 0.6 -T PMs without and with steel center posts. The rotor configuration without center posts has a higher torque capability. Figure 5.22 shows the percentage of torque capability loss due to the steel center posts. Note the percentage loss at $50 \mathrm{~A}$ is significant, about $30 \%$, because the center posts are not saturated at this low current. During higher-current operation, the loss is much less severe, typically $5 \%$ or less.

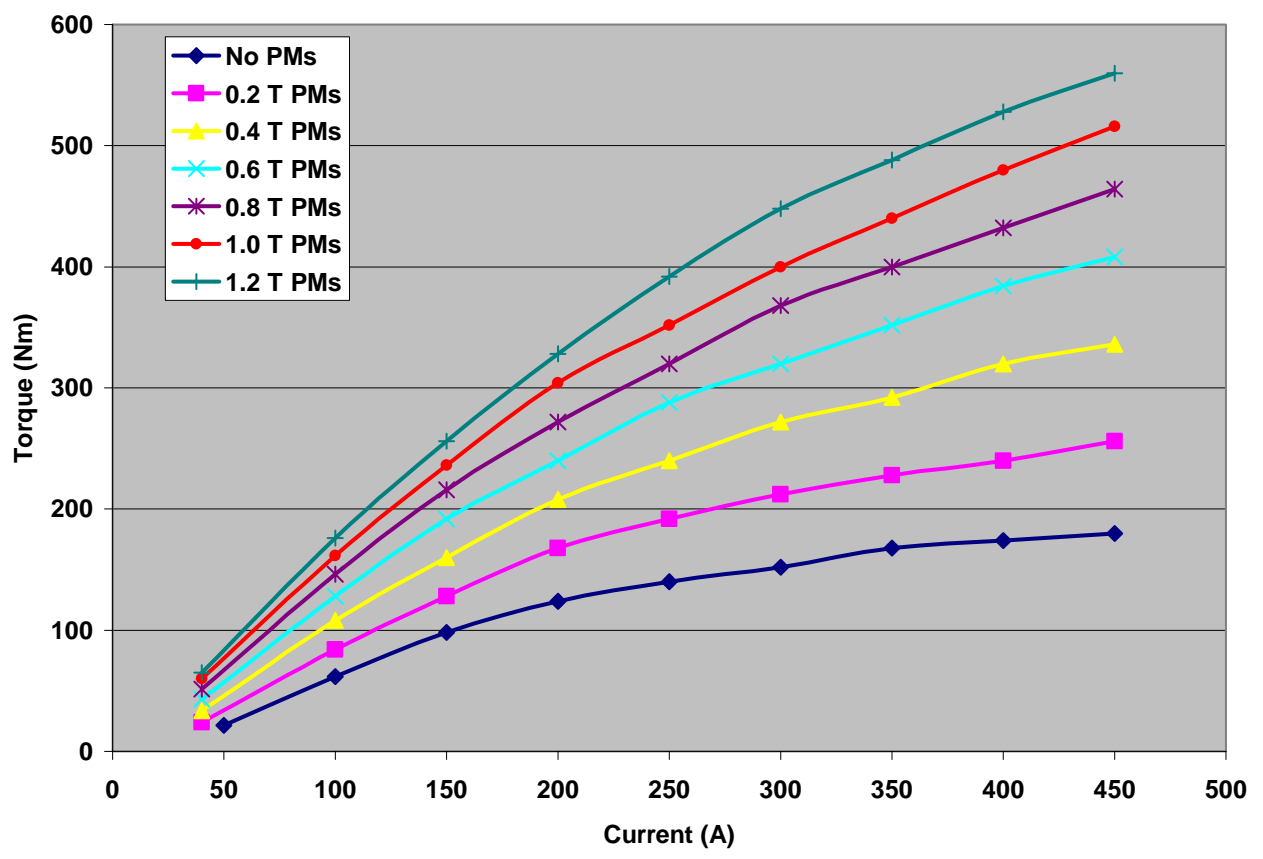

Fig. 5.17. Torque vs. phase current for multi-layered IPM machine with steel center posts. 


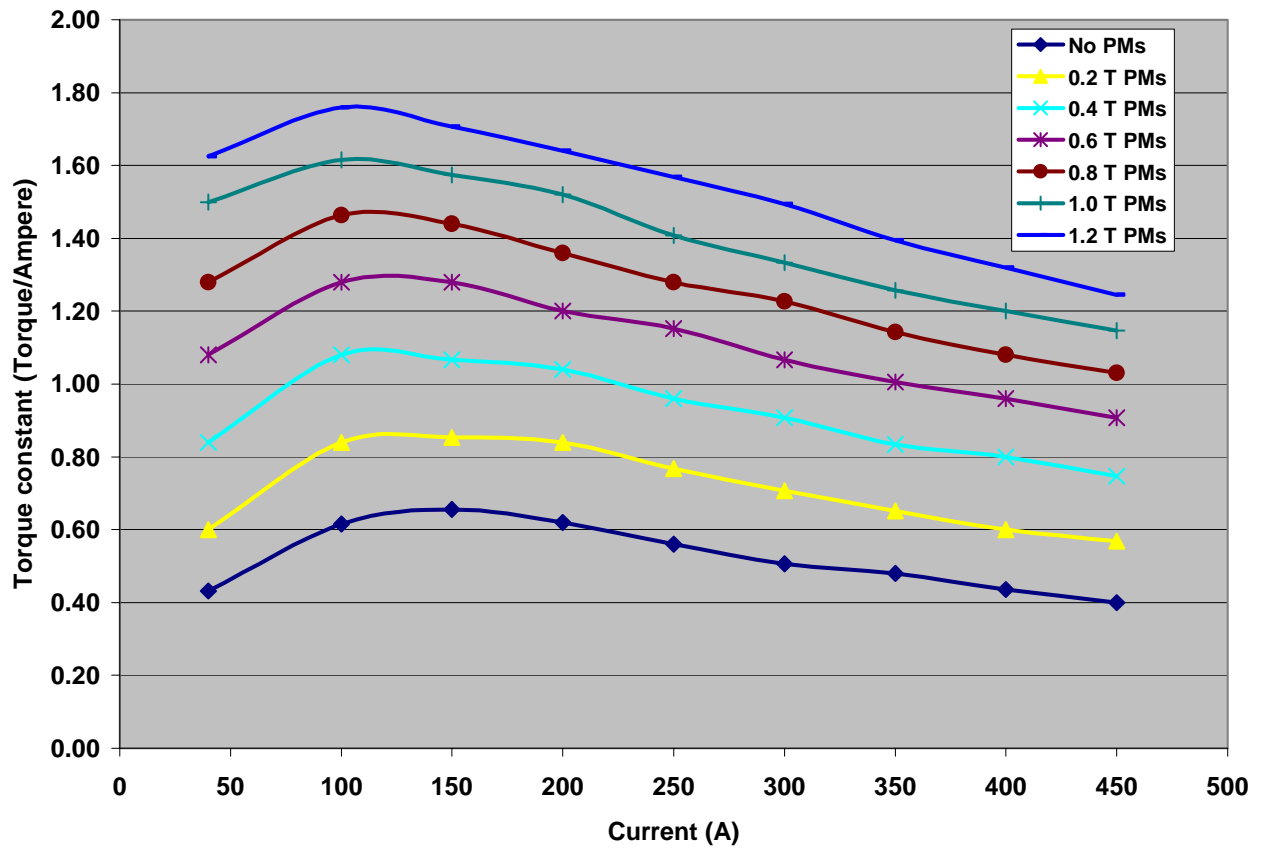

Fig. 5.18. Torque constant vs. phase current for multi-layered IPM machine with steel center posts.

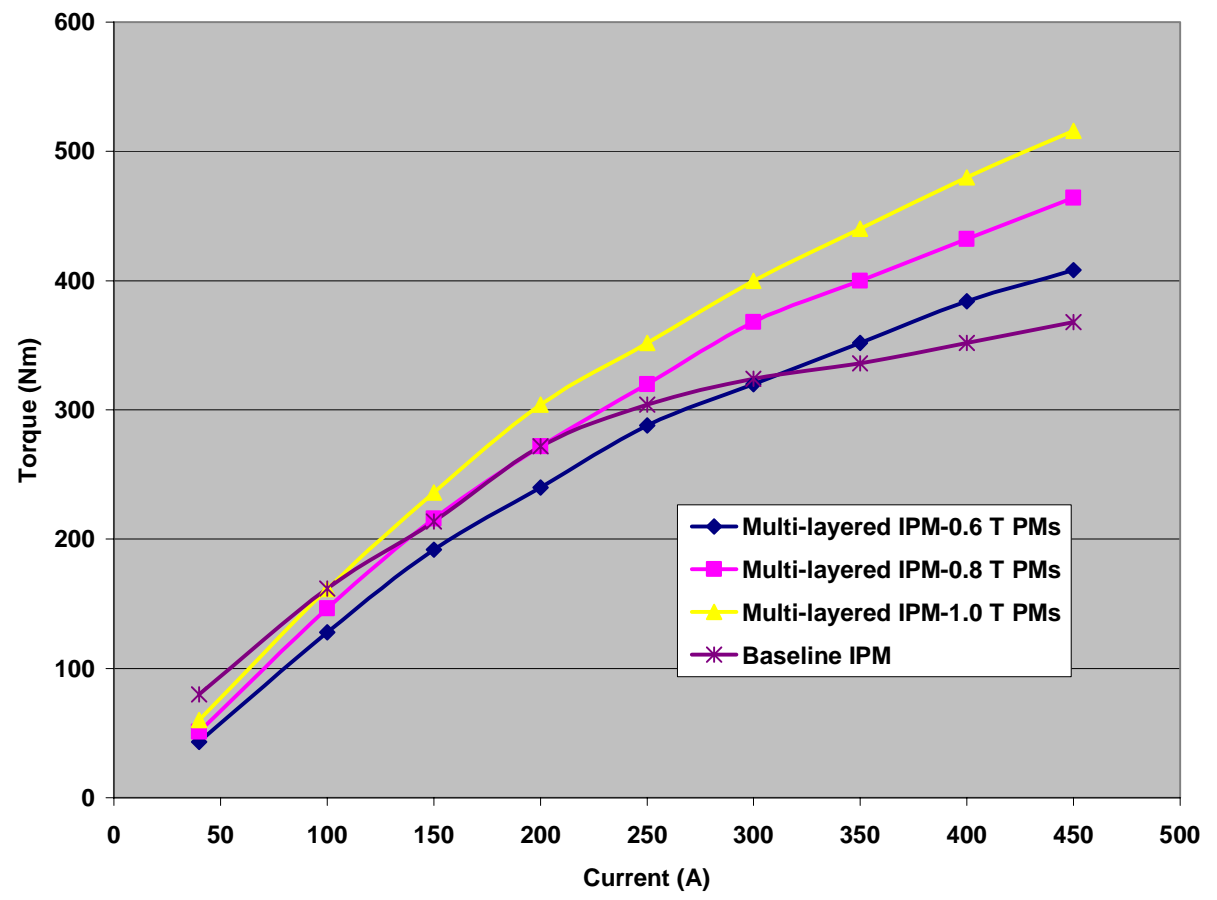

Fig. 5.19. Torque comparison of multi-layered IPM and baseline IPM machine with steel center posts. 


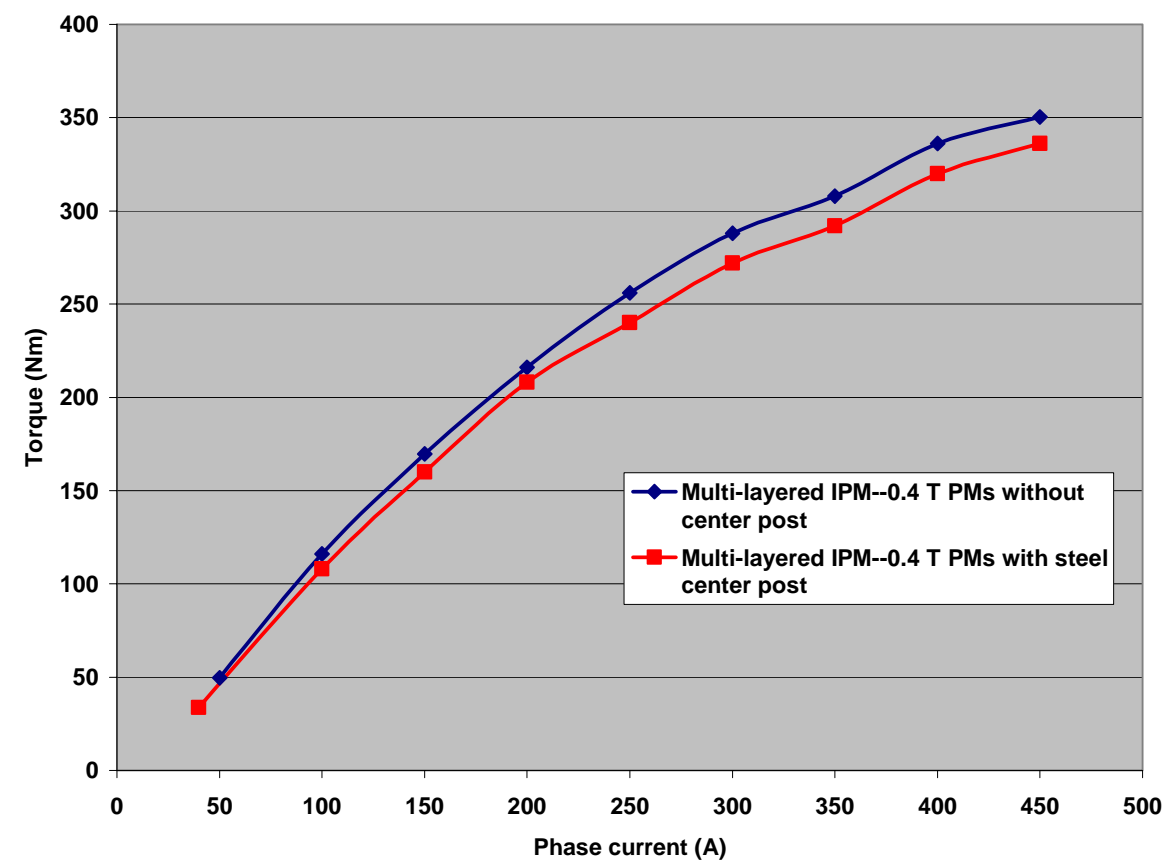

Fig. 5.20. Torque comparison of multi-layered IPM with 0.4-T PMs with and without steel center posts.

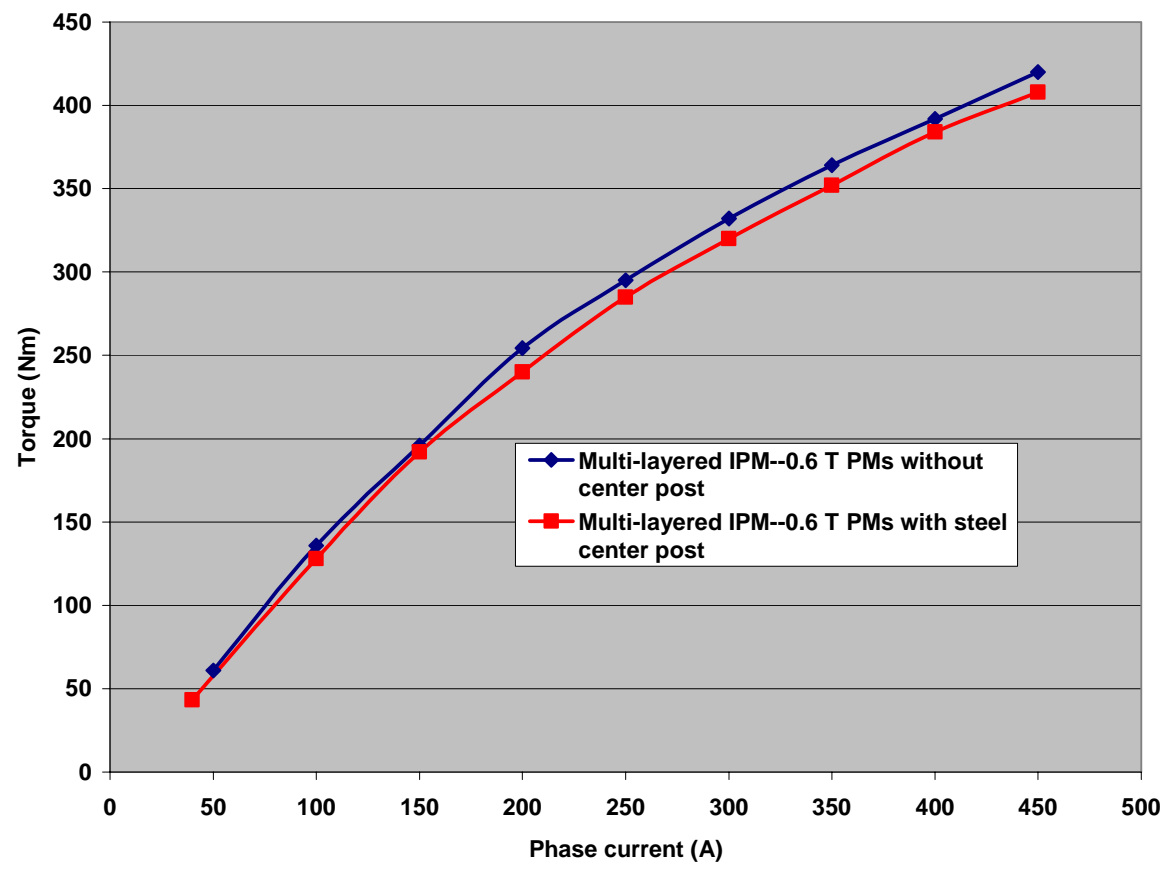

Fig. 5.21. Torque comparison of multi-layered IPM with 0.6-T PMs with and without steel center posts. 


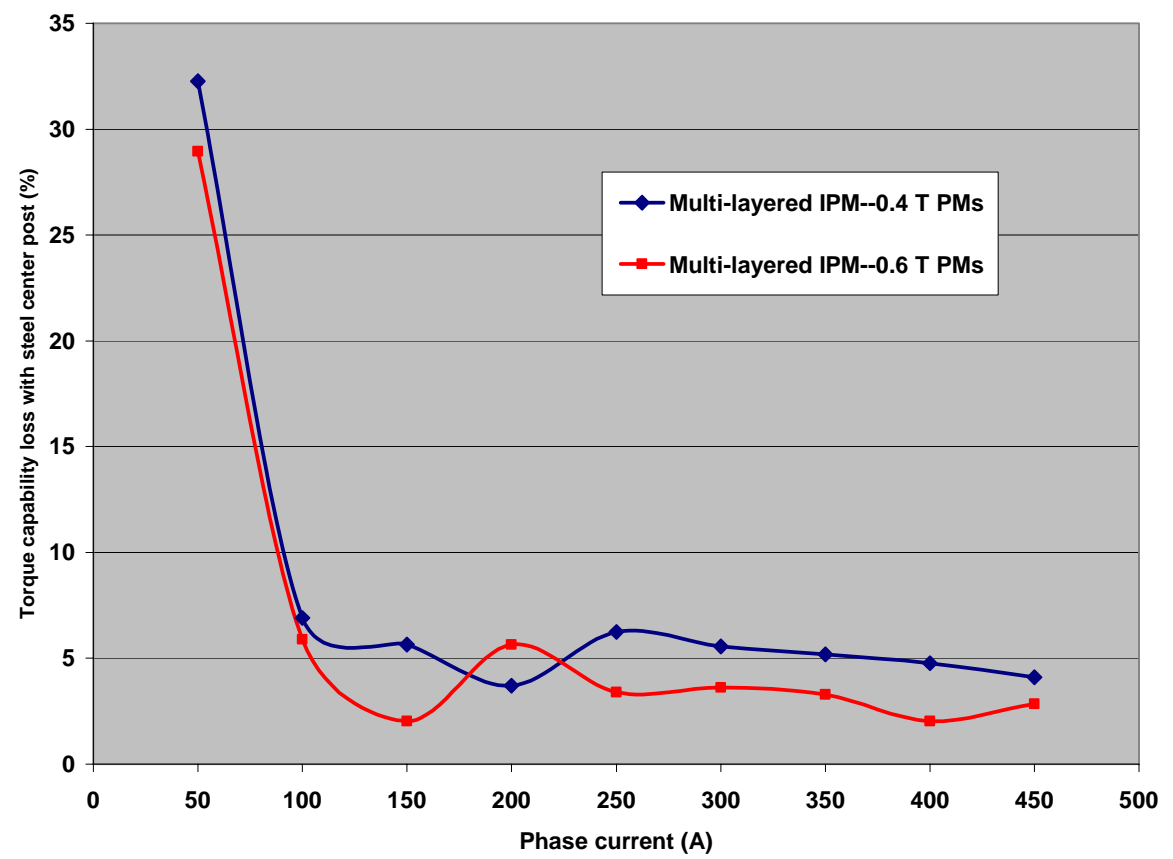

Fig. 5.22. Percentage torque capability loss of multi-layered IPM machine with 0.4- and 0.6-T PMs due to steel center posts.

\subsubsection{FEA Modeling Results for Bi-State Center Posts and Bridges}

Research has shown that the normally high magnetic permeability of bi-state material can be permanently reduced to that of air in localized regions by means of heat treatment. Most of the rotor lamination could retain the high magnetic permeability that is desired, while localized regions could be changed to a low permeability state. IPM machine center posts and bridges are two regions that could greatly benefit from the incorporation of bi-state material. Figures 5.23 and 5.24 compare the torque capability of multi-layered IPM machines with 0.4- and 0.6-T PMs with bi-state and steel bridges and center posts. Figure 5.25 charts the percentage torque increase due to bi-state bridges and center posts. At $50 \mathrm{~A}$, a significant increase of $50 \%$ in torque capability of the machine is estimated as a result of the flux leakage in steel bridges and center posts at low saturation conditions. When the current (and saturation of the ferromagnetic materials) is increased, the increase in torque is in the 10 to $18 \%$ range. 


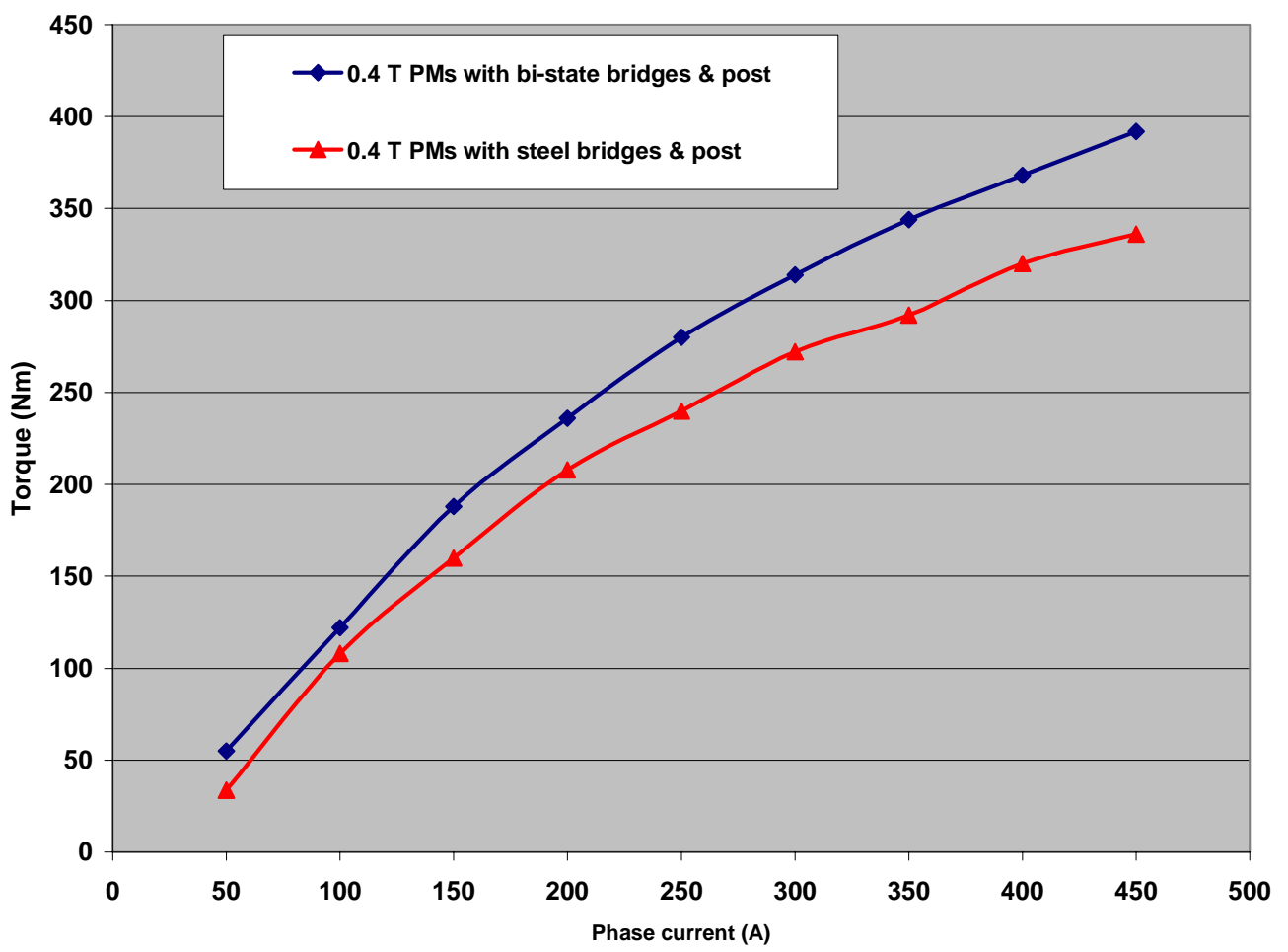

Fig. 5.23. Torque comparison of multi-layered IPMs with 0.4-T PMs with bi-state and steel bridges and center posts.

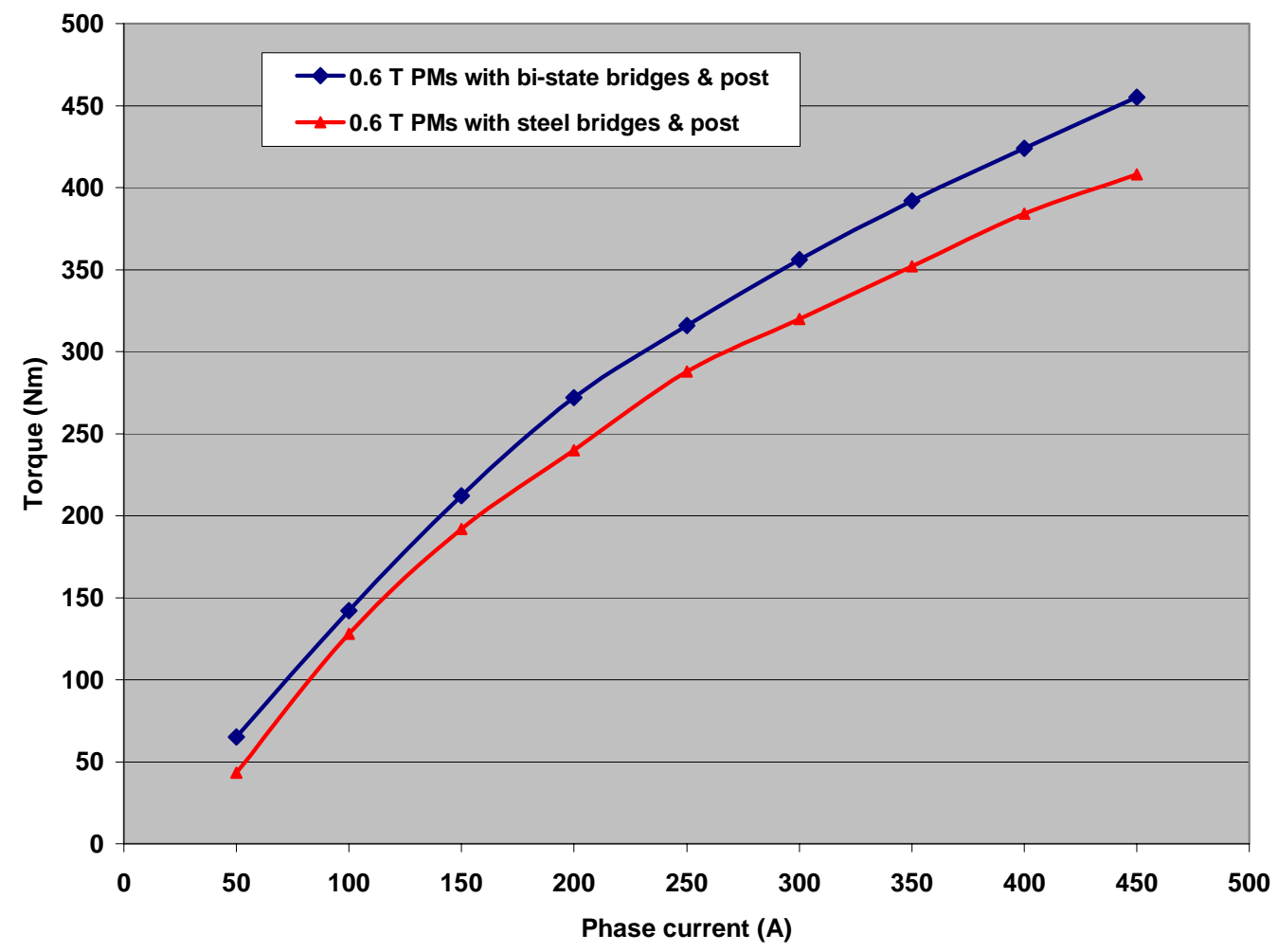

Fig. 5.24. Torque comparison of multi-layered IPMs with 0.6-T PMs with bi-state and steel bridges and center posts. 


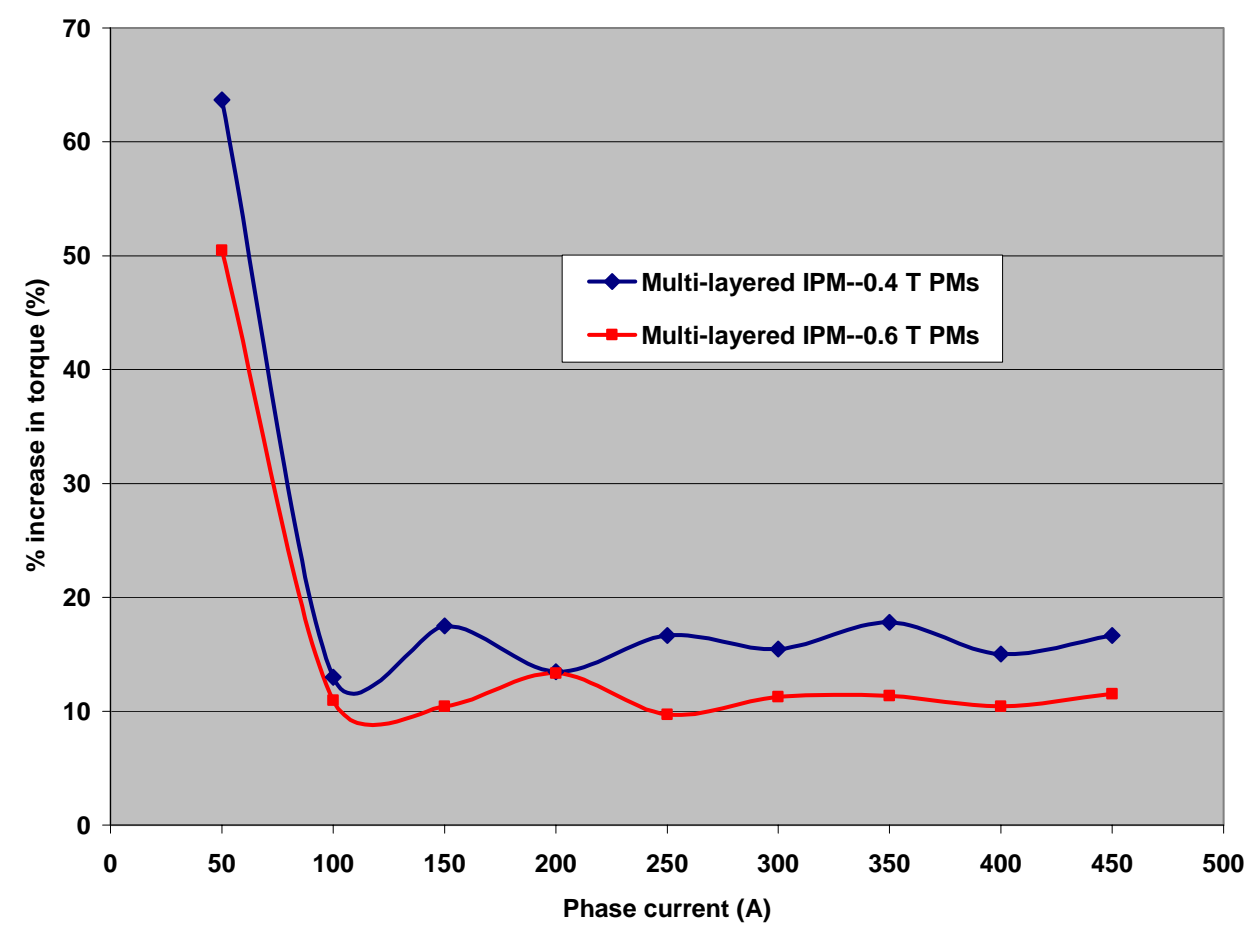

Fig. 5.25. Percentage torque capability increase of multi-layered IPM machine with 0.4- and 0.6-T PMs due to bi-state bridges and center posts.

\subsubsection{FEA Modeling Results for Two-Layer IPM with Steel Center Posts}

An FEA was performed for a two-layered IPM. Layers 1 and 2 (see Fig. 5.13) contain 0.4 T PMs with layer 3 replaced with steel. Figure 5.26 compares the torque capability of the three-layered and two-layered IPM configuration with 0.4-T PMs. The difference in torque capability of the two machine configurations increases with increasing phase current. 


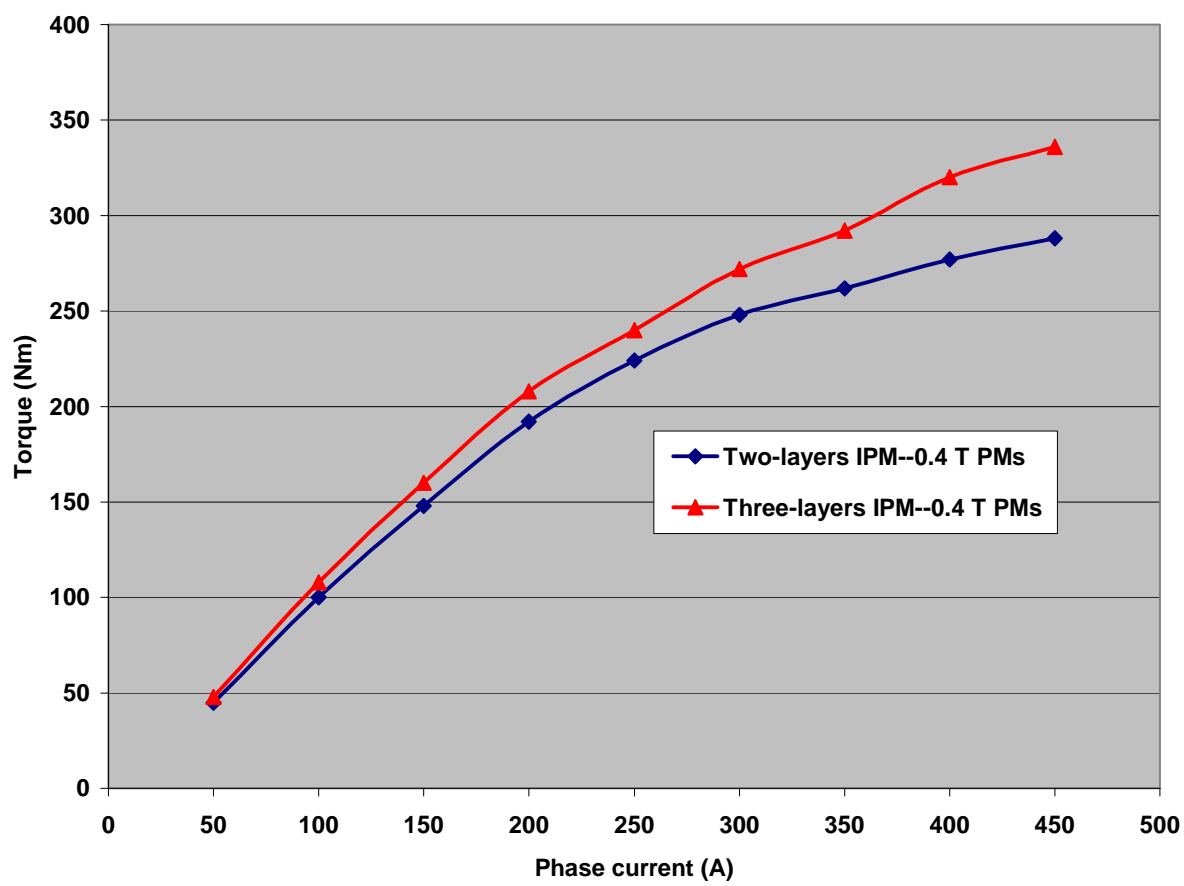

Fig. 5.26. Torque capability comparison of two- and three-layered IPM machine with 0.4-T PMs.

\subsection{Recessed Magnet Machine}

Two recessed magnet PM machines, an 8 and a 12-pole machine, are evaluated in this section of the report. Both machines have high strength magnets (i.e. Br of $1.12 \mathrm{~T}$ ) with a stack length of $83.57 \mathrm{~mm}$. Fig. 5.20 shows the geometry of the recessed magnet machines, and Table 5.12 shows some of the key dimensions of the machines. Simulation runs were performed with the baseline stator for the 8-pole recessed magnet machine and a customized stator for the 12-pole machine. Both machines were analyzed with a lumped-parameter model, and results are shown in Tables 5.13 and 5.14 for the 8 and 12-pole machines respectively.

Table 5.12. Selected dimensions of the recessed-magnet machines

\begin{tabular}{|l|c|c|}
\hline \multicolumn{1}{|c|}{ Selected dimensional parameter } & Abbrev. & Value \\
\hline Stator outside radius, $\mathrm{mm}$ & Rad3 & 134.62 \\
\hline Radial distance to end of slot, $\mathrm{mm}$ & Rad2 & 119.3 \\
\hline Rotor outside radius, $\mathrm{mm}$ & Rad1 & 80.19 \\
\hline Shaft radius (minus ring), $\mathrm{mm}$ & RadSH & 56.3 \\
\hline Lamination stack length, mm & Lstk & 83.57 \\
\hline Magnet width, mm & MagWid & 41.51 \\
\hline Magnet thickness, mm & LM & 8.31 \\
\hline
\end{tabular}




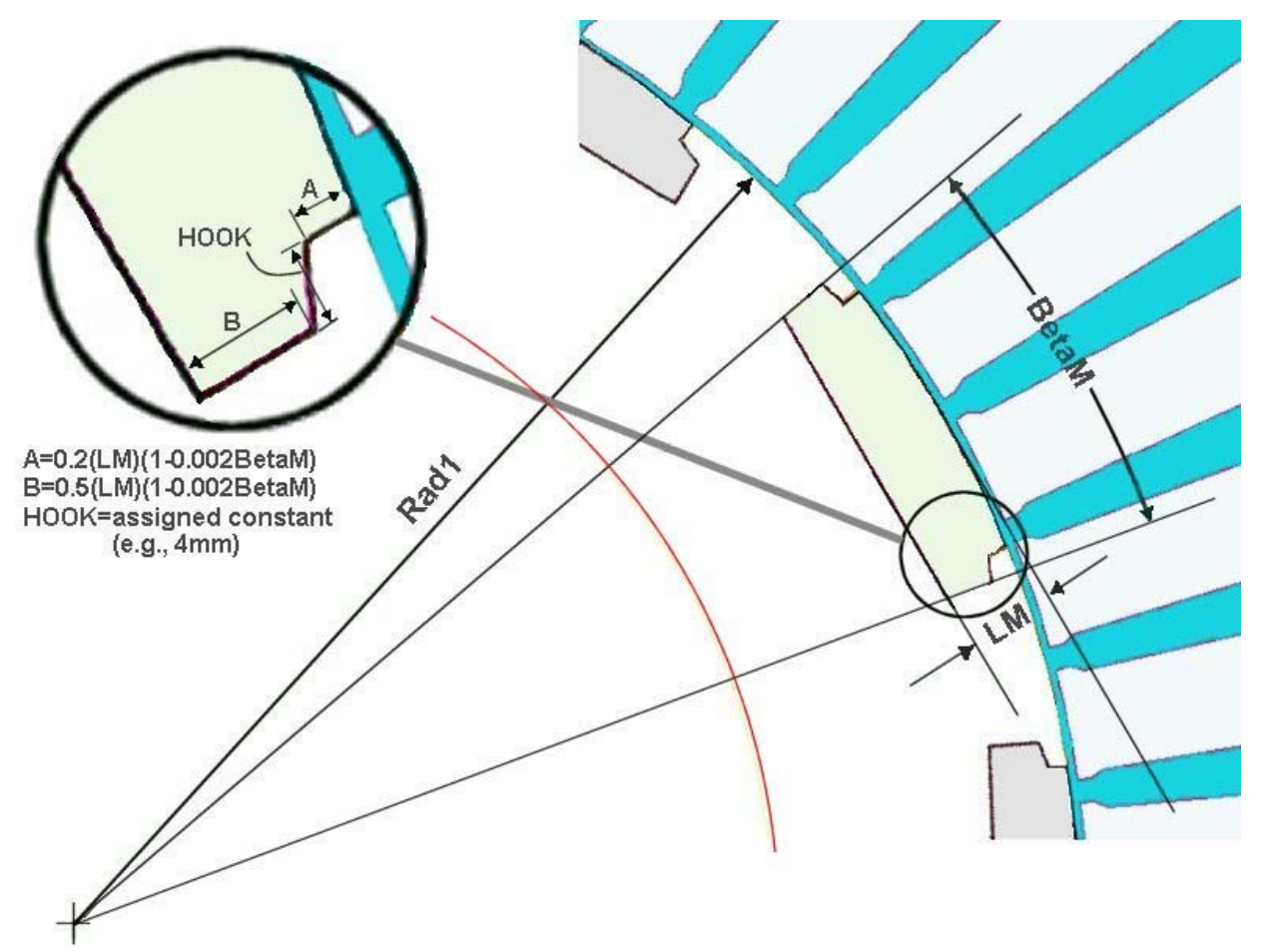

Fig. 5.27. Recessed-magnet machine geometry.

Table 5.13. Selected lumped parameter results for 8-pole recessed-magnet machine

\begin{tabular}{|l|l|c|c|}
\hline \multicolumn{1}{|c|}{ Selected parameter } & \multicolumn{1}{c|}{ Abbrev. } & Low speed & Medium speed \\
\hline Total machine torque, Nm & Torque & 278.6 & 158.8 \\
\hline Mechanical power, W & Pmech & 30,350 & 33,270 \\
\hline Efficiency, \% & Eff & 90.1 & 95.1 \\
\hline Peak current in winding, A & IWpk & 200.2 & 114.6 \\
\hline RMS current in winding, A & IWrms & 140.1 & 80.2 \\
\hline
\end{tabular}

Table 5.14. Selected lumped parameter results for 12-pole recessed-magnet machine

\begin{tabular}{|l|l|c|c|}
\hline \multicolumn{1}{|c|}{ Selected parameter } & \multicolumn{1}{c|}{ Abbrev. } & Low speed & Medium speed \\
\hline Total machine torque, Nm & Torque & 302.4 & 160 \\
\hline Mechanical power, W & Pmech & 32,930 & 30,000 \\
\hline Efficiency, \% & Eff & 89.1 & 95.0 \\
\hline Peak current in winding, A & IWpk & 187.9 & 106.8 \\
\hline RMS current in winding, A & IWrms & 133.8 & 78.3 \\
\hline
\end{tabular}




\section{ROTATING ELECTRIC MACHINES WITH SURFACE-MOUNTED MAGNETS}

At the beginning of this study, the target design specifications were those shown in Table 6.1. A desired speed was not included in this specification; however, considering the capabilities of the Toyota Prius motor, it was decided to design the machines as described in this section to have a base speed of $1500 \mathrm{rpm}$, a CPSR of 4, and a base power of $30 \mathrm{~kW}$. Such a machine would be capable of short $55-\mathrm{kW}$ bursts. During peak power bursts, the inverter current is not to exceed $300 \mathrm{~A}$ rms. Between 1500 and $6000 \mathrm{rpm}$, there must be some type of field weakening.

Table 6.1. Old target design specification for power electronics and electric machines

\begin{tabular}{|l|c|c|c|}
\hline \multicolumn{1}{|c|}{ Requirement } & Inverter & Motor & $\begin{array}{c}\text { Integrated } \\
\text { system }\end{array}$ \\
\hline Specific power @ peak load (kW/kg) & $>12$ & $>1.3$ & $>1.2$ \\
\hline Volumetric power density (kW/1) & $>12$ & $>5$ & $>3.4$ \\
\hline Cost per kW & $<\$ 5$ & $<\$ 7$ & $<\$ 12$ \\
\hline Efficiency, 10-100\% speed, 20\% rated torque (\%) & $>97$ & $>93$ & $>90$ \\
\hline Peak power (kW) & 55 & 55 & 55 \\
\hline Continuous power (kW) & 30 & 30 & 30 \\
\hline Battery operating voltage ( $\left.\mathrm{V}_{\mathrm{dc}}\right)$ & $325(200-450)$ & $325(200-450)$ & $325(200-450)$ \\
\hline Maximum current, rms (A) & 300 & 300 & 300 \\
\hline Torque ripple (\%) & $\mathrm{NA}$ & 5 & 5 \\
\hline Coolant inlet temperature & 105 & 105 & 105 \\
\hline
\end{tabular}

\subsection{ROTOR MAGNET CONTAINMENT}

As the base speed increases, magnet containment becomes a critical problem. For a machine with surface-mounted magnets operating as a brushless direct current motor (BDCM) with trapezoidal back-emf, there are four options:

1. Wrap the magnets with a suitable B-stage prepreg glass tape.

2. Encase the rotor in a non-magnetic can.

3. Use an "inside-outside configuration" in which the stator is inside the structure containing the magnets and rotor laminations. The centrifugal forces on the magnets are then restrained by this structure.

4. Use an axial gap configuration. In this arrangement, the stator and rotor are in the shape of a toroid. The armature current is in the radial direction and the magnets are charged in the axial direction. The air gap is in the axial direction and the centrifugal force on the magnets is in the radial direction. Thus a restraining ring can be used that does not impact the air gap volume.

Two control methods have been developed to drive a BDCM with surface-mounted magnets. The first method, conventional phase advance (CPA), was developed by UQM Technologies. ${ }^{6}$ This method uses a conventional voltage source inverter to drive the motor. The second method is dual mode inverter control (DMIC), developed by ORNL. ${ }^{7}$ A condensation of its basic operation is included in Appendix E. The success of either of these two methods is highly 
dependent upon the value of the machine inductance; the required values are summarized in Table 6.2.

Table 6.2. Limiting values of inductance for BDCM operation

\begin{tabular}{|l|l|l|l|}
\hline Mode & $\mathbf{L}_{\max }$ & $\mathbf{L}_{\min }$ & Comments \\
\hline DMIC & $\pi \operatorname{sqrt}(91 / 1215) \mathrm{E}_{\mathrm{b}} / \Omega_{\mathrm{b}} \mathrm{I}_{\mathrm{r}}$ & $\pi \operatorname{sqrt}(1620) \mathrm{E}_{\mathrm{b}} / \Omega_{\mathrm{b}} \mathrm{I}_{\mathrm{rms}}$ & \\
\hline CPA & $36 \mathrm{~V}_{\mathrm{dc}} \mathrm{E}_{\mathrm{b}} / / \pi 3 \Omega_{\mathrm{b}} \mathrm{P}_{\mathrm{r}}$ & $\begin{array}{l}\operatorname{sqrt}\left(2 \mathrm{~V}_{\mathrm{dc}} 2 / \mathrm{CPSR}+72 \mathrm{E}_{\mathrm{b}} 2 / \pi 2-\right. \\
\left.24 \mathrm{E}_{\mathrm{b}} \mathrm{V}_{\mathrm{dc}} / \pi \mathrm{CPSR}\right) / \pi \Omega_{\mathrm{b}} \mathrm{I}_{\mathrm{rms}}\end{array}$ & $\mathrm{L}_{\infty}=8.485 \mathrm{E}_{\mathrm{b}} / \pi 2 \Omega_{\mathrm{b}} \mathrm{I}_{\mathrm{rms}}$ \\
\hline $\begin{array}{l}\text { Link } \\
\text { Voltage }\end{array}$ & $\mathrm{V}_{\mathrm{dc}}=2 \mathrm{E}_{\mathrm{b}}+1.489 \Omega_{\mathrm{b}} \mathrm{LI}_{\mathrm{rms}} / \pi 2+2.236 \mathrm{RI}_{\mathrm{rms}}$ & $\mathrm{L}<\mathrm{L}_{\max }$ of the DMIC \\
\hline
\end{tabular}

A machine with surface-mounted magnets can also have a sinusoidal back-emf; this is referred to as a PMSM. Two options are available to control such a machine:

1. Design the motor with the inductance within the range shown in Table 6.2.

2. Design a structure as in the Honda motor $^{3}$ to contain the magnets. In the Honda motor, this structure also contributes reluctance torque.

Late in this study, the AEMD specifications of Sect. 4.3 were introduced. It was decided to continue as before but to emphasize the parameters that would limit the operation at the AEMD levels. Designs that showed promise would then be analyzed for mechanical and thermal limitations at a later date. Eleven configurations have been analyzed, using both software developed by the Power Electronics and Electric Machinery Research Center (PEEMRC) and T. J. E. Miller's SPEEDCAD software. Their parameters are shown in Table 6.3. All cases have three phases and an air gap of 60 mils to facilitate the use of prepreg glass tape wrap or metal cans for magnet containment. Case 9 has been designed to meet the AEMD specifications, excluding thermal and mechanical requirements that will be taken up in the next phase of this study. Case 11 is based on the latest Honda design. These cases are now discussed in the body of this chapter.

\subsection{DESIGN CASES}

As seen in Table 6.3, there are four radial-gap, 18-pole design cases (1, 2, 3, and 4) with the rotor interior to the stator. The difference between these is in the turns per coil and the stack length. There are three 8-pole inside-rotor designs (5,6, and 10). The difference between these is in the number of turns per coil. Case 7 is an axial gap design using the ORNL Bailey module, which employs two stators with the rotor between them. Case 8 is an "inside-outside" design where the stator is interior to the rotor. Case 9 is a fractional-slot winding, and case 11 is a Honda type design. 
Table 6.3. Case parameters for cost study

\begin{tabular}{|c|c|c|c|c|c|c|c|c|}
\hline Case & $\begin{array}{c}\text { Rso* } \\
\text { (in) }\end{array}$ & $\begin{array}{c}\text { Rro** } \\
\text { (in) }\end{array}$ & Rotor & Mode & $\begin{array}{c}\text { Slots/pole per } \\
\text { phase }\end{array}$ & Poles & Turns/coil & $\begin{array}{c}\text { Length } \\
\text { (in) }\end{array}$ \\
\hline 1 & 5 & 3 & inside & BDCM & 1 & 18 & 8 & 1.969 \\
\hline 2 & 5 & 3 & inside & BDCM & 1 & 18 & 4 & 1.969 \\
\hline 3 & 5 & 3 & inside & BDCM & 1 & 18 & 4 & 3.938 \\
\hline 4 & 5 & 3 & inside & BDCM & 1 & 18 & 2 & 3.938 \\
\hline 5 & 6.5 & 3 & inside & BDCM & 1 & 8 & 8 & 3.938 \\
\hline 6 & 6.5 & 3 & inside & BDCM & 1 & 8 & 4 & 3.938 \\
\hline 7 & 5.3 & 4 & $\begin{array}{c}\text { Axial } \\
\text { gap }\end{array}$ & BDCM & 1 & 18 & 6 & 5 \\
\hline 8 & 5 & 4 & outside & BDCM & 1 & 18 & 2 & 4 \\
\hline 9 & 6.5 & 3 & inside & PMSM & 0.5 & 10 & 8 & 1.969 \\
\hline 10 & 6.5 & 3 & inside & BDCM & 1 & 8 & 2 & 3.938 \\
\hline
\end{tabular}

$*$ Rso $=$ outer radius of stator.

** Rro $=$ outer radius of rotor.

The discussions evaluating these designs will proceed as follows:

1. Cases 1, 2, 3, 4, 5, 6, and 10 are part of a cost study discussed in Sect. 7, where pole count and stack length are varied. Interesting design features are discussed in Sect. 6.2.2.

2. A mechanical study of the magnet containment capabilities of metallic cans and B-stage glass tape placed over the magnets will be presented.

3. Section 6.3 presents the design of a surface-mounted PM motor with an external rotor.

4. The PEEMRC has developed an axial gap motor to be used with the DMIC. It has been driven to $6600 \mathrm{rpm}$ with the dynamometer to ensure its mechanical integrity and is in the PEEMRC Test Cell 1 for measurement of torque, power, and efficiency as a function of speed. A similar motor designed for this study is discussed in Sect. 6.4.

5. The PEEMRC is exploring a radial gap motor with self-supporting, surface-mounted magnets in the shape of an inverted wide " $T$ ". The magnets are separated by several millimeters of rotor, as in the Honda motor, giving rise to saliency. Its design will be discussed in Sect. 6.5.

6. Since inductance plays a critical role, a fractional-slot design is presented in Sect. 6.6.

\subsubsection{Design Study of Cases 1, 2, 3, 4, 5, 6, and 10}

The performance parameters of these cases are summarized in Table 6.4. The first four cases have 18 poles, and the next three have 8 poles. Their stack lengths have a value of either 1.969 or 3.938 inches. The turns per coil of the 18-pole motors are varied as 8, 4, 4 and 2 . The stack length of the 8-pole design remains at 3.938 inches, but the turns per coil vary as 8, 4, and 2 . These values were chosen to illustrate how these parameters impact motor inductance. 
Table 6.4. Comparison of high- and low-inductance motors

\begin{tabular}{|c|c|c|c|c|c|c|c|}
\hline \multirow{3}{*}{$\begin{array}{ll} & \text { Parameters } \\
\text { Case } & \end{array}$} & \multicolumn{7}{|c|}{ Numerical values } \\
\hline & \multicolumn{4}{|c|}{18 Pole } & \multicolumn{3}{|c|}{8 Pole } \\
\hline & $\# 1$ & \#2 & $\# 3$ & $\# 4$ & $\# 5$ & $\# 6$ & $\# 10$ \\
\hline Rated power, $\mathrm{P}_{\mathrm{r}}, \mathrm{W}$ & 30000 & 30000 & 30000 & 30000 & 30000 & 30000 & 30000 \\
\hline Torque, N-m & 191 & 191 & 191 & 191 & 191 & 191 & 191 \\
\hline Speed, rpm & 1500 & 1500 & 1500 & 1500 & 1500 & 1500 & 1500 \\
\hline Outer radius of stator, $\mathrm{R}_{\mathrm{so}}$, in & 5 & 5 & 5 & 5 & 6.5 & 6.5 & 6.5 \\
\hline$O$ radius of rotor, $R_{\text {ro, }}$ in. & 3 & 3 & 3 & 3 & 3 & 3 & 3 \\
\hline Inner radius of rotor, $\mathrm{R}_{\mathrm{ri}}$, in. & 2.453 & 2.453 & 2.453 & 2.453 & 2.009 & 2.009 & 2.009 \\
\hline Stack length, L, in. & 1.969 & 1.969 & 3.938 & 3.938 & 3.938 & 3.938 & 3.938 \\
\hline Supply voltage, $V_{d c}, V$ & 529.31 & 264.26 & 408.19 & 203.71 & 409.11 & 204.47 & 102.23 \\
\hline Number of magnets & 18 & 18 & 18 & 18 & 8 & 8 & 8 \\
\hline$\Omega_{\mathrm{b}}$, elect. rad/s & \multicolumn{4}{|c|}{1413.721413 .721413 .721413 .72} & 628.3 & 628.3 & 628.3 \\
\hline $\mathrm{T}_{\mathrm{c}}$, turns/coil & 8 & 4 & 4 & 2 & 8 & 4 & 2 \\
\hline $\mathrm{T}_{\mathrm{s}}$, turns/slot & 16 & 8 & 8 & 4 & 16 & 8 & 4 \\
\hline \multicolumn{7}{|l|}{ Line-to-neutral back-emf at } & 34.63 \\
\hline$I_{\text {peak }}=P_{r} /\left(2 E_{b}\right), A$ & 102 & 204 & 102 & 204.42 & 108.29 & 216.58 & 433.15 \\
\hline$I_{\mathrm{rms}}=\operatorname{sqrt}(2 / 3) \mid \mathrm{peak}$ & 83.28 & 166.56 & 83.28 & 166.90 & 88.42 & 176.83 & 353.67 \\
\hline Phase inductance, L, uH & 1270 & 316 & 624 & 156 & 1560 & 390 & 97 \\
\hline Phase resistance, $\mathrm{R}$, ohms & 0.0673 & 0.0168 & 0.0249 & 0.006 & 0.0153 & 0.0038 & 0.0009 \\
\hline Wire gage & 16 & 16 & 16 & 16 & 16 & 16 & 16 \\
\hline Wires per turn & 6 & 12 & 12 & 25 & 27 & 55 & 111 \\
\hline Wire area, $\mathrm{mm} 2$ & 1.308 & 1.308 & 1.308 & 1.308 & 1.308 & 1.308 & 1.308 \\
\hline Copper area in slot, mm2 & 133 & 133 & 133 & 133 & 583 & 583 & 583 \\
\hline Current Density, A/mm2 & 13.00 & 13.00 & 6.50 & 6.25 & 3.07 & 3.01 & 2.98 \\
\hline $\mathrm{L}_{\text {DMICmin }}, \mathrm{uH}$ & 97 & 24 & 97 & 24 & 195 & 49 & 12 \\
\hline $\mathrm{L}_{\text {DMICno cont. cur, }} \mathrm{uH}$ & 839 & 210 & 839 & 209 & 1674 & 419 & 105 \\
\hline $\mathrm{L}_{\text {DMICmax }}, \mathrm{uH}$ & 1074 & 268 & 1074 & 267 & 2144 & 536 & 134 \\
\hline \multicolumn{8}{|c|}{ The following inductances use Lawler's $V_{d c}$. They are best when $L<L_{D M I C \max }$} \\
\hline $\mathrm{L}_{\mathrm{CPAmin}}, \mathrm{uH}$ & 568 & 142 & 684 & 170 & 1315 & 329 & 82 \\
\hline $\mathrm{L}_{\text {CPAinf. }}, \mathrm{uH}$ & 1074 & 268 & 1074 & 267 & 2144 & 536 & 134 \\
\hline $\mathrm{L}_{\text {CPAmax }}, \mathrm{uH}$ & 2131 & 532 & 1643 & 409 & 3491 & 872 & 218 \\
\hline
\end{tabular}

Cases 1 and 2 were initially designed for geometrically similar motors having widely different inductances, $1270 \mathrm{uH}$ and $316 \mathrm{uH}$, respectively, to compare how well they would respond to CPA control and to DMIC. From Table 6.4, we find that even though the inductances differ by a factor of 4, they are both sufficiently large that CPA is more efficient than DMIC. CPA is capable of operation at infinite CPSR if resistances are neglected. The current density, however, is quite high at $13 \mathrm{~A} / \mathrm{mm}^{2}$. Hendershot ${ }^{1}$ recommends that the range be between 4 and $10 \mathrm{~A} / \mathrm{mm}^{2}$, 
with the lower number for totally enclosed motors and the upper number for forced-air-cooled motors. The Case 1 and 2 motors would have to be liquid cooled.

Since the inductance is proportional to the square of the number of turns per coil and the length of the coil, the stack length of Cases 3 and 4 was increased so that the number of turns could be reduced. The cost of the material associated with the additional length was $\$ 160$, making the low-inductance motor more expensive. The current density was reduced to a more acceptable value of $6.5 \mathrm{~A} / \mathrm{mm}^{2}$ in Case 4; and, in both cases, the motor inductance is slightly below the minimum required for using CPA, indicating that the DMIC control is superior. The efficiency calculation confirms DMIC superiority by 2 percentage points for Cases 3 and 4 . The reason is that the DMIC rms current is $60 \%$ of that drawn by CPA.

Cases 5, 6, and 10 employed a larger diameter to make more room for the stator wires so that the current density could be reduced while a wide range of inductances is explored. The current density is reduced to $3 \mathrm{~A} / \mathrm{mm}^{2}$, and the inductances range from about 100 to 400 to $1600 \mathrm{uH}$ as the turns per coil range from 2 to 4 to 8, respectively. In all three cases CPA will work, but the rms current for DMIC control is $70 \%$ of the current drawn by CPA.

\subsubsection{PM Rotors with Magnet Encasement}

The magnets of high-speed PM motors must be encased to ensure that they do not separate from the rotor and that they do not shift, which could cause imbalance problems. Examples of materials used for encasement are aluminum, 304 stainless steel, Inconel 718, wound fiberglass tape pre-impregnated with phenolic resin, wound fiberglass composites, and wound carbon fiber composite material. The metals and carbon fiber composite are conductors, a fact that must be considered if they are used. Prepreg fiberglass tape is a relatively low-cost insulator and may be applied and oven-cured. The problem with all the encasements is that they occupy space in the gap between the magnets and the stator teeth, limiting the amount of encasement that may be used.

An interesting feature of a metal can is that it is a conductor and as such can generate torque like a squirrel cage induction motor until synchronous operation is achieved. For synchronous operation, the non-magnetic properties of the aluminum allow the rotor to behave like a conventional surface-mounted PM motor.

\subsection{THE OUTER ROTOR MOTOR}

Figure 6.1 shows the input of Case 8, the outer rotor motor which was analyzed using SPEEDCAD software. Its dimensions are shown in Table 6.3. This motor operates in BDCM mode, and its circuit parameters at a base speed of $1500 \mathrm{rpm}$ are

Rated power, $\mathrm{P}_{\mathrm{r}}=30 \mathrm{~kW}$, Number of poles, $\mathrm{p}=18$, Back-emf per phase, $\mathrm{E}_{\mathrm{b}}=101.8 \mathrm{~V}$, Rms phase current, $\mathrm{I}_{\mathrm{b}}=155 \mathrm{~A}$, Inductance per phase, $\mathrm{L}=219 \mu \mathrm{H}$, and 
Resistance per phase, $\mathrm{R}=15 \mathrm{~m} \Omega$.

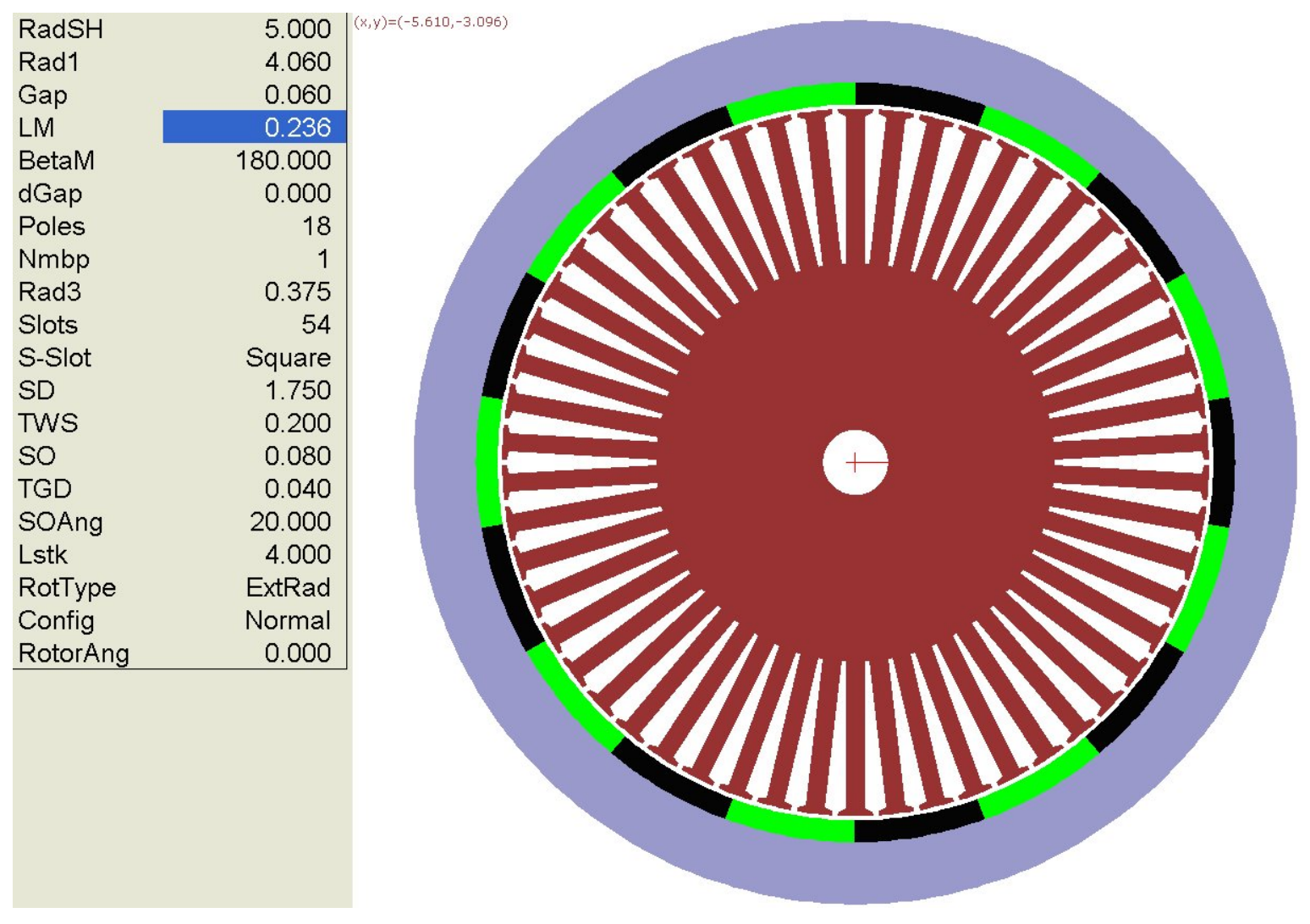

Fig. 6.1. Configuration of the outer rotor PM motor.

At $30,000 \mathrm{~W}$ and $1500 \mathrm{rpm}$, the efficiency is $93 \%$. The active component weights are shown in Table 6.5, and losses are summarized in Table 6.6.

Table 6.5. Component weights of the Case 8 outer rotor motor

\begin{tabular}{|c|c|}
\hline Material & Weight, lb \\
\hline Rotor and stator-Iron & 26.68 \\
\hline Magnets-NeFeB & 3.05 \\
\hline Wire-Cu & 5.69 \\
\hline Total & 35.42 \\
\hline
\end{tabular}


Table 6.6. Outside rotor motor losses at $30 \mathrm{~kW}$ useful power

\begin{tabular}{|c|c|c|}
\hline Type & Loss at $\mathbf{1 5 0 0} \mathbf{~ r p m , ~ W}$ & Loss at 6000 rpm, W \\
\hline $\mathrm{Cu}$ & 732 & 124 \\
\hline $\mathrm{Fe}$ & 929 & 12272 \\
\hline Magnet & 599 & 9566 \\
\hline Total & 2160 & 21962 \\
\hline
\end{tabular}

In the SPEEDCAD software, 10-mil laminations are used and the magnets are not segmented; consequently, the losses at 6,000 rpm are quite high. This emphasizes the need for a small volume of iron, segmented magnets, and a laminate that has low losses at high electrical frequencies. ${ }^{8}$

\subsection{THE AXIAL-GAP MOTOR}

Dimensions of the axial-gap motor are shown in Table 6.3, and Fig. 6.2. shows the components of ORNL's axial gap PM motor, which is similar to but heavier than the motor of Case 7 discussed in this section. The two stators are wired in series. There is a 40-mil air gap between each stator and the magnet. Each stator is $2.4 \mathrm{in}$. thick, and the magnets are $0.1 \mathrm{in}$. thick (the magnets in ORNL's motor are 0.2 in. thick). Since the motor is designed to operate as a BDCM, there are 54 slots. Each double-layer coil has three turns, placing six turns in each slot. The motor parameters for a base speed of $1500 \mathrm{rpm}$ are

$$
\begin{aligned}
& \text { Rated power, } \mathrm{P}_{\mathrm{r}}=30 \mathrm{~kW}, \\
& \text { Number of poles, } \mathrm{p}=18 \text {, } \\
& \text { Back-emf per phase, } \mathrm{E}_{\mathrm{b}}=80 \mathrm{~V} \text {, } \\
& \text { Inductance per phase, } \mathrm{L}=434 \mu \mathrm{H} \text {, and } \\
& \text { Resistance per phase, } \mathrm{R}=17.4 \mathrm{~m} \Omega \text {. }
\end{aligned}
$$

The motor is designed for operation at $6000 \mathrm{rpm}$ to achieve a CPSR of 4 . Since it operates in the BDCM mode, two phases are on at any one time. Thus the total back-emf at base speed is $160 \mathrm{~V}$, while at $6000 \mathrm{rpm}$ the total back-emf is $640 \mathrm{~V}(320 \mathrm{~V} /$ stator $)$. The active material weights are shown in Table 6.7.

ORNL's 30-kW axial-gap PM motor was mechanically designed using elastic equations that were symmetric about an axis to determine the required interference at the titanium ring/magnet interface and at the magnet/hub interface. The design analysis did not evaluate the effect of bending, which occurs because of the 18 equiangular loads from the magnets. The titanium ring solved the differential expansion problem that had allowed the magnets to slip on the hub when the temperature increased during operation. Furthermore, the higher strength of the titanium ring allowed the motor rating to be increased to $30 \mathrm{~kW}$, its original design goal. Although the motor and fan have remained intact while they were driven by the dynamometer at $6600 \mathrm{rpm}$ for a half hour, an FEA will provide a clearer picture of the stresses during operation. 


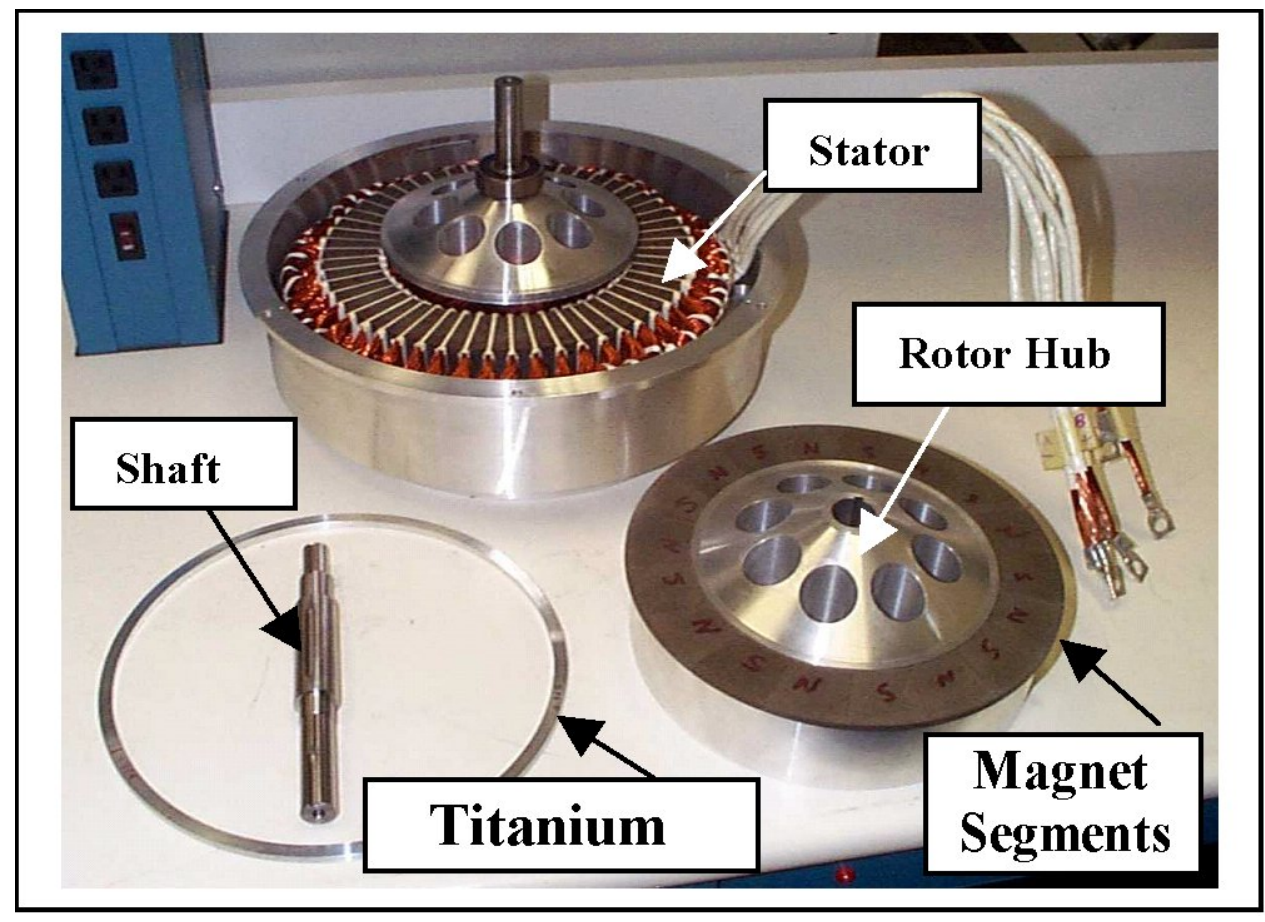

Fig. 6.2. Elements of ORNL's axial-gap PM motor.

Table 6.7. Component weights of the Case 7 axial-gap PM motor

\begin{tabular}{|l|c|}
\hline \multicolumn{1}{|c|}{ Material } & Weight, lb \\
\hline Stators (2) 0.005-in. silicon steel tape & 31.1 \\
\hline Magnets- $-\mathrm{NeFeB}$ & 1.07 \\
\hline Wire- $\mathrm{Cu}$ & 16.46 \\
\hline Rotor- $\mathrm{Al}$ hub with Ti support ring & 2.13 \\
\hline \multicolumn{2}{r}{ Total } \\
\hline
\end{tabular}

\subsection{SALIENT POLE PM MOTOR}

In FY 2000, ORNL conceived the idea of a PM motor with self-supporting magnets, which would slide into a slot at the surface of the rotor and which would depend upon the strength of the magnet to support itself and the strength of the rotor material to hold it in place. The magnet shape would be in the shape of a fat inverted "T," and a ledge or tab machined into the rotor material would grip the inside of the T's overhang.

Two obvious possibilities exist for such a motor configuration. Originally, the thought was to place the magnets as close together as possible so that the magnets would appear as conventional radial-gap surface-mounted magnets, with a magnet fraction slightly larger than normal because of the presence of the support tab. Recently, however, Honda has used this approach, with increased separation of the magnets to make use of reluctance torque, which ORNL had not considered. The separation was optimized to maintain sufficient reluctance torque while using less magnet material. Greater magnet separation also lightens the load on the tabs and correspondingly lightens the reaction load on the magnets, which increases the possible rotor speed. 
Figure 6.3 shows the configuration initially being examined. The web between the magnets in this configuration is $4 \mathrm{~mm}$. The magnets are $7 \mathrm{~mm}$ thick. For this configuration, the outer radius of the rotor is $3.1 \mathrm{in}$. and the inner radius is $2.2 \mathrm{in}$.

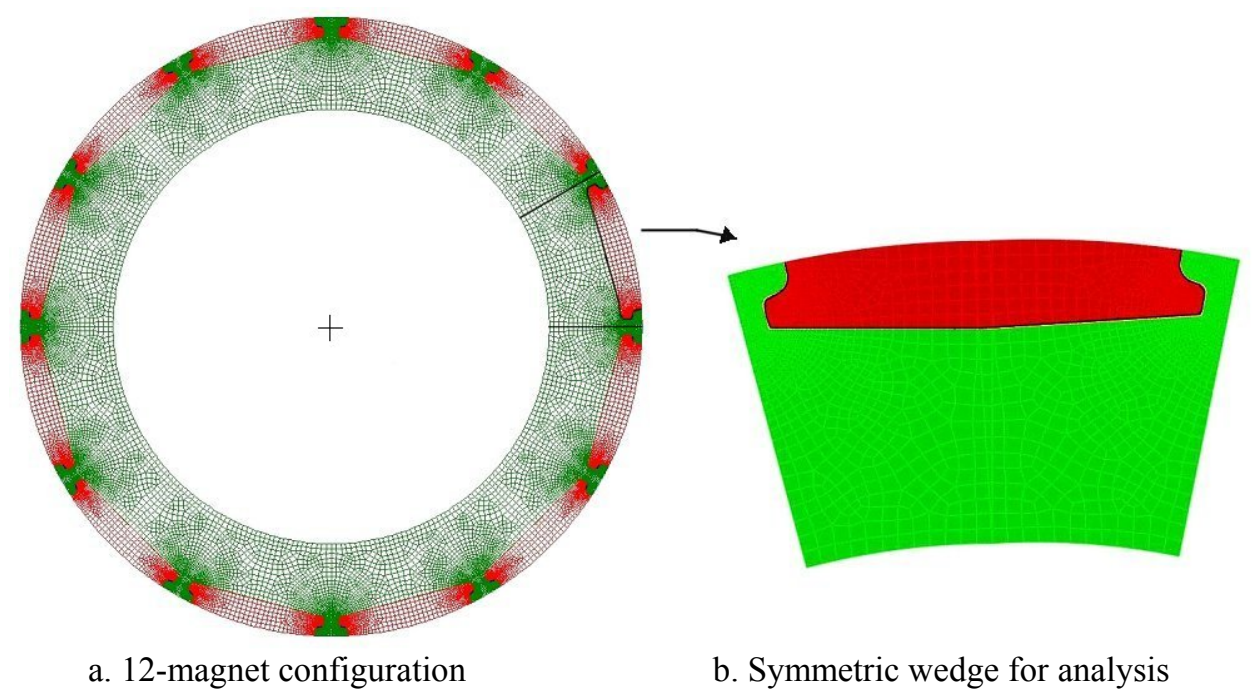

Fig. 6.3. Rotor with self-supporting magnets.

Gap elements are placed between the magnet and the rotor so that the variation of the load distribution from the magnets on the rotor may be examined. The load is along the gap element, which is drawn normal to the two surfaces it is separating. Gap elements are chosen so that they do not enter the calculation unless the gap is reduced from its initial value during the solution. The solution is iterative; consequently, the magnet must be supported by a weak spring in the finite element model so that during the initial calculation, it may determine which gap element first began to decrease. The stiffness of that gap, which is the modulus of the surrounding material, is then included in subsequent calculations.

Figure 6.4 shows the compressive loads in pounds at each of the nodes along the magnet/rotor interface. The largest load is $-164 \mathrm{lb}$. It also shows the load on the weak spring, which is about $0.1 \mathrm{lb}$, which will have little effect on the solution. Figure 6.5 shows the von-Mises stress between the magnet and rotor, as well as the stress caused in the rotor by the magnet load. Figure 6.6 confirms that the radial stresses between the rotor and magnet are compressive and that the radial stresses in the rotor near the inner corner of the magnet are tensile because of bending of the tab. Plastic deformation in the silicon steel occurs at $9237 \mathrm{rpm}$. This number will rise as the web increases and the magnet material decreases. Figure 6.7 shows the radial displacement of the magnet and the M-19 silicon steel tab at maximum speed, revealing that intrusion into the gap is small, even at this high speed. 


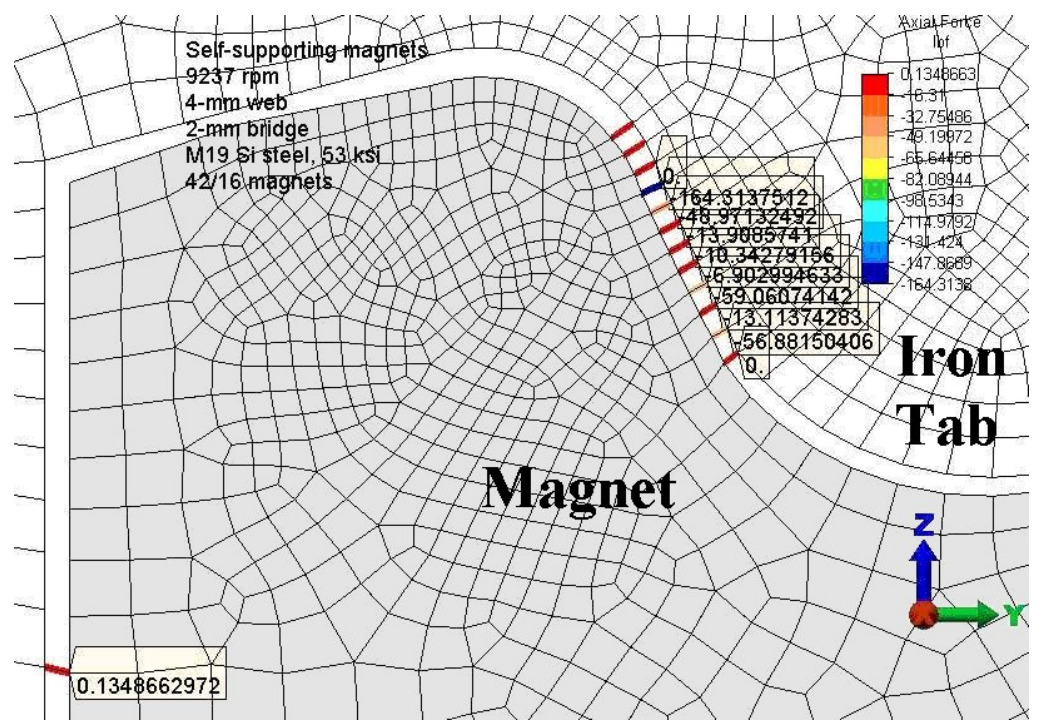

Fig. 6.4. Self-supporting load along the magnet/rotor interface.

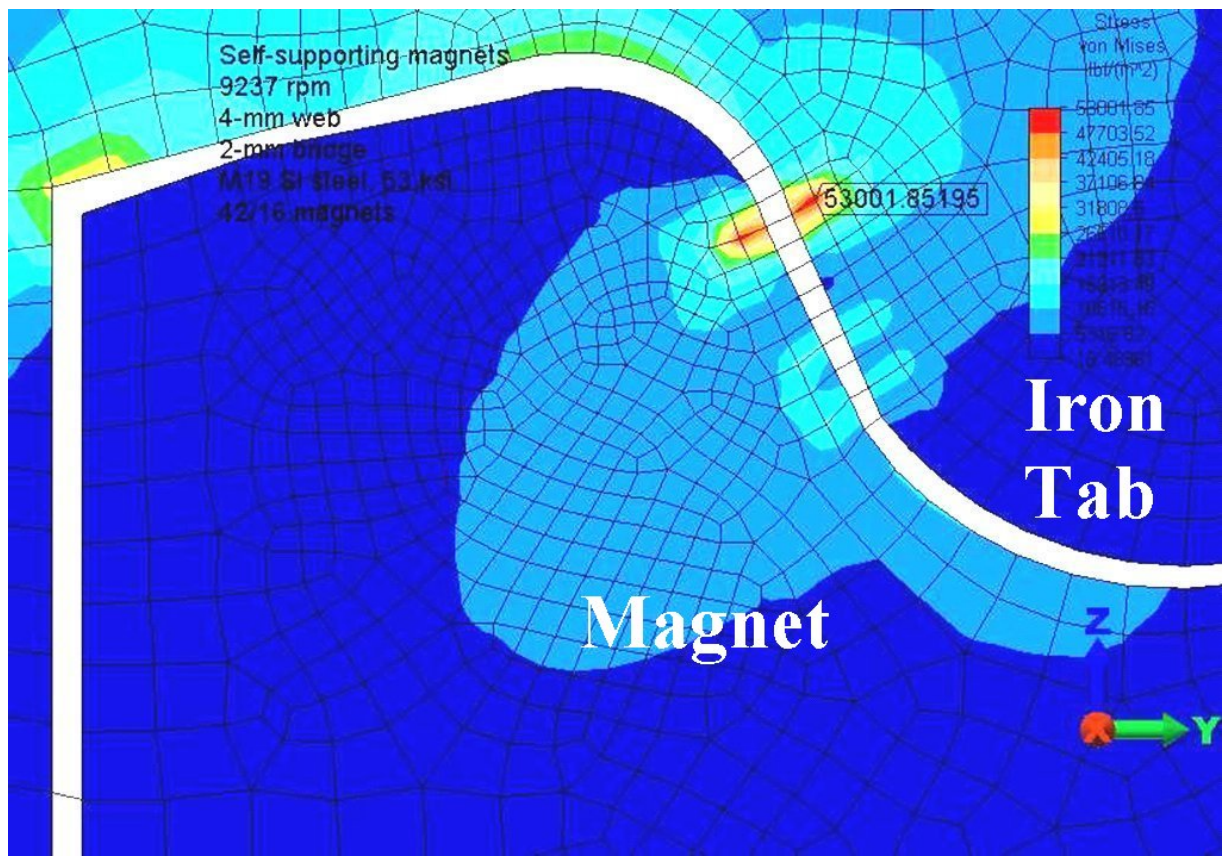

Fig. 6.5. Von Mises stresses induced by rotor bending and magnet loading. 


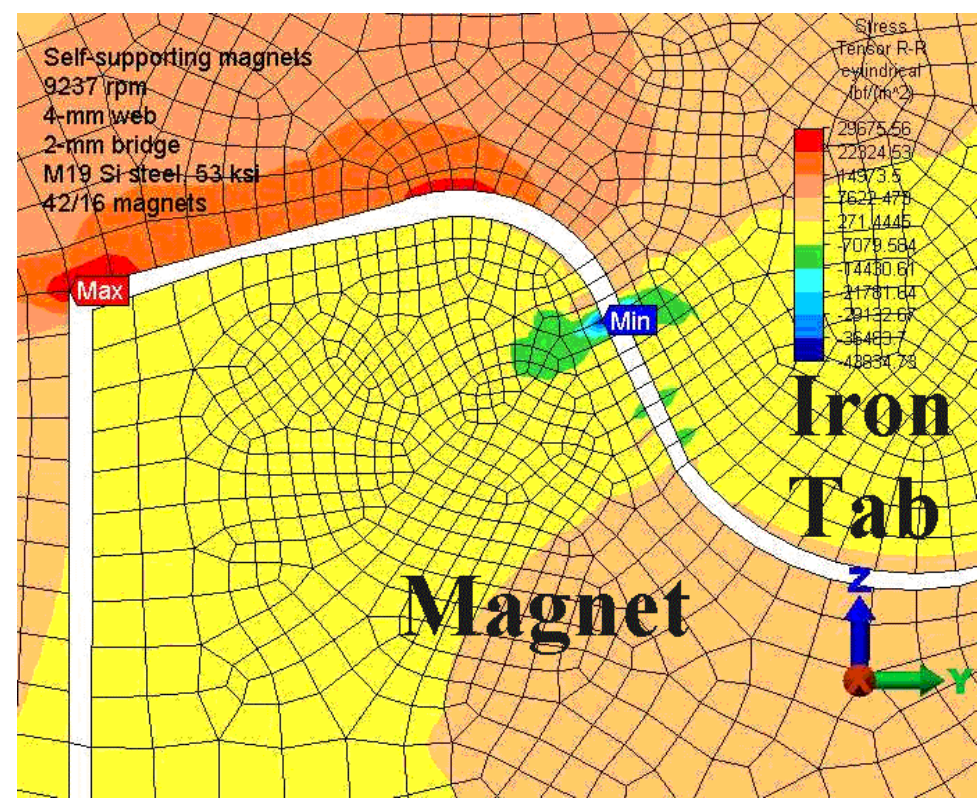

Fig. 6.6. Radial stresses confirming compression at magnet/rotor interface and rotor bending at base of tab.

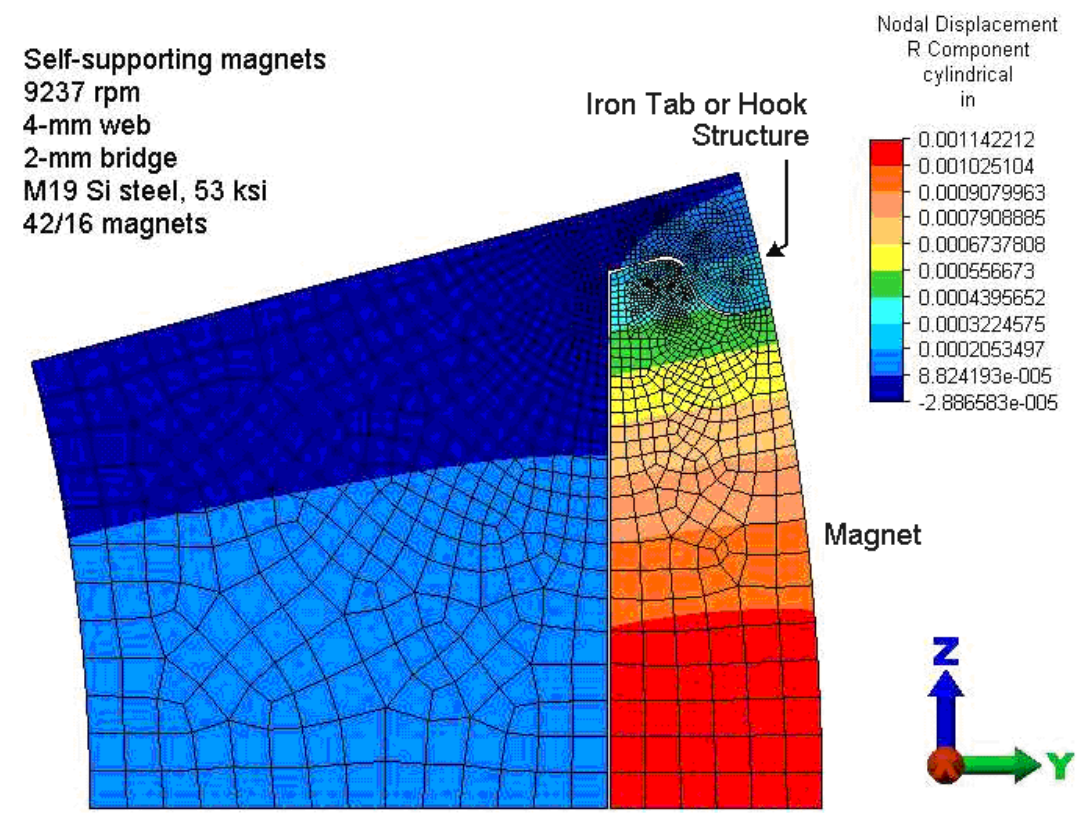

Fig. 6.7. Radial displacement of the self-supporting magnet.

\subsection{FRACTIONAL-SLOT WINDING}

A fractional-slot motor is shown as it appears in the SPEEDCAD software in Fig. 6.8. At a base speed of $2000 \mathrm{rpm}$, the circuit parameters are

Rated power, $\mathrm{P}_{\mathrm{r}}=30 \mathrm{~kW}$, Number of poles, $\mathrm{p}=10$, 
Back-emf per phase, $\mathrm{E}_{\mathrm{b}}=48.5 \mathrm{~V}$,

RMS phase current, $\mathrm{I}_{\mathrm{b}}=30000 /(3 * 48.45)=206 \mathrm{~A}$,

Inductance per phase, $\mathrm{L}=234 \mu \mathrm{H}$, and

Resistance per phase, $\mathrm{R}=5.25 \mathrm{~m} \Omega$.

Iterating between Eqs. (5) and (17) of Appendix E leads to a minimum inductance value of $185.3 \mu \mathrm{H}$ for constant lead-angle control. Since the circuit parameter is $234 \mathrm{uH}$, the motor can be controlled in the PMSM mode.

The motor meets the efficiency specifications at $2000 \mathrm{rpm}$ because its efficiency at $20 \%$ torque is $94.6 \%$; however, at $20 \%$ torque and $10,000 \mathrm{rpm}$, the efficiency is $82.7 \%$. The problem is increased core loss and the loss in the magnets as shown in Table 6.8.

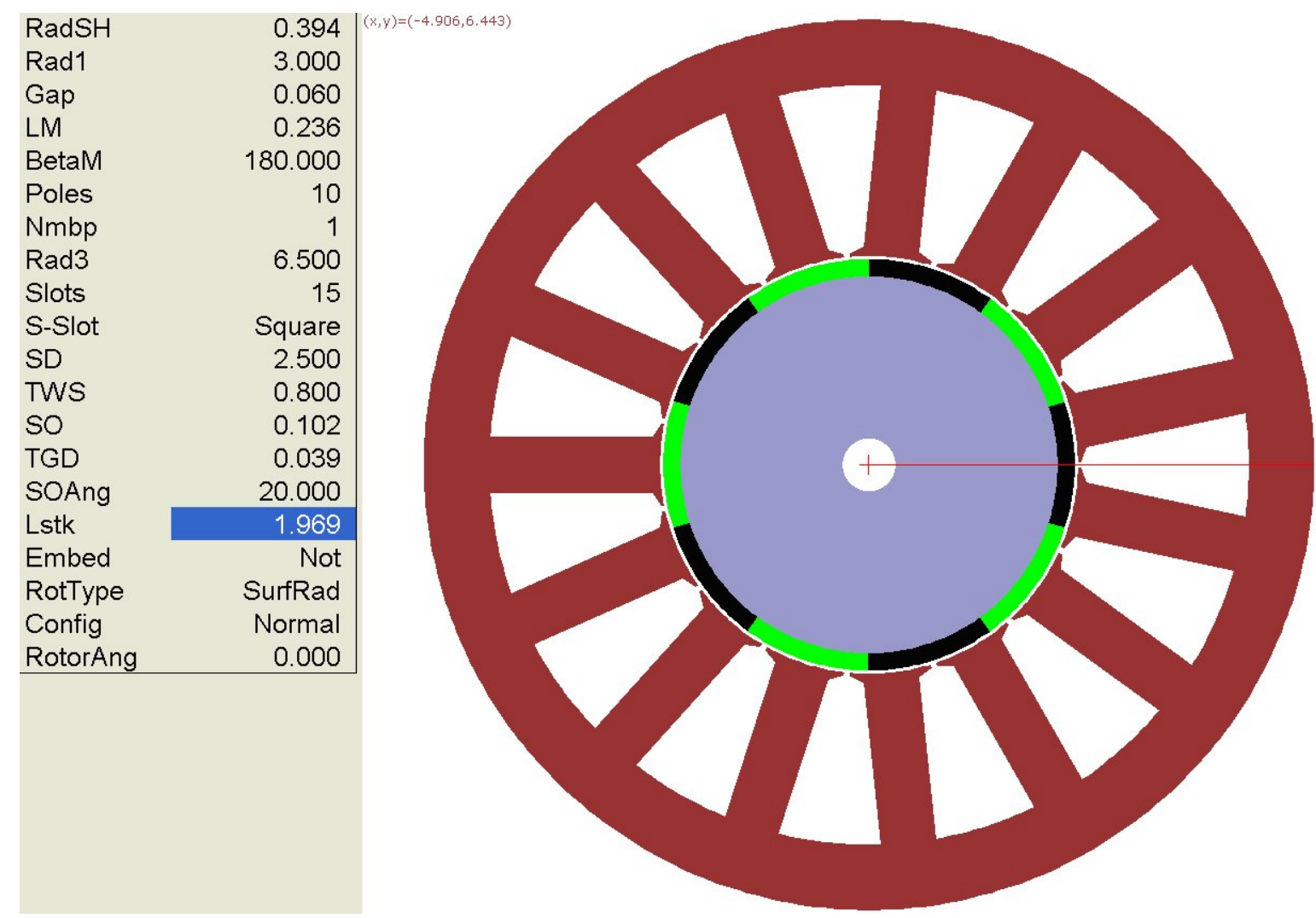

Fig. 6.8. A fractional-slot motor.

Table 6.8. Losses of the fractional-slot motor at $20 \%$ torque

\begin{tabular}{|c|c|c|c|c|}
\hline Speed, rpm & $\mathbf{P}_{\mathbf{C u}}, \mathbf{W}$ & $\mathbf{P}_{\text {core }}, \mathbf{W}$ & $\mathbf{P}_{\text {mag }}, \mathbf{W}$ & $\mathbf{P}_{\text {total }}, \mathbf{W}$ \\
\hline 2000 & 32 & 152 & 154 & 338 \\
\hline 10,000 & 44 & 2400 & 3874 & 6318 \\
\hline
\end{tabular}


In the PEEMRC data, the laminations are 10 mil thick, and the magnets are not segmented. Assuming a 50\% core loss reduction from employing 5-mil laminations and a 50\% magnet loss reduction from employing segmented magnets, an estimate of the power loss and efficiency at $10,000 \mathrm{rpm}$ for $30 \mathrm{~kW}$ useful power is

$$
\begin{aligned}
\mathrm{P}_{\text {loss }} & =1200+1937+44=3181 \mathrm{~W} \\
\mathrm{E}_{\text {motor }} & =30000 /(30000+3181) \times 100=90.4 \% .
\end{aligned}
$$

These values emphasize the need to have a low-loss lamination material and segmented magnets. 


\section{COST ANALYSIS}

With few exceptions, motor cost estimates currently available are at the aggregate level, providing no detailed mass and cost distribution of motor constituent elements (Cuenca et al., 1999). It is important that cost analysis be performed at the motor component level when several competing alternative motor designs need to be evaluated based on both performance and cost.

\subsection{METHODOLOGY AND ASSUMPTIONS}

The focus of this cost analysis is to examine the relative cost-effectiveness of alternative motor designs. Other major electric drive components, such as the controller and gear drive, have not been included in this analysis. A spreadsheet-based cost modeling framework was developed for electric motor cost estimation that would allow an examination of performance vs. cost trade-offs among the competing alternative designs. This framework is designed so that it also allows adjustments, at the component level, for changes in material prices, substitutions, or design to further refine the estimate and to test the sensitivity of overall motor cost to changes in component costs. Although the initial focus of the cost estimation was at the major component level, additional design details such as different magnet shape and strength were also incorporated as design progressed.

The cost estimation in this study assumes a bottom-up approach in a large-scale motor manufacturing facility. The cost structure for a motor manufacturing facility was developed based on conversations held with a few brushless PM machine manufacturers. Each motor is broken down into seven main constituent elements that include magnets, rotor lamination, rotor shaft, stator lamination, copper windings, housings, and cooling. Housings mainly include rotor end caps, motor frame, and frame end caps. Since different magnet design configurations have been the focus for an examination of the IPM machine design alternatives here, magnet cost estimates were done at a detailed level and data were obtained directly from a limited number of magnet suppliers still operating in the United States today ${ }^{11,12}$. Motor component sizing information obtained from SPEEDCAD runs is used as essential input for the cost estimation.

It is assumed that the production of these components takes place under realistic, favorable economic conditions with volumes high enough to justify a significant level of automation and full realization of raw-material volume discounts. Raw materials for various motor components are purchased from suppliers, and they are assembled in a motor manufacturing facility. Laminations are usually sold as a set for both rotors and stators, and cost in this case is mostly dictated by the stator size, number of slots, and magnet poles. Although lamination dies made of carbide materials are expensive, in the range of $\sim \$ 200 \mathrm{~K}$, a long die life of about 70 million parts results in this cost being a relatively small fraction of the overall lamination cost. Rotor shaft material is assumed to be cold drawn steel. The motor frame and end caps are manufactured from extruded aluminum and die-cast aluminum, respectively. The cost of motor cooling has not been determined explicitly, but it is estimated to be $10 \%$ of the total manufacturing cost. Labor and overhead are assumed to take into account the cost of machining operations necessary for the motor housing and end caps. Thus, the manufacturing cost of the complete motor is determined by adding the individual element costs plus the labor and overhead, which includes the cost of assembly and testing, and is estimated to represent $\sim 25 \%$ of the total motor component material 
costs. Finally, the OEM cost is estimated by adding the profit margin of $10 \%$ for a large-scale production volume to the manufacturing cost.

\subsection{COST ESTIMATES FOR THE ALTERNATIVE IPM MACHINE DESIGNS}

The Prius 2004 IPM motor design is considered as the baseline design having V-shaped magnets, against which two alternative IPM machine designs are compared. One of the alternative IPM machine designs considers three layers of magnet arcs (known as the multi-layer design, as discussed before), whereas the other one is a "high-speed" design having motor dimensions significantly lower than those of the baseline design. In addition, the motor cost sensitivity was examined but was limited to the multi-layer design by varying the magnet strength, considering the in-situ magnets as the alternative magnet manufacturing option, and having the option of steel center posts of 1-mm width in magnets, as discussed earlier. The magnetic strengths for the multi-layer design were varied in the range of 0.2-1.2 $\mathrm{T}$ and in increments of $0.2 \mathrm{~T}$. The in-situ magnet manufacturing technique has the advantage of fewer processing steps, because both fabrication and magnetization are done directly in the rotor slot; and magnetization is much easier because the magnets are hot. However, it offers certain disadvantages that may increase the overall magnet manufacturing cost. These disadvantages include higher tooling costs, slower cycle time, more cost to modify the design because of larger equipment requirements, and higher scrap rates. There exists a trade-off between higher output (under conventional technology) vs. higher capital cost (under the in-situ technology). A consideration of steel center posts in magnets was considered as one of the sensitivity analysis parameters to improve mechanical magnet stability. Since magnet cost contributes to the major share of motor cost, in addition to consideration of specific magnet designs, we examine magnet cost in detail at first, followed by the total motor cost and sensitivity analyses.

\subsubsection{PM Cost}

The cost of the PMs is one of the barriers besides consideration of alternative designs such as IPM requiring a reduced amount and strength of it towards the large scale use of it in electric propulsion systems. Until recently, the raw materials cost has accounted for less than half of the price of finished $\mathrm{NdFeB}$ magnets. With some of the key process patents for manufacturing $\mathrm{NdFeB}$ magnets beginning to expire in 2004, new suppliers are pressing to significantly reduce the price components not related to the raw materials. In addition, the recent aggressive entry and expansion of Chinese manufacturers into the rare-earth magnet marketplace has helped in lowering the magnet cost. China has the natural advantage of rich deposits of rare-earth materials that are now being more fully exploited to make Chinese manufacturers major players in the high-strength PM market. Because of fierce price competition, most U.S. PM suppliers have either shut down or moved overseas. The most prominent manufacturer, Magnequench - the original developer of neodymium-iron-boron magnet material-has divested all of its businesses and completely moved to offshore Asia.

Depending on the required PM strength, three manufacturing methods (i.e., injection molding, compression molding, and sintering) are generally used. The first two manufacturing methods produce bonded magnets that are composite materials produced by mixing isotropic magnetic powder with a polymer binder (generally nylon and epoxy for injection and compression 
molding, respectively). Then a shaped magnet part is formed in which magnetic particles are interspersed within the bonding matrix. Many different types of binders and forming methods can be used. This high degree of flexibility is one of the most important advantages of bonded magnets, offering significant opportunities for high-volume, low-cost net-shape manufacturing of magnetic parts or assemblies. Remanence and energy product of a bonded magnet are directly linked to the amount of binder used, typically $2-\mathrm{wt} \%$ in compression molded magnets and $8-15$ $\mathrm{wt} \%$ in injection molded magnets. Magnetization is done after the bonded magnet is formed, thereby providing a tremendous flexibility in terms of the magnetization patterns and orientations that can be created. Between the two molded magnet types, compression molded magnets have a higher remanence because of the improved loading when blended with epoxy resin. This molding technique also produces better magnetic properties than does injection molding, yielding a magnet with higher energy density.

The sintered magnets require microcrystalline anisotropic powders (unlike nanocrystalline isotropic powders for bonded magnets). By modifying alloy composition and manufacturing conditions, different needs for magnetic properties can be satisfied. A conventional sintering route is used in this case, starting with ingot casting, pulverization with a coarse grind, and then jet-milling for the initial powder preparation. The resulting powder is then aligned in a magnetic field and pressed into a partially dense compact. Next, the dense compacts generall are sintered, followed by a post-sinter heat to refine the grain boundary texture and relieve internal stresses. Cylindrical, arc, and rectangular bars are typical shapes for sintered components. Sintering is fundamentally limited in its ability to produce net-shape components, as the green compacts can lose up to $25 \%$ in volume through shrinkage during the sintering treatment. In addition, they require machining to the desired dimensions and coating with a protective layer of nickel (for higher-value magnetic parts), zinc (for lower cost applications), aluminum, or epoxy. Compared with bonded magnets, sintered magnets are heavier, higher in strength, and consequently more expensive.

The particular alloy selection under each scenario was based on meeting the typical automotive operating temperature range of $160-180^{\circ} \mathrm{C}$. Magnet cost quotes were obtained directly from the suppliers and based on a large annual production volume of 100,000 pieces. For higher-strength magnets (i.e., about $1.12 \mathrm{~T}$ ) sintered neodymium-iron-boron magnets are used. The raw material for these sintered magnets is assumed to be Vacodym 655AP with a density of $7.67 \mathrm{gm} / \mathrm{cm}^{3}$, obtained from the European supplier Vacuumschmelze (known as VAC Magnetics in the U.S.). For the magnet strength sensitivity analysis of the multi-layered design, we assume injection molding for lower-strength magnet scenarios (i.e., less than $0.7 \mathrm{~T}$ ), using MQP-B+ powders produced by Magnequench as the raw material. It provides the best compromise between the range of magnet strength and operating temperature requirements. This is an isotropic $\mathrm{Nd}-\mathrm{Fe}-\mathrm{Co}-$ $\mathrm{B}$ alloy composition magnet powder that is rapidly solidified into a thin metal ribbon and milled into powder. The Co content is $5 \mathrm{wt} \%$, suitable for the manufacture of bonded magnets. The compounded magnet powder cost is assumed to be $\$ 48 / \mathrm{kg}$, which includes the cost of mixing with the binder as well. The suitability of the powder is limited to applications with a magnet strength of $0.7 \mathrm{~T}$ because the powder has a remanance of $0.9 \mathrm{~T}$ and a curie temperature of $360^{\circ} \mathrm{C}$. The 0.4-0.6 T range of magnet strength used for this material is obtained by adjusting the magnet powder weight loading. In the case of lower magnet strength of $0.2 \mathrm{~T}$, ferrite material of $88-\mathrm{wt} \%$ loading at a cost of $\$ 6.05 / \mathrm{kg}$ is assumed. 
Sintered neodymium-iron-boron magnets for higher strength are commercially available only at around 1.2 $\mathrm{T}$ today. To achieve the magnet strength in the range of $0.8-1.0 \mathrm{~T}$ considered in the magnet strength sensitivity analysis of the multi-layered design, either samarium-cobalt rare earth alloys or additions of dysprosium and terbium rare earth metals to neodymium-iron-boron magnets can be used. Dysprosium and terbium additions lower the magnet remanence but also provide the benefit of improving the temperature stability for magnets. Both samarium-cobalt alloys and dysprosium and terbium are expensive alternatives today until they are used commercially in the future. Vacomax 145S and Vacodym 688AP from VAC Magnetics were used for $0.8 \mathrm{~T}$ and $1.0 \mathrm{~T}$ sintered magnets, respectively, considered for the sensitivity analysis of the multi-layered design. Vacomax $145 \mathrm{~S}$ is a samarium-cobalt alloy with the chemical composition of $\mathrm{SmCo}_{5}$ and density of $8.47 \mathrm{gm} / \mathrm{cm}^{3}$, whereas the other is based on neodymiumiron-boron based alloys with a density of $7.76 \mathrm{gm} / \mathrm{cm}^{3}$.

Table 7.1 shows magnet specific gravity, total weight, and cost in $\$ / \mathrm{kg}$, including the magnet powder type and the weight percentage loading of the magnet powder (applicable only for bonded magnets) to obtain the desired strength under three different scenarios. The magnet cost estimates provided here indicate that the raw material cost is a major share of total magnet cost, and thereby any potential cost reductions in the future will consequently lower the magnet cost significantly. For example, for the 0.4-T multi-layered conventional manufacturing magnet design, the raw material cost at $\$ 48.40 / \mathrm{kg}$ contributes about $\$ 40.90$ to the total magnet cost of $\$ 57.30 / \mathrm{kg}$, as shown in Table 7.1. The magnetization cost thereby also forms a significantly smaller share of the overall magnet cost. At the highest magnet strength of $1.2 \mathrm{~T}$ considered here, the difference in magnet cost between the baseline and high-speed vs. multi-layered scenarios (i.e., $\$ 88 / \mathrm{kg}$ vs. $\$ 211.80 / \mathrm{kg}$ ) is due to a more difficult configuration having a higher aspect ratio in the latter case. The multi-layered sintered magnets (i.e., for 0.8-1.2 T strength) need to be manufactured from two separate parts, i.e., center and side pieces, and machining is likely to be one of the major contributors to the overall magnet cost. The magnetization orientation for these two different types of pieces is assumed to be perpendicular to the magnet surface. Since sidepieces have an angle with a tapered thickness, they are projected to be significantly more expensive than centerpieces (i.e., about double the cost). Also because of high production volume requirements, the less expensive die-press process is assumed, rather than the isostatic pressing process. The sensitivity of magnet weight and cost for the magnet strength considered for the multi-layered design is shown in Fig. 7.1. The magnet cost and weight increase with its strength, as would be expected. The SmCo alloy is the most expensive magnet material because of limited commercial applications; therefore, its cost is estimated to be the highest, i.e., $\$ 327.30 / \mathrm{kg}$ assumed here for the 0.8-T multi-layered design. No significant pricing difference exists between the Vacodym $655 \mathrm{AP}$ and $688 \mathrm{AP}$ magnet powders assumed here for $1.0 \mathrm{~T}$ and 1.2 $\mathrm{T}$, respectively, but the small difference in magnet cost for these cases is mainly due to the magnet material density difference. 
Table 7.1. Estimated magnet cost of alternative IPM motor design scenarios

\begin{tabular}{|c|c|c|c|c|c|c|}
\hline Scenario & $\begin{array}{l}\text { Remanence } \\
\text { (T) }\end{array}$ & $\begin{array}{l}\text { Magnet } \\
\text { powder }\end{array}$ & $\begin{array}{c}\text { Specific gravity } \\
\left(\mathrm{gm} / \mathrm{cm}^{3}\right)\end{array}$ & $\begin{array}{l}\text { Magnet weight } \\
\text { (kg) }\end{array}$ & Cost (\$/kg) & Source \\
\hline $\begin{array}{l}\text { Prius'04 } \\
\text { (Baseline) }\end{array}$ & 1.2 & $\begin{array}{l}\text { Vacodym } 655 \\
\text { AP }\end{array}$ & 7.67 & 1.01 & $\$ 88$ & Bell (2004) \\
\hline \multirow[t]{6}{*}{ Multi-layered } & 0.2 & $\begin{array}{l}\text { Ferrite }(88 \\
\text { wt } \%)\end{array}$ & 2.95 & 1.29 & $\begin{array}{c}\$ 14.10 \\
(\$ 10.70)^{*}\end{array}$ & \multirow[t]{6}{*}{$\begin{array}{l}\text { McPherson } \\
\text { (2004) }\end{array}$} \\
\hline & 0.4 & $\begin{array}{l}\text { MQP-B+ } \\
(84.5 \mathrm{wt} \%)\end{array}$ & 3.99 & 1.74 & $\begin{array}{c}\$ 57.30 \\
(\$ 54.30)^{*}\end{array}$ & \\
\hline & 0.6 & $\begin{array}{l}\text { MQP-B+ } \\
(93.0 \mathrm{wt} \%)\end{array}$ & 5.40 & 2.35 & $\begin{array}{c}\$ 51.80 \\
(\$ 53.70)^{*}\end{array}$ & \\
\hline & 0.8 & $\begin{array}{l}\text { Vacomax } \\
145 \mathrm{~S}\end{array}$ & 8.47 & 3.69 & $\$ 327.30$ & \\
\hline & 1.0 & $\begin{array}{l}\text { Vacodym } 688 \\
\text { AP }\end{array}$ & 7.76 & 3.38 & $\$ 211.80$ & \\
\hline & 1.2 & $\begin{array}{l}\text { Vacodym } 655 \\
\text { AP }\end{array}$ & 7.67 & 3.34 & $\$ 211.80$ & \\
\hline High Speed & 1.2 & $\begin{array}{l}\text { Vacodym } 655 \\
\text { AP }\end{array}$ & 7.67 & 0.60 & $\$ 88$ & Bell (2004) \\
\hline
\end{tabular}

Values inside the parenthesis indicate the "in-situ" multi-layered magnet costs.

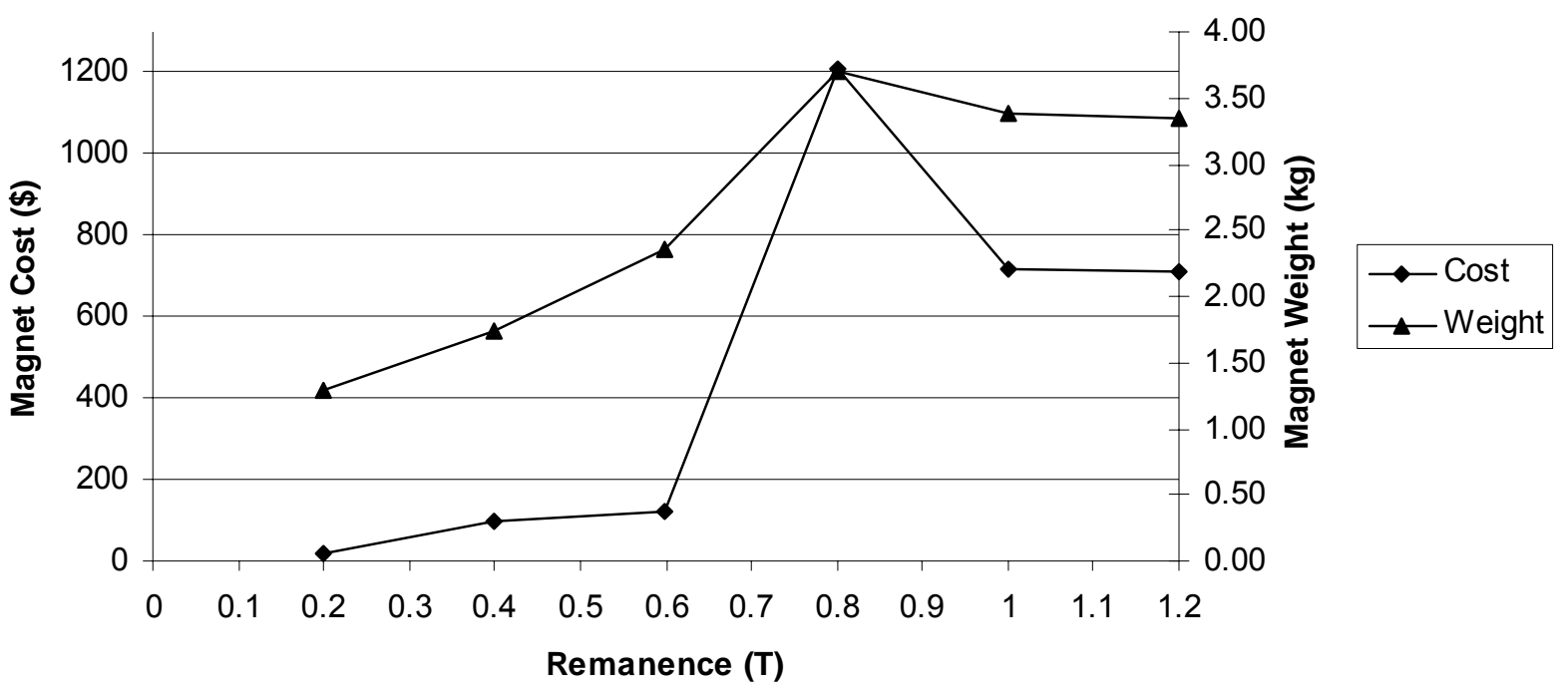

Fig. 7.1. Multi-layered IPM weight and cost sensitivities to magnet strength.

Since bonded magnets provide the flexibility of magnetization patterns and orientations, an insitu magnetization configuration with substantial cost reduction potential is applicable only for the lower magnet strength range, i.e., up to $0.6 \mathrm{~T}$, as shown in Table 7.1. The multi-layered insitu design magnet cost is lower than the conventional magnet manufacturing technology, as one would expect. However, at a higher magnet strength of $0.6 \mathrm{~T}$, the cost trend of in-situ design is seen to be different because of the higher material scrap rate in this case. Note that the assembly cost of magnets under the in-situ design will be minimal. Also, for the multi-layered design, the cost estimates provided in Table 7.1 assume molding and magnetization is done in three arcs for a single magnet pole per shot under conventional manufacturing technology. All 24 arc segments are done at the same time under the "in-situ" case. 


\subsubsection{Alternative IPM Motor Design Cost}

Table 7.2 shows the mass and cost of distribution of three alternative $50-\mathrm{kW}$ (peak) and $30-\mathrm{kW}$ continuous power motor designs under consideration in this phase of this study. The relatively small size of the high-speed IPM motor design, compared with the 2004 Prius design cost, results in a low manufacturing cost, about $\$ 300$. The motor cost in terms of $\$ / \mathrm{kW}$ is estimated to be 8.6 and 6.0 for the 2004 Prius and the high-speed IPM designs, respectively. These costs are considerably higher than the desired $<\$ 2.2 / \mathrm{kW}$ AEMD motor specification. Not only is the manufacturing cost the least for the high-speed motor design, but also its various lower component weights provide an opportunity for fuel economy benefits. The magnet cost is one of the dominant motor cost components, as shown in Table 5.2, and the wide fluctuation seen for it in the market place creates an increased uncertainty in the motor cost estimation.

Table 7.2. Motor mass and cost distribution of three alternative IPM designs

\begin{tabular}{|l|c|c|c|c|c|c|}
\hline \multirow{2}{*}{$\begin{array}{c}\text { Motor } \\
\text { components }\end{array}$} & \multicolumn{2}{|c|}{ Prius 04 } & \multicolumn{2}{c|}{ High-speed } & \multicolumn{2}{c|}{ Multi-layered } \\
\cline { 2 - 7 } & Mass (lb) & Cost (\$) & Mass (lb) & Cost (\$) & Mass (lb) & Cost (\$) \\
\hline Magnets & 2.2 & 89 & 1.3 & 53 & 5.2 & 122 \\
\hline Rotor lamination & 11.7 & 16 & 7.0 & 9 & 13.5 & 18 \\
\hline Rotor shaft & 25.5 & 46 & 15.1 & 27 & 25.5 & 46 \\
\hline Stator lamination & 39.4 & 52 & 30.8 & 42 & 37.9 & 51 \\
\hline Copper windings & 13.2 & 44 & 12.0 & 39 & 13.2 & 44 \\
\hline Housing & 16.7 & 38 & 11.7 & 28 & 16.2 & 37 \\
\hline Cooling & $\mathrm{n} / \mathrm{a}$ & 36 & $\mathrm{n} / \mathrm{a}$ & 25 & $\mathrm{n} / \mathrm{a}$ & 40 \\
\hline $\begin{array}{l}\text { Labor and } \\
\text { overhead }\end{array}$ & $\mathrm{n} / \mathrm{a}$ & & $\mathrm{n} / \mathrm{a}$ & & $\mathrm{n} / \mathrm{a}$ & \\
\hline & & & & & & 79 \\
\hline Mfg. cost & $\mathrm{n} / \mathrm{a}$ & 392 & $\mathrm{n} / \mathrm{a}$ & 273 & $\mathrm{n} / \mathrm{a}$ & 436 \\
\hline & & & & & & \\
\hline Profit margin & $\mathrm{n} / \mathrm{a}$ & 39 & $\mathrm{n} / \mathrm{a}$ & 27 & $\mathrm{n} / \mathrm{a}$ & 44 \\
\hline \multicolumn{1}{|c|}{ OEM price } & & & & & & \\
\hline
\end{tabular}

The multi-layered design is the most expensive option considered here, about $10 \%$ higher than the baseline design. Although the expensive sintered magnet has been considered for the other two designs, the magnet quantity increases substantially, as a lower strength of $0.6 \mathrm{~T}$ and bonded magnets have been assumed in the case of the multi-layered design. For this particular design, the increase in magnet quantity was more than the decline in magnet unit cost due to the use of the less expensive bonded magnets. Potential fuel economy impacts due to the higher rotor weight may not be significant. Improvement in fuel efficiency due to a reduction in current with the improved motor design is estimated to be $0.04 \mathrm{mpg} / \mathrm{A}^{13}$. As discussed in the following section, the power capability of the multi-layered design, which is due to the higher magnet content, is likely to be significantly higher than that of the other two designs considered here. It is appropriate, then, that cost comparisons of alternative designs be made based on the equivalent performance level. The gear drive cost was not included in the analysis because program targets did not require inclusion. 


\subsubsection{Multi-layered IPM Motor Cost Sensitivity}

The multi-layered motor cost sensitivity to magnet strength is shown in Fig. 7.2, including the effect with and without a steel center post of $1 \mathrm{~mm}$ width. With the exception of PM weights due to the change of its strength, all other motor component weights for these alternative motor designs were assumed to be the same. Since magnet cost contributes a major share of motor cost, the latter cost follows exactly the same trend related to the magnet cost as shown earlier in Fig. 7.1. As a result of use of non-commercial SmCo alloy for the $0.8 \mathrm{~T}$ motor design, the motor cost is estimated to be $\$ 2123$ - the highest of all the designs considered here. It is anticipated that the motor cost variation will follow a linear trend in the future with the commercial availability of $\mathrm{NdFeB}$ magnets in the range of around $0.8 \mathrm{~T}$. Since the number of layers of arcs is assumed to be the same for different magnetic strengths here, the power capability of the motor increases, i.e., from 19 to $37 \mathrm{~kW}$ (for the case without a steel center post) with the change in magnet strength from 0.2 to $1.2 \mathrm{~T}$ (Fig. 7.2). With the exception of the $0.6-0.8 \mathrm{~T}$ range, for the unit magnet strength increase, the power capability increase is higher than the motor cost. But the motor cost increase per unit of power capability increase is substantial, an estimated $\$ 8.25 / \mathrm{kW}-\$ 24.80 / \mathrm{kW}$ in the low magnet strength range. Since at a higher magnet strength, sintered magnets are comparatively more expensive, it would be interesting to examine whether a lower motor cost with similar power capability could be obtained by increasing the number of layers at a lower magnet strength. However, it has been found that the use of multiple layers to increase the saliency ratio of the motor reaches a diminishing point after a critical number of layers is reached.

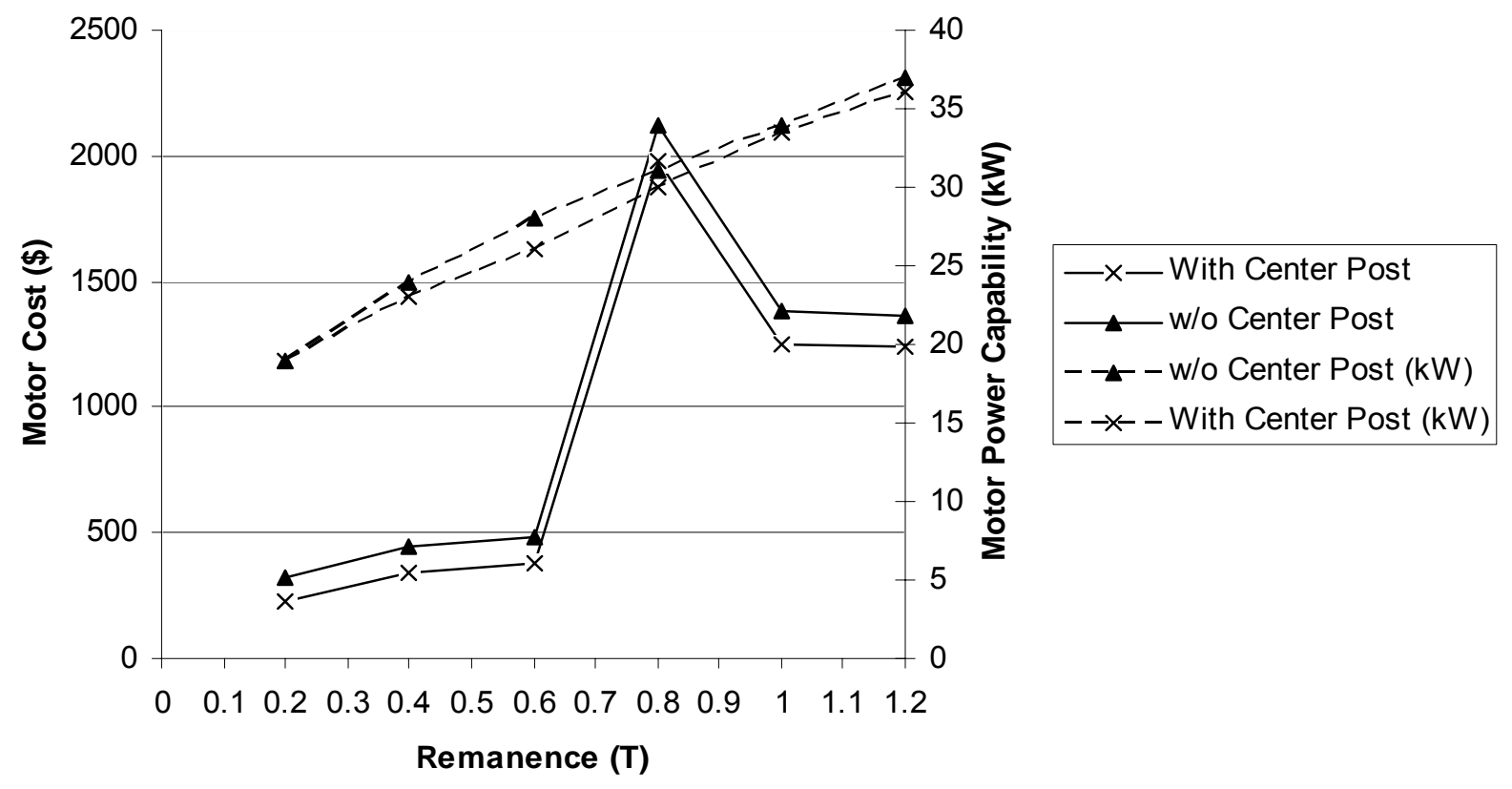

Fig. 7.2. Multi-layered IPM motor cost sensitivity to steel center post.

At a given PM strength, the difference in power capability with and without a steel center posts is very small; in some cases there is no difference because of rounding errors, as shown in Fig. 7.2. Motor cost impacts estimated here are mainly based on the lower magnet weight caused 
by the replacement of magnet material with a steel post - a considerably less expensive material. At a lower magnet strength, the decrease in motor cost due to the steel center post is more than $20 \%$, compared with less than $10 \%$ in the sintered magnet strength range, i.e., greater than $0.6 \mathrm{~T}$. The advantage of the steel center post lies not only in the improvement of mechanical magnet stability but also in motor cost. There is not much compromise in the motor power capability if no additional costs are required for the magnet assembly.

Figure 7.3 shows the multi-layered design motor cost sensitivity to alternative magnet manufacturing technologies, i.e., conventional vs. in-situ. The in-situ magnet manufacturing option not only lowers the magnet cost (as shown in Table 1) but also saves in the final motor assembly cost, which has been taken into consideration here. Estimated cost savings from the insitu manufacturing option range between 3.4 and $8 \%$, with the highest savings projected for the 0.4-T design. Even in the case of 0.6-T magnet strength, although the magnet cost was higher for the in-situ case (as shown in Table 7.1) a reduction in labor overhead during motor assembly makes it cost-effective. As noted, magnet processing including magnetization cost contributes to a relatively smaller share of total magnet cost; therefore, the overall impact due to consolidation of processing steps from the in-situ magnet processing will not be large.

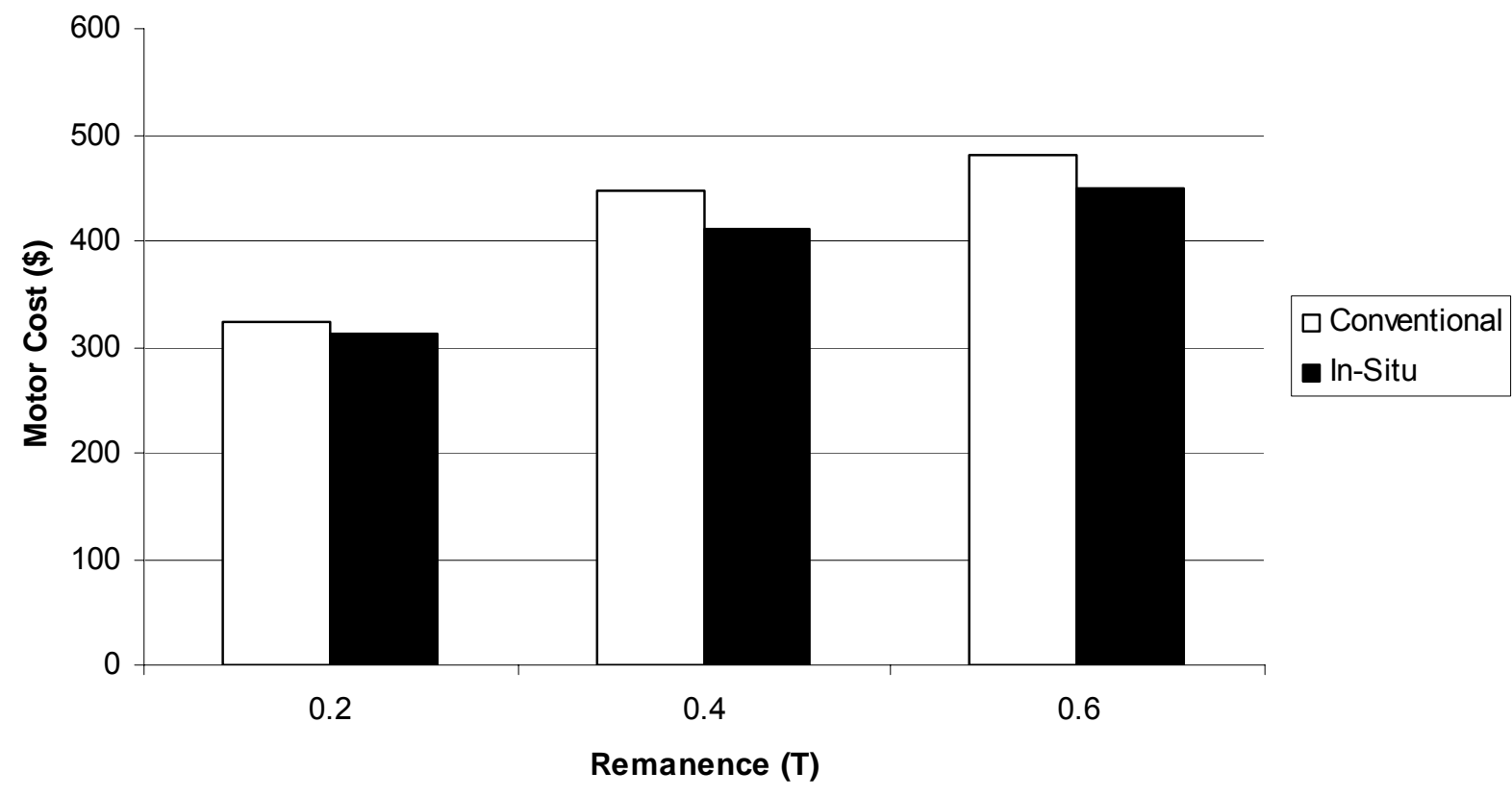

Fig. 7.3. Multi-layered IPM motor cost sensitivity to alternative magnet manufacturing technologies. 


\section{SUMMARY}

This report provides background and summary information that describes parametric studies conducted over recent years, and testing programs that demonstrate both the potential capabilities and technical limitations of

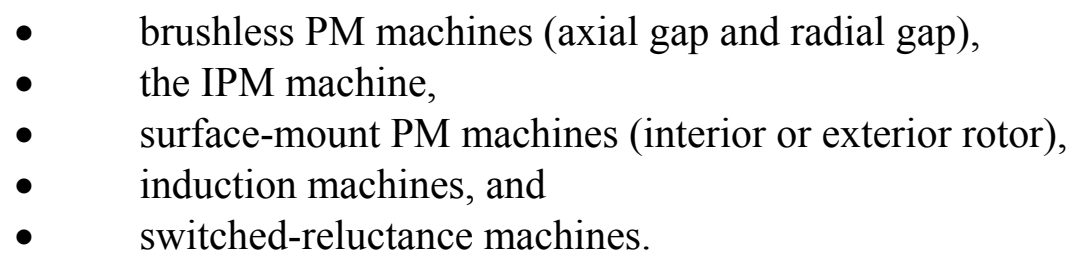

This section described the general findings and accomplishment of the study.

\section{$\underline{\text { IPM Machine Modeling }}$}

This study relied on numerous, complex-modeling executions (i.e., lumped parameter and FEA) where scripting subroutines were necessary for varying numerous parameters to arrive at machine designs that exhibit optimized performance. The results of the FEAs were used to improve the accuracy of the LPM results. The modeling effort first required that both the models and the modeling approach be verified by modeling a machine with known performance characteristics. The only IPM machine filling this requirement was the traction motor in the Toyota Prius. After considerable effort and many SPEEDCAD and Flux2D runs, the analysts were able use FEA model results effectively in "fine-tuning" the LPM. Specifically, the impact of magnetic saturation required adjusting the lumped parameter code because it was not able to accurately simulate saturation as an FEA code can.

It is interesting to note that for the baseline IPM machine (i.e. 2004 Prius), the efficiency is above $95 \%$ for all speeds except speeds below $1200 \mathrm{rpm}$, where efficiency ranges from $77 \%$ at $520 \mathrm{rpm}$ to $88 \%$ at $1100 \mathrm{rpm}$. The analysts believe that meeting program machine target goals in the overall project will likewise be dependent on machine speed.

The next effort in the study was to take the adjusted LPM and model a high-speed (i.e. reducedsize) IPM machine that would be able to operate at the target design specification speed. Scaling the IPM machine down in size to one that would operate at high speed required a rotor that would experience the same stresses at $8000 \mathrm{rpm}$ as the baseline design at $5400 \mathrm{rpm}$. The rotor was scaled by about 0.8 and the stator and stack length were adjusted based on other considerations, including multiple modeling runs with a scripting subroutine. The analysts were generally pleased by the resulting machine design, but additional analysis will be required to confirm the modeled results for the higher speed machine. Additional FEA performance modeling of the high-speed IPM machine is planned to ensure that magnetic saturation levels are reasonable and to verify that there is good agreement with the LPM.

A multi-layered IPM machine configuration with three layers of PMs in the rotor was analyzed in the report, and some variations to the basic multi-layered IPM machine were considered. The strength of the PMs (i.e. flux density was varied from $0.2 \mathrm{~T}$ to $1.2 \mathrm{~T}$ in steps of $0.2 \mathrm{~T}$ and the 
performance capability of the machine was analyzed with varying phase currents. FEA was used extensively to analyze the torque capability of the multi-layered IPM machine. The torque capability of a multi-layered IPM with 0.6 T PMs without steel center posts is very comparable with the baseline IPM machine. Further research should be considered for multi-layered IPM machines with 0.4 and $0.6 \mathrm{~T}$ PMs. Optimization of the geometry of the rotor, number of layers of PMs, and stator design should be considered for future research.

Two recessed magnet PM machines, an 8 and a 12-pole machine, are evaluated in the report by LPMing. FEA should be performed for these machine configurations and optimization of a stator for the recessed magnet rotor should be performed.

\section{$\underline{\text { IPM Design Issues }}$}

As rotor speed increases, mechanical balance at all possible load and cooling conditions becomes more critical. In addition, magnetic losses in the rotor become more important due to the higher frequencies and thus high-quality steel and laminated construction becomes imperative. In highspeed PM machines, rotor magnet retention and rotor structural integrity are critical and must be adequately addressed. In the IPM design, the greatest mechanical stresses in the rotor are in the bridge areas (i.e., a pair of thin strips of metal retaining both the magnets and a triangular steel segment above the magnets called the polar cap). Increasing the width of the bridge reduces the mechanical stress but it increases the amount of magnetic energy leaking through it (up to $25 \%$ of the magnetic potential may be lost.) A low magnetic saturation limit in the bridge's material will effectively limit the impact of this magnetic flux leakage path. Mechanical requirements for the bridge are discussed in Sect. 4.1.2.2. Alternative ways to hold the magnets and polar cap in place may have to be considered.

In high-power-density IPM machines, it is unavoidable that both the rotor and stator operate at or near saturated conditions in many regions specifically during peak power operation, which creates electromagnetic design issues. The high current at low speeds results in significant levels of magnetic saturation in the stator teeth and the rotor bridge is designed to operate at saturated conditions to prevent flux leakage. The study will continue to make use of FEA modeling to analyze IPM machines, particularly conditions prevailing at the stator teeth and the rotor bridge. FEA results are discussed in Sect. 5.

\section{$\underline{\text { Non-IPM Designs }}$}

Because the FreedomCAR program retains a strong interest in alternative machine designs, LPMing of the following PM machines was performed:

- four 18-pole, radial gap (with cost study)

- three 8-pole, radial gap (with cost study)

- one outer-rotor

- one fractional-slot winding

- one Honda-type (T-shaped PMs with tabs for retention)

- axial gap - analysis begun (to continue) 
These machines were designed to have a base speed of $1500 \mathrm{rpm}$, a CPSR of 4 and a base power of $30 \mathrm{~kW}$ to reflect performance targets in effect earlier in the study, when much of the work took place. The machines would be capable of short $55-\mathrm{kW}$ bursts. During peak power bursts, the inverter current would be limited to 300 Arms. Between 1500 and $6000 \mathrm{rpm}$, some type of field weakening would be used.

Although a study with fully integrated LPMing/FEA was not performed for these machines as it was for the IPM, modeling has produced results for most of the listed machine types. The Honda-type machine with T-shaped PMs was also analyzed using FEA to determine stresses in the PMs. Analyses will continue for assessing PM-retention rotor wraps and machine performance in general.

\section{$\underline{\text { Cost Study }}$}

Material types for the full-size and high-speed IPM machine components were assumed to be similar in both cases, but most component weights of the high-speed IPM design are less because of the reduced rotor size. The large-plant, high-production manufacturing cost for the high-speed IPM machine is $\$ 300$, compared with $\$ 432$ for the baseline machine. The expected cost of a multi-layered IPM machine with 0.6 T PMs is $\$ 480$. The higher cost is due to the higher cost of the PMs.

As expected, the cost of magnets dominates the overall motor material cost distribution. In two IPM cases, baseline machine and high speed machine, sintered magnets at a price of about $\$ 40 / 1 \mathrm{~b}$ were specified, which is the most expensive class of magnets used in electric motors. The magnet material prices vary widely in the market today, resulting in increased uncertainty for estimating motor cost. The multi-layered machine uses $0.6 \mathrm{~T}$ bonded magnets with a cost of about $\$ 23 / 1 b$.

\section{$\underline{\text { Future Research }}$}

Future research should investigate a higher-speed IPM machine with "V-shaped" and multilayered PMs. For the "V-shaped" PM machine, the use of steel center posts and bi-state bridges and center posts should be investigated. The development of a multi-layered IPM machine with 0.4 and $0.6 \mathrm{~T}$ PMs should continue. Optimization of the geometry of the rotor and the design of a specific stator for the selected rotor should be investigated. 


\section{REFERENCES}

1. J. R. Hendershot, Jr., and T. Miller, Design of Brushless Permanent-Magnet Motors, Magna Physics Publishing, Hillsboro, OH, and Clarendon Press, Oxford, 1994.

2. D. Hanselman, Brushless Permanent Magnet Motor Design, 2nd ed., The Writer's Collective, Cranston, RI, 2003.

3. Satoh et al., "Development of Traction Motor for Fuel Cell Vehicle," paper No. 2004-010567in Proceedings of the 2004 SAE World Congress, Detroit, March 8-11, 2004.

4. MMC Magnetics, www.mmcmagnetics.com, Hauppauge, New York.

5. R. C. Perrine, Sr., Design Handbook for PM Motors and Techometers, Magna Physics Publishing, Hillsboro, OH, 1999.

6. Cambier et al., Brushless DC Motor Using Phase Timing Advancement, U.S. Patent Number 5,677,605, October 14, 1997.

7. Lawler et al., Constant Power Speed Range Extension of Surface Mounted PM Motors, U. S. Patent Number 6,236,179 B1, May 22, 2001.

8. Yabumoto et al., Electrical Steel Sheet for Traction Motors of Hybrid/Electric Vehicles, Nippon Steel Technical Report No. 87, July 2003.

9. R. M. Cuenca, L. L. Gaines, and A. D. Vyas, Evaluation of Electric Vehicle Production and Operating Costs, Report ANL/ESD-41, Argonne National Laboratory, Argonne, IL,

10. Motorsoft, SPEEDCAD-User's Manual for Windows ${ }^{T M}$ Versions of SPEED Programs, University of Glasgow, Department of Electronics and Electrical Engineering, May 2002.

11. B. K. Bell, VAC Magnetics, Elizabethtown, Kentucky, September 17, 2004.

12. M. W. McPherson, Personal communication with Sujit Das, Oak Ridge National Laboratory, Tengam Engineering Co., Otsego, Michigan, August 19, 2004 and September 7, 2004.

13. A. C. Morcos and P. Campbell, "Neo Magnets Boost Fuel Economy," Machine Design, September 5, 2002. 


\section{APPENDIX A: SUMMARY OF PRIOR CRADA STUDY}

The purpose of the machine study CRADA was to evaluate the various high-potential machine technologies that can be applied to electric hybrid vehicles and machine tool applications. This appendix describes both the scope of the study and the results of motor testing performed at the end of the study.

The axial-gap PM machine demonstrated efficiencies 5-7\% higher compared to the SRM during testing. The axial-gap PM machine has a peak efficiency of about $97 \%$ when operated with sinusoidal pulse width modulation (PWM) at higher torque levels. The axial-gap PM machine had efficiencies of $\geq 95 \%$ over a wide speed range with three electrical drive conditions: standard PWM, modified PWM, and sinusoidal PWM. The efficiency of the SRM ranged from about $86-90 \%$. The acoustic noise emitted by the SRM was greater than $90 \mathrm{db}$ for all speeds. The acoustic noise levels must be reduced in order to potentially be used in a traction motor application.

\section{A.1 CRADA STUDY SCOPE}

The study focused on a number of different machines that were designed, optimized, and simulated to operate in either a motor or generator mode. Extensive design and analysis was conducted on the inverter electronics necessary to drive and control the machines. Loss and efficiency calculations, performance ratings, and weight and cost analyses were performed for each machine and for the inverters. The study also examined the cooling, packaging, and sensor issues associated with each machine system.

The 10 tasks that made up the electric machine study CRADA are as follows.

1. Design analysis-This task consisted of the parametric study and evaluation of different inverter topologies, control schemes, and machine types. Through the use of computer analyses, machine and inverter performances were simulated so that valid comparisons could be drawn. The analysts examined and modeled both hard- and soft-switching inverter topologies.

2. Drive system simulation-In this task, the analysts studied various machine technologies by analytically placing each machine into a HEV platform. Series and parallel hybrid electric drive line architectures were simulated over the same drive schedule. The task compared the hybrid drive trains with a conventional drive train. The analysts compared various parameters, including performance, efficiency, fuel economy, and cost. Operating characteristics were derived for each of the technologies.

3. Machine design-This task pertained to the design of an axial-gap PM machine and SRM. The axial-gap PM machine was designed with two wound stators and one rotor with magnets mounted on each side of the rotor iron. The stator phases were connected in series to ensure an identical current flow in each.

4. Manufacturing study - The manufacturing study focused on several important design, manufacturing, assembly, and operation issues pertaining to the axial air gap motor. These issues are (a) axial force determination and impact during and after assembly due 
to the magnets; (b) air gap tolerance determination and impact; (c) balance requirements and approaches that would be effective for the relatively large rotor diameter used in this type of motor; (d) PM retention methods, primarily for significant production operations where tolerances, in-place magnetization, and bonding methods are considered; (e) stator winding; (f) assembly techniques applying primarily to the prototype; and (g) multiple rotor or stator configurations for increased horsepower designs.

5. Electronics design-This design and development process was for a $45-\mathrm{kW}$ inverter to drive the trapezoidal motor. It involved the construction and testing of a "test bed" inverter to demonstrate snubbing and packaging concepts and then the next-generation "universal" inverter. The snubbing circuit used in both protected the IGBTs from voltage stress and reduced switching losses. The inverter system was quite elaborate, including an encoder for speed and position feedback and a digital signal processor (DSP) controller to process commands and synthesize signals for the inverter drive bus.

6. Machine hardware construction-This task planned the construction of axial-gap and SRMs based on concepts developed in the manufacturing study (Task 4 above). ORNL subcontracted the actual motor construction activities.

7. Electronic hardware construction-The DSP inverter control system was built upon a PC computer system with interfaces to the inverter and motor. The motor controller was designed to control the axial-gap motor and a variety of other types of motors using current sensors and an absolute position encoder. A 16-bit I/O bus fed a data acquisition system.

\section{Testing of axial-gap PM motor and an SRM}

a. Axial-gap PM motor testing-Motor testing was conducted at a CRADA team member facility in August of 1994. Performance was measured based on electrical, thermal, and mechanical characteristics. The primary electrical indices used were voltage, current, power, and efficiency. Tests included no-load, motor characteristics, system characterizations at 25 and $60^{\circ} \mathrm{C}$ coolant temperatures, mechanical, and thermal. Test results and conclusions are provided in Sect. A.3.1.

b. SRM testing-An SRM and inverter system test was performed at a CRADA team member facility in January 1995. The general scope of the test and the types of data indices collected are the same as for the axial-gap PM motor. Test results and conclusions are provided in Sect. A.3.2.

9. Noise study - This study was to investigate the high-noise problem that is encountered in SRMs. The study successfully determined that commutation-related noise frequencies were prevalent at various motor speeds and that commutation-related noise suppression measures must be developed such as optimizing air-gap length and number of poles. Manufacturing tolerance (i.e., uneven machining or punching) in diametrically opposite poles can create uneven magnetic pull in the radial direction.

10. Final analysis-Based on the results of the design simulation of six motor configurations, the axial-gap PM motor and the SRM were selected for construction and testing. These machine tests were conducted at a CRADA team member facility and the results and recommendations for technology/test improvements were developed and documented. 
Drive system specifications were established at the start of the project and the requirements applied to all motor designs included in the Task 1 parametric electric machine study. These designs include the following:

- Radial air gap PM machines

- Axial-gap PM machines

- Induction machines (radial and axial)

- SRMs

- Switched reluctance

The CRADA study was also based on a corresponding set of electric power generating performance specifications that is not applicable to the FreedomCAR study and therefore is not shown.

\section{A.2 SUMMARY OF RESULTS OF THE PARAMETRIC STUDY}

Parametric studies consist of analytical models that can be extremely useful in conducting machine/system analyses quickly and without the cost, inevitable delays, and logistical problems that tend to plague testing of actual hardware. Researchers who have been involved with hardware-based, experimental testing of new technologies are well acquainted with the problems that frequently arise. The parametric studies summarized in this section obtained results without the peripheral issues and complications of data acquisition inadequacies, calibration issues, bearing overheating, magnet demagnetization, magnet mounting, etc. that are evident in Sect. A.3. It is true that hardware-related problems must be discovered, and that is why tests of hardware are conducted. However, the logic and wisdom of first pursuing parametric studies for machine selection cannot be disputed.

The motor performance for three stator diameters and the efficiencies at selected low and high rotational speeds were determined. For each motor type, 7-in, 11-in, and 15-in stator diameters were considered, and typically a range of poles.

The motor efficiency derivations were determined by measuring the power consumption of the motor and determining the segregated motor losses. If the segregated losses are totaled, efficiency $=1-$ (total losses)/(total power to motor).

The types of motor losses include the following (listed from largest loss to smallest loss in the case of a radial PM motor representative of this study):

- Stator resistive $\left(I^{2} \mathrm{R}\right)$ loss

- Rotor iron and magnet loss

- Stator eddy current

- Stator hysteresis

- Friction

- Windage 


\section{A.3 SUMMARY OF THE RESULTS OF MOTOR TESTING}

The motor testing was pursued with the goal of meeting the motor design specifications listed at the beginning of this appendix.

\section{A.3.1 Axial-Air-Gap PM Machine, Inverter, and Universal Controller Testing}

A complete axial air gap PM motor and inverter system test was conducted to evaluate the entire system performance under motoring and regenerating modes. The efficiency of the combined system including motor and inverter reached $90 \%$ at full speed and half torque. The specification called for $81 \%$ efficiency at the design point, and the system performed well beyond expectations based on simulation.

The motor data obtained in this test are considered inaccurate and should be used carefully. The error is due to the power meter's lack of bandwidth and the inability of the instruments to distinguish between the inverter's and the motor's contribution to power loss. The overall system performance measurements are considered accurate. More-reliable motor measurements could have been obtained if a power meter with higher sampling frequency, more memory storage, and faster computation speed had been available.

In the first regenerative mode test, the machine was run up to $-100 \mathrm{ft}-\mathrm{lb}$ torque at $600 \mathrm{rpm}$. The magnet was partially demagnetized when the torque exceeded $-95 \mathrm{ft}-\mathrm{lb}$ torque. The demagnetization was completely unexpected and needs to be studied further in terms of the loading effect on PMs. The demagnetization likely reduced the motor or inverter efficiency because it results in a lower back-emf, which requires higher armature current to achieve the same output torque. The effect on motor efficiency is unknown but is expected to lower efficiency.

Based on an analysis of the test results, axial-gap PM machine improvements include

- reducing the back-emf by $15 \%$ from the original design to allow battery voltage $(200 \mathrm{~V})$ operation

- avoiding demagnetization by considering both temperature and armature effects

- securing the magnet to avoid physical damage by external forces

Table A.1 lists motor efficiency for various motor speed and torque levels for three electrical drive conditions: (1) standard PWM operation, (2) modified PWM operation, and (3) sinusoidal PWM operation. Table A.2 lists motor efficiency and torque for various motor speeds for the same three electrical drive conditions. Sinusoidal operation at high torque levels produced the highest efficiency measurements. 
Table A.1. Efficiency as a function of motor torque

\begin{tabular}{lccc}
\hline & Motor speed (RPM) & $\begin{array}{c}\text { Peak motor torque } \\
\text { (ft-lb) }\end{array}$ & Motor efficiency (\%) \\
\hline Standard PWM & 2800 & 91.2 & 94.4 \\
operation & 2100 & 99.8 & 93.6 \\
& 1400 & 99.9 & 91.1 \\
& 700 & 99.9 & 88.3 \\
Modified PWM & 2800 & 55.0 & 92.1 \\
operation & 2100 & 100.8 & 94.4 \\
& 1400 & 100.2 & 93.4 \\
& 700 & 99.7 & 88.8 \\
Sinusoidal PWM & 2800 & 89.0 & 96.2 \\
operation & 2100 & 90.8 & 95.5 \\
& 1400 & 88.8 & 93.0 \\
\hline
\end{tabular}

Table A.2. Efficiency as a function of motor speed

\begin{tabular}{lccc}
\hline & Motor speed (RPM) & $\begin{array}{c}\text { Peak motor efficiency } \\
(\mathbf{\%})\end{array}$ & Motor torque (ft-lb) \\
\hline Standard PWM operation & 2800 & 96.5 & 30.4 \\
& 2100 & 96.5 & 29.7 \\
& 1400 & 96.3 & 10.2 \\
Modified PWM & 700 & 96.1 & 20.6 \\
operation & 2800 & 96.7 & 30.0 \\
& 2100 & 96.8 & 30.1 \\
& 1400 & 97.1 & 20.5 \\
Sinusoidal PWM & 700 & 94.4 & 30.2 \\
operation & 2800 & 97.4 & 50.3 \\
& 2100 & 97.6 & 30.1 \\
& 1400 & 99.4 & 10.2 \\
\hline
\end{tabular}

\section{Standard PWM Operation}

Efficiency as a function of load torques - Overall efficiency at high speed or high torque was higher than that at low speed or low torque. However, the motor efficiency is almost constant, at $95 \%$, over the entire range except when the torque was less than $20 \mathrm{ft}-\mathrm{lb}$. Therefore, the overall performance has the same pattern as the inverter efficiency profile. At low speeds, the inverter efficiency and system efficiency is far worse than at high speeds.

Efficiency as a function of speed - Normally, one would expect that a higher load torque would have a higher efficiency, but the test results indicate an opposite trend where higher load torque corresponds to a lower motor efficiency. This implies that the power meter is not accurate at low load torques. 


\section{Modified PWM Operation}

The purpose of the modified PWM operation was to modulate only one switch at a time, which should give much smoother current and torque. The only disadvantage of the modified PWM operation was the slow response when adapting to the dynamic or transient conditions. The inverter efficiency was expected to be better than the standard PWM method. For the motor efficiency, whether or not the modified PWM method was better than the standard PWM method is unknown.

Efficiency as a function of load torques-The test was done before magnet demagnetization, the back-emf exceeded the supply voltage at $2400 \mathrm{rpm}$, and the torque could not be fully developed beyond this speed. This suggests that the full torque can be developed only when the speed is below $2200 \mathrm{rpm}$. The maximum developed torque at $2800 \mathrm{rpm}$ appears to be about $60 \mathrm{ft}-\mathrm{lb}$, which is $5 \mathrm{ft}-\mathrm{lb}$ more than the simulation result.

Efficiency as a function of speed-Optimum efficiency is at full speed, $50 \%$ rated torque condition, which has a system efficiency of $90 \%$, inverter efficiency of $93 \%$, and motor efficiency of $96.5 \%$. As expected, the efficiency at high speeds is always better than that at low speeds for the inverter and the entire system. For the motor efficiency, a conclusion cannot be reached because of instrument errors; therefore, data should be used with care.

\section{$\underline{\text { Sinusoidal PWM Operation }}$}

The sinusoidal input current is not a good choice for the trapezoidal PM machine. However, the experiment was performed for comparison. The sinusoidal PWM controller allows the machine to operate in both the motoring and regenerating modes.

Considering efficiency as a function of load torque produces the results that agree with the previous two methods where high speed corresponds to high efficiency.

The system efficiency obtained at $50 \mathrm{ft}-1 \mathrm{~b}$ torque has very little difference from that measured at $90 \mathrm{ft}-1 \mathrm{~b}$ torque. The inverter efficiency profile shows the same pattern as the system efficiency profile. The motor efficiency profile is again very unreasonable because of instrument error. Factoring in the no-load losses, we know that the overall motor efficiency should be worse than what was derived from test data.

\section{$\underline{\text { System Efficiency Comparison between Different Control Methods }}$}

The comparison is limited to system efficiency only because of the accuracy of the instrumentation.

Efficiency as a function of load torque - The modified PWM method improved the efficiency by $3 \%$ at $100 \mathrm{ft}-\mathrm{lb}$ torque and more than $10 \%$ at torque below $30 \mathrm{ft}-\mathrm{lb}$. At $10 \mathrm{ft}-1 \mathrm{~b}$ torque, the efficiency difference widened to $15 \%$. 
Efficiency as a function of speed -The modified PWM method was the overall winner because it produced the highest efficiency for a broader range of speeds and torques. The sinusoidal PWM method had lower efficiency at lower speeds compared with the standard PWM method. However, its efficiency numbers surpass those of the standard PWM method at high speeds. The sinusoidal PWM method has the same efficiency as the standard PWM method at half speed. When the speed is higher, the sinusoidal PWM method becomes more efficient.

\section{A.3.2 Switched-Reluctance Machine}

A complete SRM and inverter system test was conducted at a CRADA team member facility to evaluate the system performance parameters, including electrical, thermal, and mechanical characteristics. Emphasis was placed on collecting electrical characteristics (voltage, current, power, and efficiency) for use in future design improvements of the SRM and power inverter.

The SRM constructed for the test was designed using the PC-SRD software (SPEEDCAD), developed by Glasgow University.

\section{$\underline{\text { Setup }}$}

The test setup for the motor and inverter included a dc dynamometer load, a dc power supply, a control unit, and a data acquisition system. System, inverter, and motor efficiency calculations are based on three power measurements that were made at the dc input, inverter output, and motor output.

The load was a dc motor-based dynamometer that had a separated field weakening control for different speed settings. The source was a bidirectional de power supply that provided power to the inverter during motoring and took the energy back to the utility line during the regenerative mode.

The motor controller included an HCTL-1100 motion control computer, a motion control board, and an inverter to establish the dc bus voltage, current limit, dynamometer speed, and field weakening. The motion control board monitors an encoder signal and compares it with the register information in the computer to determine the output PWM signals for the inverter. The inverter was a conventional two-switch, two-diode-per-phase, IGBT-based inverter.

The data acquisition system was a computer-controlled unit that retrieved data from a general purpose interface bus (GPIB). All instruments were equipped with a GPIB bus and were triggered simultaneously.

\section{$\underline{\text { Stator Winding Temperature Tests }}$}

Four temperature sensors were attached to the stator windings while the motor was tested at four different speeds $(700,1400,2100,2800 \mathrm{rpm})$ and four different torque settings $(25,50,75$, and $100 \mathrm{ft}-\mathrm{lb}$ ). The motor was cooled by a chiller adjusted to $23^{\circ} \mathrm{C}$. At each load condition, the temperature among the windings varied by only $20^{\circ} \mathrm{C}$. From the measured stator winding temperature, the temperature inside the motor rotor was expected to be greater than $90^{\circ} \mathrm{C}$. The high temperature from the bearing was not detected by the stator windings. 


\section{Efficiency Tests}

The inverter output power measurement needed four channels. As a result of constraints of the data acquisition system, only three channels were used to project the total inverter output power. The accuracy was unknown, but the results tended to favor the motor and gave it a higher than expected efficiency measurement at low speeds. The numbers look more reasonable at high speeds.

The measurement of the system efficiency seemed to be accurate and consistent to the team analysts. Typically, a low-speed, low-torque condition gave lower efficiency and vice versa. The overall system efficiency was significantly lower than that obtained from the PM machine drive, which had $90 \%$ maximum system efficiency. The efficiency value was also lower than that projected by the PC-SRD software.

Motor efficiency for the SRM at $2800 \mathrm{rpm}$ ranged from approximately $76 \%$ for low torque to about $88 \%$ at high torque. For low speed $(700 \mathrm{rpm})$, the efficiency ranged from approximately $86 \%$ at low torque to $90 \%$ at high torque. Table A.3 lists the motor efficiency for the SRM.

Table A.3. SRM efficiency test results

\begin{tabular}{ccccc}
\hline $\begin{array}{c}\text { Target motor } \\
\text { speed (rpm) }\end{array}$ & $\begin{array}{c}\text { Actual motor } \\
\text { speed (rpm) }\end{array}$ & $\begin{array}{c}\text { Motor torque } \\
\text { (ft-lb) }\end{array}$ & $\begin{array}{c}\text { Motor power } \\
\text { (watts) }\end{array}$ & $\begin{array}{c}\text { Motor efficiency } \\
\text { (\%) }\end{array}$ \\
\hline 700 & 730 & 25.5 & 4,320 & 86.1 \\
& 760 & 49.9 & 8,040 & 88.6 \\
& 785 & 75.7 & 12,480 & 90.0 \\
1400 & 815 & 102.4 & 17,520 & 89.6 \\
& 1430 & 25.2 & 5,117 & 80.6 \\
& 1460 & 51.6 & 10,698 & 88.0 \\
& 1485 & 75.1 & 15,836 & 88.3 \\
2100 & 1510 & 100.4 & 21,528 & 88.5 \\
& 2130 & 24.2 & 7,320 & 78.4 \\
& 2155 & 50.0 & 15,300 & 84.9 \\
2800 & 2190 & 75.0 & 23,323 & 86.8 \\
& 2220 & 100.0 & 31,524 & 87.8 \\
& 2830 & 25.7 & 10,328 & 76.3 \\
& 2860 & 49.7 & 20,184 & 85.1 \\
& 2890 & 74.7 & 30,655 & 86.8 \\
\hline
\end{tabular}

Measurement Results at Regenerative Mode

Only two regenerative mode measurement points were taken ( $700 \mathrm{rpm}$ at $25 \mathrm{ft}-\mathrm{lb}$ and $50 \mathrm{ft}-\mathrm{lb}$ ). The phase A voltage waveform indicates IGBT chopping during PWM operation, compared with the motoring mode where only one IGBT operated during operation. The current ripple shows the same order of magnitude for both the motoring and regenerative modes.

The dc link current oscillated at a frequency close to the utility supply possibly due to noise pickup. 


\section{$\underline{\text { Mechanical Vibration and Noise Measurement Results }}$}

The mechanical vibration was tested at three target speeds $(700,1400$, and $2100 \mathrm{rpm})$ by placing vibration pickups at the front and back bearings. The frequency spectrum for the mechanical vibrations is a function of the component specifications and the electrical commutation frequency. The commutation frequency is equal to the product of the motor's speed and the number of rotor poles divided by 60 .

Power measured at the second, third, and fourth harmonics is about the same as the fundamental frequency, indicating that the four stator torque pulses are reasonably balanced.

Acoustic noise was picked up that related to the commutation frequencies. The lower-frequency acoustic noises (below $200 \mathrm{~Hz}$ ) were suppressed by the mounting bed. The measurement results indicated that the overall acoustic noise level was greater than $90 \mathrm{db}$ for all speeds. The noise frequencies were commutation-related and clustered below $3.5 \mathrm{kHz}$. The noise of the PWM switching frequency ( 3 to $4.5 \mathrm{kHz}$ ) did not stand out in most cases, except at 700-rpm, $25 \mathrm{ft}-\mathrm{lb}$ load. Therefore, SRM acoustic noise reduction should focus on commutation related noises. 


\section{APPENDIX B: \\ SUMMARY OF THE AEMD TEAM 1 STUDY}

AEMD Team 1 engineers considered several machine configurations for the AEMD machine design. These included sinewave PM machines, induction machines, and SRMs. Machine designs were developed according to AEMD specifications and guidelines provided by the EETTs. For each configuration, the best machine design of the favored topology was selected and documented.

The research and development (R\&D) emphasis was different for each machine type, depending on where the technical challenges were or what needed to improve to make each a stronger contender. The effort was directed toward the evaluation of low-cost technology for the induction machine, design for large CPSR for the PM machine, and investigation of various drive topologies for the SRM.

As part of the AEMD project, Team 1 has developed a parallel induction machine that was tested in part at ORNL. The machine performed well and, because of its mature and well-understood technology, represents a low risk. For the size of interest, the induction machine has a lower efficiency and power density when compared to the PM machine. Only small improvements are expected to the performance characteristics of the induction machine in the future; thus, the PM machine appears to be better suited for traction drive applications. AEMD Team 1 also developed a series PM machine with an outer rotor configuration. The motor testing demonstrated a fairly wide speed range with efficiencies $\geq 93 \%$. The outer-rotor PM machine is well suited for medium and high-speed applications. The outer-rotor design may pose a potential rotating hazard if not properly shielded. The IPM machine has higher power density when compared to the outer rotor machine. This appendix summarizes the activities and results for each of the motor projects.

\section{B.1 TOP-TIER TARGETS AND COMPARISON OF MACHINE TYPES}

The overall goal of the AEMD task was to develop traction motors for potential HEV applications. These targets are listed in Table B.1 for a series machine.

Table B.1. Targets for the AEMD program

\begin{tabular}{lc}
\hline \multicolumn{1}{c}{ Parameter } & Target \\
\hline Cost & $\$ 450$ \\
Peak power & $53 \mathrm{~kW}$ \\
Continuous power & $30 \mathrm{~kW}$ \\
Battery nominal operating voltage & $200-450 \mathrm{~V} \mathrm{@} 400 \mathrm{~A}_{\mathrm{rms}}$ \\
& $\mathrm{max}$ \\
Motor fundamental electric frequency (max) & $1000 \mathrm{~Hz}$ \\
Efficiency (10-100\% speed, 20\% rated torque) & $93 \%$ \\
Electric motor/speed reducer mass & $35 \mathrm{~kg}$ \\
\hline Electric motor/speed volume & 11 liters \\
\hline
\end{tabular}

As summarized in this appendix, a CRADA member facility evaluated a conventional induction machine, a low-cost induction machine, an outer-rotor PM machine, and a SRM. The estimated 
performance comparison of the machines, summarized in Table B.2, shows that the PM machine exhibited superior efficiency at the rated speed point and at both full-rated torque and 20\% torque. However, the high-speed, part-load efficiency of the PM machine was lower than for the other machines. The table indicates that the PM machine has a significant advantage in packaging, as reflected in the measures of stack length and mass. All the machines were designed to meet packaging requirements for the program. The ac rms phase current necessary to meet the rated motoring point was similar among the designs, with the PM machine requiring the least current. The induction machine represents the lowest risk because the technology is very well understood. Both the induction and SRM machines can potentially be constructed from lowcost and easily manufactured components.

Table B.2. Comparison of selected performance parameters for AEMD Team 1 machines

\begin{tabular}{|c|c|c|c|}
\hline Parameter & Induction & Outer-rotor PM & SRM \\
\hline $\begin{array}{l}\text { Efficiency@ rated power and } \\
1600 \text { rpm, \% }\end{array}$ & 85.7 & 94.4 & 82.3 \\
\hline $\begin{array}{l}\text { Efficiency@20\% rated power } \\
\text { and } 1600 \mathrm{rpm}, \%\end{array}$ & 87.6 & 95.7 & 79.4 \\
\hline Stack length, mm & 71 & 45 & 80 \\
\hline Active material mass, $\mathrm{kg}$ & 18.6 & 12.8 & 18.7 \\
\hline $\begin{array}{l}\text { Max rms phase current@ rated } \\
\text { torque/speed, } \mathrm{A}_{\mathrm{rms}}\end{array}$ & 185 & 155 & 205 \\
\hline Relative risk & Low & High & High \\
\hline Machine cost & Low & High & Low \\
\hline
\end{tabular}

\section{B.2 PARALLEL INDUCTION MACHINE}

A conventional machine for parallel hybrid vehicles was designed and tested by AEMD Team 1. In addition, a means was sought to give this very mature technology an additional competitive edge in cost, especially in light of less-than-favorable packaging requirements. Therefore, it was decided that certain low-cost design and manufacturing changes would be explored to see what effect, if any, they might have on performance. This effort produced a low-cost design that was similarly tested. Although both designs include a power generation capability, the emphasis in this project summary will be on the motoring capability, since only motoring is of interest in the present series HEV study.

\section{B.2.1 Conventional Design}

Since the induction machine was being designed for a potential parallel hybrid vehicle application, the geometry was driven by packaging constraints. It was not unexpected that the geometry constraints were related to machine cost. The packaging requirements dictated a large inner diameter, large ratio of machine OD to inner diameter, and short stack length. These geometry constraints led to a machine design having a high pole number. With stamped laminations in the rotor, the same constraints led to high material scrap during rotor manufacturing; this problem is addressed in the low-cost design (see Sect. B.2.2). The machine design also contained some compromises in the interest of the regenerative mode performance, which was an AEMD requirement. 
The conventional machine design was completed using common 26-gage, M-36 silicon steel. A design optimization parametric study was completed showing the trade-offs in performance as a function of geometry. This study used a AEMD Team 1 proprietary design program that implements a Monte Carlo design synthesis routine, where machine parameters are varied over a range of interest and machine performance parameters are calculated and tabulated. The AEMD requirements indicate that the efficiency at $20 \%$ load, from $10-100 \%$ speed, should be $93 \%$. The Team 1 modeling study showed that this was not attainable at the load points selected, given the machine packaging constraints. Using a similar approach, parameters such as mass, electrical generation, and inertia were evaluated.

The design process continued until it arrived at the design geometry summarized in Table B.3.

Table B.3. Design geometry of the conventional induction machine

\begin{tabular}{|r|l|}
\hline Stator & \\
\hline OD, $\mathrm{mm}$ & 360 \\
\hline Inner diameter, $\mathrm{mm}$ & 318.6 \\
Stack length, $\mathrm{mm}$ & 71 \\
\hline Stator slots & 96 \\
\hline Stator winding & \\
\hline Turns per coil & 5 \\
\hline Parallel paths & 4 \\
\hline Strands & 4 \\
\hline $\mathrm{AWG}$ & 18.5 \\
\hline Rotor & \\
\hline Onner diameter, $\mathrm{mm}$ & 285 \\
\hline ODm & 317 \\
\hline Stots & 144 \\
\hline &
\end{tabular}

Testing the machine in the motoring mode at $267 \mathrm{Vdc}$, the machine showed good full-load efficiency characteristics, $\sim 90 \%$ or above, over a broad speed range from $2500-5500 \mathrm{rpm}$. While still in the motoring mode, the efficiency testing at $20 \%$ load torque resulted in a $>90 \%$ efficiency from 3000-6000 rpm; however, this fell short of the AEMD performance goal.

\section{B.2.2 Low-Cost Design}

Team 1 took mature and well-understood induction machine technology and explored the adaptation of certain low-cost manufacturing processes such as the use of a powdered iron rotor with a segmented stator. Team 1 also reduced the rotor slot combination and controlled the form factor to facilitate the powder metal press operation. Although the performance analysis ultimately favored the conventional design, certain low-cost techniques, such as the use of segmented or slinky laminations, showed promise with little degradation in performance. Less promising in the near term was the powdered iron rotor, which exhibited a lower material saturation level than laminated electrical steels.

The design study relied on the Team 1 Proprietary Induction Machine Design Program. Key design variables were varied over predetermined ranges to identify trends and design limitations. 
The low-cost design made use of 26-gage, M36 silicon steel for the stator, with modifications to the loss characteristics to account for additional iron losses due to low-cost manufacturing processes such as a slinky- or helically-wound stators or segmented stators with numerous welds.

The rotor design called for the use of 45-P sintered powdered iron rotor material. The material exhibits resistivity that is 30 times higher than in silicon steel, but it is not laminated as is silicon steel. The 45-P material has a lower saturation flux density and has generally lower permeability than silicon steel.

The design process continued until it arrived at the design geometry summarized in Table B.4. The parameters for the conventional design are repeated in Column 3 from the previous table for comparison purposes. Note that the low-cost design required a greater stack length than the conventional design.

Table B.4. Design geometry of the low-cost induction machine

\begin{tabular}{lrll}
\hline Stator & & Low cost & Conventional \\
\hline \multirow{4}{*}{ Stator winding } & OD, mm & 360 & same \\
& Inner diameter, mm & 317.4 & 318.6 \\
Stack length, mm & 78 & 71 \\
Stator slots & 96 & same \\
& & \\
Rotor & Turns per coil & 9 & 5 \\
& Parallel paths & 8 & 4 \\
Strands & 3 & 4 \\
AWG & 20 & 18.5 \\
& & \\
& Inner diameter, mm & 285 & same \\
OD, mm & 315.9 & 317 \\
& Stack length, mm & 78 & 71 \\
\hline Slots & 112 & 144 \\
\hline
\end{tabular}

The low-cost machine performance relative to the specifications must be weighed against the ac current requirements in both the motoring and generating modes.

The machine peak torque vs. speed profile at $267 \mathrm{Vdc}$ shows that the performance goals were met over the entire range of speeds specified. If higher current was permitted, the machine would be able to provide additional torque over most of the speed range. A maximum rms phase current of $\sim 190 \mathrm{~A}$ was required to provide $180 \mathrm{Nm}$ of shaft torque.

The machine efficiency vs. speed profile at peak torque at $267 \mathrm{Vdc}$ shows that the machine efficiency was $\sim 90 \%$ from $2500-6000 \mathrm{rpm}$. Under the same conditions, but at $20 \%$ torque, the target efficiency of $93 \%$ could not be met given the geometry and fundamental frequency constraints. The efficiency of the low-cost machine was still quite respectable at $>90 \%$ from $\sim 2700-6000 \mathrm{rpm}$ and was almost as high as for the conventional induction motor.

Both the conventional design and the low-cost design were able to meet torque and speed requirements. However, the low-cost design required a $10 \%$ larger stack size, while opportunities exist for applying low-cost fabrication techniques such as laminated rotors to the conventional 
design. There was also a slight efficiency loss (1\%) in the low-cost design at $20 \%$ rated load. Therefore, it was concluded that the conventional machine was the most attractive design option.

\section{B.3 OUTER ROTOR PM MACHINE}

The Team 1 proof-of-concept testing focused on a series, outer-rotor, PM machine that featured coaxial shaft output. The testing of this machine was both rigorous and comprehensive. Overall, the project is designed to proceed through four discrete stages: (1) initial testing of the proof-ofconcept machine, (2) design changes, (3) hybrid GAP analysis, and (4) risk assessment. Each of these is discussed below.

The original machine design is designated the proof-of-concept machine because it demonstrates a design concept developed during the modeling phase. The subsequent modified design is considered to be the "deliverable" design, and a future third design will encompass certain other changes such as a single-shaft output. These three designs are summarized in Table B.5.

Table B.5. Summary of design changes for the AEMD Team 1 outer-rotor PM machine

\begin{tabular}{l||ccc}
\hline Subassembly & POC & Deliverable & Future \\
\hline Laminations & 26 gage, M36 & 29 gage, M15 & 29 gage, M15 \\
Winding & 3 coils/phase & 6 coils/phase & 6 coils/phase \\
Magnets & 18 segment arcs & 30 segment arcs & Tile magnets \\
Rotor material & Solid steel & Solid/laminated & Solid/laminated \\
Housings & Slip fit stator to & Shrink fit stator to & Eliminate 1 of 3 housings and \\
& housing & housing & simplify design \\
Gearing on output & Dual output & Dual output & Single output \\
& Double reduction & Double reduction & Single reduction \\
& $10: 1$ ratio & $8.5: 1$ ratio & $3: 1$ ratio \\
Shafts and hubs & - & - & Eliminate 3 shafts \\
\hline Bearings & - & - & Eliminate several bearings \\
\hline
\end{tabular}

The testing activities and design changes are summarized as follows:

1. Initial test results - The back-emf and core loss correlated well with model predictions. Efficiency was higher than predicted because of an error in the loss prediction calculation. Torque data were obtained from motor operation at several different speeds. Test results showed that the machine speed apparently is limited by the material selection for the motor. The rotor experienced rapid heating starting at $\sim 7000 \mathrm{rpm}$, and rotor demagnetization occurred as a result of excessive heating at $9000 \mathrm{rpm}$.

2. Design changes - Changes were necessitated by the need to improve performance and update cost estimates. Changes to improve performance included laminating the rotor to reduce rotor core losses, using a salient pole winding to reduce rotor harmonics, increasing the number of magnet segments to reduce magnet losses, changing the lamination steel to 29-gage M-15 to reduce stator core loss, reducing the gear ratio to 8.5:1 to minimize friction and windage losses and oil drag losses, and shrink-fitting the stator to the housing to reduce the thermal resistance. 
3. Gap analysis - This analysis compared the ambitious target goals of the FreedomCAR program with actual or predicted performance of the proof-of-concept, deliverable, and future machine designs. The future machine design is predicted to have some areas of deviation from the performance and physical target specifications. These deviations are primarily in the areas of current (slight deviation of $+15 \mathrm{~A})$, frequency $(+200 \mathrm{~Hz})$, vehicle speed above $77 \mathrm{mph}$, efficiency at $>50 \%$ speed, mass (slight deviation of $<4 \mathrm{~kg}$ ), and cost (\$70). The EETT had agreed to increase drive frequency prior to this analysis. Targets are predicted to be fully met for torque at the driveshaft and machine volume.

4. Risk assessment-Each of the changes needed to produce the future design was considered relative to program risk. In all, 15 changes affecting 7 subassemblies were predicted, and the risk was deemed "low" for each change with one exception. The exception is a high risk for replacing segmented and bonded magnets with as-pressed bar magnets while adopting a new high-speed assembly process.

The configuration of the deliverable series electric machine that was tested included a single reduction gear assembly. Torque vs. speed mapping of the machine was performed with dc link voltages of 325 and $200 \mathrm{Vdc}$. The machine was tested from $500 \mathrm{rpm}$ to $12,000 \mathrm{rpm}$ in intervals of $500 \mathrm{rpm}$ with torque loads of $100 \%, 80 \%, 60 \%, 40 \%$, and $20 \%$ and of $10 \%$ rated torque.

The deliverable series machine met the continuous and peak mechanical power goals from 3,000-12,000 rpm with the minimal dc link voltage, $200 \mathrm{Vdc}$. The machine met the peak torque requirement of $596 \mathrm{Nm}$ from approximately 500-2500 rpm during the tests with a dc link voltage of $325 \mathrm{Vdc}$. The machine-demonstrated efficiencies of $\geq 93 \%$ from $2997-6003 \mathrm{rpm}$ with mechanical loads $\geq 30 \mathrm{~kW}$ and from 3500-6001 rpm with mechanical power levels $\geq 55 \mathrm{~kW}$ with the minimal dc link voltage. The machine had slightly higher efficiencies when operated with the dc link voltage of $325 \mathrm{Vdc}$ when compared to $200 \mathrm{Vdc}$. At mechanical power levels $\geq 55 \mathrm{~kW}$, the machine demonstrated efficiencies of $\geq 93 \%$ from $3511-7507 \mathrm{rpm}$ and $\geq 90 \%$ from $2496-9528 \mathrm{rpm}$ with a dc link voltage of $325 \mathrm{Vdc}$.

\section{B.4 SWITCHED-RELUCTANCE MOTOR}

Team 1 considered a concentrated-winding SRM appropriate for a potential parallel hybrid vehicle application since it is predicted to have high performance over a wide speed range. A number of full-pitched configurations were also considered, including machines based on a unipolar, $120^{\circ}$ conduction configuration and SRMs using a conventional inverter topology of $120^{\circ}$ conduction and $180^{\circ}$ conduction. Full-pitched machines are unique in that they generate torque from changing mutual inductance instead of from changing the self-inductance characteristic of the conventional concentrated coil machines. The full-pitch winding was used to reduce copper loss below base speed (given that more of the copper is utilized at any given time), but this approach led to high self-inductance, which tends to be exhibited by these machines.

The advantages of low-cost materials and simplicity of construction for which SRMs are known must be weighed against certain inherent drawbacks. One of these is machine size; however, this drawback was driven partly by the need for low-speed generation requirements that does not apply to the present study on a series application motor. The risk of continuing to pursue this technology is high also because of the following: 
1. Machine efficiency significantly below the target at $20 \%$ load, over the speed range

2. Questions regarding the selection/packaging of the position sensor

3. The need to mitigate acoustic noise and transmitted vibration

4. The complexity of integrating the machine with an appropriate drive topology 


\section{APPENDIX C: SUMMARY OF THE AEMD TEAM 2 AXIAL-GAP MOTOR STUDY}

A multi-party team recommend an axial-gap traction motor system in support of AEMD's development program for a future SHV configuration. Several iron-filled and ironless axial-gap PM BDCM and controller combinations were analyzed. Most combinations for this study were eliminated because of incompatibilities or a determination that the technology did not warrant extensive evaluation. This study summary presents the results from analyzing the leading motor/controller candidates.

The axial-gap machine developed by AEMD team 2 experienced thermal problems when operated continuously. The cooling strategies for this machine must be significantly improved. This motor has a very limited constant power operating speed range which greatly limits its potential use as a traction drive motor. The machine demonstrated about a $6-8 \mathrm{~kW}$ constant power capability.

\section{C.1. IRON-FILLED AND IRONLESS AXIAL-GAP MACHINE DESIGNS}

This section provides a brief discussion of the potential advantages of adding iron to the stators of axial gap machine designs.

\section{C.1.2. PMBLDC, Axial-Gap, Ironless Motors}

The ironless axial-gap PM brushless dc (PMBLDC) machine is able to maintain efficiency on a wider speed range than iron-filled motors because it does not have ac flux return losses. This configuration can also be designed to have a flatter plateau on the torque-speed curve. The ironless motors exhibit zero cogging torque. In general, axial-gap motors have the advantage that there is a potential for designing them with a higher active volume than a radial PM BDCM. This motor configuration also has the advantage of offering a more robust method of magnet retention without impacting performance significantly. Unlike the radial gap PM machine, the axial-gap machine's magnets may be retained by an outer radial lip that does not interfere with the magnetic air gap. However, because there is no flux-carrying member between the magnets, more magnet material is required than in the iron-filled counterparts, penalizing this design for material cost. In addition, because this motor contains no iron in the stator, it has an inductance too low to be compatible with CPA techniques. And because the wire is not shielded by iron, a high-strand-count stranded wire must be used in order to reduce eddy-current losses, impacting material cost.

\section{C.1.3. PMBLDC, Axial-Gap, Iron-Filled Motors}

The most significant benefit of adding iron to the stator of the axial flux machine is that such designs require significantly less magnet material. In addition, introducing iron to the axial-gap PM machine increases inductance, thereby allowing CPA techniques to be employed. The ironfilled motor also has the flexibility of being configured as a stator-rotor-stator design, facilitating cooling of the stator and hence improving power density. However, these benefits do not come without some cost. The addition of iron brings with it significant cogging and ac flux return 
losses, causing a slight reduction in efficiency. Even with these concerns, the system may offer the greatest potential for meeting the performance goals with improved cooling.

\section{C.1.4. Iron-Filled vs. Ironless Axial-Gap Motors}

The preferred method for addition of iron was determined to be through the use of iron-filled epoxy (IFE). It allows a very specific and controlled percentage of iron fill to be added to the motor. For purposes of comparison, an ironless motor design with similar power and speed characteristics was compared with a $15-\mathrm{kW} 75 \%$ IFE motor design. Some of the most important variables are shown in Table C.1.

Table C.1. Ironless motor comparison with $75 \%$ iron-filled motor

\begin{tabular}{|c|c|c|c|c|}
\hline Parameters & 0\% Fill & $75 \%$ Fill & Change & \% Ironless \\
\hline \multicolumn{5}{|l|}{ Performance } \\
\hline Output power, kW & 15 & 15 & 0 & $100.0 \%$ \\
\hline Rated speed, rpm & 3600 & 3600 & 0 & $100.0 \%$ \\
\hline Efficiency at rated torque, $\%$ & 96.3 & 92.3 & -4 & $95.8 \%$ \\
\hline Efficiency at $20 \%$ rated torque, $\%$ & 97.4 & 97.7 & 0.3 & $100.3 \%$ \\
\hline \multicolumn{5}{|l|}{ Dimensions } \\
\hline Outer motor diam (est.), mm & 291.8 & 210.3 & -81.5 & $72.1 \%$ \\
\hline Outer motor vol (est.), Liter & 4.319 & 2.621 & -1.698 & $60.7 \%$ \\
\hline \multicolumn{5}{|l|}{ Weights } \\
\hline Magnets, $\mathrm{kg}$ & 2.146 & 1.041 & -1.105 & $48.5 \%$ \\
\hline Copper in coils, $\mathrm{kg}$ & 2.257 & 0.985 & -1.272 & $43.6 \%$ \\
\hline Iron in the stator, $\mathrm{kg}$ & 0 & 0.668 & 0.668 & \\
\hline Flux return, kg & 2.481 & 2.824 & 0.343 & $113.8 \%$ \\
\hline Motor (est.), kg & 9.294 & 7.448 & -1.846 & $80.1 \%$ \\
\hline \multicolumn{5}{|l|}{ Losses (at rated torque) } \\
\hline Copper, watts & 517.70 & 980 & 462.3 & $189.3 \%$ \\
\hline Core loss in IFE, watts & 0 & 157 & 157 & \\
\hline Eddy currents loss in coils, watts & 28.98 & 48 & 19.02 & $165.6 \%$ \\
\hline Eddy currents loss in PM, watts & 0 & 55 & 55 & \\
\hline Mechanical, watts & 28.3 & 28.3 & 0 & $0.0 \%$ \\
\hline Total losses, watts & 575.01 & 1268.4 & 693.39 & $220.6 \%$ \\
\hline
\end{tabular}

The IFE motor design is decidedly advantageous in the areas of copper and magnet material mass, motor diameter, and total motor volume. At partial power (up to about $25 \%$ rated power at $100 \%$ rated speed), the IFE motor is also competitive from an efficiency standpoint. In areas above $25 \%$ rated power, the ironless motor has a substantial advantage over the IFE machine. Higher currents were designed into this machine because the higher copper density and lower thermal resistance associated with the use of magnet wire, as opposed to Litz wire, allowed much higher thermal dissipation capabilities in the IFE machine. The impact of additional iron on the machine appears to be an approximately $50 \%$ reduction in the machine cost with a $4 \%$ drop in efficiency at $100 \%$ rated load at $100 \%$ rated speed. It is anticipated that the motor could be designed to achieve 93\% efficiency over a very broad speed range by reducing the phase current with a slight increase in magnet material. Further analysis is required at the vehicle system level to determine the overall impact on vehicle system efficiency, based on anticipated real-world operating points derived from typical driving cycles. If the motor is run for significant periods of 
time at partial load, the impact of this efficiency differential may be less significant than the associated cost benefits.

\section{C.2. MACHINE SYSTEMS FOR COMPARATIVE ANALYSIS}

This section describes a baseline radial-gap machine design and five axial-gap machine configurations that were compared in the AEMD Team 2 study.

\section{C.2.1. System 1 (Baseline): PMBLDC Radial-Gap CPA Motor System}

For comparison, a representative PM, radial gap design motor was selected, primarily because it is the only technology currently used in production HEVs such as the Toyota Prius. Specifically, the Model EV53 motor from UQM Technologies, Inc., was selected because it is also commercially available and detailed information about the motor is readily available.

\section{C.2.2. System 2: Ironless PMBLDC Axial-Gap DMIC Motor System Loss and Cost Analysis}

The ironless (DMIC) motor design is intended for use with a conventional variable-frequency inverter using CPA. In addition to the conventional inverter, a DMIC add-on is included to block the extremely high diode currents that the ironless motor would see above the base speed. Without the DMIC addition, this particular motor would be usable over a very small (no more that 2:1) CPSR. In this design, the motor's base speed is equal to the peak motor speed divided by the CPSR, as in any CPA design. The addition of DMIC allows the motor to be sized thermally for the rated power rather than for the elevated current levels typically experienced in a CPA control scheme. This motor has a substantially higher peak torque capability than a similar iron-filled machine. The DMIC motor design has slightly higher peak efficiency, with the entire peak efficiency plateau occurring within the motor's normal operating range. Of all the axial flux motors modeled, the ironless DMIC motor is the most expensive solution. The cost is primarily due to the higher magnet mass required because of the lower winding turn count and low base speed required in this approach. The advantage of this approach is that a CPSR much greater than 5:1 could be achieved (potentially 10:1 or greater with proper design) because of the current-blocking capabilities of the DMIC and the low-speed-related losses in the ironless motor design.

\section{C.2.3. System 3: Ironless PMBLDC Axial-Gap H-Bridge Motor System Loss and Cost Analysis}

The ironless PMBLDC H-bridge motor was designed to be used with an inverter using oversized current switches. In this system, a CPSR capability is approximated by designing the motor to have a base speed equal to the system's max speed with a continuous rated torque capable of providing $30 \mathrm{~kW}$ at a speed equal to the peak speed divided by the CPSR. This motor has a substantially higher torque capability at the peak speed, but most of the plateau defining the peak efficiency falls outside the normal operating torque/speed range. Of the ironless motors studied, the H-bridge concept resulted in the lowest motor cost. At a system level, this cost is offset by 
the cost of the higher switch ratings required for the high continuous current required at low speed.

\section{C.2.4. Systems 4 and 5: Iron-Filled PMBLDC Axial-Gap DMIC/CPA Motor System Loss and Cost Analysis}

The iron-filled DMIC motor is very similar to the ironless DMIC motor, except that it can also be operated using a variable-frequency inverter using CPA without DMIC and still achieve a significant CPSR. This is a distinct cost advantage at the system level because of the simple inverter architecture that can be used. The addition of iron affects the DMIC motor in much the same way that it affected the iron-filled H-bridge motor. The general behavior is very similar to that of the ironless machine, with the peak efficiency plateau roughly $3 \%$ lower than the ironless version of the motor.

The iron-filled DMIC motor cost is approximately 33\% above the cost of the iron-filled H-bridge motor. At a system level, this difference changes significantly as a result of the capability to use a standard variable-frequency inverter. This approach will likely lead to a motor that will be only slightly over the AEMD specification for mass and volume. Overall, this motor is a likely candidate for future work, although a fully dense iron-filled motor would possibly be a more appealing approach. Because of the capabilities of the DMIC, it is likely that this motor would look substantially different depending on whether the system uses CPA with DMIC, or CPA without DMIC. In the case of the DMIC-based approach, a partial iron fill would be used to reduce mass, volume, and cost; but a fully dense iron fill would not be used to reduce the spinrelated losses that will ultimately limit the CPSR of the DMIC approach. On the other hand, a strictly CPA approach with a variable-frequency inverter would likely result in a fully dense iron-filled motor to reduce the diode currents above base speed.

\section{C.2.5. System 6: Iron-Filled PMBLDC Axial-Gap H-Bridge Motor System Loss and Cost Analysis}

The iron-filled H-bridge motor was scaled from the ironless design using FEA results from earlier $75 \%$ iron-filled epoxy FEA. Functionally, the motor is nearly identical to the ironless $\mathrm{H}$ bridge motor. The primary performance difference between the ironless and iron-filled motors is the peak efficiency of the machine. The behavior of the efficiency map is very similar to that in the ironless machine, but the peak efficiency plateau is approximately $3 \%$ lower. This results in a substantially higher thermal dissipation requirement. Shielding of the wire by the iron allows the use of very low strand count magnet wire (or solid magnet wire, in the case of fully dense iron fill), which greatly increases the thermal conductivity in the radial direction. This higher thermal conductivity allows the motor to operate at the lower efficiency point and can substantially shrink the motor diameter as well. From a motor cost standpoint, this is the least expensive solution studied. As with the earlier ironless H-bridge motor, however, the switch ratings of the inverter must be increased above those of a CPA inverter by the base rating times the CPSR required. 


\section{C.2.6. Rotor/Stator/Rotor vs. Stator/Rotor/Stator Construction of Axial-Gap Motors}

One area that warrants further research is the configuration of rotor and stator relative to each other in the machine. For ironless machines, the only configuration that is reasonable for singleslice, power-dense, axial-gap motors is a single stator between two rotors (rotor-stator-rotor, or RSR). In single-slice iron-filled axial-gap machines, however, it is possible to configure the motor with two stators with a rotor between them or two rotors with a stator between them. Both machines have similar losses associated with them, but this tradeoff offers several other items for consideration:

- The stator-rotor-stator (SRS) configuration offers simple cooling passage architectures (passages do not have to be integrated into the stator platter) because one face of each stator is exposed to the housing directly. This offers the advantages of a higher power density and lower machine temperature.

- SRS motors can be designed with a higher active volume using conventional magnet wire windings because no offset of the magnet face to accommodate the inner edge turns is required on the rotor.

- The SRS design affords a lighter rotor design for high-speed operation because of the elimination of the need to accommodate the inner edge turns with a rotor offset.

- Based on previous motor designs, it is anticipated that the SRS configuration would most likely result in higher axial loading of the bearings in cases where the rotor is slightly offcenter, or skewed, relative to the stators. Further research is required to quantify the impact of this loading on the machine design.

\section{C.3. SYSTEM COMPARISON}

A Pugh analysis was used in comparing the machine designs. This analysis qualitatively rates machine characteristics as better $(+)$, worse $(-)$, or the same $(0)$ as the baseline. Table C.2 lists the comparison results from the Pugh analysis. In this case, superior (S) was added as another comparative measure, and it can even apply to the base case if the base case ranks with the best of all designs in the comparison. Based on the summary in the table, the most appealing noninduction motor option appears to be the IGBT inverter system using CPA with the Y-connected machine and some level of iron fill (system four). The primary driver for this selection is the low cost associated with both the inverter and motor.

The second most appealing option, based on the Pugh tradeoff and cost analysis, is the DMICbased system (the fifth system in the table). Although cost analysis of currently available silicon devices appeared to indicate that the sixth system would be less costly because of a lower motor cost, research indicates that the silicon-controlled rectifier devices of the fourth system could be substantially less costly than system five's substantially larger current switches. With proper design, system five also offers an opportunity to substantially improve the CPSR over the baseline system as well as systems three, four, and six. 
Table C.2. Pugh analysis results for the baseline and axial-gap motor designs

\begin{tabular}{|c|c|c|c|c|c|c|}
\hline System & 1 (Baseline) & 2 & 3 & 4 & 5 & 6 \\
\hline $\begin{array}{c}\text { Motor } \\
\text { description }\end{array}$ & $\begin{array}{l}\text { PMBLDC } \\
\text { radial gap }\end{array}$ & $\begin{array}{c}\text { PMBLDC } \\
\text { axial-gap } \\
\text { RSR, } \\
\text { ironless }\end{array}$ & $\begin{array}{c}\text { PMBLDC } \\
\text { axial-gap } \\
\text { RSR, } \\
\text { ironless }\end{array}$ & $\begin{array}{c}\text { PMBLDC } \\
\text { axial-gap } \\
\text { RSR or } \\
\text { SRS, iron } \\
\text { filled } \\
\end{array}$ & $\begin{array}{c}\text { PMBLDC } \\
\text { axial-gap } \\
\text { RSR or } \\
\text { SRS, iron } \\
\text { filled }\end{array}$ & $\begin{array}{c}\text { PMBLDC } \\
\text { axial-gap } \\
\text { RSR or } \\
\text { SRS, iron } \\
\text { filled }\end{array}$ \\
\hline $\begin{array}{c}\text { Winding } \\
\text { configuration }\end{array}$ & $\begin{array}{c}\text { 3-phase } \\
\text { Y- } \\
\text { connected }\end{array}$ & $\begin{array}{c}\text { 3-phase } \\
\text { Y- } \\
\text { connected }\end{array}$ & $\begin{array}{l}\text { 3-phase H- } \\
\text { bridge }\end{array}$ & $\begin{array}{c}\text { 3-phase } \\
\text { Y- } \\
\text { connected }\end{array}$ & $\begin{array}{c}\text { 3-phase } \\
\text { Y- } \\
\text { connected }\end{array}$ & $\begin{array}{l}\text { 3-phase H- } \\
\text { bridge }\end{array}$ \\
\hline Switch type & IGBT & IGBT & MOSFET & IGBT & IGBT & MOSFET \\
\hline $\begin{array}{l}\text { Inverter add- } \\
\text { ons }\end{array}$ & CPA & DMIC & $\begin{array}{c}\text { Current } \\
\text { weakened }\end{array}$ & CPA & DMIC & $\begin{array}{c}\text { Current } \\
\text { weakened }\end{array}$ \\
\hline $\begin{array}{c}\text { Gear } \\
\text { reduction }\end{array}$ & Yes & Yes & Yes & Yes & Yes & Yes \\
\hline $\begin{array}{l}\text { Peak power } \\
\text { ratio }\end{array}$ & 1.66 & + & + & $\mathrm{S}$ & + & $\mathrm{S}$ \\
\hline Peak power & $53 \mathrm{~kW}$ & + & + & $\mathrm{S}$ & + & + \\
\hline Peak torque & $240 \mathrm{Nm}$ & + & + & $\mathrm{S}$ & + & + \\
\hline $\begin{array}{c}\text { Continuous } \\
\text { torque }\end{array}$ & $150 \mathrm{Nm}$ & $\mathrm{S}$ & $\mathrm{S}$ & $\mathrm{S}$ & $\mathrm{S}$ & + \\
\hline System weight & $53.1 \mathrm{~kg}$ & $\mathrm{~S}$ & + & + & + & + \\
\hline System volume & $\mathrm{S}$ & - & + & + & + & + \\
\hline CPSR & $3.7: 1$ & + & $\mathrm{S}$ & $\mathrm{S}$ & + & $\mathrm{S}$ \\
\hline $\begin{array}{c}\text { System } \\
\text { efficiency }\end{array}$ & $90 / 94$ & $+/-$ & $+/ \mathrm{S}$ & $\mathrm{S} / \mathrm{S}$ & $\mathrm{S} /-$ & $+/-$ \\
\hline $\begin{array}{l}\text { Motor torque } \\
\text { ripple }\end{array}$ & Low & + & + & - & - & - \\
\hline $\begin{array}{l}\text { System fault } \\
\text { tolerance }\end{array}$ & Fair & + & + & $\mathrm{S}$ & + & + \\
\hline $\begin{array}{l}\text { System cost in } \\
\text { volumes of } \\
250 \mathrm{k} / \text { year }\end{array}$ & $\mathrm{S}$ & - & - & $\mathrm{S}$ & - & - \\
\hline $\begin{array}{c}\text { System } \\
\text { development } \\
\text { cost }\end{array}$ & $\mathrm{S}$ & - & $\mathrm{S}$ & - & - & - \\
\hline $\begin{array}{c}\text { System } \\
\text { material cost }\end{array}$ & $\mathrm{S}$ & - & - & $\mathrm{S}$ & - & - \\
\hline $\begin{array}{c}\text { System mfg } \\
\text { cost }\end{array}$ & $\mathrm{S}$ & $\mathrm{S}$ & + & $\mathrm{S}$ & - & - \\
\hline
\end{tabular}

MOSFET $=$ metal oxide semiconductor field effect transistor

\section{C.4. SUGGESTIONS FOR CONTINUING MOTOR TECHNOLOGY RESEARCH}

The suggested motor architecture for future development is the axial-gap PM BDCM. This was based on the expectation that, properly implemented, this configuration offers a superior solution to other high-technology motor designs under development from a standpoint of weight, volume, and efficiency. It is further believed that with certain improvements, this technology can also be made cost-competitive with these other options. The primary finding related to this motor type was that in order to meet cost objectives using PMBLDC technology, it is necessary to use some level of iron fill in the motor to reduce magnet cost. The amount and procedure for the added 
iron was not finalized during this study and will require further development. The amount could vary from a $30 \%$ by volume IFE to a fully dense iron stator structure. The amount of iron added and the procedure for accomplishing the effort will require new model development and substantial manufacturing process research.

Another significant factor related to PMBLDC machines is that the cooling strategies related to this motor must be significantly improved. If fully dense iron stator construction is used, it is worthwhile to study the SRS construction discussed earlier. Using this approach would afford a simple method of adding external cooling passages for each of the stators. This solution would not be useful if the approach chosen were fractional iron fill through use of IFE. Another potential approach would be use of an oil spray cooling technique similar to that used in some large generator and motor applications. Use of such a system would help reduce magnet and coil temperature significantly, which would in turn reduce the required magnet materials and greatly improve the power density of the machine. This type of system would also allow the use of a number of different bearing options as a result of the capability to oil-lubricate bearings and eliminate the need for a sealed bearing. Seal drag and windage loss in the bearing set due to the high viscosity grease used are significant contributors to motor efficiency losses. A change to this type of cooling/lubricant system would greatly improve losses in this area.

One of the primary limitations in the use of this motor type was determined to be the lack of an inherent constant power operation capability. This study revealed no technologies that would significantly enhance this feature without modification to the inverter, control technique, or fundamental motor architecture. An area not covered by this study that has been identified for potential future study is the effect of changes to the motor that would perform either field weakening by mechanical means or variable winding geometry that can be changed during use. 


\section{APPENDIX D: \\ PARAMETER DEFINITIONS FOR SPEEDCAD MODEL}

This appendix illustrates, lists, and defines parameters used in the SPEEDCAD model.

Figure D.1 illustrates many of the physical parameters used in the model. The figure makes use of an IPM rotor and stator configuration with the shaft center point on the left-hand side.

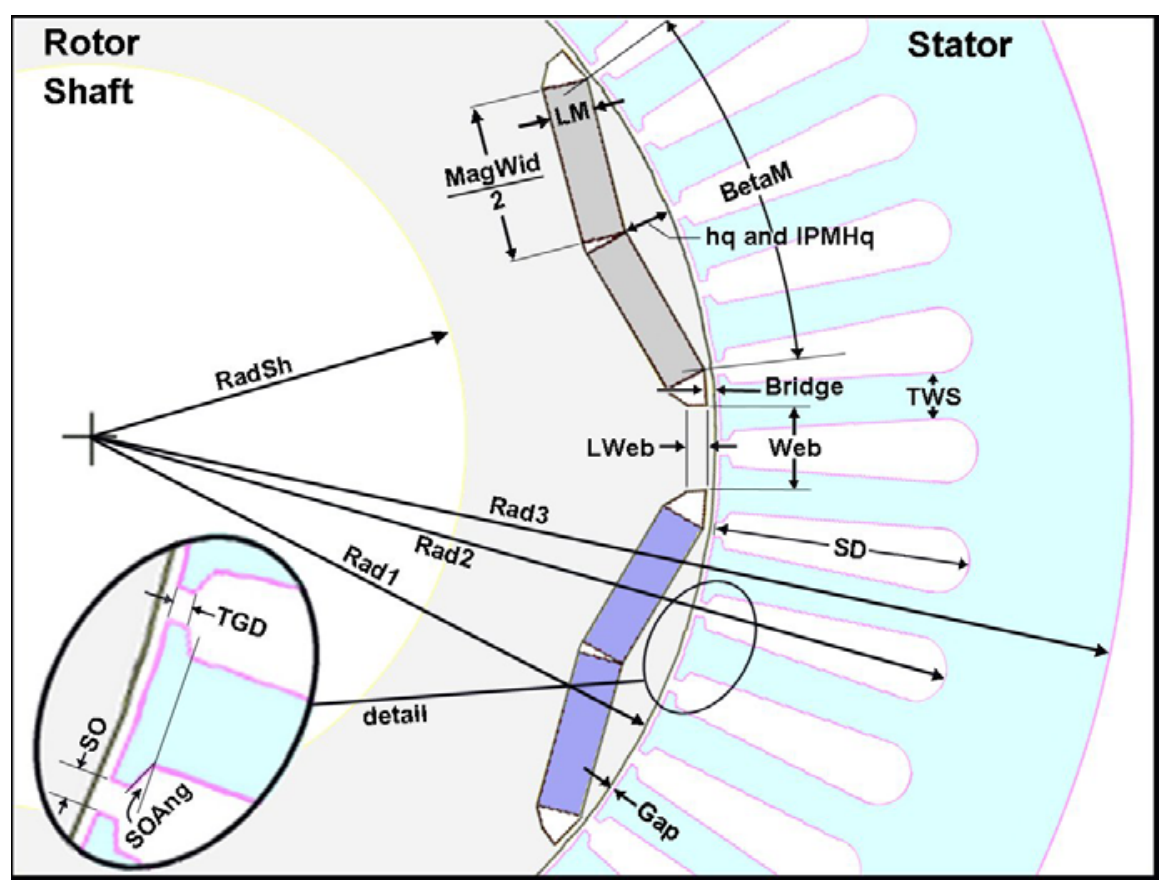

Fig. D.1. Physical parameters used in the SPEEDCAD model (IPM machine).

The summary tables in this appendix segregate the full set of parameter types/definitions by the following categories:

Table D.1 - Dimensions

Table D.2 - Magnet data

Table D.3 - Control data

The parameter names above are listed in alphabetical order. The tables are intended to provide a quick and concise definition of a large number of parameters. More complete definitions of parameters can be found in the Motorsoft User's Manual. ${ }^{10}$ 
Table D.1. SPEEDCAD parameters relating to machine dimensions

\begin{tabular}{|c|c|c|}
\hline $\begin{array}{c}\begin{array}{c}\text { Variable } \\
\text { name }\end{array} \\
\end{array}$ & Description & $\begin{array}{c}\text { Default } \\
\text { units }\end{array}$ \\
\hline AmagSlot & ptReal Area of one magnet slot in IPM lamination & $\mathrm{mm}^{\wedge} 2$ \\
\hline BetaM & ptReal Magnet pole arc $[\mathrm{mDeg}]$ & mDeg \\
\hline Bridge & ptReal IPM bridge & $\mathrm{mm}$ \\
\hline BSlit & ptReal Lam. width at inner end of rotor slits & $\mathrm{mm}$ \\
\hline DHub & ptReal Rotor hub width, measured along the d-axis & $\mathrm{mm}$ \\
\hline Embed & ptList Embedded magnet type & \\
\hline Gap & ptReal Airgap length & $\mathrm{mm}$ \\
\hline $\mathrm{hq}$ & ptReal Radial depth of pole-piece; q-axis cross-flux goes through it & $\mathrm{mm}$ \\
\hline IPMHq & ptReal Depth of pole cap, measured along d-axis & $\mathrm{mm}$ \\
\hline LM & ptReal Thickness of magnet in the direction of magnetization & $\mathrm{mm}$ \\
\hline LM_min & ptReal Smallest length through one magnet in direction of magnetization & $\mathrm{mm}$ \\
\hline Lrotor & ptReal Effective rotor length & $\mathrm{mm}$ \\
\hline LShaft & ptReal Shaft length & $\mathrm{mm}$ \\
\hline Lstk & ptReal Stack length & $\mathrm{mm}$ \\
\hline Lweb & ptReal Radial length of web in IPM Embed type 4 & $\mathrm{~mm}$ \\
\hline MagWid & ptReal Magnet width in spoke-type rotor & $\mathrm{mm}$ \\
\hline MEdge & ptReal Magnet edge & $\mathrm{mm}$ \\
\hline $\mathrm{MOH}$ & ptReal Magnet overhang at each end of the rotor & $\mathrm{mm}$ \\
\hline MslotWid & ptReal Magnet slot width in IPM rotor & $\mathrm{mm}$ \\
\hline $\mathrm{Nmbp}$ & ptInteger Number of magnet blocks per pole & \\
\hline Poles & ptInteger Number of poles & \\
\hline Rad1 & ptReal Rotor radius & $\mathrm{mm}$ \\
\hline $\operatorname{Rad} 2$ & ptReal Radius to stator slot bottom & $\mathrm{mm}$ \\
\hline $\operatorname{Rad} 3$ & ptReal Stator outer radius & $\mathrm{mm}$ \\
\hline RadSH & ptReal Shaft radius & $\mathrm{mm}$ \\
\hline RotorOD & ptReal Rotor OD & $\mathrm{mm}$ \\
\hline RotType & ptList Rotor type & \\
\hline RYoke & ptReal Radial thickness of the rotor yoke & $\mathrm{mm}$ \\
\hline SD & ptReal Slot depth (NB. from slot bottom to stator bore) & $\mathrm{mm}$ \\
\hline Skew & ptReal Stator skew [slot pitches] & \\
\hline Slits & ptList Rotor has slits or not & \\
\hline Slots & ptInteger Number of stator slots & \\
\hline $\mathrm{SO}$ & ptReal Slot opening & $\mathrm{mm}$ \\
\hline SOAng & ptReal Undercut angle of stator tooth tip (slot opening) & $\mathrm{mDeg}$ \\
\hline S-Slot & ptList Slot shape (round or square bottom, or Pll. slot) & \\
\hline StatorOD & ptReal Stator lamination OD & $\mathrm{mm}$ \\
\hline Stf & ptReal Lamination stacking factor & \\
\hline SYoke & ptReal Radial thickness of the stator yoke & $\mathrm{mm}$ \\
\hline TGD & ptReal Radial depth of stator tooth tip (slot opening depth) & $\mathrm{mm}$ \\
\hline TSlit & ptReal Lam. width at outer end of rotor slits & $\mathrm{mm}$ \\
\hline TWS & ptReal Stator tooth width & $\mathrm{mm}$ \\
\hline Web & ptReal IPM web & $\mathrm{mm}$ \\
\hline wMag & ptReal Width of magnet & $\mathrm{mm}$ \\
\hline WSlit & ptReal Width of rotor slits & $\mathrm{mm}$ \\
\hline
\end{tabular}


Table D.2. SPEEDCAD parameters relating to the magnets

\begin{tabular}{|l|l|c|}
\hline $\begin{array}{c}\text { Variable } \\
\text { name }\end{array}$ & \multicolumn{1}{|c|}{ Description } & $\begin{array}{c}\text { Default } \\
\text { Units }\end{array}$ \\
\hline $\mathrm{Br}$ & ptReal Magnet remanence at $20^{\circ} \mathrm{C}$ & $\mathrm{T}$ \\
\hline $\mathrm{CBr}$ & ptReal Temperature coefficient of $\mathrm{Br}$ & $\% / \mathrm{DegC}$ \\
\hline $\mathrm{CHc}$ & ptReal Temperature coefficient of $\mathrm{HcJ}$ & $\% / \mathrm{DegC}$ \\
\hline $\mathrm{DMag}$ & ptReal Density of magnet material & $\mathrm{kg} / \mathrm{m} 3$ \\
\hline $\mathrm{Hc}$ & ptReal Intrinsic coercivity & $\mathrm{kA} / \mathrm{m}$ \\
\hline $\mathrm{MuRec}$ & ptReal Recoil permeability & \\
\hline
\end{tabular}

Table D.3. SPEEDCAD parameters relating to control data

\begin{tabular}{|c|c|c|}
\hline $\begin{array}{c}\text { Variable } \\
\text { name }\end{array}$ & Description & $\begin{array}{c}\text { Default } \\
\text { Units }\end{array}$ \\
\hline dq0 & ptBoolean dq0 equations (sinewound, three-phase wye only) & \\
\hline Drive & ptList Sine/square wave or AC volt drive & \\
\hline $\mathrm{DuCy}$ & ptReal Voltage-PWM duty cycle [0-1] & \\
\hline EMFCalc & ptList Method of EMF calculation & \\
\hline fChop & ptReal Voltage-PWM chopping frequency [kHz] & $\mathrm{kHz}$ \\
\hline fChopAct & ptReal Chopping frequency calculated from actual No. of chops & $\mathrm{kHz}$ \\
\hline FixfChop & ptList Is a fixed chopping frequency used (Yes/No) & \\
\hline Freq1 & ptReal Fundamental frequency & $\mathrm{Hz}$ \\
\hline gamma & ptReal The phase angle between Iph1 and the q-axis (Eq1) [deg] & deg \\
\hline $\mathrm{HB} \%$ & ptReal Width of hysteresis band as a percentage of ISP & \\
\hline HBA_act & ptReal Actual value of hysteresis band adjustment (HBA) used in calculation & \\
\hline HBtype & ptList Constant or variable hysteresis band width (sine-wave) & \\
\hline ISLA_Act & ptReal Value of integration step length (ISLA) used to form solution & \\
\hline ISP & ptReal Current regulator set-point current & A \\
\hline ISP Act & ptReal Value of set point current (ISP) used to form solution & A \\
\hline RPM & ptReal Speed [rpm] & $\mathrm{rpm}$ \\
\hline $\mathrm{Rq}$ & ptReal On-state resistance of one transistor $\{$ ohms $\}$ & ohm \\
\hline Sw_Ctl & ptList Voltage PWM/current hysteresis control & \\
\hline $\mathrm{t}$ q & ptReal Transistor switching time [us] & us \\
\hline Tol_Act & ptReal Value of tolerance (Tol) used to form solution & \\
\hline $\mathrm{Vd}$ & ptReal Forward voltage drop of one diode & $\mathrm{V}$ \\
\hline $\mathrm{Vq}$ & ptReal Forward voltage drop in one transistor & $\mathrm{V}$ \\
\hline Vs & ptReal dc supply voltage to the controller & $\mathrm{V}$ \\
\hline X_EMF & ptReal Adjustment factor for back EMF & \\
\hline XBgap & ptReal Old emf adjustment factor. From v. 6 set $=1$ and use X_EMF instead & \\
\hline $\mathrm{XL}$ & ptReal Adjustment factor for inductance & \\
\hline
\end{tabular}




\section{APPENDIX E: \\ FIELD-WEAKENING TECHNIQUES FOR SURFACE-MOUNTED PM MOTORS}

An important attribute of traction drives is that they provide a wide CPSR. In this discussion, CPSR is defined as the ratio of the highest speed at which rated power can be developed, to the lowest speed at which rated power can be developed while operating within the motor's rated current. The lowest rotor $\mathrm{rpm}$ at which rated power can be developed is referred to as base speed, $N_{b}$. Relative rotor speed, denoted as $n$, is the ratio of the rotor rpm, $N$, to the base speed.

PM motors lack a dedicated field winding; consequently, operation in a constant power mode above base speed must be achieved through appropriate control of the inverter that supplies the armature winding. The control achieved is not "field weakening" per se, but the effect is functionally similar to reducing the current in the field winding of classical doubly fed machines, such as the wound rotor synchronous motor.

The armature winding of PM motors with surface-mounted magnets can be distributed so as to achieve a sinusoidal back-emf or concentrated to achieve a trapezoidal back-emf. Machines with sinusoidal backemf are commonly referred to as PMSMs, while those with trapezoidal back-emf are called BDCMs. The field weakening of these two classes is discussed separately. The discussion is condensed from several references [A-Z]. For both the sinusoidal and trapezoidal back-emf wave shapes, the primary factor limiting the ability of the motor to operate over a wide CPSR is the armature winding inductance. Explicit formulas are given for each machine type to show the limitation that inductance places on CPSR.

The analysis neglects second-order effects such as speed-sensitive losses, which include friction, windage, hysteresis, eddy currents, and skin effect in winding resistance. These speed-sensitive losses will limit the CPSR of any practical motor to a finite value.

The sinusoidal back-emf PMSM is considered first.

Impact of Inductance on the CPSR of the PMSM

Figure E. 1 shows a schematic of the three-phase PMSM driven by a common variable-speed inverter. The figure also defines the various parameters. The air-gap flux is established by the PM field, and there is no field winding. Thus this machine is singly fed. The line-to-neutral back-emf of the PMSM is sinusoidal, and the motor runs on sinusoidal phase currents. The magnitude of the emf is linear in motor speed; and the voltage constant, $K_{v}$, with units of rms volts per electrical radian per second, is fixed. Thus the rms value of the back-emf at any speed is given by

$$
\begin{aligned}
E & =K_{v} \Omega \\
& =\frac{\Omega}{\Omega_{b}} K_{v} \Omega_{b}, \\
& =n E_{b}
\end{aligned}
$$

where $E_{b}$ is the rms magnitude of the line-to-neutral back-emf at base speed and $n$ is relative speed. Similarly, the motor reactance can be expressed as 


$$
\begin{aligned}
X & =\Omega L \\
& =\frac{\Omega}{\Omega_{b}} \Omega_{b} L, \\
& =n X_{b}
\end{aligned}
$$

where $X_{b}$ is the reactance at base speed.

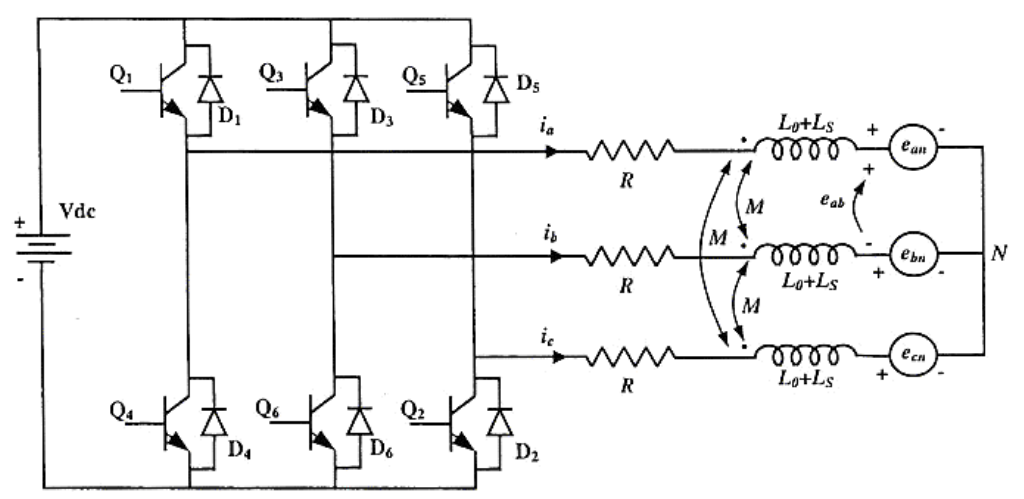

$$
\begin{aligned}
p & =\text { number of poles } \\
N & =\text { actual rotor speed in rpm } \\
N_{b} & =\text { base speed in rpm } \\
n & =\text { relative speed }=\frac{N}{N_{b}} \\
\Omega_{b} & =\text { base speed in electrical radians/sec } \\
& =\frac{p}{2} \cdot \frac{2 \pi N_{b}}{60} \\
\Omega & =\text { actual rotor speed in electrical radians/sec } \\
& =n \Omega_{b} \\
E_{b} & =\text { rms magnitude of the phase-to-neutral emf at base speed } \\
I_{r} & =\text { rated rms motor current } \\
P_{r} & =\text { rated output power }=3 E_{b} I_{r} \\
L_{s} & =\text { self inductance per phase } \\
L_{o} & =\text { leakage inductance per phase } \\
M & =\text { mutual inductance } \\
L & =\text { equivalent inductance per phase }=L_{o}+L_{s}+M \\
R & =\text { winding resistance per phase } \\
v_{a n} & =\text { applied phase A to neutral voltage } \\
e_{a n} & =\text { phase A to neutral back-emf } \\
e_{a b} & =\text { phase A to phase B back-emf }
\end{aligned}
$$

Fig. E.1. Common variable-speed inverter topology and PMSM motor model.

A simplified, per phase, fundamental frequency phasor model of the motor and inverter is shown in Fig. E.2. In the figure, $\bar{V}$ is the line-to-neutral fundamental frequency voltage phasor applied by the inverter to the motor. The angle of the applied voltage phasor, $\delta$, is called the inverter lead angle. $\bar{E}$ is the back-emf voltage phasor, line-to-neutral, and $\bar{I}$ is the motor current phasor. 


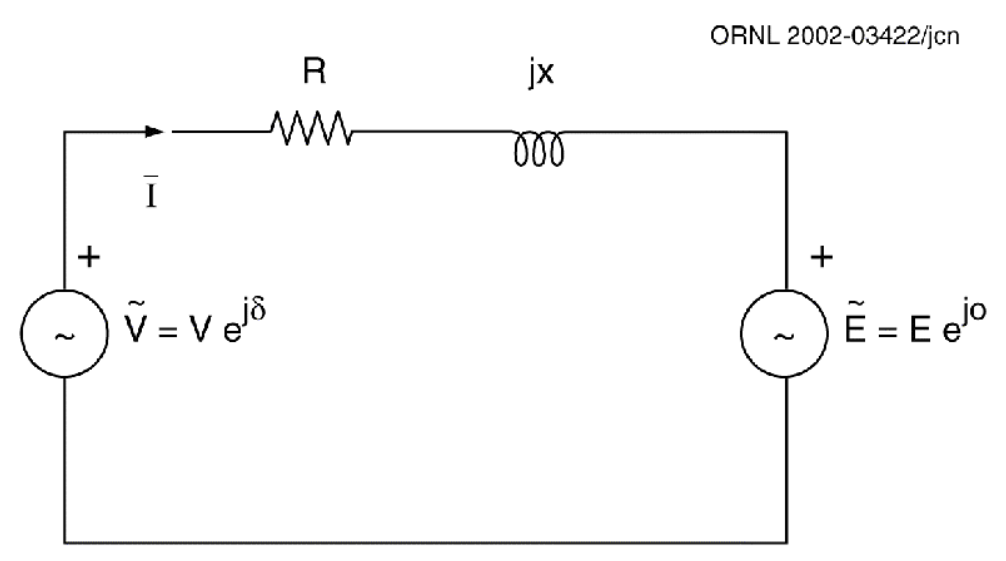

Fig. E.2. AC circuit used in power flow discussion.

Up to base speed, the magnitude of the applied voltage, $V$, and the lead angle, $\delta$, can be adjusted, allowing the motor current phasor to be put in phase with the back-emf. This maximizes the torque produced per ampere. Voltage magnitude $V$ and lead angle $\delta$, required to support any relative speed below base speed, $n \leq 1$, and rms current, $I$, are found from

$$
\begin{aligned}
\bar{V} & =n E_{b}+I\left(R+j n X_{b}\right) \\
& =\sqrt{\left(n E_{b}+I R\right)^{2}+\left(n I X_{b}\right)^{2}} e^{j \tan ^{-1}\left[\frac{n I X_{b}}{n E_{b}+I R}\right]}
\end{aligned}
$$

Neglecting the winding resistance, Eq. (E.3) becomes

$$
\begin{aligned}
\bar{V} & =n E_{b}+j n I X_{b} \\
& =\sqrt{\left(n E_{b}\right)^{2}+\left(n I X_{b}\right)^{2}} e^{j \tan ^{-1}\left[\frac{n I X_{b}}{n E_{b}}\right] .}
\end{aligned}
$$

The rms magnitude of $\bar{V}$ increases with speed and is limited by the available dc supply voltage and the type of modulation used to control the inverter switches. The maximum magnitude is obtained at base speed where $\mathrm{n}=1$ and at rated rms motor current for which $I=I_{r}$, then

$$
V_{\max }=\sqrt{\left(E_{b}\right)^{2}+\left(I_{r} X_{b}\right)^{2}}=\sqrt{\left(E_{b}\right)^{2}+\left(I_{r} \Omega_{b} L\right)^{2}} .
$$

Similarly, the lead angle $\delta$ at base speed and rated current is given by

$$
\delta=\tan ^{-1}\left(\frac{I_{r} X_{b}}{E_{b}}\right) .
$$

The power developed at base speed and rated current is the rated power of the motor, and since the current is in phase with the back-emf, we have 


$$
P_{r}=3 E_{b} I_{r}
$$

The dc supply voltage necessary to support operation at base speed and rated current depends on the modulation level allowed in the inverter. If the inverter control scheme is sinusoidal PWM without linear modulation, then the required dc supply voltage is

$$
V_{d c}=2 \sqrt{2} V_{\max },
$$

However, if over-modulation is allowed, a smaller dc supply voltage can be used to obtain the same fundamental frequency voltage,

$$
V_{d c}=\frac{\pi V_{\max }}{\sqrt{2}}
$$

Let us restrict our attention to operation above base speed such that $n>1$ and $V=V_{\max }$. Neglecting the armature resistance, the phasor current of the motor is

$$
\bar{I}=\frac{V_{\max }}{n X_{b}} \sin \delta+j\left[\frac{E_{b}}{X_{b}}-\frac{V_{\max }}{n X_{b}} \cos \delta\right],
$$

which has rms magnitude

$$
I=\frac{\sqrt{V_{\max }^{2}-n 2 V_{\max } E_{b} \cos \delta+n^{2} E_{b}^{2}}}{n X_{b}} .
$$

The total power injected into the motor by the inverter is

$$
\bar{P}_{\text {in }}=3 \operatorname{Re}\left(\bar{V} \vec{I}^{*}\right)=\frac{3 V_{\max } E_{b}}{X_{b}} \sin \delta,
$$

while the total power converted by the motor is

$$
\overline{P_{m}}=3 \operatorname{Re}\left(\bar{E}^{*}\right)=\frac{3 V_{\max } E_{b}}{X_{b}} \sin \delta
$$

Since we have neglected the winding resistance, $P_{i n}$ equals $P_{m}$ and the common value is

$$
P_{m}=P_{i n}=\frac{3 V_{\max } E_{b}}{X_{b}} \sin \delta
$$

This expression shows that it is easy to control the motor to deliver rated power above base speed. All that is necessary is that the inverter lead angle, $\delta$, be held fixed at that value that causes $P_{m}$ in Eq. (E.14) to be equal to the rated value $P_{r}$ given in Eq. (E.7), that is 


$$
\begin{aligned}
\delta & =\sin ^{-1}\left(\frac{X_{b} P_{r}}{3 V_{\max } E_{b}}\right) \\
& =\cos ^{-1}\left(\frac{E_{b}}{V_{\max }}\right)
\end{aligned}
$$

While constant lead angle control allows the PMSM to operate at constant power above base speed, it is not a certainty that doing so results in operating within the rated current. The critical factor is the motor inductance, as shown below.

Equation (E.11) gives the rms motor current, $I$, when operating at any speed above base speed. Using lead angle $\delta$ from Eq. (E.15) so that rated power is produced, we require that the rms current in Eq. (E.11) be no greater than the rated value $I_{r}$, that is

$$
\begin{aligned}
I & =\frac{\sqrt{V_{\max }^{2}-n 2 V_{\max } E_{b} \cos \delta+n^{2} E_{b}^{2}}}{n X_{b}} \leq I_{r} \\
& =\frac{\sqrt{V_{\max }^{2}-n(n-2) E_{b}^{2}}}{n X_{b}} \leq I_{r} \\
& =\frac{\sqrt{V_{\max }^{2}-n(n-2) E_{b}^{2}}}{n \Omega_{b} L} \leq I_{r}
\end{aligned}
$$

Evaluating the inequality in Eq. (E.16) at relative speed $n$ equal to the CPSR yields a minimum requirement on the motor inductance,

$$
L_{\min }=\frac{\sqrt{V_{\max }^{2}+C P S R(C P S R-2) E_{b}^{2}}}{C P S R \Omega_{b} I_{r}} .
$$

Since $V_{\max }$ as given by Eq. (E.5) depends on $L$, Eq. (E.17) has to be applied iteratively to get an exact inductance boundary for fixed values of CPSR, $E_{b}, I_{r}$, and $\Omega_{\mathrm{b}}$. For example beginning with $V_{\max }=E_{b}$, Eq. (E.17) is processed to get a value of $L$. That value of $L$ is used in Eq. (E.5) to get a corresponding value of $V_{\max }$, and the process is then repeated. Typically, the value of $L$ converges within a few iterations.

Note that Eq. (E.17) implies that an infinite CPSR can be achieved provided the motor inductance is greater than

$$
L_{\infty}=\frac{E_{b}}{\Omega_{b} I_{r}}
$$


While Eqs. (E.17) and (E.18) place lower bounds on the motor inductance to achieve either a finite or an infinite CPSR, there is also an upper bound that can be found by recognizing in Eq. (E.14) that the lead angle cannot exceed $90^{\circ}$. This results in a maximum inductance

$$
L_{\max }=\frac{3 V_{\max } E_{b}}{P_{r} \Omega_{b}}=\frac{V_{\max }}{\Omega_{b} I_{r}} .
$$

As an example of the use of these formulas, consider a PMSM with the following parameters

$$
\begin{aligned}
V_{d c} & =190 \mathrm{~V} \Rightarrow V_{\max }=85.53 \mathrm{~V} \text { (assumes over-modulation) } \\
E_{b} & =\frac{74.2}{\sqrt{2}} \mathrm{Vrms}, I_{r}=203 \mathrm{Arms} \\
\Omega_{\mathrm{b}} & =1634 \text { elec. } \mathrm{rad} / \mathrm{sec} \\
C P S R & =9
\end{aligned}
$$

For this example, the limiting inductance values are

$$
\begin{aligned}
L_{\min } & =142 \mu \mathrm{H} \\
L_{\infty} & =158 \mu \mathrm{H} \\
L_{\max } & =258 \mu \mathrm{H}
\end{aligned}
$$

The CPSR performance of a PMSM with a finite CPSR is shown conceptually in Fig. E.3. 


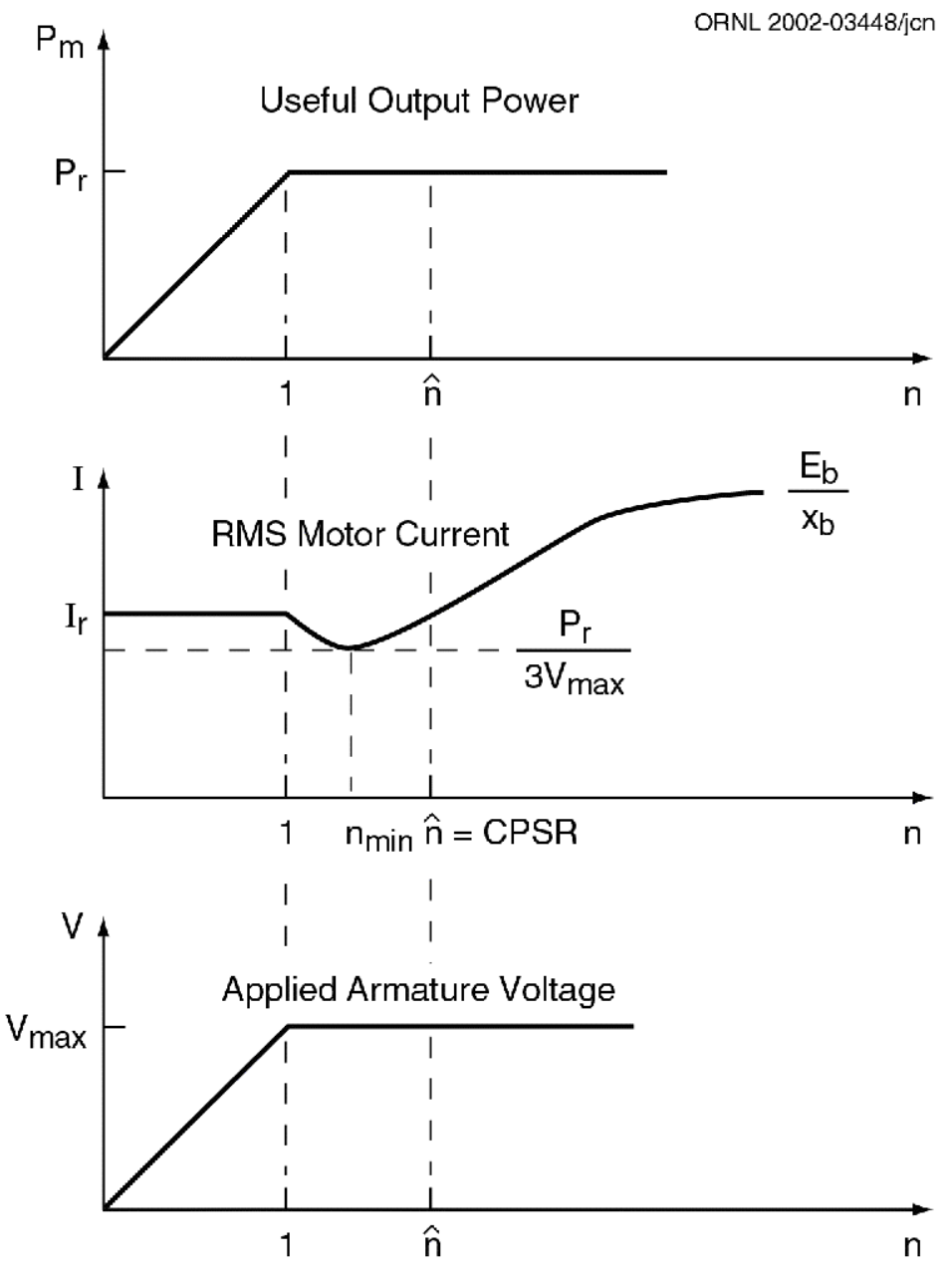

Fig. E.3. Constant power performance of the PMSM driven by sinusoidal PWM.

The key parameter in determining the CPSR capability of the sinusoidal back-emf PMSM is the motor inductance. This is also true for the trapezoidal back-emf BDCM. 


\section{DISTRIBUTION}

\section{Internal}

1. D. J. Adams

2. J. M. Bailey

3. S. Das

4. E. C. Fox

5. L. D. Marlino

6. J. W. McKeever

7-8. Laboratory Records
9. P. J. Otaduy

10. B. Ozpineci

11. R. L. Smith

12. R. H. Staunton

13. L. M. Tolbert

14-15. Laboratory Records

\section{External}

14. R. A. Kost, U.S. Department of Energy, EE-2G/Forrestal Building, 1000 Independence Avenue, S.W., Washington, D.C. 20585.

15. S. A. Rogers, U.S. Department of Energy, EE-2G/Forrestal Building, 1000 Independence Avenue, S.W., Washington, D.C. 20585.

16. E. J. Wall, U.S. Department of Energy, EE-2G/Forrestal Building, 1000 Independence Avenue, S.W., Washington, D.C. 20585. 